

\section{CREATING THE ANCIENT RHETORICAL TRADITION}

This book explores the history of rhetorical thought and examines the gradual association of different aspects of rhetorical theory with two outstanding fourth-century ВСE writers: Lysias and Isocrates. It highlights the parallel development of the rhetorical tradition that became understood, on the one hand, as a domain of style and persuasive speech, associated with the figure of Lysias, and, on the other, as a kind of philosophical enterprise which makes significant demands on moral and political education in antiquity, epitomized in the work of Isocrates. There are two pivotal moments in which the two rhetoricians were pitted against each other as representatives of different modes of cultural discourse: Athens in the fourth century вСЕ, as memorably portrayed in Plato's Phaedrus, and Rome in the first century BCE when Dionysius of Halicarnassus proposes to create from the united Lysianic and Isocratean rhetoric the foundation for the ancient rhetorical tradition.

LaURa vildebaum is an assistant professor in Classics at New York University. Her research focuses primarily on ancient rhetoric and ancient literary criticism, but she also has a long-standing interest in the way these fields relate to ongoing philosophical discussions. Recently, she has received a distinguished Humboldt fellowship to launch her new project on Aristotle's Rhetoric. 


\section{CAMBRIDGE CLASSICAL STUDIES}

\section{General editors}

J. P. T. CLACKSON, W. M. BEARD, G. BETEGH, R. L. HUNTER, M. J. MILLETT, S. P. OAKLEY, R. G. OSBORNE, C. VOUT, T. J. G. WHITMARSH 


\title{
CREATING THE ANCIENT RHETORICAL TRADITION
}

\author{
LAURA VIIDEBAUM \\ New York University
}

\section{图.国 CAMBRIDGE \\ (4) UNIVERSITY PRESS}




\section{CAMBRIDGE UNIVERSITY PRESS}

University Printing House, Cambridge св2 8вs, United Kingdom

One Liberty Plaza, 2oth Floor, New York, NY Iooo6, USA

477 Williamstown Road, Port Melbourne, vIC 3207, Australia

3I4-32 I, 3rd Floor, Plot 3, Splendor Forum, Jasola District Centre,

New Delhi - I I0025, India

I03 Penang Road, \#05-06/o7, Visioncrest Commercial, Singapore 238467

Cambridge University Press is part of the University of Cambridge.

It furthers the University's mission by disseminating knowledge in the pursuit of education, learning, and research at the highest international levels of excellence.

\section{www.cambridge.org}

Information on this title: www.cambridge.org/978 I I08836562 DOI: IO.IOI7/978I I08873956

(C) Faculty of Classics, University of Cambridge $202 \mathrm{I}$

This work is in copyright. It is subject to statutory exceptions and to the provisions of relevant licensing agreements; with the exception of the Creative Commons version the link for which is provided below, no reproduction of any part of this work may take place without the written permission of Cambridge University Press.

An online version of this work is published at doi.org/Io.IoI7/978I I08873956 under a Creative Commons Open Access license CC-BY-NC-ND 4.0 which permits re-use, distribution and reproduction in any medium for non-commercial purposes providing appropriate credit to the original work is given. You may not distribute derivative works without permission. To view a copy of this license, visit https://creativecommons.org/licenses/by-nc-nd/4.o

All versions of this work may contain content reproduced under license from third parties.

Permission to reproduce this third-party content must be obtained from these third-parties directly.

When citing this work, please include a reference to the DOI IO.IOI7/978 I I08873956

First published $202 \mathrm{I}$

A catalogue record for this publication is available from the British Library.

ISBN 978-I-I08-83656-2 Hardback ISBN 978-I-I08-8I 258-o Paperback

Cambridge University Press has no responsibility for the persistence or accuracy of URLs for external or third-party internet websites referred to in this publication and does not guarantee that any content on such websites is, or will remain, accurate or appropriate. 
A Mattia e alle nostre ragazze 


\section{CONTENTS}

Acknowledgements

page ix

Abbreviations

Introduction

I From Plato to Dionysius of Halicarnassus ... 6

2 ... and from Lysias to Isocrates IO

3 Creating the Ancient Rhetorical Tradition I5

Part I Lysias, Isocrates and Plato: Ancient Rhetoric in Athens

I Lysias in Athens $\quad$ I9

I.I Lysias ...

I.2 $\ldots$ and the Corpus Lysiacum 27

2 Reflections on Lysias and Lysianic Rhetoric in the Fourth Century BCE $\quad 32$

2.I Plato's Lysias 38

2.2 After Plato 55

3 Isocrates and His Work on Rhetoric and Philosophy 62

3.I Challenging the Poetic Tradition 65

3.2 Isocrates on Prose 68

3.3 On What Is and What Is Not Philosophy 74

4 Isocrates on Socrates $\quad 92$

5 Contemporary Reflections on Isocrates and His

Role in Rhetoric and Philosophy 106

5.I Alcidamas 106

5.2 Plato's Isocrates I IO

5.3 Isocrates and Aristotle I 26 


\section{Part II Creating the Ancient Rhetorical Tradition:} Dionysius of Halicarnassus in Rome

6 From Athens to Rome: Lysias, Isocrates and the Transmission of Greek Rhetoric and Philosophy

6. I Post-Fourth-Century BCE and Hellenistic Receptions of Lysias and Isocrates

6.2 Ps. Demetrius on Lysias and Isocrates

6.3 The Reception of Lysias and Isocrates in Cicero and Philodemus

7 Dionysius of Halicarnassus on Lysias, Rhetoric and Style

7.I Context and Contemporaries

7.2 Dionysius and Lysias

7.3 Dionysius and Lysias' Charm

7.4 Lysias - a Greek Writer for Rome

8 Isocrates and Philosophy in Dionysius of Halicarnassus' Rhetorical Writings

8. I Dionysius' On Isocrates

8.2 Dionysius on True Rhetoric, True Philosophy and True Isocrates

Bibliography

Index 


\section{ACKNOWLEDGEMENTS}

I have always found speeches somewhat embarrassing. From family gatherings (with all those awkward toasts) to presidential addresses, speeches force a person into spotlight and such close scrutiny is weird, unusual, potentially embarrassing and hard to bear out with grace. For all the same reasons, they can be difficult to listen to. And of course, the harder the challenge the sweeter are the rewards that one can reap from a successful performance. Speeches can make or break careers, communities and countries. I have long been fascinated by our continuous love for speeches and by the fact that we are willing to put up with so many embarrassing exemplars to experience one that will capture the moment, express our collective feelings and give perspective and direction to our everyday lives. How does that work? This book presents my first sustained efforts at approaching the ever-complicated field of rhetoric and persuasion. It seemed best to start my search with fourthcentury BCE Athens, when ideas of rhetoric and its demarcation from philosophy and other discourse became topical in a way that may prove helpful to us, as we are constantly addressing and renegotiating these same dynamics. In fact, I am increasingly of the opinion that the still widely oral culture of the ancient world has many useful insights to offer us and our text-centered existence, especially as we are entering a new era of oral culture with its own technological advancements.

This book started life a number of years ago as a Cambridge dissertation under the generous supervision of Richard Hunter, whom I should like to thank first and foremost for not only being an ideal guide and extremely insightful critic throughout the graduate years, but for also offering an inspiring environment for my professional growth and for 
continuing his support to my projects and plans ever since. I have been truly privileged and am grateful to be able to acknowledge my deep debt to him. I have expressed my warmest thanks to friends and colleagues who were close to me and involved in the dissertation writing process elsewhere. Here, I would like to take the opportunity to mention the many supportive readers and interlocutors who have helped to turn the dissertation into a book and from whose insights the book has greatly benefited. The present work would not have been the same without the direct or indirect input by Emilia Barbiero, Alessandro Barchiesi, Joshua Billings, David Blank, Claire Bubb, Chris Carey, Joan Connelly, Joy Connolly, Raffaella Cribiore, Jyl Gentzler, Stephen Halliwell, Liz Irwin, Casper de Jonge, Larry Kim, Bryant Kirkland, David Konstan, Barbara Kowalzig, David Levene, Toomas Lott, Marko Malink, Daniela Manetti, Peter Meineck, Andy Monson, Helen Morales, Jessica Moss, Mike Peachin, Irene Peirano Garrison, Valeria Piano, James Porter, Lucia Prauscello, Nicholas Rynearson, Adele Scafuro, David Sider, Ellisif Wasmuth, Tim Whitmarsh, Chris Whitton, Nancy Worman, and Harvey Yunis. NYU's Department of Classics is a place I proudly call my academic home and I am grateful to all my colleagues and graduate students for offering me such warm welcome, for never ceasing to provide intellectual stimulation and for cheering me on in my professional and personal ventures. Here, I should like to single out in particular David Levene, who has been nothing short of simply amazing in his role as a faculty mentor. He has been a role model not only for being truly learned in the widest sense of our increasingly professionalizing discipline, but also for being savvy about the inside workings of academic institutions and academia as a way of life. I also want to express deep gratitude to friends and first teachers who oversaw my initial steps in academia and have fundamentally shaped my perception of academia, Classics, and life: Juhan Aru, Riin Kõiv, Marju Lepajõe†, Anne Lill, Maria-Kristiina Lotman, Janika Päll, Uku Tooming, and Ivo Volt. Aitäh! 


\section{Acknowledgements}

The Dean's First Book Colloquium award at NYU enabled me to discuss my work in close (and sometimes painful) detail with Jyl Gentzler, David Konstan, David Levene, Adele Scafuro and Harvey Yunis. I am infinitely grateful for this opportunity and to all my readers for their invaluable comments, criticisms and encouragement. Two external readers at Cambridge University Press offered further excellent comments that have significantly helped to sharpen the arguments and to think through some of the implications emerging from my interpretations. This book would not have been half as readable without all these readers and would probably have been twice as readable had I been able to take on board all their advice. But writing and rewriting must come to an end at some point. Ohe, iam satis est, ohe, libelle!

Writing this book has coincided with several life events and I am thankful to my family and friends for all their support. This book is dedicated to the four people who have been most intimately involved in those moments: my husband Mattia and our three daughters. 


\section{ABBREVIATIONS}

References to the rhetorical works of Dionysius of Halicarnassus (DH) are to the chapter and section number of the Budé editions by G. Aujac, Denys d'Halicarnasse: Opuscules rhétoriques, Tome I (I978), 2 (I988), 4 (I99I) and 5 (I992); and G. Aujac and M. Lebel, Denys d'Halicarnasse: Opuscules rhétoriques, Tome 3 (198I). References to Plato and Lysias follow the most recent Oxford Classical Texts editions. References to Isocrates are to the Budé editions by G. Mathieu and É. Brémond (I928-62). Unless indicated otherwise, English translations of the Greek and Latin authors are borrowed and adapted from the Loeb Classical Library series.

Authors' names are in general abbreviated as in the ninth edition of Liddell and Scott, and for the sake of clarity I have kept the Latinized names (e.g. 'Isocrates', not 'Isokrates').

Abbrevations for collections of texts, journals and works of reference are as follows:

\begin{tabular}{|c|c|}
\hline$A J P$ & American Journal of Philology \\
\hline$C Q$ & Classical Quarterly \\
\hline$F G r H$ & $\begin{array}{l}\text { F. Jacoby, Die Fragmente der griechischen } \\
\text { Historiker, Berlin and Leiden } 1923-58\end{array}$ \\
\hline GRBS & Greek, Roman and Byzantine Studies \\
\hline LSJ & $\begin{array}{l}\text { H. G. Liddell and R. Scott, rev. H. S. Jones (with } \\
\text { revised supplement I996), A Greek-English } \\
\text { Lexicon, Oxford I996 }\end{array}$ \\
\hline Suda & $\begin{array}{l}\text { Suidae Lexicon, ed. A. Adler, vols. I-V, Leipzig } \\
\text { I928-38 }\end{array}$ \\
\hline TAP & $\begin{array}{l}\text { Transactions of the American Philological } \\
\text { Association }\end{array}$ \\
\hline
\end{tabular}

xii 


\section{INTRODUCTION}

When Marju Lepajõe, a famous cultural historian and literary critic in Estonia, was asked what she wished for the Estonian people for the country's centennial anniversary, she said simply 'I wish that everyone would have style.' ${ }^{\text {I }}$ Style, not in the sense of following the latest fashion outbreak, but as a cultivated surface reflection of one's deeper (examined) self. In this sense, style is an intrinsic part of one's self-manifestation and in order to have style, she suggested, one has to spend time trying to figure out who one really is and how to translate that deeper internal understanding of oneself to the outside world. Socrates had style and Marju Lepajõe herself, widely erudite and painstakingly careful about the words she used, certainly had lots of style. People with style, one might add in passing, often acquire cult status, and so did she (and of course, so did Socrates). Two important topics emerge from what appears to have been expressed as a very casual insight: first, style is undetachable from thought, and secondly, style is something that can be cultivated and learned, practised and improved upon.

One might say that connecting style with thought (and with a deeper reflection of oneself) is a commonplace. ${ }^{2}$ It is nevertheless true that many studies in rhetorical theory and practice from antiquity onwards have focused either on the one or the other side: Plato's Phaedrus (266c-9d) reacts against an

I Interviewed on 3 February 2015 for 'Plekktrumm': http://arhiiv.err.ee/vaata/plekk trumm-marju-lepajoe/similar-I 77897 (last accessed 23 December 2019).

${ }^{2}$ I am conscious here of the fact that my concept of style itself requires deeper reflection, especially as far as the fascinating relationship between style and rhetoric unfolds in the history of rhetoric. For present purposes, however, it suffices to think of style as a study of 'how to say' things (as opposed to 'what to say'), as suggested in

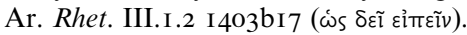


apparently established practice among textbook writers and teachers of rhetoric to conceive of good rhetoric primarily in terms of appropriating preconfigured models, tropes and arrangement. Aristotle is even more illuminating as an example. For all its polemic engagement with rival conceptualizations of rhetoric, his Rhetoric makes a sustained effort to bring together the content (i.e. the argument) with the presentation (i.e. style). And yet the third book dedicated to style has long been regarded as a dubious afterthought to his 'real' contribution to rhetoric - the enthymeme. ${ }^{3}$ The idea that rhetoric is divided, or divisible, seems to go at least as far back as the aforementioned authors and the debates that their works contain. Hence, when contemplating studies that would exemplify this insight, it does not seem to me too far-fetched to suggest that Heinrich Lausberg's Handbuch der literarischen Rhetorik: eine Grundlegung der Literaturwissenschaften (München, I960) could be conceived of as an example of rhetorical theory concerned strictly with style and ornamentation, developed to its fullest expression. Indeed, as an invaluable sourcebook for elements of style and rhetorical composition, it is a compulsory reading for everyone interested in concepts and applications of style and arrangement in classical authors. It has less to say about the philosophical, argumentative and educational aspects of rhetoric. And similarly, it may be argued that Chaïm Perelman and Lucie Olbrechts-Tyteca's Traité de l'argumentation - la nouvelle rhétorique (Paris, I958), a fundamental contribution to argumentation and logic, goes in the other direction of regarding rhetoric as a theory of argumentation and logic (or logos), obliterating the aspect of style from this conversation. The list could easily be expanded (though there are surely exceptions to this broad generalization), ${ }^{4}$ but the overall point is clear

${ }^{3}$ Burnyeat (I996), 9I: 'Aristotle's doctrine of the enthymeme is one of his greatest and most original achievements.'

${ }^{4}$ In academic circles, one would be hard pressed to find scholars working, for example, on stylistics who would deny the intricate connection between these two sides of rhetoric - style (expression) and thought (argument) or content and form. Nevertheless, works on style - manuals, handbooks, reference works - do seem to 
enough: even though style and thought seem so intricately connected in our conceptualization and use of rhetoric, they are not at all easy to combine in one work.

Scholars working on (the history of) rhetoric, from antiquity onwards, have recognized the difficulty of conceiving rhetoric as a unified comprehensive set of theories, authors and practices and have therefore often felt compelled to supply an overarching narrative for the art that would create a sense of continuity in thought and practice. ${ }^{5}$ Even though such sweeping narratives have become very rare among Classicists, they are a central focus of study for rhetoric scholars working primarily in the English and Communication Studies departments in the US, ${ }^{6}$ where the rhetorical tradition and their readings are often interpreted and viewed against the urgency of contemporary academia in their respective fields. ${ }^{7}$ These studies tend to be highly ambitious and provocative in their outlook (e.g. to change existing narratives of rhetoric and degravitate the field away from canonized authors), though they seem to end up exercising little (if any) impact on mainstream Classics. This may be due to the fact that their interpretations sometimes exhibit lack of sophistication and understanding of the ancient rhetorical context which they claim to make

operate with an underlying divide in mind between the person (developing an argument) and the means of expressing herself (and the argument).

5 Attempts to offer classifications of the art and its practitioners are present in various forms in all writers of ancient rhetoric. This approach is equally well represented in groundbreaking works on rhetoric of the nineteenth and twentieth centuries. See, for example, Blass' distinction between sophistic and practical oratory (sophistische und praktische Beredsamkeit) (I887), 4. Kennedy's outdated study of the art of persuasion recognizes the division into 'practical and philosophic tradition', but then somewhat surprisingly defies his instincts and regards the history of rhetoric ultimately as 'the growth of a single, great, traditional theory to which many writers and teachers contributed' (1963, 9).

${ }^{6}$ Even though it seems odd to mark such division along the (arbitrary) disciplinary boundaries at universities, the isolation of the two groups from one another is very much real and evident from the fact that they rarely (if at all) contribute to the same edited volumes or participate in the same conferences. There are a few exceptions, e.g. Poulakos and Depew (2004).

7 See, for example, O'Gorman's (2006) review of Graff, Walzer, Atwill (2005), where he considers the too lightweight engagement with contemporary academia and its power and economic struggles relations a legitimate shortcoming of the otherwise respectable volume. 
contributions to. ${ }^{8}$ Whatever the reasons for their mutual disregard, the concept of 'rhetorical tradition' is something that a good number of (American) rhetoric scholars are interested in and, much in line with the way in which Classicists have been prompted to rethink the use and influence of canons, traditions and classics in their broadest and narrowest senses, ${ }^{9}$ so too the rhetorical tradition has become a widely questioned and challenged concept in studies on the history of rhetoric. ${ }^{\text {IO }}$ By now, there is no doubt that the 'rhetorical tradition' is a contentious topic and that even the assumption of the existence of some monolithic tradition of rhetoric itself requires an explanation.

The title of this book, Creating the Ancient Rhetorical Tradition, refers to a conscious and perhaps even somewhat polemical engagement with this discourse, primarily in two ways. First, when contemporary scholars of rhetoric dispute the continuity or existence of a single 'rhetorical tradition' they generally tend to assume that the ancient rhetorical tradition was one unified single entity and that the 'tradition' of rhetoric becomes questionable when traced as a discipline over time. ${ }^{\text {I }}$ By explicitly discussing the 'ancient rhetorical tradition', this study parts from those approaches that think of tradition as a continuity from the ancients to contemporary uses of rhetoric. This is not to say that an idea of continuity is implicitly in the background, but the explicit focus of this present book lies elsewhere and thus it claims no particular insight into the

${ }^{8}$ Gaines (2005), 64. See also Usher's (I989) review of Vickers (I988).

9 Most helpful guide to date on the 'classical tradition' is Silk, Gildenhard, Barrow (20I4). See also Greenhalgh (I990), especially where he distinguishes classicism from the 'classical tradition' ( $\mathrm{p}$. Io); and the various essays from the edited volume by Porter (2006) with bibliography.

ro The edited volume by Graff, Walzer, Mailloux (2005) offers thought-provoking though also not unproblematic material on this subject. For a brief overview of the ways in which scholarship has dealt with the concept of rhetorical tradition in the recent past, see Graff and Leff (2005) from this volume. Many contemporary rhetoric scholars have responded to the challenge of rethinking the rhetorical tradition by dividing it between two rather different pulls: one to theory and another to education or teaching (e.g. Hauser 2004 seems to summarize the view held by many).

II This certainly seems to be the basic assumption of Halloran (I976), which is sometimes regarded a foundational study for the emergence of 'tradition' criticisms in rhetoric scholarship. 
subsequent post-classical development of the rhetorical tradition. It is the unity of the ancient rhetorical tradition that is itself under investigation. Secondly, unlike many other rhetoric scholars, ancient and modern, who maintain that continuity and comprehensiveness in the field of ancient rhetoric emerge through a set of theories or practices of rhetoric, I will explore the possibility that the rhetorical tradition might have been more reliant on the perception and role of individual authors as guides to a particular way of approaching rhetoric. Hence, the following chapters will take a closer look at two critical moments that were crucial for establishing the overarching framework of the ancient rhetorical tradition, first as a sketch of Lysias and Isocrates in Plato (fourth-century BCE Athens) and then further elaborated and fixed in the critical works of Dionysius of Halicarnassus (first-century BCE Rome).

The dissimilarity of all these four authors to one another is obvious: Lysias counts among the most obscure of the wildly prolific authors from the period and Isocrates, by contrast, is an author who puts himself on every page he writes. ${ }^{\text {I2 }}$ Plato is the most revered philosopher of all time, whereas Dionysius of Halicarnassus has only recently received appreciation as an author in his own right beyond being conceived simply as a valuable compendium for poetry and criticism. ${ }^{\mathrm{I} 3}$ Bringing together those four authors in one study will inevitably put pressure on the readers' imagination, since dissimilarities between the authors are in turn reflected in the ensuing dissimilarities in the respective treatments of these authors. But embracing the perceived asymmetry between our writers will also help us comprehend the broad reach of rhetoric as a discipline in the making. All these four very different authors were contemplating the use and meaning of rhetoric as an

I2 On problems with Lysias and his corpus, see the provocative (though still highly valuable) contribution by Dover (I968). Isocrates is sometimes counted among the earliest biographers (or autobiographers) - see Momigliano (I97I), esp. 43-65; Hägg (20I2), 30-4I.

13 This may be an exaggeration, though 'Dionysius' revival' (or the need thereof) is discussed in the introductory pages of most recent contributions on this author. See, for example, Luraghi (2003); de Jonge (2008); Wiater (20I I); de Jonge and Hunter (2018). 


\section{Introduction}

object of study that could range from the technical and philosophical to the literary, from visual to aural, from poetic to the political. Hence, the breadth of authors represented in this project will hopefully result in a more wide-ranging and inclusive overview of the rhetorical tradition as it was first conceived of in antiquity.

\section{From Plato to Dionysius of Halicarnassus ...}

Plato's Phaedrus famously starts with a discussion of Lysias,

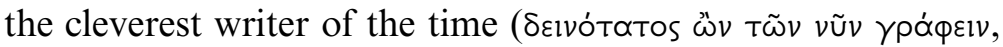
228a2), and with an examination of his playful speech about love. Whether or not the speech is actually by Lysias or presents (more plausibly) a Platonic exercise in Lysianic style,${ }^{14}$ there is a suggestion running through the whole dialogue that Lysias' speech is representative of a kind of rhetoric that was practised and presumably popular at the time. ${ }^{15}$ Indeed, the dialogue ends with Socrates sending a message to Lysias about what 'true' rhetoric ought to be about, in the

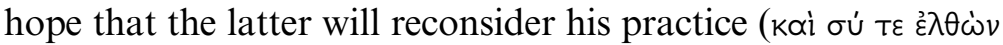

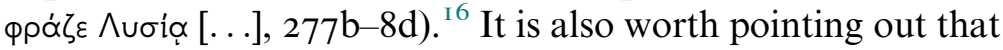
in the course of the dialogue, many more rhetoricians and speechwriters are mentioned and discussed, giving the reader a sense of liveliness that may have surrounded the topic of rhetoric at the time. But not only that, Plato characterizes and categorizes the practitioners he mentions (266d-68a) and thus offers a more structured approach to this buzzing field. By the end of the dialogue, Phaedrus realizes that an important, perhaps even crucial, player of the contemporary rhetorical stage has been left out - Isocrates. The question about how to

\footnotetext{
${ }^{14}$ The most recent commentator on the Phaedrus does not even consider the possibility that it could have been Lysias' own composition - Yunis (20 I I), 3: 'Plato, who composed the speech attributed to Lysias in the dialogue .... Hermeias of Alexandria, the earliest ancient commentator on the Phaedrus (fifth century CE), appears to have considered Lysias' speech as authentic; see Bernard (I997), 37.

${ }^{15}$ Cf. Yunis (20 I I), 8. I am very sympathetic to the discussion in Usher (2004) on the popularity of Lysias.

${ }^{16}$ Lysias is portrayed repeatedly throughout the dialogue as someone who needs to be turned to philosophy. See also $257 \mathrm{~b}$.
} 
understand this sudden reference to Isocrates at the end of the dialogue, after Socrates has set out the conditions for 'true' rhetoric, has puzzled readers since antiquity. ${ }^{17}$ Regardless of Plato's own specific views about Isocrates and his art that are discussed at more length below, the mere fact that Isocrates is evoked at this point in the dialogue seems to suggest that Plato is making a statement about rhetoric more generally. In the midst of the seemingly disparate practitioners of rhetoric, Plato envisions the field as a dyad: rhetoric could either be conceived of in the vein of Lysias or in that of Isocrates.

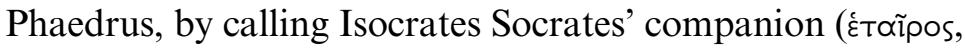
278e4), certainly seems to associate Isocrates with the true (philosophical) art of rhetoric that Socrates had just outlined previously. The fundamentally opposing views regarding philosophy and its methods advocated by Plato and Isocrates make any easy link between Isocrates and 'true' Platonic rhetoric impossible. Hence, many have noticed that Socrates remains only half enthusiastic about his friend Isocrates, and thus interpret this entire paragraph as Plato's ironical commentary on Isocrates' career and contributions to philosophy. ${ }^{18}$ Interpreting Socrates' words as negative irony seems wholly dependent on later developments of philosophy and the retrospective assessment of Isocrates as firmly belonging outside the history of this discipline. While Isocrates was surely his rival in their competing claims to philosophy and education, Plato's dialogues reveal, however, the broad extent of different views and educational context available for contemporary Athenians, and of those, Isocrates' school does seem to be among the more benign forms of education and one that stands closer to Plato than to many other contemporaries. Hence, it may be well worth taking Socrates' statement at the end of the Phaedrus at face value. He does express a

${ }^{17}$ See Cicero's comments on this section in Orator $4 \mathrm{I}-2$, where the context suggests that his interpretation of this last section of the dialogue might be regarded as unorthodox (me autem qui Isocratem non diligunt una cum Socrate et cum Platone errare patiantur).

${ }^{18}$ Many hold this view. See, for example, Yunis (20II), 22-3 and 243-6 with further bibliography. 
sentiment of hope in Isocrates' treatment of rhetoric and claims famously that 'there is some philosophy in this man's mind'. ${ }^{\text {I9 }}$ Unlike the exaggerated evaluations of previous rhetoricians and speechwriters, the qualification ('there is some philosophy') in the statement suggests that this might be Plato's first positive assessment of a contemporary writer and teacher. Isocrates is surely not perfect (i.e. he is not the consummate philosopher by any means), but there is something valuable in his teaching and work, something that sets him at a higher level than other practitioners of rhetoric. In other words, this final section of the dialogue shows Socrates comparing Isocrates' work favorably with all other teaching available at the time in Athens. Most specifically, however, the comparison is drawn between the Lysianic and Isocratean conceptions of rhetoric, and in this sense Plato's Socrates is not only creating competing notions of 'good' and 'bad' rhetoric, but he associates these conceptualizations with concrete figures - Lysias and Isocrates.

Plato's Phaedrus was a widely read and influential contribution to the subsequent development of rhetorical and critical thought. $^{20}$ His assessment of Lysias and Isocrates, but in particular of Lysianic style, in this dialogue paved the way for various critical engagements with Plato's own style. Dionysius of Halicarnassus clearly had this last section of the dialogue in mind when he wrote his critical essays on Lysias and Isocrates as part of his study of the ancient orators. When he tries to explain the differences between Lysias and Isocrates, Dionysius proposes that the latter is more impressive with grand subjects, perhaps because 'there is some grandeur in his nature', ${ }^{2 I}$ thus expressing a very similar assessment to that found in Plato's Phaedrus ('there is some philosophy'). ${ }^{22}$

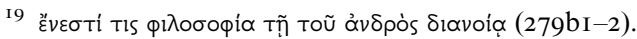

20 See Yunis (20II), 25-30 with further bibliography. Excellent discussions of specific moments in the reception of Phaedrus are Trapp (I990) and Hunter (20I2), I5I-84.

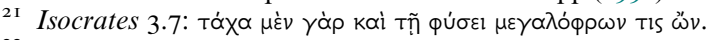

22 Dionysius has a complicated relationship to Plato and some of his more outrageous assessments of the philosopher have certainly deprived him of benevolent scholarly attention. A helpful discussion of Dionysius' treatment of Plato (and Plato's style in particular) is Hunter (2OII), chap. 4. 
Dionysius has, however, other plans with this material and his work on Lysias and Isocrates paved the way for expounding his educational program and practice in the Roman environment. ${ }^{23}$ His observations on both writers have exercised a long-lasting impact, first, on the way these two authors have been received and read in the subsequent rhetorical and critical tradition, and, second, on the way rhetorical criticism itself has been practised in antiquity and beyond. ${ }^{24}$ Even in most recent times, views on Lysias' importance as the leading figure of simple Attic style and the breakdown of the particular characteristics of his writerly skills go back to Dionysius' essay on the orator. ${ }^{25}$ His contribution to Isocratean scholarship has been, similarly to his impact on the reception of Lysias, crucial for subsequent perceptions of Isocrates as a prose author with significant claims to political philosophy. ${ }^{26}$ In fact, anyone planning to take a serious interest in philosophy amidst their rhetoric studies, ought to make Isocrates their frequent companion and source of philosophical education (Isocrates 4.4). Even though, as will be shown, Isocrates appears always to have had his loyal followers, Dionysius' aim to raise him from mere stylistic study to (what might be called) philosophical rhetoric was instrumental to conceptualizing Isocrates' position as central to the history of rhetoric and political thought. In Dionysius' essays, then, Lysias and Isocrates have become the pillars of the rhetorical tradition.

${ }^{23}$ Hidber (I996) is the locus classicus for showing how Dionysius of Halicarnassus' critical essays (and the introduction to Ancient orators in particular) functioned as a literary-political manifesto.

${ }^{24}$ In this context, see for example de Jonge (2005) on Dionysius' technique of 'metathesis'.

25 See, for example, the introductions to the editions of Lysias' speeches, such as Carey (I989), 6: 'All modern judgements on Lysias' style take as their starting-point the perceptive essay of Dionysius of Halicarnassus in his collection On the Ancient Orators'; Avezzù (199I), 9-I0; Edwards (1999), esp. 6-8; Todd (2000), 7-8. Dionysius is the predominant dialogue partner also in Usher's (I999, 54-II 8) discussion of Lysias' rhetorical technique.

${ }^{26}$ While his dependence on Isocratean thought has informed many recent studies of Dionysius' writings (e.g. Wiater 20 I I), Dionysius' influence on Isocratean scholarship appears to be a far less examined territory. 
But who were Lysias and Isocrates? And why would these two figures, of all important rhetoricians and orators of the ancient world, come to play such a central role in the development of the rhetorical tradition?

\section{2 ... and from Lysias to Isocrates}

Lysias, the famous speechwriter and one of our major sources for the socio-cultural history of the fourth century $\mathrm{BCE},{ }^{27}$ is nowadays relatively rarely talked about as an artist and rhetorician in his own right. Plato's Phaedrus suggests that his contemporaries might have considered him not only a speechwriter for the law courts, but more like an intellectual whose entertaining skill in narrative and argumentation gained him many admirers. ${ }^{28}$ Indeed, the ancient reception of Lysias suggests that his works were particularly appreciated as models for rhetorical writings and he appears to have played an important role in the literary-critical tradition from ancient to modern times. However, since Dover's provocative and groundbreaking work on Lysias (published in I968), there has been very little work done on Lysias as a literary or rhetorical figure. ${ }^{29}$ The first two chapters of this book aim to pay closer attention to the influence of Lysias' work on ancient notions of style and rhetoric, and to the perception and portrayal of Lysias amidst his contemporaries. By tracing the

27 As has been long noted, Lysias' speeches provide an invaluable perspective on the lives of Athenian citizens, and not only of the wealthiest and most powerful. For a brief overview of Lysias' importance as a historical source, see the brief introduction (with further bibliography) of Todd (2007), I-5. The relevance of Attic orators for history is illuminatingly discussed by Todd (I990). Recent work on Lysias seems to verge towards historical scholarship, and this tendency is illustrated in the literary overview of Lysias scholarship (between 1905-2000) in Weissenberger (2003).

${ }^{28}$ In his analysis of Lysias' rhetorical technique, Usher (I999), I I6 argues that it was indeed his creativity in non-argumentative sections of the speech, and in particular in his narratives, that made his speeches stand out among previous and contemporary writers.

29 Despite the dissenting responses to Dover's unsettling claims about Lysias and his corpus (especially vocally expressed in Usher (1976)), this work seems to have remained a difficult presence in Lysianic scholarship. Exceptions include (among others) Lateiner (I98I), Carey (I994). 
Lysianic tradition from the early fourth until the first century $\mathrm{BCE}$, we will follow the rise and fall of the appreciation of Lysias' talent and explore the background to later Roman interest in his writing. A pervasive thread in the ancient reception of Lysias is to be found in the fascination for his effective and enchanting style of writing, so much so that he becomes the primary representative of the kind of rhetoric that is concerned with stylistic features and their alluring associations with persuasion.

Ever since Isocrates entered the canon of (ten) Attic orators, ${ }^{30}$ he has been granted a secure position in the history of rhetoric, accompanied, however, almost always by a certain unease about the 'real' place of his works in ancient literary and philosophical writing. ${ }^{3 \mathrm{I}}$ It seems that, at least partly, this unease stems from the dual character of Isocrates' writing: his discourses are on the one hand deeply concerned with public life and rhetoric; on the other, however, they play down the importance of oral culture and propagate openly the idea of philosophy and institutionalized education, thus undermining the value of speechwriting as a means to achieve the latter. ${ }^{32}$ Isocrates, who opened his school in Athens around the $390 \mathrm{~s}$ BCE and, as it appears, was probably the first to establish his own institutionalized school, called his teaching 'philosophy'. ${ }^{33}$ The last three chapters of the first part of this book

${ }^{30}$ It is plausible that such cataloguing might have taken place in the latter half of the first century вCE, i.e. contemporaneously to Dionysius' writing of his essays on the orators. For a helpful discussion, see Worthington (I994) and O'Sullivan (I997).

${ }^{31}$ For a summary of different ways scholars have attempted to categorize and think about Isocrates' work, see Too (I995), I3-35.

${ }^{32}$ It is very plausible that Isocrates never performed his speeches. Despite the fact that his work strongly advocates written style as a sign of culture and education, his writings are nevertheless cast in the fictitious form of oral presentation. See, for example, Usener (I994), I 8 with further bibliography.

33 Numerous scholars have discussed Isocrates' usage of the term and his rivalry with Plato (and, later on, with Aristotle) over the right to claim the notion 'philosophy' for his work. One of the most thorough discussions on this topic is Eucken (I983). The standard conclusion drawn in the scholarship is expressed by Nightingale (I995), I3-59 who claims that Plato won the combat over the correct application of philosophy, which has in turn determined the subsequent reception (and relative neglect) of Isocrates. I will offer here a more nuanced picture of the rivalry between Plato and Isocrates and suggest that the latter continued to have followers who also took seriously his notion of philosophy. 
take a closer look at the construction of Isocratean rhetoricphilosophy, both as he conceived it in his own works and how his work and contributions were perceived by his contemporaries and in later reception. The main focus of this inquiry is to establish Isocrates' own perspective on rhetoric and philosophy and, then, to contextualize his contributions to rhetorical thought.

Isocrates was undoubtedly an influential figure in fourthcentury BCE Athens and, as will emerge from this study, he was considered a respected rival by Plato and famous for promoting an all-round education in areas essential to the practical demands of human life. His emphasis on writing as the best way to cultivate education or paideia ( $\pi \alpha 1 \delta \varepsilon i \alpha)$ explains the painstakingly polished style of his writings, and this aspect appears to have divided his followers into two groups: those who followed Isocrates' stylistic/formalist practices in writing (a group about which we have very limited information), and those who were inspired by his insights into the workings of education and culture. It is this latter trend that became, in certain moments in history, a particularly dominant way to conceptualize the moral and political demands of rhetoric and practical philosophy.

But what about Demosthenes? By focusing on Lysias and Isocrates, are we not missing out the most influential orator of the ancient world, Demosthenes, the one who becomes conceived in later rhetorical theory as the consummate orator? ${ }^{34}$

Even though Demosthenes will prove a useful comparative figure for the following analyses on Lysias and Isocrates, there are two main reasons why his influence on the development of rhetorical tradition will be treated as secondary. First and foremost, Demosthenes was a famous Athenian politician and was not associated with rhetorical education, philosophers or the sophists. His rivalries with other contemporary politicians (especially with Aeschines) are well recorded and these constitute invaluable sources for the political circumstances of

34 E.g. Cic. Brut. 35, D. H. Is. 20, Quin. Inst. Or. I0.I.76. 
fourth-century BCE Athens. In fact, he does not seem to be associated with the theoretical or educational side of rhetoric until somewhat later. ${ }^{35}$ Peripatetic philosophers after Aristotle may have played a part in the construction of the image of Demosthenes as a hard-working and cultivated (rather than naturally talented) orator, ${ }^{36}$ but neither Plato, nor Aristotle those involved in sketching the outlines of the rhetorical tradition - mention Demosthenes or associate him with anything other than politics. ${ }^{37}$ Later, Demosthenes will be associated with the development of symbouleutic theory, ${ }^{38}$ but in the late fifth- and early fourth-century contexts - when thinking about rhetoric as a separate field first arises - distinctions between deliberative and judicial rhetoric were very difficult to draw. ${ }^{39}$ In other words, while Demosthenes receives an important place in the subsequent history of rhetoric, the central moments of conceptualizing the field seem to occur a generation earlier through the dyad of Lysias and Isocrates.

Secondly, the circumstances under which Demosthenes appears to be added to rhetorical theory in the first century $\mathrm{BCE}$, and indeed conceived as the paragon example of successful rhetoric, seem to be politically motivated. Even though he is already singled out in Ps. Demetrius as an example of

35 Cooper (2000), 224. Demosthenes' rise to prominence in rhetorical theory underpins most contributions in Martin (2018b), including Martin (2018a) and Wooten (2018) with bibliography.

${ }^{36}$ The various Peripatetic attitudes to Demosthenes are persuasively explored in Cooper (2000).

37 Isocrates, unsurprisingly, makes no mention of Demosthenes. Aristotle's Rhetoric refers to Demosthenes three times, but scholarship seems unusually uniform in regarding only one of the three mentions to refer to the famous politician (II.24 I4OI 32 ; the fallacy introduced shows Demosthenes in a negative light). In other cases, he seems to have a namesake in mind. On Aristotle's Rhetoric, see Cope (I867), 45-6 and Trevett (I996), 37I-2 with bibliography. On the mainstream of Demosthenes' afterlife as strictly a political business, see Canfora (20I8). It seems that Demosthenes' writerly style, presumably influenced by Isocrates, had already aroused attention during his lifetime (see Canfora (20I8)), but this does not seem to have been picked up in literary scholarship until somewhat later.

${ }^{38}$ Demosthenes becomes for example an important rhetorical influence for Hermogenes who does seem to regard Demosthenes as a practitioner and a theorist. On Hermogenes' relationship to Demosthenes, see Rutherford (I998).

39 See, for example, Harris (2013). 
'forceful' style (245), ${ }^{40}$ his real recognition as a genius of rhetoric comes first with Cicero and, subsequently, in the essays of Dionysius of Halicarnassus. ${ }^{4 \mathrm{I}}$ Cicero's admiration for Demosthenes is clearly tinged by his felt affinity with Demosthenes as a politician and orator. In Cicero's conception, Demosthenes is not the man for the masses, but rather a sophisticated educator of the Athenian people, and Cicero finds close affinity with Demosthenes in his own mission in the Roman political scene of the time. ${ }^{42}$ Furthermore, in Cicero's Orator, Demosthenes is not associated with any particular innovation, but rather conceived as an orator-politician who excels in all three styles: the plain, the middle, the grand (69). Similarly to Cicero, Dionysius of Halicarnassus views Demosthenes as the consummate orator who is not to be associated with any style in particular, but who vacillates between different existing styles like Proteus, who can assume any shape he wants (Demosthenes $8.2-3) .{ }^{43}$ In other words, Demosthenes is cast among the first-century BCE critics as the perfect practitioner of rhetoric, moving between existing categories of style and modifying his speeches so as to surprise and arouse admiration for his rhetorical competence. However, he does not seem to be conceived as contributing to the development of the overarching structure of rhetoric. At least not primarily and, as such, a closer analysis of Demosthenes' participation in the development of the ancient rhetorical tradition will have to await another study.

$4^{0}$ This is not, however, a category reserved only for Demosthenes. Ps. Demetrius also discusses examples drawn from Aeschines or Lysias (259) under the "now so fashionable' deinotes (245). On Ps. Demetrius and Demosthenes, see Cooper (2000), 229-34.

${ }^{4}$ I Ps. Plutarch's Life of Demosthenes records the critical reception of Demosthenes among the Peripatetics and also suggests that while beloved by the masses, Demosthenes was less popular among the elite. This might explain why Demosthenes has not been recorded in rhetorical theory until Ps. Demetrius and was not given more prominence until, eventually, Cicero.

${ }^{42}$ A good recent overview of Cicero's treatment of Demosthenes is Canfora (2018) with bibliography.

43 See also Wooten (2018). 


\section{Creating the Ancient Rhetorical Tradition}

The parallel lives of the two rhetorical traditions, the 'Lysianic' and the 'Isocratean' conceptualizations of rhetoric, that both gained impetus in the fourth century BCE are, for the first time, brought together by the Augustan critic and historian Dionysius of Halicarnassus. Dionysius arrives in Rome at the end of the civil war (30/29 BCE) and his prolific career overlaps with the first decades of Augustus' reign. ${ }^{44}$ This means that the cultural and political revolutions of Rome have left an imprint on Dionysius' writings, in history as well as in criticism and rhetoric. ${ }^{45}$ Dionysius considered himself primarily a historian, ${ }^{46}$ but his critical work has been an invaluable source for our understanding of ancient literary criticism (in theory and practice), theories of language and verse, contemporary debates in style, and so on. He plays such an important role in all these fields of inquiry that his actual arguments and positions are sometimes overlooked in search for the sources that he discusses. ${ }^{47}$ This has probably affected especially the fate of Dionysius' critical work On Composition of Words, which has now received meticulous analysis and appreciation in its own right in the work of de Jonge (2008). Dionysius' critical essays on ancient orators have, however, found fewer admirers in contemporary scholarship. With the exception of his Demosthenes, ${ }^{48}$ there is no recent extensive study dedicated to understanding Dionysius' attitude to and treatment of

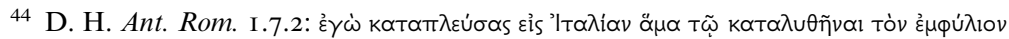

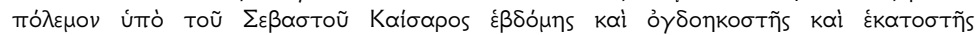

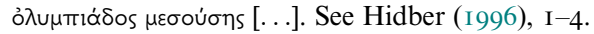

45 De Jonge (2008), I-48 provides a useful overview of Dionysius' intellectual contacts in Rome. Wallace-Hadrill (2008) is a persuasive account of Rome's cultural revolution.

${ }^{6}$ D. H. Ant. Rom. I.I.2, where he describes his historical work as $\mu \nu \eta \mu \varepsilon \tilde{\alpha}$ тก̃

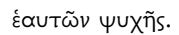

47 These and other dangers in Dionysius scholarship are discussed in de Jonge (2008), 3-9.

${ }^{48}$ Even in the case of van Wyk Cronjé (I986), which is a comprehensive examination of the difficult composition history of Dionysius' Demosthenes, there is little discussion of his engagement with Demosthenes and its relationship to the former's ideas of rhetoric and education. 
ancient orators, ${ }^{49}$ or to the particular role of Lysias and Isocrates in his conception of rhetoric.

The second part of the book hopes to address this lacuna in the scholarship and explores the possibility of regarding Dionysius of Halicarnassus not only as another critic participating in the development of the rhetorical tradition, but indeed as someone with whom the ancient rhetorical tradition as a whole is conceived as a finished product, ready to be passed on to his contemporaries and future students. I will hence reject the generally accepted view of Bonner (I939), who considered Dionysius' essays on Lysias and Isocrates (the first two essays of the volume On the Ancient Orators) as his preliminary and somewhat inept attempts in rhetorical criticism that were to be surpassed in thought and technique by his later works. Instead, the last two chapters of the book (Chapters 7 and 8), in many ways the culmination of this current project, argue that these two essays, dedicated to Lysias and Isocrates respectively, actually manifest Dionysius' fundamental commitments to rhetorical theory that were expanded and further developed in his later works. Moreover, it will be argued that Dionysius' observations of the two writers, though influenced by the previous strand of thinkers (and Plato's Phaedrus in particular), were innovative at the time when he wrote his essays (the first century BCE) and have remained groundbreaking in the scholarship and practice of ancient rhetoric ever since. In other words, Dionysius of Halicarnassus emerges from this book as a teacher of rhetoric, whose associations of ancient rhetorical thinking with Lysias and Isocrates mark a crucial moment in the creation of the rhetorical tradition.

49 The closest to this is Hidber's (I996) extremely valuable edition, translation and commentary on the introductory essay of Dionysius' Ancient Orators. Bonner (I939) remains the most influential treatment of Dionysius' critical essays and, as such, an important dialogue partner for my interpretation of Dionysius' thought. 
PART I

LYSIAS, ISOCRATES AND PLATO: ANCIENT RHETORIC IN ATHENS 


\section{LYSIAS IN ATHENS}

Lysias is as prominent a figure in the Greek rhetorical tradition and prose canon as he is a shadowy one. While surely among the most widely read Greek authors, we do not really know much about him and questions around the authorship of the so-called Lysianic corpus have troubled critics since antiquity. In fact, the large number of speeches that had been attributed to him by the first century BCE prompted Dionysius of Halicarnassus to have a longer discussion of the methods of testing Lysianic authorship (Lysias IO-I2). ${ }^{\text {I }}$ Throughout antiquity and until the mid-twentieth century, the absence of solid biographical information and of any conclusive evidence about the author did not prevent scholars from constructing full-scale narratives about Lysias' life and works, mostly based on Lysias' own speeches and possible reconstructed encounters with other contemporary intellectuals. ${ }^{2}$ It was the groundbreaking (and highly controversial) work by Kenneth Dover

${ }^{\text {I }}$ Ps. Plutarch, Lives of Ten Orators 836a claims to know of 425 speeches circulating under the name Lysias. He also reports there that Dionysius cut the number of authentic speeches down to 233.

${ }^{2}$ In the ancient biographical tradition, for example, Ps. Plutarch's account offers more biographical details, reported with higher certainty, than we see in Dionysius. He reports, for example, the names of Lysias' grandfather and great-

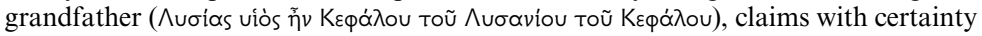

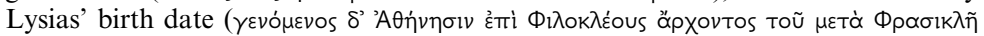

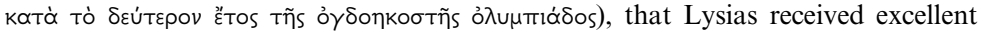
education in Athens and later instruction in rhetoric from Tisias and Nicias (кỏk

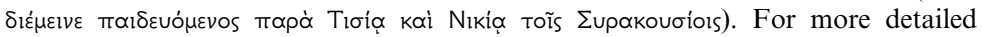
discussion, see Schindel (I967), esp. 33-4I; Todd (2007), 8 n. 29. Useful appraisal of Ps. Plutarch's mode of writing and its relationship to different source texts is Pitcher (2005). Edwards (1998) persuasively argues for a more positive evaluation of the whole Ps. Plutarchan project. Closer to contemporary times, Blass (I868) constructs in his authoritative account of Greek orators a detailed bibliographical account of Lysias' life: 'Ueber die Lebensumstände dieses Mannes haben wir ziemlich reichhaltige Quellen' (33I). 
which brought about a change in Lysias studies. ${ }^{3} \mathrm{He}$ argued for a very different view of Lysias (and, as Usher noted, ${ }^{4}$ implicitly of all Attic orators) by questioning the ability of the existing texts to point us towards the 'actual' speeches of the historical Lysias. In his skepticism, Dover's work was very much in keeping with the contemporary preoccupations and literary theories of the I96os. Dover argues that the attribution of works to Lysias and the building up of his corpus to the size that Dionysius reports by the first century $\mathrm{BCE}$ was a process that had started already during the orator's lifetime, and that there was probably a particular boost for literary forgeries to be passed off under Lysias' name immediately after his death. ${ }^{5}$ In other words, through the examination of chronology, ideology and artistry, Dover concluded that there is very little that we can say with full confidence about Lysias and, in particular, about Lysias' authorship of the speeches in the corpus. The many stages that go into the emergence of a text, from the litigant to the speechwriter to the bookseller to publication, processes that we generally ignore for the sake of simplicity, ${ }^{6}$ are all highly susceptible to modification and could easily cast a shadow on any comfortable attribution of texts to an author 'Lysias' whom we actually know very little about.

There are problems with this view that have since been highlighted by others. For example, Dover uses pervasively the concept of a 'consultant' for the Greek translation of

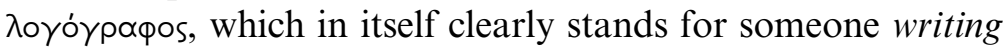
the speech (rather than an advisor); in subsequent criticism, Lysias is regarded as the writer and author of these speeches, and we see no hint in Dionysius of Halicarnassus' treatment of Lysias for a view of Lysias as a consultant and not a prose artist. ${ }^{7}$ Dover's challenge, which was met with significant

\footnotetext{
3 Dover (I968). $\quad{ }^{4}$ In his response to Dover's Corpus Lysiacum, Usher (I976), 40.

5 Dover (I968), 23-7.

${ }^{6}$ Or because we 'have become accustomed to treat oratory as if it were philosophy, history, poetry or technical literature' (I95-6).

7 Many more arguments have been brought against Dover's thesis. It is worth mentioning also Kennedy's suggestion $($ I970, 497) that speeches were out there to benefit the writer and so it was more likely that the speechwriter had a final say about the published form. Usher (I976) evokes some anecdotes about speechwriting
} 
resistance upon its publication, has nevertheless been a productive one and has since pushed scholars further to explore the less visible elements of rhetorical practice. ${ }^{8}$

Lysias' corpus has since been fruitfully examined as a historical source for this extremely fascinating time period (c.403-380 BCE) for which it provides valuable and unique information, thus offering a rare window into the actual lives of Athenians. ${ }^{9}$ In this context, it has mattered less whether or not the author of these speeches is Lysias or somebody else trying to come off as Lysias, as long as the texts could be relatively securely dated to the fourth century BCE. This approach would have been unusual for ancient critics, who looked at the orators primarily (if not exclusively) as masters of style and rhetoric. ${ }^{\text {IO }}$ The earliest moment of Lysias' reception in Plato's Phaedrus, which in many ways (as will be argued below) came to determine the orator's name and reception for posterity, is a good example. This chapter will follow the figure of Lysias and his image that emerges through his own writings but in particular through his reception in the works of others. In other words, we will not try to establish historical information about the actual person Lysias who lived and wrote in Athens of the fifth and fourth centuries

that similarly indicate that the traditional view of speechwriting was more common in the ancient sources. In general, the most straightforward rejection of Dover's suggestion after the publication of Corpus Lysiacum was Usher (I976), which should still be read alongside Dover's book, as it brings many reasonable counterarguments against Dover's composite authorship hypothesis. Todd provides a useful recent assessment of Dover's claims and the responses and criticisms made against it $(2007,28-9)$. Todd is certainly more optimistic about the authenticity of Lysias' speeches than Dover, but he readily acknowledges that for him the question of authenticity is secondary to the value of these speeches as historical documents.

${ }^{8}$ A good example is the question of publication itself, for which see also Worthington (I993). Rubinstein (2000) has undertaken to explore the idea of consultation in classical Athens.

9 Stephen Todd has produced the most authoritative accounts of the Lysianic corpus as a historically relevant and unique contribution to our knowledge of the fourth century BCE. See Todd (1993) and (2007), I-5 and 26-32 with further discussion and bibliography.

Io Todd (2007), 38 acknowledges this fact and offers a helpful - if necessarily very brief - overview of the kind of commentary tradition that Lysias' corpus has received from antiquity to contemporary times. It has always been one dominated by questions of style and rhetoric. 
BCE, but rather examine the importance of the persona of Lysias, how this name 'Lysias' became significant in rhetorical studies, what kind of rhetorical tradition it was associated with, and how understanding and treatment of Lysias and his work changed from the fourth to the first century BCE. This is no arbitrary choice, for the mentioned time frame captures the two crucial moments for the reception of Lysias and his corpus: the fourth century BCE that marks Lysias' activity as a speechwriter in Athens, and the first century BCE when critics indicate that Lysias has become a chief representative of the tradition of rhetoric which is primarily concerned with style. Dover had once demonstrated our inability to get hold of the historical Lysias and to assess the authenticity of his corpus, but this chapter moves further and looks at what is left of tò Nuolakóv (the 'Lysianic'), taking therefore a closer and more cautious look at the figure of 'Lysias' and his shadow in his contemporary fourth century $\mathrm{BCE}$ and later literaryrhetorical culture. Hence, without an ambition to tell a story of the practices and works of the historical person, this chapter will aim to ask (and answer) what is at stake in evoking the name (and author) Lysias.

\section{I.I Lysias ...}

Our primary evidence for Lysias' life is limited to the following sources: Lysias' speech I2 (Against Eratosthenes) and Against Hippotherses, Plato's Phaedrus, Cleitophon and the Republic, and Apollodorus' Prosecution against Neaira (\$\$2 I-3). ${ }^{\text {I }}$ Lysias' speech I 2 and Against Hippotherses (fr. 70 Carey), the latter of which survives in fragmentary form (we have roughly the last 200 lines of this speech), are generally taken to have been written by Lysias for his own court cases. The tone and first-person address make it highly likely that speech

${ }^{I}$ All references to the speeches of Lysias and to the extant fragments are based on Carey (2007). Even though Prosecution against Neaira circulated among the Demosthenic corpus, the speech was not written by him and was probably authored instead by Apollodorus. For more extended discussions of Lysias' biography, see Dover (I968), 28-46; and Todd (2007), I-I7 with further bibliography. 
I 2 was delivered by Lysias himself; Against Hippotherses, however, refers to Lysias in the third person which indicates that it had been delivered by someone else on his behalf. ${ }^{\mathrm{I} 2}$ Which of the speeches was first, is unclear and depends on how we interpret the ambiguous and lacunous evidence of Lysias' involvement in the restoration of democracy and - further whether and how we look at the broader context of his career (including his possible literary ambitions). ${ }^{\mathrm{I}}$

The two speeches tell us that Lysias was a son of Cephalus, a wealthy Syracusan who moved to Athens at the invitation of Pericles and lived there as a metic when Lysias was born (I 2.4:

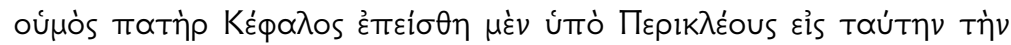

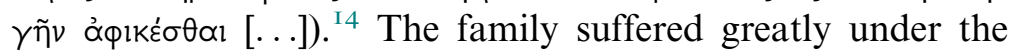
Thirty (the main topic of both speeches), though probably not losing all its fortune, for Lysias seems to have been able to still give substantial support to the democrats after having fled and been deprived of his family property (fr. 70, I63 ff.). It is generally believed that after the Thirty Tyrants were overthrown in $403 \mathrm{BCE}$, Lysias, in order to recover from financial

I2 For the complicated issue of Lysias' naturalization and the legal rights of metics or

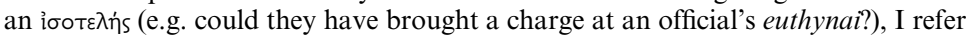
to Todd's excellent discussion (2007), I2-I7. Todd also points out an interesting possibility: even if Lysias was prevented from delivering speech $\mathrm{I} 2$ in person, it is conceivable that he might have written the piece as if it was (meant to be) delivered and circulate it to show what he would have said on the occasion. Todd (2000), I I4, repeated in (2007), I3-I4.

13 Todd (2007), against Loening (198I) and (1987), argues for an earlier composition date for speech I2, but readily admits that this is a genuine question which is difficult to answer satisfactorily. The question hangs largely on how to interpret lines $195^{-6}$ in fr. 70 which talk about building walls - is it building or rebuilding the walls? Both Indelli (2000), 203 and Medda (2003), I8I-8 argue for the later rebuilding, which would mean that the terminus post quem of Against Hippotherses is 394 BCE. The relative chronology of the two speeches does not play a crucial role in the following discussion, though it seems possible that the question of legal genre is more crucial to the discussion than Loening suggests. It is probable that Lysias could not, or would not want to, pursue a public trial to recover his property, especially as he has been branding himself as someone happy to invest in

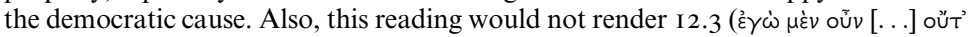

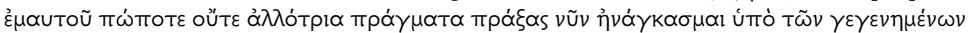

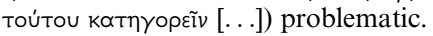

${ }^{14}$ Aside from speech I2, Dover (I968), 40-I shows that Against Hippotherses was probably an important source for later biographical accounts of Lysias' life and provided the information that could not be obtained from speech I 2 and Plato. On this fragmentary speech (and P.Oxy I606) see the recent edition by Medda (2003). 
difficulties, launched his career as a speechwriter. ${ }^{15}$ Thus, speech I2 Against Eratosthenes on the murder of his brother Polemarchus appears to be the earliest speech in the corpus, and certainly one of the outstanding moments to determine his writerly success. This speech is also one of our best sources for the events that took place in Athens under the Thirty, and the speech itself displays very strong democratic and antioligarchical language. We have no independent evidence of Lysias' political views, and it is very probable that this ideological language can be explained by the fact that at the time when the speech was delivered it was common to appeal to democratic values and governance in order to secure the benevolence of juries. ${ }^{\mathrm{I}}$ Nevertheless, the fact that speech I 2 exhibits these democratic sympathies in such vehement fashion and that these pro-democratic emotions come from one of the wealthiest metics in Athens might have played an important role for the subsequent image of 'Lysias'. ${ }^{17}$ Furthermore, it is conceivable that the political implication of Lysias' pro-democratic self-fashioning is also reflected in the reception of 'Lysias' in Plato and other philosophers.

The biographical tradition complicates the picture significantly in multiple ways. Dionysius of Halicarnassus is the author of the earliest, and most reliable, biography. He adds that at the age of fifteen Lysias left Athens with his brother Polemarchus to join the colonists at the founding of Thurii in Magna Graecia (D. H. Lysias I.2), but returned to Athens in 4I2/I I after being

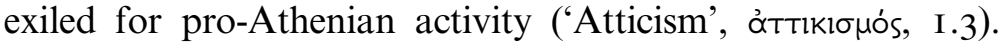
From this data, Dionysius adduces the birth date for Lysias to around $459 / 8$ and death to around $379 / 8$ or $378 / 7$. Ps. Plutarch's

${ }^{15}$ E.g. Shuckburgh (I979), I2; Carey (I989), 2-3; Edwards (I999), 2; Todd (2007), I3.

${ }^{16}$ Dover (1968), 47-56 on the impossibility to conclude anything about Lysias' own personal politics.

${ }_{17}$ The pro-democratic image is enhanced also by his Hippotherses where he draws attention to his benefactions towards the democratic counter-revolutionaries, and I wonder whether we might potentially add here also the spurious speech On His Personal Benefactions (frag. sp. LII), which is cited three times by Harpocration. Todd (2007), 6 is cautious and suggests that the latter might simply be an alternative title for the speech Hippotherses, but - whether this is true or not - it nevertheless draws further attention to Lysias' democratic outlook/commitments. 
account of Lysias' life is dependent on Dionysius' and supplemented by information derived from Lysias' speeches and other material. The most relevant, if also most problematic, addition is the association of Lysias with the teaching of Tisias and Nicias. The latter is an unknown name in Sicily, probably a textual corruption, ${ }^{18}$ but Tisias is - of course - famously linked to the early beginnings of rhetoric. The ancient tradition after Dionysius, who does not mention Lysias' possible connections to the Sicilian rhetoricians, ${ }^{19}$ continues to make references to the association of Lysias with rhetorical teaching (cf. Cicero Brutus 48).

The main complications added by the biographical tradition are twofold: first, there are some chronological challenges that emerge with dating Lysias' birth to as early as $459 / 8$, a tradition that seems to start with Dionysius and is followed by all other ancient sources. ${ }^{20}$ This early date is somewhat difficult to reconcile with the information we have about Lysias' life from Apollodorus, ${ }^{21}$ but it also poses difficulties for the dramatic date of Plato's Phaedrus. ${ }^{22}$ I would like to reiterate at this point that the question of the dramatic date is not in itself a problem, in as far as we are not trying to establish an actual or historical moment where Lysias would have met Phaedrus. There are plenty of historical inaccuracies, deliberate or not, in Plato's work to make it clear that Plato's attitude to his characters was not driven by aims for historical accuracy but rather by artistic and philosophical ambition. ${ }^{23}$ His envisioned character meetings were fictional and thus do not require us to

${ }^{18}$ Roisman et al. (2015), I25.

19 'Tisias and Nicias' in D. H. Lysias I is Usener's emendation based on Ps.-Plutarch.

${ }^{20}$ For a full-scale discussion of all challenges, see Todd (2007), 5-I7.

${ }^{21}$ Information about Lysias in his Against Neaira, dated to the 340 , suggests that if an earlier birth date is to be accepted, Lysias' mother would have lived to a very advanced age and Lysias was keeping a mistress in his late seventies. Not impossible, but quite unlikely. Dover (I968), 34-8; Todd (2007), Io.

${ }_{22}$ Dover (I968), 28-46; Nails (2002), I90-4, and 3 I4.

${ }^{23}$ Ancient sources have presented Plato's inaccuracies in anecdotal form. See, for example, Athenaeus II.505d reporting Gorgias' response to Plato's Gorgias or Diog. Laert. 3.35 about Socrates' own reaction to Plato's reading out loud his Lysis. See Riginos (I976), esp. 93-4 and 55. On Plato's playful use of historical characters, see Blondell (2002), 3I-7. 
conclude anything about an actual historical encounter. ${ }^{24}$ More important is the way in which Plato's imagined dramatic date contributes to the overall representation of the character in view. In our case, a dramatic date before 4I5 BCE (Dover's 4I 8-I6 BCE is an attractive proposal) would simply mean that Lysias spent quite some time in Athens between then and 403 BCE when he allegedly took up speechwriting without engaging with rhetoric or at least without leaving for posterity evidence of any such potential (rhetorical or otherwise) activity. And as such, it turns out that the question whether the dialogue is envisioned to take place in the early or late $4 \mathrm{IOS}$ is not in itself a major one.

The second, and arguably more problematic, question emerges from the representation of Lysias' rhetorical teaching and practice in that dialogue. The ancient evidence (the biographical tradition seems here in agreement with, or perhaps even dependent on, Plato's Phaedrus 228a2) presents Lysias as having engaged in rhetorical activity (either through studying or teaching) much earlier than the proposed start of his speechwriting career. ${ }^{25}$ Even though it is often acknowledged in modern scholarship, the biographical tradition is not a reliable source and, with the absence of any independent evidence, Lysias' possible pre-403 rhetorical activity is generally brushed aside. ${ }^{26}$ While it is indeed rather unlikely (and definitely not alluded to in the Phaedrus) that Lysias would have authored a technical handbook, Lysias' overall characterization in the dialogue seems to make more sense if we consider the possibility of Lysias having had a sort of intellectual or rhetorical following before his speechwriting career started soon after

${ }^{24}$ Even though Plato's characters are all (with the possible exceptions only of Callicles and Diotima) actual historical people. Blondell (2002), 3I; Nails (2002), 307-8; Graham (2007); Yunis (20I I), 8.

${ }^{25}$ Suda $\lambda 858$ (Lys.) attributes a technical handbook to Lysias. Yunis (20I I), 8 takes this reference to rhetorical activity in the Phaedrus as support for the dramatic date of the dialogue as not much earlier than $403 \mathrm{BCE}$, thus not giving much weight to the possibility of Lysias having had a successful career in rhetoric before taking up speechwriting.

26 Todd (2007), I2 explains away the identification of Lysias with an established contemporary writer as his 'back-projection' from the time of writing. 
the restoration of democracy in $403 \mathrm{BCE}^{27}$ An independent source that seems to corroborate this view is Apollodorus' Against Neaira, where Lysias is referred to as a sophist (бoфıтtń, §2I). ${ }^{28}$ Whether or not we should accept this detail about Lysias' possible rhetorical activity in Athens before 403 $\mathrm{BCE}$, it is clear that the closer the dramatic date is to $403 \mathrm{BCE}$, the more time Lysias has had to gain reputation in Athens and thus to deserve the wholehearted praise of Phaedrus as one of

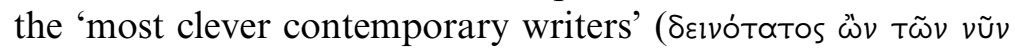
үрóфııı, 228a2).

\section{I.2 ... and the Corpus Lysiacum}

Let us move on from Lysias' life to his output. Estimating by the number of speeches attributed to Lysias by the first century $\mathrm{BCE}$, he was either extremely prolific (especially given his 'late' start) and/or highly regarded enough to be used as a 'mark of quality' to raise the literary status of speeches written by others. In fact, the number of items (425) attributed to him in antiquity makes him by far the most productive speechwriter; the number of speeches that are attributed by Ps. Plutarch to other Ten orators, for instance, never exceeds $75 .^{29}$ In comparison with the 233 speeches that Dionysius accepted as genuine in the first century BCE, our modern editions present 34 or 35 speeches, plus fragments which in

${ }^{27}$ Accepting the tradition of Lysias as somehow active in the rhetorical scene of the day also gives Plato another playful inconsistency in his presentation of Lysias. Namely, in the beginning of the dialogue Lysias is portrayed as an entertainer and borderline teacher of rhetoric, while in the later part of the dialogue reference is made to his logographic activity (257c5). Is he both? At any rate, Plato's Phaedrus seems to be the first place where Lysias' rhetoric is discussed as extending to two different genres, the playful display discourse and the court speech.

${ }^{28}$ So does Cicero's Brutus (48), though this is certainly not independent from Plato's Phaedrus.

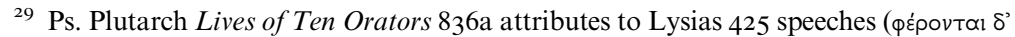

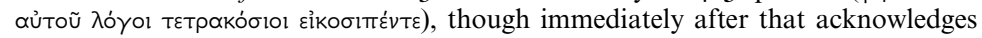

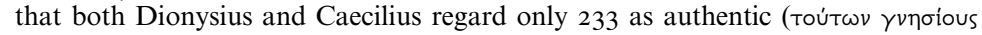

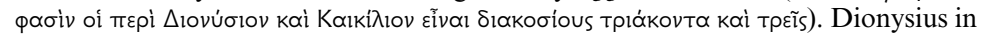
his Lysias claims more vaguely that Lysias has written 'no less than two hundred

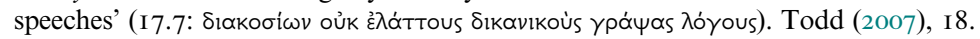


the most recent OCT edition amount to $\mathrm{I} 45 .^{30}$ All of the preserved speeches are contained in Codex Palatinus Graecus 88 , now by scholars unanimously designated as MS X, which dates to the late twelfth or early thirteenth century. ${ }^{3 \mathrm{I}} \mathrm{X}$, the archetype of the majority of our medieval manuscripts, was organized largely by legal action, ${ }^{32}$ and was very probably based on an anthology, which also contained orations by other Attic orators. ${ }^{33}$

A brief look at the entire corpus Lysiacum, which I take here to encompass all titles attributed to Lysias in antiquity, reveals Lysias as an author competent in a variety of rhetorical genres and legal proceedings. This tradition should be treated, however, with caution and no doubt some attributions go back to biographical details that have been attached to Lysias' life and were later accepted as facts about his literary output. ${ }^{34}$ In antiquity, Lysias was credited with: ${ }^{35}$

I Display (epideictic) speeches, e.g. 'Eтाтópıs (speech 2),

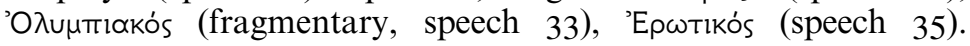
Given the importance of Plato's Phaedrus for the reception of Lysias, most references to this category of epideictic speeches primarily discuss, or depend on, the 'Epwtıkós.

${ }^{30}$ As Todd (2007), I 8 notices, the distinction between fragments and speeches is not always very clear-cut: speech 35, for instance, is the Lysianic speech from the Phaedrus (probably written by Plato and not Lysias), and speech 32 is really a fragment from Dionysius' essay Lysias.

${ }^{31}$ Sosower (1987) discusses the medieval and Renaissance manuscript tradition of Codex Palatinus Graecus 88. Some of the problems of this work are briefly highlighted in MacDowell (1988).

${ }^{32}$ Carey (2007), ix. Cf. also Dover (I968), Io.

33 Sosower (1987), 4 labels it the hyperarchetype $\Omega$. Carey (2007), x proposes that this anthology could either have been composed in the fourth century CE ('at a time when the range of reading in general was narrowing'), or, alternatively, that 'it was made earlier but initially had limited influence on the readership', and concludes that both hypotheses are plausible and consistent with the evidence of the papyrus fragments.

34 This is probably a parallel development to the treatment of ancient poets, whose works were frequently used to reconstruct details about their personal lives. The central work on this subject is Lefkowitz (20I2).

35 In the following classification I will review items that have been associated with or attributed to Lysias in antiquity, which will shed light on the ancient perception of his versatility as a writer. This is why speeches whose authenticity has been doubted (e.g. the 'Epwtikós from the Phaedrus which has been moved to the corpus by modern editors who, however, generally dispute its authenticity) are on this list. 
2 Dionysius preserves an example of a public or deliberative speech,

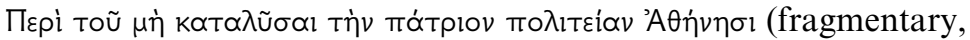
speech 34). It is difficult to imagine, however, how or in what circumstances this speech could have been delivered by Lysias.

3 Various sources suggest that Lysias authored letters and other writings of private content. ${ }^{36}$ Dionysius of Halicarnassus announces rather unexpectedly that he is not interested in Lysias' letters, amatory discourses or the other works, because he wrote them for amusement ( $\mu \varepsilon \tau \dot{\alpha} \alpha \pi \alpha \delta \delta \tilde{\alpha} s) .{ }^{37}$ This is surprising indeed, especially since Dionysius was not interested in the legal argumentation but in Lysianic style and one would think that having access to variety of genres would have given Dionysius an even better and broader overview of Lysias' art. This conundrum will be taken up with the closer examination of Dionysius' criticism below.

4 Both Ps. Plutarch (836b) and the Suda suggest that Lysias wrote a handbook or technical treatise on rhetoric. This, along with Lysias' possible rhetorical activity, will be discussed below.

5 The most important group of Lysias' writings are his private courtroom speeches, which, within the boundary of private speeches, encompass a whole host of writings for different legal procedures. For the present purpose it is not necessary to divide these speeches further according to their underlying legal issues; it suffices to acknowledge that even within the category of private speeches Lysias seems to have been regarded as a competent writer on, for instance, cases regarding public/personal offense, murder or examinations for the holders of public offices. ${ }^{38}$

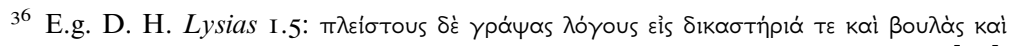

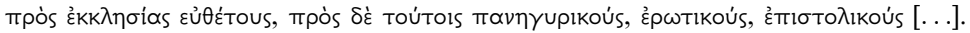

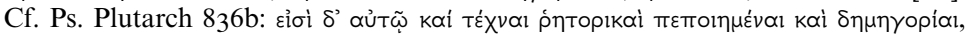

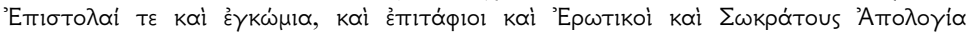

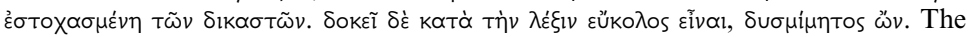

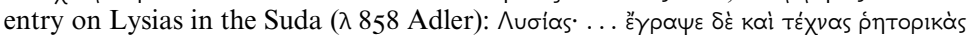

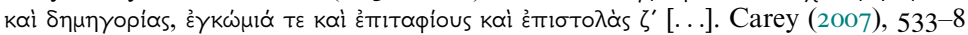
collects references to Lysias' letters.

37 D. H. Lysias 3.7. Blass (I887), 374-5 counts Lysias' speech in the Phaedrus in this

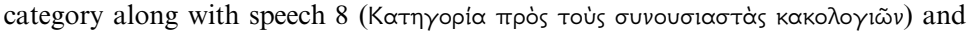
some titles from Harpocration that indicate intimate content. In the context of the Phaedrus, however, Lysias' speech seems to function more as a display of rhetorical

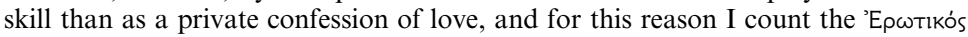
within the first category of display speeches.

${ }^{38}$ Blass (I887), 357-75 divides all existing evidence of Lysias' intellectual output (including spurious fragments and letters) into four broad categories ( $\lambda$ óyol

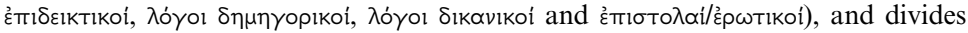

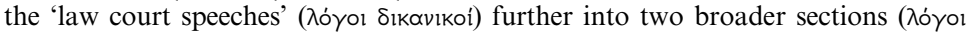

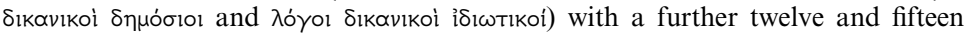


As this list demonstrates, Lysias' speeches attest to a variety of rhetorical genres and legal procedures and, for this reason, it has been pointed out that Lysias' surviving work shows a broader range of litigation than what we see in any other orator or speechwriter of the time. ${ }^{39}$ This aspect of Lysias' writings is often overlooked in modern scholarship, where Lysias is mostly regarded as a writer of forensic speeches. ${ }^{40}$ There are two main reasons for this: first, the fact that, with the exception of 'Eтıт́́ by modern scholars), the majority of the Lysianic corpus that has come down to us consists of private speeches. The second reason, which is possibly directly related to the first, is that Lysias' fame in the first century BCE seems to have rested primarily on his forensic speeches and our prime witness for this view is Dionysius of Halicarnassus, who is not particularly interested in the legal procedures of the various private speeches (which would show Lysias' capability in different legal contexts) but focuses mainly on the literary quality and style of Lysias' writing. ${ }^{4 \mathrm{I}}$ More specifically, Dionysius is interested in a very particular kind of style, and he finds the prime examples for this 'simple and effective' rhetoric in Lysias' private speeches. However, the ancient tradition (other than Dionysius) shows a close awareness of, and interest in, legal procedures. The Alexandrian edition of Lysias, for example, was organized broadly based on the underlying legal issue. ${ }^{42}$

The corpus Lysiacum brings together rhetorical writing at a rather large scale - from court speeches for a variety of juridical matters to epideictic speeches and a personal speech (speech I2) that allegedly gives us a sense of Lysias' own voice

different divisions each. Constructing such detailed categorizations, while helpful, is not the aim of this chapter.

39 Cf. Todd (2007), 3-4.

40 See, for instance, Usher's discussion $(1976,32)$ where he claims: 'While primarily a forensic speechwriter, Lysias was famous enough as an epideictic orator to have commanded an audience at Olympia in $388 / 7$ [...]'.

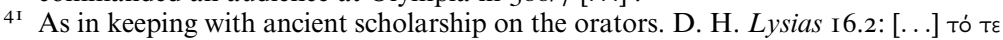

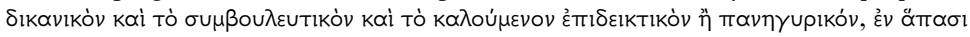

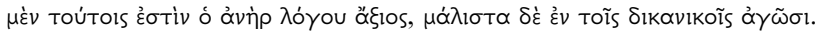

42 Carey (2007), viii. 


\section{... and the Corpus Lysiacum}

early in his career. Despite the large variety of texts that constitute the corpus at the moment, we should also remember that we do not even have Io per cent of the corpus that was available for ancient critics. In fact, none of the speeches cited and discussed by Dionysius of Halicarnassus, the most prominent critic of Lysias' rhetoric, have come to us through the manuscript tradition. From all this we can infer that Lysias was an important writer of the late fifth and fourth centuries BCE, even though we would be also justified to wonder how much we would know about Lysias and his work had there not been one text in particular that did much to immortalize his figure to the history of rhetoric - Plato's Phaedrus. 


\section{REFLECTIONS ON LYSIAS AND LYSIANIC RHETORIC IN THE FOURTH CENTURY BCE}

The only explicit reference to Lysias in the corpus of ancient orators is made in Apollodorus' speech Against Neaira, which had long been included in the Demosthenic corpus. ${ }^{\text {I }}$ This speech, dating from around the 340s, mentions Lysias in a brief passage in connection with an argument about the background of Neaira who is accused of not being a citizen of Athens, but acting as if she was in legal marriage with an Athenian citizen. Sections $\$ \S 2 \mathrm{I}-3$ make some personal, but not denigrating, remarks about Lysias: he is introduced as a

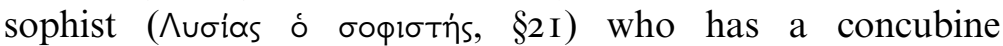
Metaneira (from the same background as Neaira), whom Lysias wanted to initiate into the Eleusinian mysteries. According to this speech, Lysias hosted both Metaneira and Neaira at his friend's place rather than in his home, because he did not want to embarrass his wife and family by the presence of the two concubines in his home. It is generally accepted that the mention of Lysias in this passage refers to the famous speechwriter Lysias, $^{2}$ and this passage is usually included among sources for Lysias' biography. As already mentioned above, it is interesting that Lysias is called here a sophist with the assumption that it will be clear to everyone who was meant. The resonance of this word in this context is not entirely clear. Perhaps referring to Lysias as a speechwriter

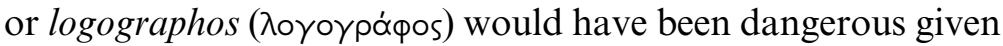
the fact that the very speech was written by Apollodorus and delivered jointly by his brother-in-law as the main accuser and

\footnotetext{
I I follow the text printed in Carey (I992). For a historical discussion of and commentary on the speech, see Wolpert and Kapparis (20II), I87-226.

${ }^{2}$ E.g. Dover (I968), 36-8.
} 
himself, ${ }^{3}$ and a reference to another speechwriter might have made the jury suspicious. On the other hand, Lysias could not have been called a rhetor ( $\rho \dot{\tau} \tau \omega \rho$ ) or orator either, because as far as we know he only delivered two speeches (if any) and could not participate in current politics. If we take Plato's Phaedrus at face value and Lysias did indeed engage in a variety of rhetorical activity (instruction of sorts together with speechwriting), it may make more sense to call him a sophist and also assume the audience's familiarity with him (cf. Phaedrus' perception of Lysias in Plato's dialogue).

It is noteworthy that the titles of speeches attributed to Lysias in antiquity mention many fifth- and fourth-century BCE intellectuals and public figures, thus suggesting that he was involved (or was perceived as someone who could have been involved) in writing speeches (either prosecution or defense speeches) for them. Among the list the most famous is probably Lysias' alleged defense speech for Socrates, ${ }^{4}$ which will be discussed in more depth below. But there are also speeches mentioning Xenophon (speech II7, fr 259), Demosthenes (speech 37, fr 79-84), Nicias (speech I I I, fr. 244), Isocrates (speech 75, fr. I78-9), Sophocles (speech I25, fr 269), Aeschines the Socratic, ${ }^{5}$ and many more public figures of fourth-century BCE Athens. Many of these titles are very possibly suspect, but it is nevertheless curious that Lysias seems to have been associated with writing speeches either in favor of or against famous public figures. The speech allegedly written by Lysias against Demosthenes' guardianship (i.e. a prosecution speech of Demosthenes?) is a case in point: the

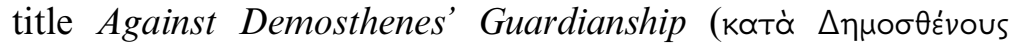

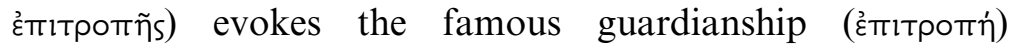
speeches of Demosthenes, which became fundamental for

3 Carey (I992), I-2; Wolpert and Kapparis (20I I), I87-I88.

4 The notorious apology for Socrates is collected in Carey (2007) as speech I27, fragments 27Ia-6.

5 There is also one later source that comments on Lysias' enmity with Aeschines. Diogenes Laertius tells us in his treatment of Aeschines the Socratic that there was a confrontation between Lysias and Aeschines: Lysias had apparently written a speech called Пврі бuкофаvтís against Aeschines, who according to Diogenes imitated the style of Gorgias (DL 2.63). 
launching Demosthenes' political career. ${ }^{6}$ On chronological grounds of course Lysias' authorship of a speech relating to Demosthenes is impossible, since Lysias probably died around 38 о вСе (379/8 вCE according to Dionysius) and Demosthenes was born in $384 \mathrm{BCE}$. Yet, the fact that Lysias was perceived to have written a speech in relation to that particular, and rather personal, event in Demosthenes' life may tell us something about the image of Lysias as a speechwriter. ${ }^{7}$ Namely that Lysias was associated with cases that mixed the highly personal with the highly political (e.g. Demosthenes' first trial on his private matter about inheritance also launched his political career; Socrates' private trial also brought philosophy to court and immortalized the philosopher). In the case of Demosthenes' guardianship speech, since it could not have been written by Lysias for delivery in the actual trial, two solutions present themselves: either this fragment is a genuine speech by Demosthenes' opponents (or the speechwriter they hired) wrongly attributed to Lysias, or a rhetorical exercise from a later period depicting an encounter between Lysias and Demosthenes. In both cases, attaching the speech to the Lysianic corpus manifests the biographical interests of later scholarship in finding links between famous ancient personages about whom they no longer possessed affirmative biographical information. Be that as it may, the extant speeches, fragments and titles have shaped our perception of Lysias as an author: he is depicted as a speechwriter who is most closely associated with private and personal cases, and it is worthwhile to explore whether this association was already made in the earliest reception of his works.

If (as our sources suggest) Lysias' perceived talent in speechwriting did not lie in specialization in any particular kind of legal procedure or in any specific genre of rhetoric (forensic,

${ }^{6}$ Worthington (2013), 26. A good detailed overview of Demosthenes' guardianship speeches can be found in MacDowell (2009), 30-58.

${ }^{7}$ I think that fr. 82 (Carey) of Lysias 37, a reference by Harpocration in which both Lysias' speech and another preserved speech by Demosthenes are mentioned side by side, might confirm that it was indeed the famous Demosthenes that was associated with Lysias' speech. 
epideictic, deliberative), it is probable that his reputation had something to do with his approach to certain themes or particular elements he used in composing his speeches. By merely looking at the corpus (including fragments), we will find little evidence to say anything more specific about this possibility. It is striking, however, that the Corpus, admittedly consisting of authentic and non-authentic speeches by 'Lysias', shows a great number of defense speeches, ${ }^{8}$ and this is a genre that Usher has found to give most room for character portrayals. ${ }^{9}$ Indeed, among Lysias' extant speeches, some of his most vivid and well-known characters are developed in defense speeches. ${ }^{\text {IO }}$ This attempt to deduce characterization as the prime characteristic of Lysias' speeches and the reason for his logographic fame is however based on a circular argument: from the content of the Corpus as we have it now suggestions are made about the particular abilities of 'Lysias', which are then taken to have preceded the Corpus and to have actually determined the focus of the existing corpus. Hence, while this discussion has not brought us closer to the early reception of, and reactions to, Lysias' career and writings, this closer scrutiny of the various items of the Lysianic corpus seems to confirm that at the later stages of his reception when his speeches were collected more systematically by scholars and editors in Alexandria and Rome, Lysias' fame does become associated with his success at characterization.

Valuable sources for the earliest reception of Lysias' career and work are Plato's dialogues, which, however, have their own particular focus and agenda and thus cannot be taken as genuine historical records of Lysias' contemporary reception. Yet, before turning to Plato's treatment of Lysias, I would like to briefly explore one of the most curious titles in the Lysianic

${ }^{8}$ Fragments of Lysias that seem to be defense cases are: speech I4 (?fr. 3I), 24 (fr. 54-5), 29 (fr. 65-7), 35 (fr. 75-7), 42 (fr. 98), 50 (fr. I06-7), 57 (fr. I I 7-19), 60 (fr. I2 I), 76 (fr. I80-5), 77 (fr. I86), 80 (fr. I89-90), 9I (fr. 204), 94 (fr. 206-7), 108 (fr. 240), I I I (fr. 244), I I 5 (fr. 257), I I6 (fr. 258), I 24 (fr. 233), I 27 (fr. 27 I-6), I 35 (fr. 286-7), I37 (fr. 294-6), I4I (fr. 303).

9 Usher (1965).

ro I am thinking here, for example, of Euphiletos from Lysias I and the invalid from Lysias 24, but the list could easily be continued. 
corpus, The Apology for Socrates. This title stands out because it brings together two famous personages (Lysias and Socrates) around a watershed event of the early fourth century BCE, an event which shows Lysias at the beginning and Socrates at the end of his career. The Lysias-Socrates encounter, whether imagined or not, gives us an interesting insight into the development of Lysias' reception and all three versions of the story that circulated in antiquity are thus worth a closer look.

The story about the defense speech that Lysias had allegedly written and presented to Socrates is first attested in Cicero ( $D e$ oratore I.54, 23I) and is subsequently elaborated by other authors. ${ }^{\text {II }}$ It should be noted that the story and its (re)interpretations are primarily focused on Socrates' refusal of Lysias' defense speech on the grounds that it is not suitable for him. In all extant versions of the anecdote, this is clearly the main focus of interest. In Cicero's De oratore, Socrates is said to have read Lysias' speech not unwillingly (non invitus) and commended the speech as 'skillfully written' (commode scriptam esse), but rejected it eventually on the grounds that it was not manly (virilis) and stout (fortis) enough, just as he would not wear comfortable Sicyonian boots for the same reason. In other words, Lysias' speech was perceived by Socrates as not duly representing his character.

Diogenes Laertius' version of the story emphasizes the rejection of Lysias' speech by Socrates on similar grounds: Lysias'

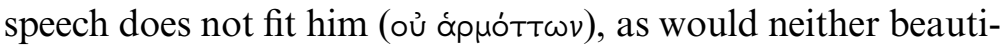

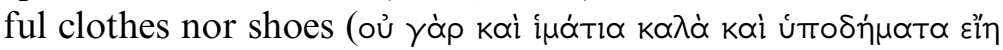

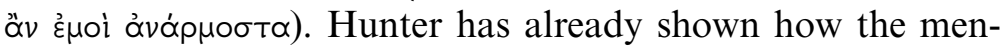
tion of clothes and garment can be seen as parallel to the rhetorical embellishments of Lysias' speech. ${ }^{\mathrm{I} 2}$ However, given that Lysias had been praised by Dionysius in the first century

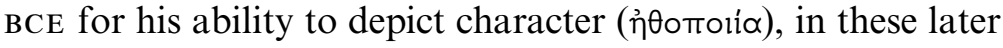
reworkings of this anecdote it must have been a deliberate

${ }^{I I}$ It is mentioned subsequently in Quintilian (Institutio 2.I5.3I, I I.I.I I), Valerius Maximus (6.4.ex2), [Plut.] ( $X$ orat. 836b), Diogenes Laertius (2.40), Stobaeus (3.7.56), and by the scholiasts of Aelius Aristides' Panathenaicus (as collected in

Carey 2007). This discussion is heavily indebted to Hunter (2012), chap. 3.

${ }^{12}$ Hunter (2OI2), IO9-I2. 
point, and somewhat of an embarrassment for Lysias, that Socrates rejects the speech because of Lysias' failure to depict a fitting character. There must have been calculated irony in sharing or transmitting these anecdotes about Socrates/Lysias while at the same time recommending Lysias as a model for characterization. As Cicero's passage suggests, had Socrates accepted Lysias' speech, he would not have lost the trial, for the speech, which probably showed Lysias at its best, was perfectly fitted to the expectations of the courtroom. ${ }^{\text {I3 }}$ Socrates rejected, then, not only the rhetoric of the courtroom, but precisely this kind of rhetoric that operates with character manipulation which Lysias was so famous for.

The connection between rhetoric and character in Lysias' speech is expressed even more strongly in the version of Valerius Maximus, where the story is narrated to exemplify the importance of gravitas among illustrious men, who have preferred death over life without gravitas. ${ }^{\mathrm{I}}$ The lack of gravitas appears to be also the criticism of Lysias' speech by Socrates, who after hearing Lysias responded by saying that nam ego, si adduci possem ut eam in ultima Scythiae solitudine perorarem, tum me ipse morte multandum concederem ('If I could be persuaded to deliver it in the farthest wilderness of Scythia, I should admit myself that I deserved death'). Moreover, Valerius Maximus concludes that spiritum contempsit ne careret gravitate, maluitque Socrates exstingui quam Lysias superesse ('he despised life lest it be without gravity and preferred extinction as Socrates to survival as Lysias'). ${ }^{\text {I5 }}$ The claim here is that accepting Lysias' speech would commit Socrates to the kind of personality and character that is depicted in that kind of speech. This, however, is regarded to be in contrast with everything that Socrates came to represent, so that he would at any moment choose death over such a life. In sum, whatever the individual nuances of these different

\footnotetext{
13 This is precisely Quintilian's point in the two passages where he discusses the anecdote.

${ }^{14}$ Valerius Maximus 6.4.ext.2.

I5 I follow here Shackleton Bailey's (2000) edition and translation.
} 
interpretations of the anecdote, all these stories make a clear association between Lysias' skill and success as a speechwriter with a particular talent for creating persuasive characters, and Socrates' refusal to profit from this skill, as it would not portray his character truthfully. This sheds some light on the perception of Lysias 'the author' in the later stages of his reception, and as will be discussed below, will find support in the way in which 'the Lysianic' is understood in Plato's Phaedrus.

\section{I Plato's Lysias}

Plato is the first critic of Lysias and his Phaedrus is before Dionysius of Halicarnassus the most valuable engagement with, and record of, Lysias as a writer and intellectual. In the following pages, we will explore the extent to which our current, and presumably also the ancient, reception of Lysias is directly indebted to Plato's dialogues, and what that means for Lysias' Nachleben and the rhetorical tradition more generally.

The suggestion that Plato is directly related to the reception of Lysias might sound at first instance surprising. Sure, they are both interested in rhetoric, but from completely different angles and with different aims. What links the two? On the one hand, their intellectual environment: they both move in (the same) high circles of Athenian elite and thus share a similar background. On the other, literary and possibly also political feud: the praise of Lysias as the most accomplished contemporary writer followed by heavy critique indicates, among other things, a sense of rivalry between the writers. Politically speaking, Lysias' speech I2 associates him strongly with prodemocratic sentiments and tries to play down his own elite status as much as possible (by emphasizing instead the struggles of the metic community). Plato's references to Lysias consistently associate him with the political and intellectual circle that is cohabited by Plato: the anti-democratic elite. In the end, Lysias' character seems to serve for Plato two different, but interconnected, functions. As a generic character he stands for speechwriters and pseudo-intellectuals (or rather, 
anti-intellectuals) in Athens more generally. This way Lysias becomes the representative of a kind of rhetoric that Plato finds particularly difficult and reprehensible. As a particular character, Plato is using Lysias to map out the field of rhetoric through its practitioners and their interrelationships in contemporary Athens.

Lysias is mentioned several times in Plato's dialogues. The most extensive focus on Lysias is in the Phaedrus, but before embarking on a closer analysis of the representation of Lysias in this dialogue, let us briefly take a look at other dialogues which feature, in a more or less significant way, Lysias. Aside from the Phaedrus, Lysias is mentioned in two other dialogues: three times in the either spurious, dubious or incomplete dialogue Cleitophon, twice in the opening section (406a2, 406a6) and once in the concluding passage (4IOe4), and once at the beginning of the Republic (328b4).

Cleitophon, which appears to present an explicit attack on Socrates and his philosophical method, is a puzzling dialogue. The authenticity of the dialogue was not questioned in antiquity, ${ }^{16}$ though scholarship from the nineteenth century onwards has been very critical of the dialogue and suspicious of its authenticity. The most important issue for scholarship has been the content of the dialogue and the fact that it lacks Socrates' response at the end, which would address the accusations made by Cleitophon. ${ }^{17}$ However, a closer look at the dialogue reveals that it has a coherent and finished structure, thus casting doubts on the notion that the dialogue was left unfinished and/or abandoned. ${ }^{18}$ Furthermore, Slings argues that the Cleitophon belongs to a separate dialogue genre that

${ }^{16}$ Slings (I999), I I traces back the hypothesis that the dialogue is not authentic to Ficino.

${ }^{17}$ For a more thorough discussion of all possible pro and contra arguments on the question of authenticity, see Slings (I999), 227-34. Slings notes (I2) that the suggestions of the nineteenth-century scholars were 'connected with the supposition that the Cleitophon was originally intended as a prooemium to the Republic', but that Plato had apparently changed his mind halfway through and made use either of the alleged dialogue Thrasymachus or of the Euthydemus instead.

${ }_{18}$ Rowe (2000), 303-7 notes, for example, that the Cleitophon reads like a commentary on the Republic and might have been an attempt of the older Academy to critically engage with Plato's political thought. 
he calls the 'short dialogue'. ${ }^{19}$ Most of Plato's shorter dialogues are included in this category (many of which have also been considered spurious), and it has its own characteristic features with which the Cleitophon seems to conform. ${ }^{20}$ For the purposes of the current discussion, it is not totally irrelevant whether Plato was the author of the dialogue, especially if there is a sense of a rivalry between Plato and Lysias, literary and/or political, that emerges from looking at the way Plato portrays Lysias in his work. Having said that, however, my reading of the relevance of Lysias in the dialogue is not overly dependent on the authorship of Plato; as long as the dialogue can be safely placed in the context of the Academy (and the fourth century BCE), something that has not really been doubted in scholarship thus far, my argument could be read independently from disputes about the authenticity of the Cleitophon.

One of the most important characteristics of short dialogues is that they go straight to the core of the problem that forms the central discussion in the dialogue, thus making every little detail and character mentioned even more relevant to the underlying issue. From this perspective, then, the fact that Plato introduced a conversation with Lysias as the starting point for the discussion in the short Cleitophon is significant. In fact, Lysias features (or is mentioned in passing) at the beginning of three of Plato's dialogues (Phaedrus, Republic, Cleitophon) and disappears from the body of the work (except for the Phaedrus where Lysias is mentioned again at the end of the dialogue). ${ }^{2 \mathrm{I}}$ Let us take a closer look at the Cleitophon to

19 Slings takes his cue from Müller (I975), even though there is a significant difference between Slings and Müller: when Müller introduced and discussed the term 'short dialogue' (Kurzdialog) he argued that they ought to be rejected on the whole as not genuinely Platonic. Slings uses the term and agrees with the generic category of 'short dialogue', but does not follow Müller's position about the unauthenticity of the genre.

${ }^{20}$ E.g. Slings discusses length, lack of individual characterization, lack of pedimental structure, etc.

2 I An excellent discussion of the role of 'first words' in interpreting Plato's dialogues is Burnyeat (1998). 
see what kind of role Lysias might have on setting up the framework and central question of the dialogue.

Mentioning Lysias at the beginning of the dialogue seems to suggest some kind of engagement with rhetoric, speechwriting or an intellectual environment where these two are discussed and/or practised. ${ }^{22}$ Slings goes further and points out that the dialogue has a clear structure that seems in line with the conventions of courtroom speeches. ${ }^{23}$ Indeed, the dialogue is essentially a long speech, incorporating dialogical (or pseudodialogical) elements, about Socrates' virtues and shortcomings as a teacher. It is certainly relevant that the discussion that Cleitophon had with Lysias concerned Socratic teaching in particular and did not appear to have reflected on education in a more abstract sense (e.g. trying to answer questions such as 'whether virtue is teachable?'). The object of criticism is not, therefore, philosophy and its usefulness, but rather Socrates' teaching methodology - how to best educate and bring pupils to one's preferred subject. We see here, then, how Lysias - in conversation with Cleitophon - has prompted a fundamental critique of Socratic teaching, clearly questioning Socrates' protreptic method and its ability to do real philosophy. Socrates is regarded as an inspiration in the beginning, but afterwards as an obstacle to his students' pursuit of philosophy. I believe that this is not a trivial question - Socrates' character and his teaching methods seem to have been hotly debated in antiquity as they are today. ${ }^{24}$ The Cleitophon,

22 According to Geffcken (I933), this dialogue is essentially a rhetorical speech. Geffcken argues, pace Friedrich Schleiermacher $(1836,347-9)$, that it was not written by Plato but is the work of the fourth-century rhetorician and dramatist Theodectes who reacted with this piece against the Platonic Socrates (and not against Socrates himself). Orwin (1987) advances an interesting view of the Cleitophon as a response to Socrates' speeches in the Apology, arguing that in this dialogue Cleitophon proposes a defense speech against the accusations of Socrates to justify (the conduct of) Athens. Some of Orwin's conclusions are similar to those advanced in this chapter, especially when he proposes (I29) a third possibility for interpreting Socrates' ambiguity with regard to the question of 'justice': Socrates is willing to say what justice is but unable to say it to Cleitophon.

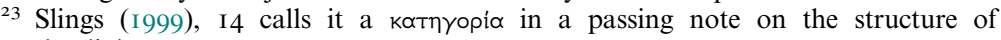
the dialogue.

${ }^{24}$ The importance of Plato's character-creation is effectively pointed out in Press (I993b). 
therefore, whether or not an authentic work by Plato, evokes a very crucial concern about the Platonic dialogues and Socratic teaching methodology in particular. In this sense, it is not unimportant that it was precisely Lysias who seems to have brought up the question about Socrates' teaching in the first place.

There are two further points that I would like to briefly mention in relation to the Cleitophon: first, our knowledge of Cleitophon and his association with Lysias, and second, the interpretation of Socrates' silence at the end of the dialogue and how this might feed into the general picture of Lysias in Plato. To start with the second point, the fact that Cleitophon casts a rather unexpected and perhaps embarrassing light on Socrates' philosophical activities seems to be agreed on by most commentators. ${ }^{25}$ If Socrates' silence at the end of the dialogue is taken as an acknowledgement or confirmation of a problem in Socratic teaching, the Cleitophon depicts a problematic defeat of Socrates by an eloquent interlocutor and the dialogue could be compared in this respect with some passages of the Euthydemus or the Gorgias. What strikes us about these comparisons is that in those dialogues (i.e. in Euthydemus and Gorgias) Socrates puts forward explicit criticisms of his interlocutors throughout the work and we are invited to take the side of Socrates who, even if ridiculed within the dramatic context of the dialogue, still has the upper hand in the overall argumentative structure of the dialogue. In Cleitophon, however, Socrates' explicit criticism of, and response to, his opponents is absent. To answer the second question, then, the dialogue certainly evokes crucial questions about Socratic method and Lysias is clearly associated with Athenian intellectuals who are overtly critical of Socrates.

The first point about Cleitophon and his character might help shed further light on the question. From the way Cleitophon is

25 Schleiermacher (1836), 347 argues that it cannot be a Platonic dialogue precisely because of this embarrassing conclusion; Slings (I 999), I 8 claims that Socrates 'has been beaten at his own game'. Rowe (2000) proposes a convincing reading of the Cleitophon as seriously challenging the philosophical method presented in the Republic. 
characterized in the dialogue, we understand that this is a man who is impatient to find out the right answers and, hoping to reach a state of clear knowledge, frequents several different philosophical schools and listens to many different philosophers who teach - we are led to assume - different things. Indeed, Cleitophon describes himself at the end of the dialogue as

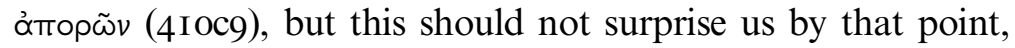
not after we have followed his restless and eclectic switching between philosophical schools and arguments. In a sense, as much as the dialogue appears on the surface to focus on Socrates' confusing protreptics, it actually gives the reader a close-up of an individual (Cleitophon) who is so enthused by and imbued in protreptic writings that he is unable to recognize philosophical thinking proper when he is confronted with it (e.g. in the Republic where he is unable to follow the discussion). ${ }^{26}$ Plato's Socrates remains silent at the end of the dialogue, according to this reading, because Cleitophon's criticisms grossly misrepresent Socrates' philosophical method to the extent that they have simply no shared ground upon which to build a constructive discussion. What should Socrates possibly reply to Cleitophon's claims of having been an ardent 'fan' of Socrates who he thought produced (praise?) songs (ú $\mu v \varepsilon \tilde{v})$ just

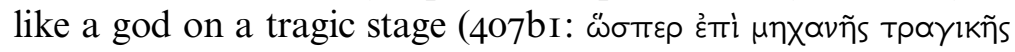
$\theta \varepsilon$ ós)? ${ }^{27}$ Most importantly, Cleitophon has no patience for this

${ }^{26}$ I hope to demonstrate this reading, and Plato's criticisms of the protreptic genre, in a forthcoming article on Plato's protreptics in more depth.

27 I follow Slings' text, which has úuvoĩs (as an optative in distributive temporal clause)

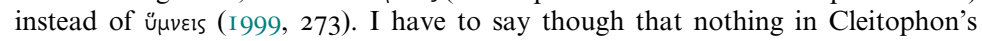
portrayal of Socrates makes much sense. If he is indeed referring, as Slings suggests, to the famous scene in Aristophanes' Clouds (vv. 2I 8-2I), "where Socrates "enters" the stage in a basket hanging on a $\mu \eta \chi \alpha \nu \eta$ and behaves (and is treated) like a deity', why mention the tragic stage? Slings suggests that Cleitophon might be referring to Socrates' speeches as too lengthy, but this does not square well with the comparison to the tragic god, for it is not necessarily obvious that gods in tragedy are perceived as embarking on extended expositions. In fact, the tragic context might suggest an interpretation of a Socrates who instead of allowing discussion to follow its natural course emerges as if out of nowhere, stops serious (philosophical) contemplation and gives orders about how to go about solving the situation and, implicitly, about how to live one's life. Yet, by the end of the dialogue we realize that this is exactly what Cleitophon is longing for - clear answers and concrete practical advice that Socrates, according to him, is unable to offer. In whatever way we try to make sense of this, then, Cleitophon's comparison is confusing in the extreme. Useful 
kind of Socratic teaching: he makes use of the Socratic question-answer method, thus showing himself to be superficially aware of it, but he uses this not for the purposes of exploring the truth together with his interlocutors (and hence becoming more knowledgeable together with them), but rather to challenge them impatiently when they fail to give him a satisfactory definition. ${ }^{28}$ When summarizing Socrates' views on justice (4IOa8-b2), Cleitophon dismisses him as merely contradicting himself or being, at best, ambiguous and undecided. This is a clear reference to Republic I, but Cleitophon's conclusion hardly represents what Socrates has to say about justice in this dialogue. We should note that the Republic is the only other dialogue by Plato where both Cleitophon and Lysias are mentioned as participating, even if not contributing (and this is important!), to the philosophical discussion. ${ }^{29}$ Lysias is a silent listener in the Republic (never directly exposed to a Socratic inquiry), but vocal among his associates about the shortcomings of Socrates' views. There is a sense of insincerity in both Lysias' and Cleitophon's behavior that is directly alluded to in the beginning of the dialogue by Socrates' direct confrontation with Cleitophon. Even though present, they expressed their criticisms of Socrates' views behind his back without aiming to engage in a serious and open discussion of the topic. And looking at what else we know of Cleitophon, this is very suggestive. Apparently Cleitophon was a well-known figure in Athens, particularly

comments on the staging of the Aristophanic scene are in Dover (I968a), I24-7 (at vv. 2I3-26).

${ }^{28}$ This is not to deny that Cleitophon's challenge about the (non)approachability of Socratic teaching might also be a genuine one. This is what Slings (I999) has in mind when he argues that Cleitophon is 'obviously the hero, not the villain, of the dialogue', and that the aim of the Cleitophon is 'to deride protreptic Socratic literature, not to suggest that the statements found in that literature are nonsense' (49).

29 Republic I 328b. Cleitophon tries to contribute to the discussion at $340 \mathrm{a}-\mathrm{b}$, but seems not to have understood the arguments and his suggestion is rejected immediately. This passage suggests rather unequivocally that Cleitophon is not depicted particularly charitably in Republic I, and it is unclear why Slings pushes for reading the character in a favorable light (or like a potential victim of bad influences, 55-6) both in the Republic I and in the Cleitophon. 
notorious for his 'flip-flopping political attitudes' ${ }^{30} \mathrm{He}$ seems to have had consistently oligarchic views and paved the way towards the oligarchy of the Four Hundred in $4 \mathrm{II} .^{3 \mathrm{I}}$ Associating Lysias, the staunch proponent of democracy (or so it appears from his speech I2), with Cleitophon could be potentially damaging to both, but perhaps especially to Lysias, one of the richest metics in Athens who seems to have gone through a great deal to present himself as suffering along with the demos in the oligarchic coups. Plato took meticulous care in crafting the characters of his dialogues and we can therefore assume that none of the people mentioned in his works are there by accident. ${ }^{32}$ So too for Cleitophon: it is certainly not accidental that Lysias' name is dropped at the beginning of the Cleitophon and that it was a conversation between Cleitophon and Lysias that triggers this dialogue. This may seem a very subtle reading of the short dialogue for modern readers, but for the immediate audience of the dialogue it may have suggested more readily that Plato's choice to bring together these two characters would cast problematic light on both Lysias' political as well as intellectual allies.

Another scene portraying Lysias together with an admirer and potential student is referred to at the beginning of the Phaedrus. There, the whole discussion about rhetoric is prompted by Phaedrus' admiration for the speeches of Lysias

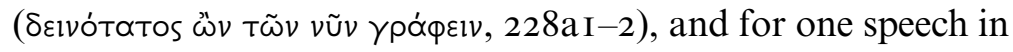
particular that he had heard delivered in Epicrates' house. Phaedrus says that he had been sitting the whole morning indoors with Lysias and needs to take a walk outside the city to freshen up (227a2-5). Whoever else was present in Epicrates' house with Phaedrus and Lysias we do not know, but the lack of references to a larger group suggests that we may plausibly suppose their encounter to have been a kind of 'private lesson' by Lysias. Phaedrus' learning process is laid out in hypothetical terms by Socrates in $228 \mathrm{a}-\mathrm{b}$ and is subsequently confirmed by

$3^{30}$ Nails (2002), I02. $\quad{ }^{31}$ See Ostwald (I986), 475 and 478.

$3^{2}$ A great discussion of the multilayeredness of Plato's characterization is Blondell (2002), esp. chaps. I and 2. 
Phaedrus: he had indeed received instruction from Lysias and had hoped to use Socrates to rehearse Lysias' speech (228c6-7, $228 \mathrm{~d}_{\mathrm{I}}-4,228 \mathrm{e} 4-6$ ). Lysias is never portrayed as eloquent with the crowds in Plato (perhaps due to his metic status), but is frequently referred to in a one-to-one instruction setting (cf. Cleitophon and he never says a word in the Republic). As such, he stands in contrast to Socrates, who is often portrayed by Plato in conversation with a larger group of Athenians. The Phaedrus is in this sense a fascinating exception, especially given its focus on rhetoric, a topic that is tackled in the Gorgias in front of a large and contentious crowd. Socrates' quest for knowledge is transparent and open for everybody to join, whereas Lysias' skill will be learned and transmitted behind closed doors. It is a paradox indeed that despite all the prodemocratic rhetoric in speech I2, Plato chooses to characterize Lysias as an elite writer and instructor, inaccessible to the demos and uncomfortable in the public spotlight. ${ }^{33}$

The association of Lysias with Epicrates is a case in point. Much like Cleitophon, Epicrates was a rather controversial figure, well known for his wealth and influence, but notorious for questionable political behavior. Epicrates fought in 403 on the side of democracy (Demosthenes I9.277), like Lysias, but was later associated with corruption and taking bribes. ${ }^{34} \mathrm{In}$ fact, alongside other sources, a speech by Lysias reveals that a certain Epicrates had a history of giving bribes (Against Epicrates 27.I-9). If this is indeed the same Epicrates mentioned in the beginning of the Phaedrus as Lysias' host, ${ }^{35}$ then the (later) reader of the Platonic dialogue might be surprised to find the two depicted as associates. ${ }^{36}$ The image is made

${ }^{33}$ It is perhaps worth reiterating that this suggestion only applies to the image of Lysias created in Plato's dialogues and has no ambition to say anything about the historical Lysias, his political orientation, friends or rhetorical teaching practices.

34 Nails (2002), I39. Pausanias 3.9.8, for example, associates Epicrates with taking bribes from Persians and stirring up war in Greece against Spartans.

35 As suggested by Nails (2002), I40. It is interesting that this appears to be the same Epicrates we encounter as the addressee of Demosthenes' Erotikos (more on this below).

${ }^{36}$ It is interesting too that Lysias associates Epicrates' wealth with war (27.I0), suggesting that the latter has made a large fortune during war time, at the expense (we might think) of other people's suffering. 
worse by mentioning Morychus, a well-known personage who was mocked in comedy for his gluttony and high living. ${ }^{37}$ The environment where Lysias stayed while in Athens was one dominated by wealth, abuse of power and political influence. In sum, we see in this first scene of the Phaedrus that Lysias is associated with morally (if not politically) dubious characters and this characterization offers another dimension to the introductory part of the dialogue, and one that challenges the overt praise with which Lysias is brought to the conversa-

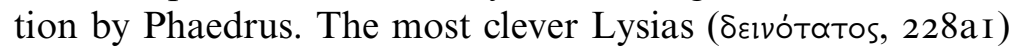
might acquire here another dimension: the clever and dangerous. $^{38}$

But what exactly was Lysias doing in Epicrates' house? Phaedrus says that he 'spent a long time there [with Lysias],

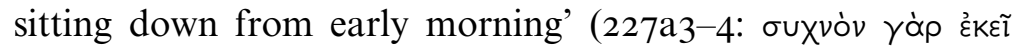

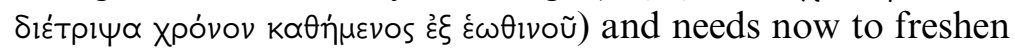
up. This description seems to suggest a longer exchange than simply attending a speech performance. Also, it seems that Phaedrus made up the whole audience. Socrates seems to suggest that Lysias offered some sort of exegetical practice after having delivered the speech. The word Socrates uses

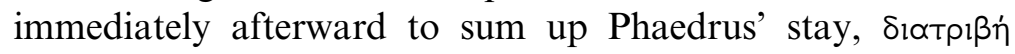
(227b6), is ambiguous and could suggest either a study or simply 'time spent'. In fact, Socrates himself finds it relevant to inquire what kind of gathering it was, only to reply to his own question immediately with a suggestion that it must have been 'a feast of speeches that Lysias offered' (227b6-7: भै $\delta \tilde{\eta} \lambda \circ v$

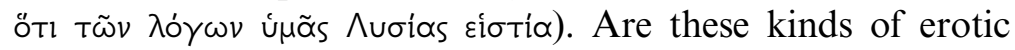
display speeches the kind that Lysias was in the habit of composing and sharing with his admirers? Let us bear in mind the fact that the dramatic date of the dialogue suggests a time well before the oligarchic coup and thus the eventual start of Lysias' speechwriting career. By the time the Phaedrus is

37 Nails (2002), 208; Yunis (201I), 86. See comic references to Morychos in Aristophanes Acharnians 887, Peace I008-9, Wasps 506.

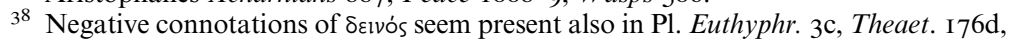
Euthyd. 304d. 
composed, the reader would of course associate Lysias with his courtroom speeches and so an interesting anticlimax is built up at the beginning of the dialogue, where Phaedrus exposes the topic of Lysias' speech: not at all a court speech for a famous personage or witty portrayal of an Athenian litigant, but rather a sophistic argument to win over a lover! In the very beginning of the dialogue, in other words, Plato turns the image of Lysias upside-down: we are not confronted with a staunch democrat and a courtroom speechwriter, but instead with an elitist intellectual who spends time with wealthy and morally questionable characters, producing and performing discourses that appear to have very little serious content to them. ${ }^{39}$

It is important to draw out another, arguably the most important, line of argument in Plato's portrayal of Lysias Lysias as an incapable practitioner of his own art. As we saw, the Cleitophon and the Republic depict Lysias as the silent character in group discussions who is not interested in philosophy (Republic), even though he seems eager to criticize in private the methods of the kind of philosophical examination conducted by Socrates (Cleitophon). The Phaedrus goes further and later on in the dialogue suggests more explicitly that Lysias does not have the mind for philosophy (279a3-b2). ${ }^{40}$

39 It is of course conceivable that the historical Lysias was engaged in a range of activities, including erotic epideixeis, and that we should not regard Plato's focus of attention as subversive or ironical any more than it is simply emphasizing one aspect of Lysias' professional career. But it nevertheless remains curious that of all the different rhetorical contexts that Lysias might have been engaged with, Plato chose to emphasize this one: Lysias as an elitist speechwriter and rhetoricianentertainer (rather than, say, populist democrat). Furthermore, Plato's portrayal also entails explicitly contradictory elements about Lysias' life, namely the fact that he started his writing and/or teaching career well before 403 (as usually listed in his biography) and the political undertones of such portrayal seem explicit enough to suggest a more critical commentary from Plato.

40 Though in $257 \mathrm{~b}$ Socrates seems to entertain the possibility that Lysias could be turned to philosophy. J. Howland (2004) argues that reading the Phaedrus and the Republic together as commenting on the passionate and erotic nature of philosophy, the former dialogue also portrays 'Lysias as unerotic and therefore unphilosophical' (I8I). Howland then makes a bolder, and in many ways a rather implausible, claim by suggesting that Plato's Republic is on one level 'meant to be a Platonic response to [Lysias'] Against Eratosthenes'. There are many problems with his argumentation, and perhaps the most obvious one is Howland's lack of attention to the differences in genre and context of works such as Lysias' Against Eratosthenes and Plato's Republic. 
While Isocrates will grow out of his present activity (preoccu-

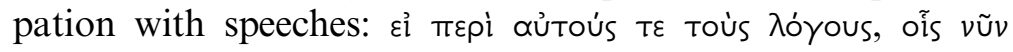

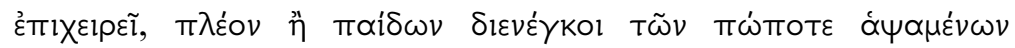
$\lambda o ́ \gamma \omega v, 279$ a -6$)$ and ascend to follow his more divine philosophical nature, as Socrates predicts, Lysias remains where he is, writing speeches as he has always done. ${ }^{4 \mathrm{I}}$ We will take a closer look below at the role and portrayal of Isocrates in this dialogue. For the time being, suffice it to say that there are good reasons for taking the comparison sketched out in this passage at face value and positioning Isocrates far higher in Plato's (or Socrates') overall estimation of contemporary rivals/teachers than has been hitherto considered.

Importantly, Lysias' proclaimed inability does not only affect Lysias' philosophical prospects. Socrates' analysis and judgement of Lysias' composition earlier in the dialogue pointed out that the latter has performed below the standards of his own (rhetorical) art. According to Socrates, Lysias' speech was unnecessarily repetitive, failed to bring out a diverse set of compelling arguments in favor of the main point (235a3-6), and badly organized (e.g. the Midas epitaph in 264d). He grants Lysias his eloquent style ('expressions are clear and well-rounded and finely turned', 234e5-6), but claims that he could easily come up, on the spot, with an equally good (or even better) speech as that of Lysias $(235 \mathrm{c} 4-5) .{ }^{42}$ The much-praised composition of Lysias that so delighted Phaedrus turns out to be an average example of the art at best. Lysias' speech will be scrutinized also at a later stage in the dialogue: from $262 \mathrm{c} 4$ onwards Socrates analyzes the beginning of Lysias' speech and finds it lacking of the kind of structure

${ }^{4}$ L Lysias is also (negatively) compared in another passage of the Phaedrus to his brother Polemarchus (257b) who has turned towards philosophy, whereas Lysias has not.

42 Perhaps this is one of the reasons why Lysias' oratory is relatively easy to imitate, or - to put it differently - why it is possible for Plato to produce a 'Lysianic' speech: there is no 'deeper level' of meaning in Lysias' work that one might miss and hence misrepresent in an imitation of his writing; as Phaedrus seems to suggest, it is sufficient to come up with an unexpected twist to the topic to make a discourse seem Lysianic. 
that he and Phaedrus had previously agreed should be exhibited in a successful composition. Throughout the dialogue, then, Lysias is constantly exposed as underperforming in an art that he is so famous for.

This tells us, of course, something about philosophy and something about rhetoric. Perhaps most obviously, by pointing to the impact of Lysias' speech on both Phaedrus and Socrates, the dialogue indicates the power of rhetoric to force the listener to forget oneself and immerse oneself in the story. ${ }^{43}$ And it also suggests, through Socrates' clear-headed analysis of Lysias' speech, that philosophical training might be a good way to resist the temptation and illogical persuasion brought about by rhetoric. That much seems obvious. There remains the question about what this means eventually to Lysias, to his reputation and to his students. I propose that Plato's discussion of Lysias has two dimensions: the general and the particular. On a general level, Plato's Phaedrus marks the beginning of sustained attempts by philosophers to systematize the field of rhetoric. By weaving into his narrative a dizzying number of references to various contemporary and ancient orators and rhetoricians Plato not only demonstrates his competence in the field, but also offers a categorization of the different contributions rhetoricians have made and how to assess those. In the midst of the crowd of rhetoricians Plato singles out Lysias and Isocrates, thus creating through them an image of rhetoric as divisible into two larger categories. On a particular or individual level, Plato's portrayal of Lysias comes to dominate the reception of Lysias and his writing. As a metic who had few (if any) opportunities for public appearance, and thus to leave a record of his persona in history other than through his own works, Plato's scathing analysis of the incompetence of Lysias was going to leave a hostile trace in the reception history of this writer. The fact that posterity was

43 The idea of forgetting and knowing oneself is central to the crucial distinctions made in the dialogue between philosophy and rhetoric, between knowledge and appearance. On self-knowledge as the unifying theme of the dialogue, see Griswold (I986). 
not always very attentive to Plato's sarcasm and seems to have missed that point on occasion (though not, as will be argued below, in the case of Dionysius of Halicarnassus), is another story. It is also relevant to note that Plato's Phaedrus effectively gives us the only other speech by Lysias where the latter is portrayed as speaking in his own voice, therefore offering a competing account to Lysias' speech I 2.

It is clear, then, that Plato wrote the Phaedrus with a message about rhetoric in mind: the outlines of the art of persuasion, in all its messy contemporary context, are effectively drawn by two characters who offer contrasting visions for the art - Lysias and Isocrates. ${ }^{44}$ Indeed, the dialogue concludes with the request to report the outcome of Socrates' conversation with Phaedrus to Lysias and Isocrates, as figures of particular importance to the field of rhetoric. ${ }^{45}$ The two are pitched against each other

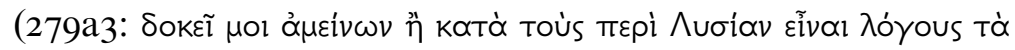

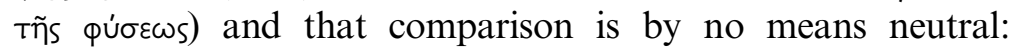
Isocrates comes out from this juxtaposition as a stronger and worthier representative of rhetoric.

We might indeed ask whether Plato was in fact fair in his assessment of Lysias' speech. Socrates appears naïve and/or insensitive to quite a few important aspects of Lysias' speech, in particular to the possibility that some of what he and Phaedrus have recognized as faults might instead have a specific (and well-calculated) function in the context of the speech. ${ }^{46}$ For example, the lack of clear definition of love at the beginning of the speech, a fault that brings Lysias' speech under renewed criticism (from $262 \mathrm{c} 4$ onwards), contributes to deliberately keeping the ambivalence about the topic and is therefore an important part of Lysias' argumentative strategy in the speech. ${ }^{47}$ Phaedrus himself showed where he thought the

\footnotetext{
44 This is not to make a claim about the main theme of the dialogue, which has vexed scholars since antiquity. Hermias' commentary on the Phaedrus (8.I 5-I2.25) from the fifth century CE seems to have been the first one expressing the problem of unity.

45 It is worth emphasizing that Plato does not claim to create a concept or discipline himself (e.g. as proposed by Schiappa I990 about coining the word rhetorike), but rather aims to shape and fix the outlines of an already existing practice of rhetoric.

${ }^{46}$ Ferrari (I987), 45-59. ${ }^{47}$ Ferrari (I987), 50-2.
} 
real contribution of Lysias' speech lies when he identified the particular twist to a commonplace topic as the very standout aspect of the speech (227c5-8). In other words, Lysias had set out to have a different agenda and strategy in composing the speech, so that Socrates' criticisms that are founded on strong commitments to philosophy and truth might strike the reader as insensitive or simply wrong when applied to Lysias. As Ferrari points out, Plato/Socrates' criticisms of Lysias run much deeper and eventually work towards a 'whole-hearted rejection of Lysias' way of life'. ${ }^{8}$

Based on what has been said thus far, it does seem that Lysias is represented in Plato's dialogues as a rather particular kind of intellectual, one that is often present in crucial contemporary philosophical debates, but never really allows his views to be directly exposed, tested or challenged. This Platonic Lysias is a representative of a kind of rhetorical practice that aims to impress with persuasive tricks and amusing twists and deliberately shuns pursuing truth and knowledge in their own right. From Phaedrus' adoring reaction we surmise that a writer like Lysias, whose plain style was appealing to the crowds but morally suspect, might have been an even more dangerous adversary to Plato's philosophical project than many (or even most) of his rivals (Isocrates, Antisthenes, or sophists who would follow the path of Gorgias, Protagoras or Euthydemus) who may have been willing to engage with Socrates' questioning of their activity. This is because Lysias' style is alluring, simple and effective in bringing about persuasion (Phaedrus is presented as a test case of the appeal of Lysianic rhetoric), but his content is driving the audience further from philosophy and, eventually, from themselves.

Plato exercised a significant impact on the reception of Lysias and his writing skills more generally. While his portrayal of Lysias as an 'anti-intellectualist' might have been his own inventive take on Lysias and one that was perhaps not

${ }^{48}$ Ferrari (I987), 55. 
that obvious to subsequent readers of the dialogue, the carefully constructed Lysianic speech of the dialogue reflects some of the most distinctive stylistic elements of Lysias' writing that have remained steadily fixed in the later perception of the writer. In particular, his Phaedrus seems to corroborate the general view of Lysias as the master of character delineation that was suggested above in analyzing other contemporary and later sources. Comparing all three speeches of the Phaedrus, we find the first, purportedly by Lysias, to stand out from the others by the number of references to characters and characterization in the speech. It is a paradox and at the same time a testament to the Lysianic writerly skill (albeit filtered through Plato) that this is perhaps also the only speech of the three that can actually be understood and delivered outside of its original context. The language of 'Lysias' is dominated by direct references to the speaker and the listener of the speech, ${ }^{49}$ clearly distinguishing the two roles in a way that we do not find in the other two discourses. The one, listener, is passively presented with the evidence and is expected to reach a decision by the end of the speech whereas the speaker is persuading the other to vote in his favor. By contrast, in his first ('Lysianic') speech Socrates, after invoking the Muses, ${ }^{50}$ begins with a mythical and a more general account of the situation at hand (237b3: $\tilde{\eta} v$

49 'Lysias" speech appears to have a structure of interchanging arguments based on a general-specific distinction. The speech begins with specific references to the

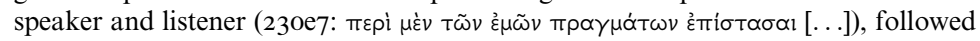
by a brief generalization of the lovers/non-lovers, then turning again to the actual

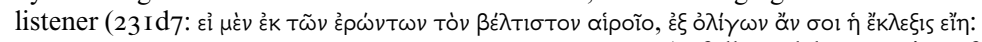

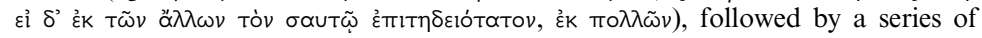

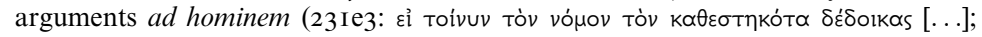

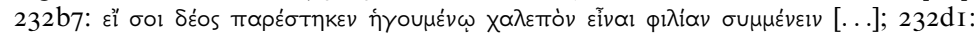

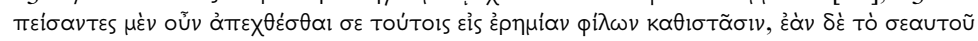

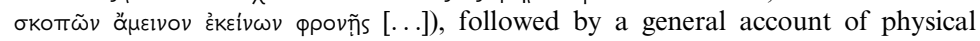
passion which is once again picked up by direct references to the speaker/listener

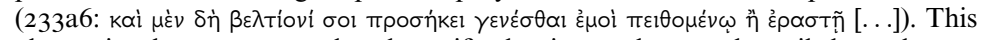
alternation between general and specific dominates the speech until the end, concluding with a very direct personal appeal and request to ask further questions.

5o This in itself is a very significant break from the previous speech by 'Lysias': there the excellence of the composition could not be attributed to anyone other than the excellence of the writer. 


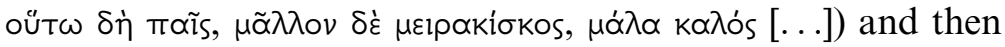
embarks on looking for a (abstract) definition of love (237c9dI). Contrary to that of 'Lysias', this speech is structured in such a way that one would see no reason to emphasize characters or to draw attention to the speaker and the listener as representing different sides of the discussion (e.g. a young desired boy at the receiving end of the speech versus the older man overcome by desire for the boy). Indeed, in this speech both are included in the narrative as if representing the same position of someone who is exploring the question of love. They are depicted as pursuing the argument together. This difference is crucial and becomes even more poignant with the conclusion of the speech, where the argument is developed into its most sinister results and reaches its climax in the horrific claim that 'just as the wolf loves the lamb, so the lover

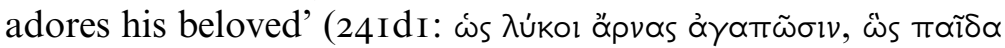
$\phi ı \lambda \circ u ̃ \sigma l v ~ \varepsilon ’ \rho \alpha \sigma \tau \alpha i)$. That kind of love will end up very badly for the beloved (he will be eaten and dead) and probably no

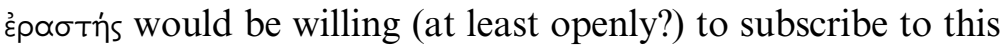
view. Thus, contrary to the first Lysianic speech, we are led to assume that the speaker of the second speech can by no means

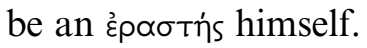

Not only is Socrates' argumentation in his first speech more abstract and general, ${ }^{5 \mathrm{I}}$ his speech is also much more serious than the first speech by 'Lysias'. In fact, part of the attraction of 'Lysias' speech is the relative ease with which one can see that the speech is not meant to be taken seriously, and that the speaker himself is clearly infatuated by the listener whom he wants to persuade. This speech plays with the listener, who probably realizes but accepts the pretense of the speaker to be a non-lover, and with the reader, who might not accept but is amused by the arguments and the particular twist in approach to the topic presented in the speech. In other words, Plato's depiction of a 'Lysianic' speech in the Phaedrus lays particular emphasis on what is later assumed to be the two particularly

5I This level of abstract argumentation is even more explicit in the 'palinode'. 
Lysianic features in speeches: ${ }^{52}$ first, the emphasis on the characters of the speech, which plays a central role in the argumentation, ${ }^{53}$ and secondly the amusing playfulness or superficiality of the speech, which is reached by not actually pursuing the arguments in any serious and thorough way, but by simply evoking different examples or commonplaces that are loosely twisted to fit the point. In order for the speech to pass among Plato's readers as potentially Lysianic, it must have exhibited some characteristic features of Lysias' writerly skills that were already acknowledged by Plato's time. ${ }^{54}$ Thus, Lysias' reputation for character delineation and amusement may well have been already established at least in some intellectual circles of the fourth century BCE. Be that as it may, Plato's portrayal of Lysias in the Phaedrus launched a tradition in the interpretation of Lysias, and all subsequent associations of Lysias with the allure and playfulness of rhetoric probably go back, in one form or another, to Plato's dialogue.

\subsection{After Plato}

Plato's possible rivalry with Lysias was picked up by at least one ancient reader - Diogenes Laertius (henceforth DL), who points out in a list of Plato's innovations that Plato was the

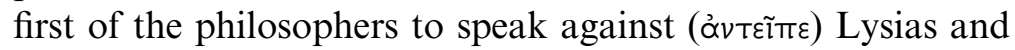
to record the latter's speech verbatim in the Phaedrus (3.25: Kai

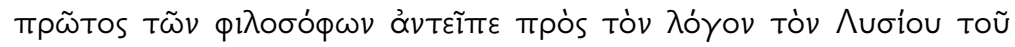

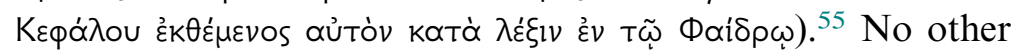
orator or rhetorician is mentioned in a context of direct rivalry with Plato, and it is remarkable that the importance of the

${ }^{52}$ Usher (I976), 33, following the debates around Dover (I968), has tried to identify the 'Lysianic' in Plato's language use, but I find his conclusion unsatisfactory as it gives us too narrow an understanding of Plato's stylistic criticism of Lysias.

53 It is, I would argue, due to our reading of the character of this 'Lysianic' speech that we do not take its argument seriously and consider the speaker as merely wanting to persuade the boy to give him sexual gratification.

54 In fact, Diogenes Laertius (see below) certainly regarded the speech as a genuine work by Lysias and the Phaedrus as depicting a confrontation between Plato and Lysias.

55 For DL I follow the recent edition by Dorandi (2013). 
Phaedrus seems to lie for DL in the fact that it is the first to challenge and analyze Lysias. ${ }^{56}$ It could of course be argued that DL is simply thinking of the beginning of the dialogue and is not really a reliable source for the contemporary reception of Lysias (be that in Plato or in other authors). However, this is a valuable reminder that Plato's Phaedrus had a very crucial role to play in the reception of Lysias. Interestingly, Lysias and his father Cephalus feature also in the list of works reported for the next head of the Academy, Speusippus, ${ }^{57}$ even though we cannot really say much more about the significance of this. ${ }^{58}$ It is perhaps surprising that as far as we can tell Lysias is not explicitly mentioned by Aristotle nor is he given much attention to in the subsequent Peripatetic tradition. ${ }^{59}$ Aristotle's possible stylistic allusions to Lysias do not enable us to say much more about his engagement with Lysias. ${ }^{60}$

${ }^{56}$ As Tarrant points out (2000), I27, however, we know from Proclus that a number of Platonic works were once seen primarily as dialectical attacks on opponents, and among those works Phaedrus was considered as a direct attack on Lysias.

57 In Dorandi's (2013) edition of DL, the works of Speusippus are listed in 4.4.45-74.

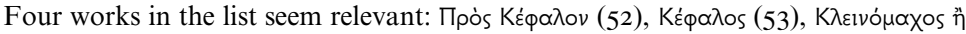

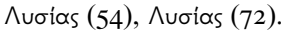

$5^{8}$ Tarán (I98I), I 3 comments that 'like Plato Speusippus was interested in the family of the orator', and Dillon (2003), 34 agrees that the titles suggest that Speusippus was probably 'dramatizing the well-known orator (whom he would have known) and his father [...], but what these dialogues were about escapes us entirely'.

59 Carey (2007), vi suggests that Aristotle quotes directly from a speech later attributed to Lysias and refers to Lysias implicitly in three passages of the Rhetoric. The direct quotation is found in Rhetoric I367bi7-I8 and the three other passages where Aristotle might be alluding to Lysias are: I399bI5 alluding to Lysias 34. I I, I4II I I-3 alluding to Lysias 2.60, and I420b2-3 alluding to Lysias I2.IOO. Blass (I887), 386 reminds us that Aristotle's omission of Lysias in his Rhetoric is not that surprising as he tends to bring examples mainly from epideictic speeches. From our previous examination of the Platonic material, however, I believe sufficient evidence was evoked to suggest that Lysias at the time was not necessarily well known only for his forensic speeches.

${ }^{60}$ In I420b2-3, which is the very last sentence of the Rhetoric, Aristotle discusses an appropriate conclusion to a rhetorical speech and gives an example of an effective

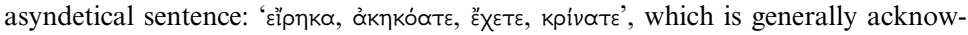

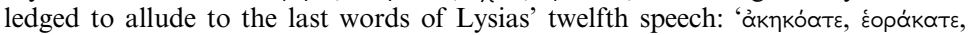

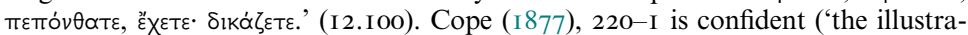
tion is doubtless a reminiscence') that this quotation refers to the closing words of Lysias' twelfth speech. If this is so, then Aristotle's choice of concluding his treatment on rhetoric (which uses mainly examples from epideictic rhetoric) with a paraphrase from Lysias' forensic speech must have been felt as an acknowledgement of the effectiveness of Lysias' style. 
The only Peripatetic who seems to have taken more interest in Lysias, or whom we at least know discussed Lysias explicitly in his work(s), was Theophrastus. Unfortunately, however, Theophrastus' views on Lysias are completely lost save for an out-of-context quotation in Dionysius' essay Lysias, where he quotes a passage from Theophrastus' On style (fr. 692 Fortenbaugh) in order to then contest the latter's views on Lysias. ${ }^{6}$ Based on a speech that Dionysius did not consider authentic, Theophrastus had apparently counted Lysias among those who are overly keen on antitheses, balanced structures and suchlike; a writer who strives for crude and overdone wording and chases after poetic effect rather than realism (fr. 692.2-3). As a response, Dionysius points out that this speech is simply not written by Lysias. In any case, the absence of any more serious engagement with Lysias in Peripatetic sources seems to indicate that a considerable difference was felt to exist between Lysias and Isocrates: while Lysias is not mentioned even once in the Rhetoric, Isocrates is the most frequently quoted contemporary author in Aristotle's Rhetoric. $^{62}$

Lysias is indeed more often compared to Isocrates and most famously so in Plato's Phaedrus, which is the only extant work until Dionysius of Halicarnassus' critical essays in the first century BCE where the two authors are explicitly compared. ${ }^{63}$ Perhaps there are further reasons than we know of for Plato to play the two against each other in his dialogue. It is quite

Scholars have recognized two further allusions to Lysias: in 2.23.I9 (I399bI5-I7) Aristotle brings an example of enthymeme and, without acknowledging the author, the verbal similarity suggests an allusion to Lysias 34. Book 3.7 (I4I I a32-I4I I b2) seems to contain yet another allusion to Lysias, this time to his funeral oration (2.60). See Carey (2007), vi.

${ }^{61}$ For Theophrastus' On style I follow Fortenbaugh's edition (I992) and commentary (2005).

${ }^{62} \mathrm{Cf}$. Benoit (I990), 252. In fact, as far as I can tell, Isocrates is the second (only after Socrates) most frequently mentioned author in the whole work.

${ }_{63}$ There is an interesting connection mentioned in Ps. Plutarch $X$ orat. 836c, where Isocrates' student Philiscus ( $\Phi_{\curlywedge} \lambda \lambda_{i \sigma \kappa o s} \delta$ 'lбokpótous $\mu \varepsilon \dot{v}$ ), also a friend of Lysias

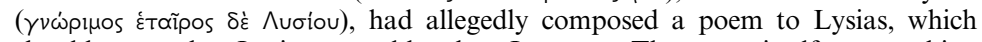
should prove that Lysias was older than Isocrates. The poem itself says nothing about the relationship between Lysias and Isocrates and it is unclear how this poem could prove the relative chronology of Lysias and Isocrates. 
plausible, for instance, and has been tentatively suggested by some scholars, that there was a personal rivalry between them. ${ }^{64}$ Whitehead goes as far as to propose that Isocrates abandoned his logographic activity due to the unsurpassable success rate of Lysias, ${ }^{65}$ and even though it is impossible to prove with any certainty, this view is quite appealing. Isocrates remains very skeptical and negative throughout his career towards speechwriters, and as far as our evidence from Plato goes, Lysias seems certainly to have been among the most accomplished speechwriters of his time. Todd points out two sets of speeches in which Lysias might have written the defense and Isocrates the accusation speeches: Isocrates' Against Euthunous (speech 2I) and Lysias' defense On behalf of Euthunous against Nikias (speech 57-8, fr. I I7-I9); Isocrates' accusation speech Trapezitikos and Lysias' Trapezitikos (speech I34, fr. 285), which has been argued to have been the defense speech from the same trial. ${ }^{66}$ In both cases Lysias is associated with the defense and Isocrates with the accusation speech. We have also fragments from a speech allegedly written by Lysias that seem to have been directed against Isocrates - тро̀ 'lookpótпv aikías (fr. I78-9 Carey, preserved in Pollux 8.46 and Photius II.236). It is unclear who delivered

${ }^{64}$ Trevett (I990); Whitehead (2004), I65-8; Todd (2007), 3I-2. Cicero's Brutus also provides potentially relevant evidence: Cicero claims (Brutus 63) that according to Aristotle Lysias was not very successful in teaching rhetoric and for this reason took up 'merely' writing speeches for others. In this sense, there is a curious similarity and contrast between Lysias and Isocrates: both arrived at their profession by a personal failure in another aspect of the discipline, Lysias in teaching or theory of rhetoric, Isocrates in practice of rhetoric; they are thus exactly opposed in their abilities and character. Further to Cicero's claim, Blass (I887), 382 analyzes Dionysius's assessment of Lysias and argues that when Dionysius claims that Lysias never repeats his introductions and is always innovative, this could be associated with the fact that Lysias is not interested in the topoi or commonplaces that one could/would use to structure the speech; his speeches seem to draw in most cases from the underlying situations rather than from theory or textbook formulas.

65 Whitehead bases his hypothesis on [Plut.] $X$ orat. $836 \mathrm{a}$.

66 Trevett (I990) analyzes this evidence closely and goes against the commonly held view according to which Lysias' Trapezitikos was the mistake of a copyist, who confused Isocrates and Lysias, hence suggesting that there actually was only one Trapezitikos, that of Isocrates. Trevett examines the existing evidence and concludes that it is highly plausible that there were two speeches: Isocrates' accusation speech and Lysias' defense. 
this speech (and of course, Lysias' authorship is anything but certain), but it could still be used as evidence for the perceived antagonism between the two, even if the historical accuracy of this source is dubious. ${ }^{67}$ In other words, even though we have no other source for the two writers being played against each other in their fourth-century BCE reception, there is some evidence that suggests that there might have been some antagonism between the two, ${ }^{68}$ not least because, a point made in Plato's Phaedrus, they advocated completely different approaches to rhetoric.

We have seen thus far a number of important aspects about Lysias and what he came to mean for rhetoric. It is important to acknowledge, first of all, that there is little evidence of Lysias outside his own works and those of Plato, which requires anyone reconstructing Lysias' legacy to depend heavily also on Plato's philosophical dialogues. Since the influence of the Phaedrus on the rhetorical tradition was enormous (as will be demonstrated throughout this book), it is very difficult to find independent evidence for Lysias' importance for his contemporary rhetorical and oratorical scene that does not draw explicitly on either Lysias or Plato. The claim, for example, that Lysias was very popular or even the best writer of the time depends solely on the description of Lysias by Phaedrus in the dialogue, and we have no other independent evidence to back this up. ${ }^{69}$ It seems reasonable enough to accept it, but we should always be careful about generalizing

${ }^{67}$ A further, if rather spurious, link between Lysias and Isocrates is suggested in DL's list of works by Antisthenes. According to some manuscript readings, Antisthenes

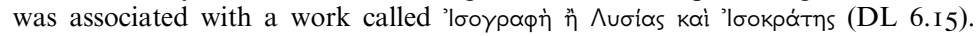

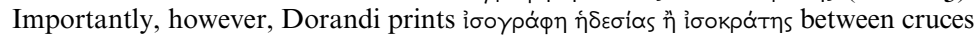
(20I3), 4I5. Either way, if there ever existed such a work it is impossible to know what this piece might have been about. Yet, if there is some validity in the title of some of the manuscripts, then this might count as another source which brings together Lysias and Isocrates on the topic of writing, perhaps regarding the two as best representing contemporary writing culture in Athens.

${ }^{68}$ It is true that their oratorical activity seems to overlap for a very short period, if we assume that Isocrates engaged in his speechwriting activity prior to opening his school in the 380 s.

69 Dionysius of Halicarnassus' later testimony seems to be wholly dependent on Plato's Phaedrus (see more below). 
such claims from our meagre outside evidence. In other words, Plato's early reception of Lysias left an immense mark on Lysias' future reception, simply through there being no other surviving external evidence.

What is, then, the image that we get from this early reception of Lysias? Lysias' own speech I 2 clearly offers an attempt to shape his image in pro-democratic and popular terms, either to win benevolence from his audience (real or imagined) at the post-Thirty euthunai trial against Eratosthenes, or to shape his reputation as a democratic writer whose services could be sought by those needing to shape up their court cases. Or both. Plato's reception clearly undermines this image and consistently portrays him as enjoying the company of morally questionable political players. This interpretation resulted from a rather meticulous and subtle reading of Plato's characterization and, as such, might have been missed by ancient readers as it certainly has been missed by most modern scholars. ${ }^{70}$ But Plato's reception of Lysias overtly challenges Lysias' reputation as the most accomplished writer of the day (as Phaedrus claims in 228a) and offers as support a critical analysis of Lysias' technique, pointing out all rhetorical faux pas and missed opportunities. Plato gets his hands dirty and demonstrates here in detail how criticism ought to be conducted, and it is in these passages that he has made an invaluable contribution to the rhetorical tradition. Equally important is the fact that Plato does not only stop there, but also offers possible improvements, here in the light of two additional speeches that he constructs in the Phaedrus in order to overcome the errors of Lysias. The latter becomes, eventually, a representative of a kind of rhetoric that makes no claims for moral improvement and invites itself to be assessed solely on the basis of style.

Plato's Phaedrus uses, then, the figure of Lysias in two separate but related ways: first, Plato makes suggestions about

${ }^{70}$ An exception here is Nails (2002), I39 who notices that 'Each time we meet Lysias s.v. in a Platonic dialogue, he is mentioned in the company of other politically inclined rhetoricians like himself, notably Thrasymachus s.v., but also Clitophon s.v., whose political allegiances, like those of Epicrates, varied over time.' 


\section{After Plato}

Lysias' intellectual circle and alludes to the moral depravity of the orator and, by implication, of the kind of rhetoric that he promotes. This is, in essence, an ad hominem attack on Lysias. An analysis of Socrates' second speech in the Phaedrus, which aims to correct the stylistic and structural mishaps of the first, but retain the argumentative core, shows clearly the unacceptable moral dispositions that underpin Lysias' rhetoric. Socrates reacts in horror and is forced to deliver a palinode. The conclusion seems to be that rhetoric ought not to be conceived in a moral vacuum and Lysias has to be informed of the implications and directed to a correct path (278c). Secondly, Plato constructs Lysias as a representative of a kind of rhetoric and singles him out from a wide array of writers and rhetoricians mentioned in the dialogue. Lysias is highlighted from all the rest and the speech Plato writes on his behalf becomes a generalizing, and hugely influential, account of rhetoric as style. 


\section{ISOCRATES AND HIS WORK ON RHETORIC AND PHILOSOPHY}

We now turn to Isocrates, a complex figure, whose reputation, appreciation and position in the tradition of rhetoric and philosophy are often debated. Focus of the following discussion will primarily center on the way in which Isocrates frames himself within this intellectual tradition and how he becomes conceptualized as a representative of a philosophicalrhetorical tradition that sees itself as separate from (though not necessarily opposed to) the kind of rhetoric epitomized in the figure of Lysias. Isocrates is an author and teacher of the elite, a writer rather than performer, a philosopher rather than entertainer.

Isocrates' works contain a substantial amount of information about his life. With hindsight we might say that the decision to draw attention to his persona in his writings gave him a privileged position to craft his own reception and reputation in an almost unprecedented way. ${ }^{\mathrm{I}}$ We learn about his family background and education, about his struggles after the Thirty, ${ }^{2}$ about his inability to pursue a political career, ${ }^{3}$ and, last but not least, about his contributions to the Athenian intellectual life of the time. ${ }^{4}$ These biographical snippets do not, of course, necessarily tell us much about the historical Isocrates, ${ }^{5}$ but they give us a sense of how Isocrates might have

\footnotetext{
I An excellent and detailed overview of Isocrates' life and work is provided in López Cruces and Fuentes González (2000). For a brief overview of Isocrates' biography, see Laistner (I927), I I-I 5; Mirhady and Too (2000), I-3. Halliwell (I990), 42-59 provides an insightful discussion of Isocrates' own treatment of character in the 'encomiastic biography' of Evagoras in the Evagoras.

2 Antidosis I6I-5. ${ }^{3}$ To Philip 8I-2, Panathenaicus 9-I I.

${ }^{4}$ Isocrates happily lists his students in Antidosis 93-IOI who have later become (he claims) respected men in the city.

5 The rhetoric of Isocrates' self-characterization is the subject of Too (I995).
} 
wanted his image to emerge from his works and support the building blocks of his philosophy. The direct tone and firstperson address of many of his discourses also enhance his image as a teacher and didactic philosopher, something that will become an important element of his reception in postfourth-century BCE rhetorical tradition. Furthermore, Isocrates seems to have regarded his work as a comprehensive whole and often refers back to, or comments on, his previous writings, explicitly denying any significant change in the character of his work. ${ }^{6}$ We might say, then, that Isocrates had developed a strong sense of ownership over his work and his literary output is planned with extreme care, thus creating (and controlling) the interpretative paradigms for its evaluation. In order to put his thought in context and elucidate what kind of contributions he expected to (and did) make, it is important to unpack the way he talks about his work and to situate it within his current intellectual landscape. This will also help us get a better sense of Isocrates' role and later prominence in rhetorical theory.

Even though few philosophers today would consider Isocrates as their intellectual predecessor, ${ }^{7}$ he was quite probably among the first to open a school of philosophy in Athens, ${ }^{8}$ and portrays himself as proposing a radical alternative to the philosophical thought of his time. ${ }^{9}$ That Isocrates conceived of a philosophical enterprise very differently than (say) Plato did, is clear from his writings and this topic has received increased attention in recent scholarship. ${ }^{\text {IO }}$ What exactly Isocrates meant with philosophia and the kind of impact he expected to exert with his work are still, however, hotly debated. In this context,

${ }^{6}$ This view is extensively defended in Too (I995), Io-73 (esp. 34-5). It is worth remembering that Isocrates had a very long life and so the stability of his thought might strike us as particularly remarkable.

7 Yet few would perhaps be as dismissive as Marrou (I965), I3 I-3.

8 The foundation of the school is often dated to the 390s BCE. Cf. Blass (I 892), I7-I 8; Kennedy (I980), 3I. Ostwald and Lynch (1994) argue that Antisthenes' school was the first one founded in Athens, closely followed by Isocrates.

9 Isocrates as the only alternative to contemporary philosophical schools that all traced themselves back to Socrates is discussed extensively in the following chapter.

Io See e.g. Nightingale (I995), chap. I; Halliwell (I997); Schiappa (I999). 
we should bear in mind two considerations: first, there was no fixed philosophical discipline at the time he was writing and the concept of philosophy itself was widely contested. As a result, we should read Isocrates' engagements with philosophy and rhetoric with an open mind and realize that the philosophical context in which he was writing and teaching was more fluid and dynamic than what we are used to today.

The following discussion in this chapter is divided into three larger subsections: the first part will focus on Isocrates' take on wisdom literature and looks at the way he fashions his own discourse as a response to contemporary educational needs for reform: to replace the poetic tradition with his own discourses. The second section investigates Isocrates' discussion of prose writing, the training of writing skills as constituting a wider formative principle of education, and the political goals of such writing practices. The third section thematizes Isocrates' approach to philosophy: how and under which terms could he be reasonably regarded as belonging to the philosophical tradition? These three strands - the poetic, prosaic-political and philosophical - are to my mind essential for appreciating the way in which Isocrates himself paves the way for his subsequent reception as an Attic writer, educator and a crucial backbone to the rhetorical tradition. My investigation shows in later chapters, surely as a surprise to some readers, that Plato and most later critics take over rather uncritically and endorse Isocrates' self-presentation and so accept his central position in the history of rhetoric. Yet, despite the fact that Isocrates himself is in full control over his image and reception, he remains an exceptional - if not even marginal - case, hard to pin down and force into generic categories of ancient texts that we have gotten used to since. Hence we notice this recurring insecurity about Isocrates, whether he ought to be regarded an Attic orator or philosopher. ${ }^{\text {I2 }}$ Even though Plato's Phaedrus has already shown a direction, in its

I Nightingale (1995), chap. I.

I2 Halliwell (I997) is essential reading for discussions on Isocrates' philosophy and rhetoric, and has in many ways prompted the present inquiry. 
characteristically suggestive way, for how to appreciate Isocrates' role in the rhetorical tradition, it will take another four centuries until Isocrates' position in the rhetorical tradition is reiterated with greater detail and fixed by Dionysius of Halicarnassus' clear expression of him as the pioneer of 'true philosophy' for rhetoric.

\section{I Challenging the Poetic Tradition}

When discussing poetic discourse, Isocrates appears mainly interested in the function of poetry in society, that is to say the role of Homer and Hesiod as teachers and educators, creators of the image of a virtuous (Hellenic) man, and the way their works have been received and interpreted as providing useful advice for 'the everyday' or for the 'monumental moments' in life. ${ }^{\mathrm{I}}$ In other words, his aim is not so much to develop an account of poetics, but rather to focus on those aspects of the role of poetry in society that merit mention and discussion in the context of education. ${ }^{\mathrm{I}}{ }^{\text {Isocrates' polished }}$ style, which aims to provide an example of the writing of a cultured and virtuous citizen, is a testament to his program of using poetic texts as (moral) examples in educational settings. Similarly to poetic works that would be quoted and discussed in classrooms as providing guidelines for different situations,

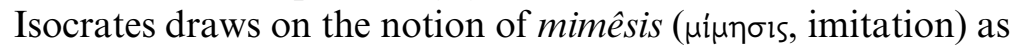
a paradigm for using his own works. ${ }^{15}$ Isocrates is not looking to question or puzzle his readers or students as Gorgias might

${ }^{13}$ For more detailed discussions of Isocrates' engagement with the poetic tradition, see Papillon (I998). An insightful and provocative interpretation of Isocrates' concept of poetics is recently put forth by Halliwell (20I I), 285-304.

${ }^{14}$ Halliwell (20II) seems to be disappointed in Isocrates' concept of poetics ('to accept the consequences of that stance for the valuation of poetry is to share Isocrates' remorselessly prosaic view of the world', 304) because he does not take into consideration Isocrates' very specific and education-driven agenda when mentioning poetic works.

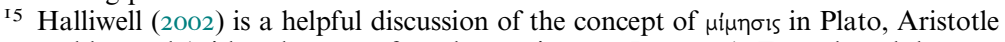
and beyond (with only a very few observations on Isocrates). Even though he puts forth persuasive and reasonable arguments for avoiding the translation of the Greek $\mu i \mu \eta \sigma / s$ as 'imitation', for the sake of convenience the following discussion will use the two - mimesis and imitation - interchangeably. 
have done with his writings, or as Plato makes his students 'wonder' by means of aporiai. Instead, Isocrates seems to devise his speeches as works that function as models for imitation for his students and readers, and would thus give concrete practical examples of written compositions. Thinking through the tradition of poetry seems therefore to be an essential stage in the process of setting up the science of speech and thought.

In his writings, Isocrates also exhibits a polemical attitude to poetry that suggests a more competitive attitude to the role of poetry in society. In some passages he indicates that his work is set in (a constructive) dialogue with poetic practices; in others, he overtly opposes his work to that of the poets. This ambivalence is crucial to Isocrates' argument, for he needs to show the benefit of those aspects of poetry that he will be associating with his own genre, and draw attention to the shortcomings that make poetry an inadequate or outdated carrier of these virtues and benefits that Isocrates' discourses promise to deliver. Examples of the first, positive, attitude can be found, for instance, in his Antidosis (46-7), where he compares his prose writing to poetry, contrasting his particular (poetic) way of writing explicitly to other kinds of prose, mostly courtroom speeches. ${ }^{I 6}$ There, Isocrates appeals to the authoritative position of poetry that he expects will soon be occupied by his own works. Examples of the critical attitude to the poetic tradition can be found in his Evagoras and To Nicocles, speeches which are closely associated with the poetic and particularly with the gnomic tradition. ${ }^{17}$

Isocrates criticizes two types of poetic works in particular the praise encomium and gnomic poetry. These are also the two that are arguably closest to his own philosophical

${ }^{16}$ Papillon (1998) explores Isocrates' constructive use of the poetic tradition, and argues persuasively that in shaping his discourse Isocrates is heavily drawing on some of the most prominent elements of poetic discourse: Isocrates makes use of a variety of styles (from the impressive Pindaric, to the smooth Bacchylidean and pedagogical/advisory Solonian), he makes use of myth, self-correction and priamel as ways to shape his discourse, and lays emphasis on the ethical dimensions of poetry.

${ }^{17}$ See Alexiou (2010), 28-37 with bibliography. 
project, ${ }^{18}$ and his comments on these two kinds of poetic production serve to map the boundaries of his own discourse. In the Evagoras, where Isocrates elaborates the idea of the prose encomium, he claims that while poetry is charming and pleasurable to listen to (Io), the words and ideas used are misleading, invented and/or wrong (II, 36). ${ }^{\text {I9 }}$ Poets have escaped these accusations because they use verse, which enchants and draws attention from content to the form of poems. The underlying implication seems to be, however, that poets are no longer fulfilling their function in society as educators, for by telling lies they are not providing the best models of behavior and are thus not able to serve society as genuine teachers of virtue. Prose writings cannot hide their faults or lack of depth in the way poetry can with the help of meter. Excellent prose writers must be, therefore, more coherent and to the point than their poetic counterparts. This produces - so Isocrates argues - overall better content, and as such ought to be preferred in educational contexts to traditional poetry.

Isocrates offers also another explanation for the need to go beyond existing poetic works. In multiple passages of To Nicocles he discusses gnomic poetry and argues that the education available for the rulers ought to be different from that of the general public. According to him, poets have focused primarily on the needs of the majority and do not provide useful advice tailored specifically for rulers, showing thus another instance where poetry might have an impact on society, but pointing out that this impact is limited and needs to be supplemented by Isocrates' own contributions. The advice given to rulers and their subjects is, according to Isocrates, necessarily different and this is evident from the behavior of the masses who, despite knowing the best course of action or what would make them

${ }^{18}$ Hunter (20 I4), 77 suggests, for example, that 'Isocrates clearly aims to write a prose version of such improving works [as Hesiod's Works and Days]'.

19 A very similar idea is expressed in Panegyricus (I68), where Isocrates draws a sharp

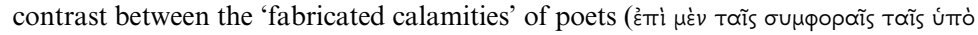

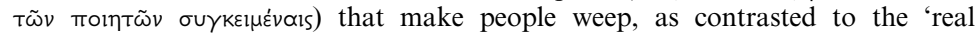
suffering' ( $\dot{\alpha} \lambda \eta \theta v \dot{\alpha} \pi \dot{\alpha} \theta \eta)$ experienced in war that people are far less bothered about. See on this passage also Halliwell (2002), 2 I2-I5. 
better men, do not act accordingly and instead 'in every way take pleasures in things that are contrary to their best interests' (45). As a consequence, the masses are not interested in those most

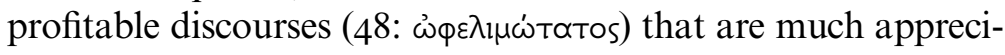
ated by the rulers, but instead follow those recommendations that abound in fictions (48: $\mu \cup \theta \omega \delta \varepsilon \dot{\sigma} \tau \alpha T O S) .{ }^{20}$ Isocrates' political prose promises to fill this gap and provide useful advice for the educated elite alone. In other words, the prose that Isocrates has to offer his students is vastly different from the simplicity and wit that seemed to have made Lysias' work so popular. The two writers, then, represent opposites in the educational elite context in Athens. For Isocrates, contrasting his work with these two kinds of poetic works has helped him, first, specify the particular contributions his discourse aims to make and, second, narrow down the audience for whom he envisions his advice to be particularly relevant. In sum, Isocrates challenges the aims and means of the poetic tradition and by moving beyond it he demonstrates how his own discourses meet the expectations of society more adequately. In particular, he claims to provide an education that is defined by its usefulness and that prepares its students for the practicalities of life and politics.

\subsection{Isocrates on Prose}

Isocrates is one of our most thorough ancient advocates of written prose. Having established his difference from poetic discourse, Isocrates dedicates substantial effort to drawing further distinctions between his own works - collectively referred

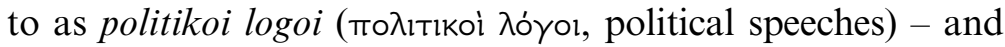
those of other prose writers by promoting the uniqueness of his ideas and emphasizing his contributions to philosophy. Given that prose had just started to become an established mode of philosophical and rhetorical writing, ${ }^{2 \mathrm{I}}$ and given his

${ }^{20}$ The examples Isocrates evokes here are Homeric epics and early tragic poetry $(48-9)$.

${ }^{21}$ For discussions on the relationship between poetry and prose, see Goldhill (2002); the collection of essays in Yunis (2003); Graff (2005). 
educational program which prioritized the ability to express oneself in written form, Isocrates had to provide an innovative approach to philosophical prose in order to stand out and legitimize his school. When discussing other prose authors or works, Isocrates mainly uses two approaches: he either corrects the methods and/or aims of their works, as they have failed to fulfil what they set out to do (or what the generic expectations demand they do), or he provides lists of various kinds of prose writings as established and well-known genres in the order of importance, where his own works always rank as superior to others.

The first approach is best exemplified in his Helen and Busiris. The method of analysis in both speeches is similar: Isocrates examines either a previous speech (Busiris) or a topic that has been subject to multiple interpretations (Helen), comments where others have gone wrong and gives his own version or solution. ${ }^{22}$ In both of these works, other - either previous or contemporary - authors seem to have misunderstood the particularities of the genre they were writing in and ended up promoting, because of their ignorance, the opposite to what they set out to do: Gorgias' Helen, supposed to be an encomium, turned out to focus mainly on the faults of Helen, ${ }^{23}$ Polycrates' Busiris, aimed to be a defense turned out to be an accusation, ${ }^{24}$ and Polycrates' other work, the accusation of Socrates, would have been received by Socrates more as an encomium than an accusation. ${ }^{25}$ By drawing attention to the mismatch between the generic expectations and the actual content of their discourses, Isocrates paves the way for his own supposedly coherent expositions on the topic. ${ }^{26}$

${ }^{22}$ Correcting previous writers: Helen $\mathrm{I} 4-\mathrm{I} 5$, Busiris 9; offering his own interpretation: Helen I6, Busiris Io.

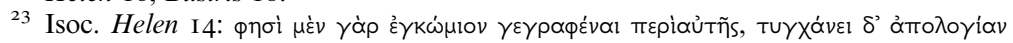

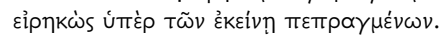

${ }^{24}$ Isoc. Busiris 4-5.

25 Isoc. Busiris 6: 'Socrates would be as grateful to you for your accusation as to any

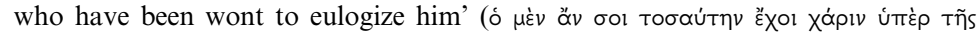

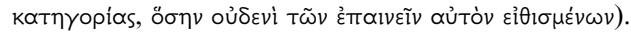

26 And so Isocrates' Helen focuses only on those aspects of her representation that can be wholeheartedly praised, and avoids getting caught up with topics that associate 
Helen in particular has a programmatic aspect to the work. The first part of the discourse gives us Isocrates' critical assessment of the current educational scene and the prose encomium that follows cannot be read in isolation from what precedes it. The potential of prose writings to tackle serious and fundamental topics had not been, at least according to Isocrates, properly exploited thus far. Hence, Isocrates' treatment of Gorgias and Polycrates entails not only, or not simply, criticisms of their generic misunderstandings of what encomia should do. More than that, Isocrates seems to suggest that they have failed to understand the true function and opportunities for serious learning that could be imparted through prose. Isocrates demonstrates instead how someone with his training and education would be able to spot inconsistencies, not be persuaded by misleading arguments, and capable of composing in the very genre better than those who had done so previously. ${ }^{27}$ Furthermore, by evoking philosophers and rhetoricians (like Polycrates), Isocrates makes a pointed gesture towards a context within which he expects his work to appear and be of relevance. In other words, he is targeting the potential students of philosophers and rhetoricians by demonstrating the failures of both of these groups as helpful educational role models. By contrast, his own teaching and writings do not deceive the recipient, they follow closely the clearly expressed aims of his discourse and, because of this coherence of purpose, his works will be more useful and beneficial for anyone interested. In other words, through his criticisms of Gorgias and Polycrates, Isocrates shapes an image of his work as serious, morally coherent and demanding.

Another way Isocrates discusses prose literature, and his own position within it, is by way of constructing lists of 'kinds of prose'. He does so in prominent positions of his Antidosis and Panathenaicus, works that qualify as perhaps Isocrates'

her with negative fame. Livingstone (200I), I2 talks about the 'pure' genre of encomium. Cf. also Zajonz (2002), I45.

27 This is of course (and not coincidentally, as I will argue below) closely reminiscent of Socrates and his criticisms of 'Lysianic speech' in the Phaedrus. 
most extensive expressions of his educational and philosophical program. The lists of prose genres given in both works differ slightly, and this might be explained by the caveat provided at the beginning of the first list, where Isocrates

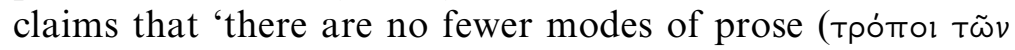
$\lambda o ́ \gamma \omega v$ ) than of verse' (Antidosis 45), thus implying that these lists are quite arbitrary and could easily look different. In Antidosis (45) he outlines six prose genres, ${ }^{28}$ emphasizing in

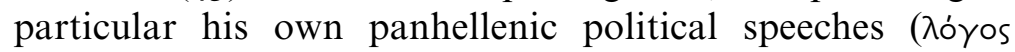

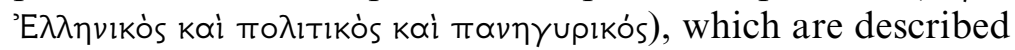
as encompassing all the compositional techniques one needs to know for creating a piece of work in any other genre. In Panathenaicus (I-2) Isocrates lists five prose genres, ${ }^{29}$ once again saving his own panhellenic discourse to last. ${ }^{30}$ In both lists, Isocrates sets up a particularly explicit opposition between his own work and that of courtroom writers. In the Antidosis, the latter are singled out as a natural point of comparison to Isocrates' writing and teaching program $(47-50) .{ }^{3 \mathrm{I}}$ This comparison comes at a crucial section in the discourse and is referred back to in the following passage as having given 'the whole truth about my power, philosophy or profession, however you want to call it' (50: $\pi \varepsilon \rho i \mu \dot{\varepsilon} v$ oũv

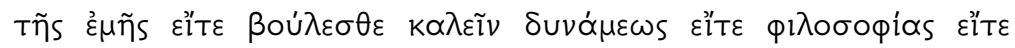

${ }^{28}$ The six prose genres are the following: (I) Researches in the genealogies of the

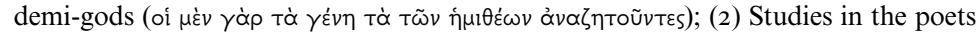

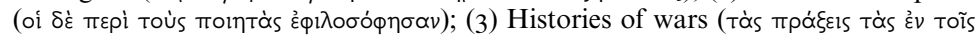

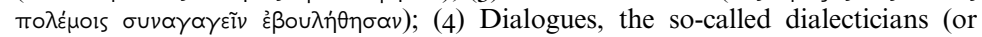

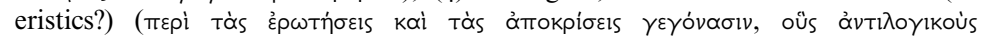

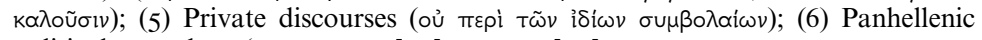

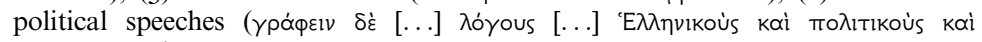

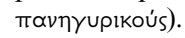

29 The five prose genres: (I) logoi which deal with mythological themes; (2) logoi about marvelous or fictitious themes; (3) logoi about historical events; (4) logoi written in plain style and aimed at persuasion in law courts; (5) logoi which give advice on the true interests of Athens and of the rest of the Hellenes, written in a rich style full with arguments.

30 Panathenaicus 2.

${ }^{31}$ E.g. 'many desire to become students [of Isocratean discourses], thinking that those who excel in this field are wiser and better and of more use than men who speak well

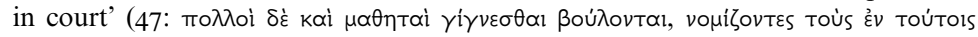

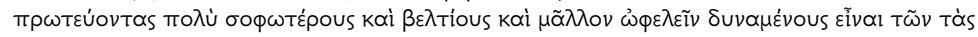

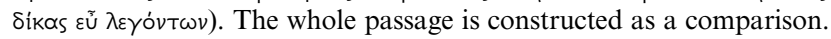




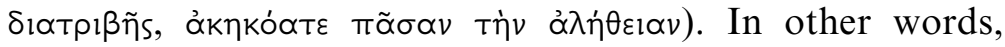
courtroom writers are depicted as among the most significant opponents of Isocrates' work.

In the Panathenaicus, Isocrates' criticism appears more generally directed towards the so-called sophists, a group who will be shown below to encompass in Isocrates' view a wide array of intellectuals, including philosophers. However, when reflecting on his youth and career, he once again compares his decision to dedicate himself to the study and writing of panhellenic matters to those who deal with private contracts and courtroom matters (II). In the opening section of the work, Isocrates gives some clarification about the characteristics of their writing. These are works that 'give the impression of having been composed in a plain and simple manner and having no embellishments, which those who are clever at lawsuits urge our young men to cultivate'. ${ }^{32}$ Should we not think here of Lysias, or at least those who are influenced by the style and writings of Lysias? ${ }^{33}$ Walberer has argued that Lysias, who might have just finished his composition of the Olympiacus (which Walberer regards as authentic), is the opponent Isocrates reacts against in the Panegyricus (I I-I 2). ${ }^{34}$ There, Isocrates discusses men who expect most elaborate writing to have to meet the standards of courtroom pleas, which essentially means in this passage the use of simple style. ${ }^{35}$ In fact, it seems that we can connect most references to the kind of rhetoric which Isocrates disapproves of to the plain style of Lysias or his followers. Isocrates' fierce criticism of this type of writing might suggest its widespread popularity and, therefore, could be taken as an additional confirmation of the

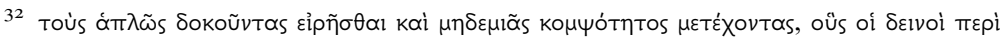

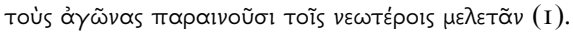

33 As far as I can see, only Norlin (I968), 373 suggests that the section might refer to Lysias.

34 Walberer (I938), 55-60.

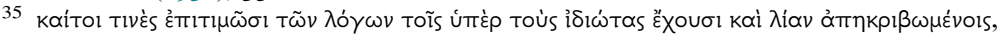

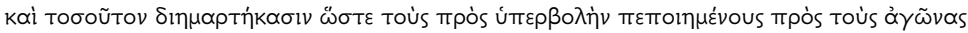

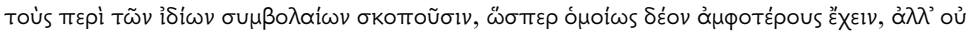

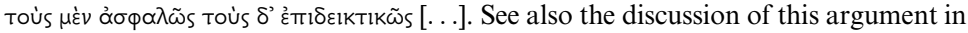
Wilcox (I943a), I I9-20. 
statement made in the beginning of Plato's Phaedrus, which referred to Lysias as one of the most successful and popular

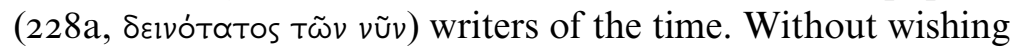
to push this point too hard, it does seem that the kind of writing and style that Lysias had come to embody by the fourth century BCE represented a major point of reference and criticism for Isocrates' own educational and philosophical program.

Going back to the two lists provided in the Antidosis and Panathenaicus, the slight differences should not come as a surprise after Isocrates' own emphasis on the arbitrariness of providing them, but what is perhaps more striking is the fact that in neither of the lists does Isocrates mention philosophical writings as a separate category. Pfister has drawn attention to this absence in his article, suggesting that Isocrates might have neglected philosophical literature as a separate genre in order to avoid associating it with the Academy. ${ }^{36}$ His discussion provoked the response of Wilcox who has attempted to explain away this surprising absence by suggesting that both the Antidosis and the Panathenaicus actually do make reference to philosophical genres; in the former it is mentioned as 'ques-

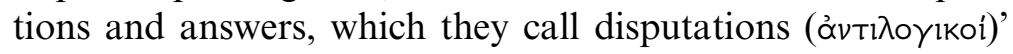
(45) and in the latter under the wider term 'logoi about marvelous or fictitious themes' ${ }^{37}$ Wilcox's discussion is persuasive in so far as he aims to establish that Isocrates refers in both works to a kind of philosophical writing, namely the Socratic dialogues, but we need not assume that this would capture a readily understandable and fixed generic category of philosophical writing. Moreover, in her commentary on the Antidosis, Too suggests that what Wilcox was keen to regard as a reference to a philosophical category is more likely to characterize sophistic works and, perhaps, those of Protagoras and his followers in particular. ${ }^{38}$ But perhaps there is a third way to explain the absence of philosophical works from the list. What if Isocrates never conceived of philosophy as a

${ }^{36}$ Pfister (I933), 458. $\quad 37$ Wilcox (I943). $\quad 3^{38}$ Too (2008), I I9-20. 
specific genre, as something that should be written down? What if philosophy was a term that Isocrates used first and foremost to refer to the (primarily oral?) practice of teaching, thinking and deliberating? It is a well-known and often stated fact that the concept of philosophy was unfixed and widely used to denote a range of different intellectual activities at the time. Yet, as this debate shows, there still lingers an expectation among scholars of finding it conceptualized in similar terms as we have since come to know it from the philosophical tradition, as a separate and self-standing written genre that Isocrates could not have been able to avoid mentioning in his work. In order to further investigate the possibility that philosophy was not conceived as a written practice or fixed written genre by Isocrates, ${ }^{39}$ let us take a closer look at Isocrates' use of philosophia in his works.

\subsection{On What Is and What Is Not Philosophy}

Aside from describing his discourse through comparisons with other genres, Isocrates also makes explicit claims about how he views his work and its effect on Athenian society. These remarks are often made jointly with his references to philosophy, a term with which he often characterizes his intellectual output. Even though Bons has argued that Isocrates' use of (rhetorical) terminology is not as technical and specific as it is among subsequent writers, ${ }^{40}$ the following analysis of Isocrates' use of the three terms - sophist (бoфıтrn's), rhêtôrl

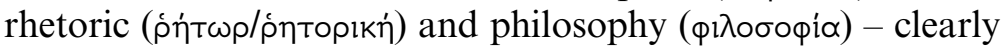
suggests that Isocrates formed distinctive interpretations of these notions and that he frequently uses them to refer either

39 Cf. Halliwell (1994), 223 who argues that philosophia became 'associated with individuals and schools of thought that aspired to comprehensive understanding of the world' and 'the world conceived as the totality of all reality'. Nightingale (1995), chap. I explores how it came about that Plato won the 'contest' for the notion of philosophy and has ever since determined the reception of Isocrates who is primarily referred to as a rhetorician.

$4^{\circ}$ Bons (I996), 4-5. 
to himself in relation to other intellectuals or to contemporary professionals and rivals.

Let us start with the concept of the 'sophist'. There are a few passages where бофıбтn's is used in a wider sense to refer to a 'wise man', ${ }^{4}$ but in these sections either the context or the qualifying words make it clear that Isocrates has in mind the

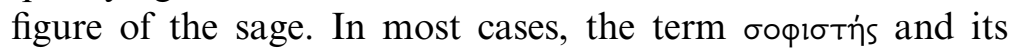
cognates occur in Isocrates' works in a negative sense. ${ }^{42}$ While Isocrates frequently uses this notion to distance his own writings from those he calls the 'sophists', 43 it remains somewhat vague throughout his works whom he considers a sophist in the first place. There are, of course, the usual suspects such as Gorgias, Protagoras and other itinerant teachers, who are included in this category. ${ }^{44}$ But we also see those listed among sophists who are now in contemporary scholarship often grouped together under the controversial label of Presocratic philosophers (Antidosis 285). There are two kinds of criticisms that Isocrates brings against the sophists most often. First, he reproaches sophists for their teaching practices and he seems to be particularly offended by the low pay that these 'sophists' ask from their students (see especially Against the Sophists 3-4). And even if some of the sophists were famous for charging large sums for their teaching, Isocrates argues that their wealth has brought no good to Athens or to themselves.

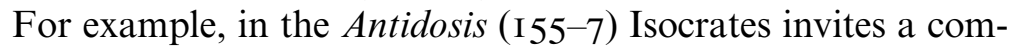
parison between himself and Gorgias, whom he regards as the most successful and wealthy sophist (of all time), but who never contributed to the city's wellbeing and at the time of his death did not leave behind a large inheritance. Contrary to the itinerant sophists, whom he describes as parasites with no home or serious commitments, Isocrates claims to have

${ }^{4 I}$ E.g. To Nicocles (13), Antidosis (235, 3I3).

${ }_{42}$ Curiously, Eucken (I983), 7 argues for the opposite case.

43 They are explicitly contrasted to Isocrates and regard Isocrates as a rival (whom they want to misrepresent) in Antidosis (2, 4), Panathenaicus (5). Sophists' activity as totally different from Isocrates' is stated or implied in Antidosis (I48, 2 I5), Panegyricus (3), Panathenaicus (I8). Sophists as different with regard to their management of finances are mentioned in Antidosis ( I55, I57).

44 Explicitly in Helen (2 and 9). 
contributed to the 'common cause' and this should be welcomed by his fellow citizens (Antidosis I 58). ${ }^{45}$ His criticism of their political uselessness is closely connected to their intellectual faults. In his educational manifesto and protreptic Against the Sophists, Isocrates maps out the contemporary educational scene and reserves the term sophists for the previous generation of intellectuals, who had 'set themselves up as being

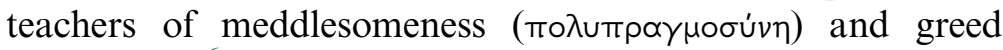
( $\pi \lambda \varepsilon \circ v \varepsilon \xi i \alpha)$ '. ${ }^{46}$ The distinguishing characteristic mentioned there is their narrow-mindedness: these sophists had been focusing on specific vocabulary and trying to teach their students success in law courts through this nit-picking activity. ${ }^{47}$ The second major criticism is the futility of their practice. Indeed, criticisms of the sophists are frequently associated with their lack of seriousness. In the Antidosis (268) and Helen (2-6), sophists are those who have pushed theoretical speculation to the extreme, to the extent of appearing ridiculous and bringing no profit whatsoever to their students. Depicted as unprincipled, unskilled and unable to manage their affairs (both in a financial and intellectual sense), they might even appear as relatively harmless. ${ }^{48}$

45 In a recent article, Thomas Blank (2014) argues that Isocrates did not in fact charge any fees from the Athenians and as such offered a 'public service', thus legitimizing his expectations of receiving public recognition for his services. Though in many ways an attractive suggestion, there seems to be very little to support it: his argument rests solely on his reading of a passage from the Antidosis (I64-5), which does confirm that he was accepting fees from foreigners, but says nothing about taking money from Athenians. This does not really mean that he did not - it is simply not what Isocrates is concerned with demonstrating in the passage. On Isocrates' school fees, see further Ostwald and Lynch (I994), especially 596 where they state that Isocrates' fees were modest in comparison to those of the famous sophists.

46 References to 'ancient sophists' are also made in Antidosis $(268,285)$.

47 This section is very obscure; see Böhme (2009), I 94.

${ }^{48}$ The note at the end of Panegyricus (I88-9) seems to be clearly addressed to sophists. That eloquence or knowledge of the means of eloquence itself is not 'dangerous' is thematized in Antidosis (236-7), that the influence of sophists can be minimal in Against the Sophists (I4), or ineffective in To Philip (I3). In one passage (Antidosis I97), Isocrates even shows awareness of the fact that his practice might be easily confused with the sophists and in another passage of Antidosis shows himself to be sympathetic to their cause and mentions the "common prejudice

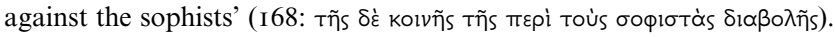


Yet, Isocrates also shows how damaging such individuals can really be. A very common reference to the sophists in Isocrates is reserved for those who are slandering his person and have thus a devastating impact not only on his general reputation, but on the Athenian educational scene more generally. This is stated at the beginning of the Antidosis, where he claims to have been long aware of the damage that the sophists have been trying to inflict on his person by associating him

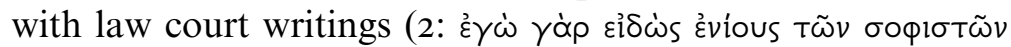

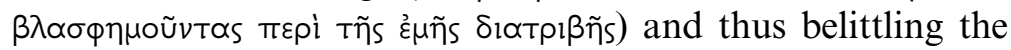
topics and approach he had taken in his discourses. ${ }^{49}$ In general, under the broad notion 'sophists' Isocrates refers both to those whom Plato and the subsequent tradition would call 'sophists' and to those later labeled as philosophers (and Presocratic philosophers in particular) whom he seems to fashion as homogeneous representatives of a tradition of philosophical thought that strongly differs from Isocrates' understanding of the notion 'philosophy'.

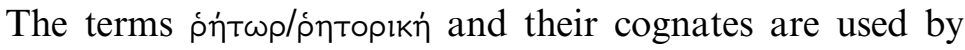
Isocrates mainly in the sense of 'public speakers' or orators who perform speeches and take an active part in politics. Isocrates suggests that this is the category in which some of his pupils can be counted, thus clearly implying that rhetoric occupies a significant role in his teaching. ${ }^{50}$ Yet, at the same time, Isocrates does not refer to himself as a rhetorician and in one passage in particular emphasizes that he should not be

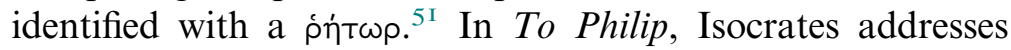
Philip and asks the latter not to be surprised if Isocrates, 'being neither a military commander nor an orator ( $\rho \hat{\imath} \tau \omega \rho)$ nor any other person of authority' (8I), has expressed himself more boldly than others. Isocrates then goes on to explain why he

49 The ancient controversy around Isocrates' law court writings is recorded in D. H. Isocrates $\mathrm{I} 8$.

$5^{\circ}$ We find this usage in On the Team of Horses (7), Against the Sophists (9), On the Peace (5), Antidosis (30, I05, I36, I38, I85, 200, 23 I), Panathenaicus (2), Plataikos $(3,38)$, To Philip (2).

5I This is surely largely due to the fact that Isocrates is not a politician and does not speak in the assembly. 
had decided not to pursue the career of a public orator and, in contrast to the quarrelsome qualities he describes one as having to develop in an oratorical context, he emphasizes his

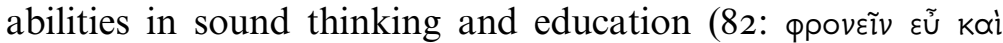
$\left.\pi \varepsilon \pi \alpha_{1} \delta \varepsilon \tilde{U} \sigma \theta \alpha 1 k \alpha \lambda \tilde{\omega} s\right)$ that are paramount to his being able to advise Athenians, Hellenes and the most distinguished of men

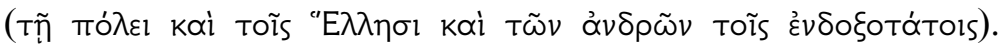
Isocrates seems to say that instead of devoting himself solely to public performances as an active public orator (i.e. politician), he has instead laid more emphasis on training his thought and cultivating general intellectual abilities that are manifested now in his ability to use written discourses to advise men who are confronted with difficult decisions. It seems that this distinction is closely related to the contrast between oral and written discourses, the ṕntopes being representatives of the oral and Isocrates' work representative of the written discourse. ${ }^{52}$ But this is perhaps the result of a more fundamental difference between Isocrates' teaching and the orators: compared to the orators, whose principal area is public speech, ${ }^{53}$ Isocrates' teaching has a far wider scope, ${ }^{54}$ and this is why his students can become professionals in a variety of areas (e.g. historians, generals and, indeed, orators).

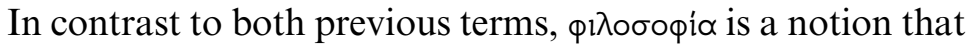
Isocrates associates closely with his own discourses, the concept and its cognates being used far more frequently throughout Isocrates' corpus than the cognates of either ṕnt

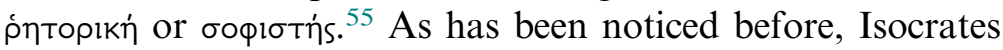

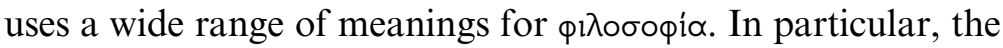
following five thematic clusters seem to be especially strongly represented in his use of the term: ${ }^{56}$ ( $\mathrm{I}$ ) philosophy as a serious

52 Isocrates addresses this explicitly in To Philip (25), and Nicocles (8). In To Philip (29) Isocrates seems to associate prejudices against sophists with those that are commonly held against written speeches.

53 Or rather, public policy as decided in the assembly and council.

54 The contrast between Isocrates' conceptions of philosophy and oratory is set up in Against the Sophists (2I).

55 I count altogether ninety occurrences of $\phi i \lambda o \sigma o \phi^{i} \alpha$ against thirty-six occurrences of фं

${ }^{56} \mathrm{Cf}$. the similar approach to Isocrates' notion of philosophy in Timmerman (I998). 
study, (2) philosophy and practice, (3) philosophy and false philosophy, (4) philosophy and teaching, (5) philosophy as a broad intellectual discipline. All of these categories are essential to Isocrates' conception of philosophia and they all contribute to a general understanding of philosophia as a practice or activity that is primarily undertaken in an educational environment for a practical purpose (e.g. preparation for public life), rather than a kind of solitary act of thinking done for its own sake that could translate into a piece of written work. ${ }^{57}$

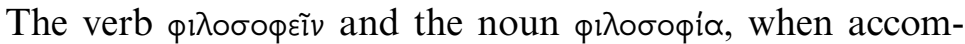

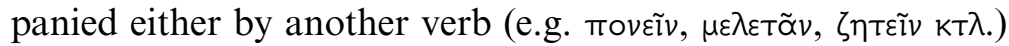

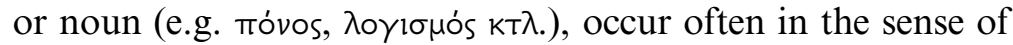
serious study that is crucial for understanding the important problems at stake. ${ }^{58}$ However, Isocrates also makes it clear that the mere contemplation of and search for theoretical solutions is not enough and in some passages he introduces a contrast between philosophy and actual practice, both being crucial to good practice. This contrast is most explicitly expressed in To Nicocles, where Isocrates argues that in order to get a thorough understanding of things under examination, one should approach these things by experience as well as by

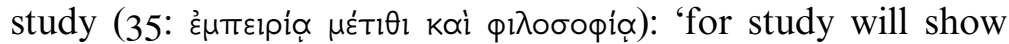
you the way, but training yourself in the actual doing of things will give you power to deal with affairs' ${ }^{59}$ Isocrates' advice to the king clearly suggests that a good understanding is reached through theoretical study (philosophy) and practice or habituation. Elsewhere, however, Isocrates debates the attribution of the notion of 'philosophy' to describe those only engaged in theoretical pursuits, and reclaims the notion for his own allencompassing practices that are beneficial in practical ways to society at large. In the Antidosis, for example, Isocrates

57 It is surprising that in her book on ancient notions of 'theory', Nightingale (2004) barely touches upon Isocrates' contributions to this debate. Isocrates is also conspicuously absent in Yunis' (2003) volume on literate culture.

$5^{8}$ For example in Panegyricus (6, I86), Antidosis (247), To Philip (29), Panathenaicus (I I), On the Peace (5).

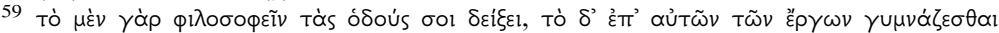

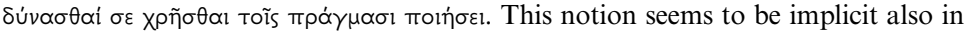
his self-evaluation in the Antidosis (I62). 
explains how his teaching helps cultivate ppóvnors (27I-87) and one of the crucial requirements for this goal, he maintains, is to understand the advantage of his approach. ${ }^{60}$ In this section (285) Isocrates expresses his particular annoyance with the following people:

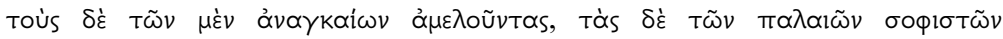

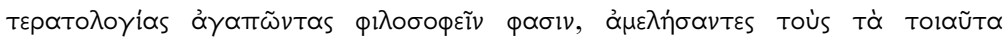

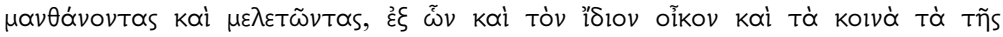

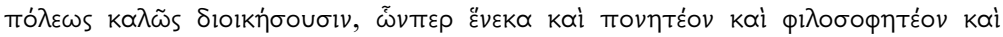

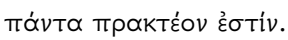

They characterize men who ignore our practical needs and delight in the mental juggling of the ancient sophists as 'students of philosophy', but refuse this name to those who pursue and practise those studies which will enable us to govern wisely both our own households and the commonwealth - which should be the objects of our toil, of our study, and of our every act.

There are many interesting aspects to Isocrates' statements here: most obviously, Isocrates claims that there is general confusion about who should be counted a philosopher and who should not. ${ }^{6 I}$ It is generally acknowledged that in the fifth and fourth centuries BCE the term 'philosophy' and its cognates were far more fluid terms than by the end of the fourth and the early third century BCE when philosophical schools had started to dominate and define research. ${ }^{62}$ To what extent this fluidity of tradition lies behind Isocrates' comments here is difficult to tell. It certainly seems from this passage, however, that an interpretation of philosophy as a solely theoretical pursuit had started to gain more prominence as the dominant (technical) use of the term 'philosophy', and that Isocrates' notion of philosophical activity would appear in this context too broad and unspecific. In a section preceding this one

6o The Isocratean notion of ppóvๆors and its difference/similarity to both Plato and Aristotle has not been much discussed in the literature. I find T. Poulakos' (2004,

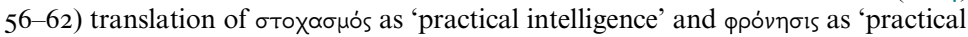
wisdom' misleading and altogether obstructing, rather than improving, our understanding of these notions. I regret that I have not been able to fully consult Roser's recent dissertation (2019), part of which is dedicated to exploring the concept of phronesis in Isocrates.

6I Cf. Antidosis (2 I5, 285), Letter to Archidamus (15), Helen (6), Panathenaicus (263).

${ }^{62}$ See, for example, Nightingale (1995), chap. I with bibliography. 
(Antidosis 284), Isocrates argues that this confusion has arisen from a fundamental misconception about the notion of 'benefit' or 'advantage' in philosophy, and has thus influenced the way in which philosophy's position in society is understood and exploited. Finally, despite Isocrates' language in this passage, those 'ancient sophists' who make a profession out of

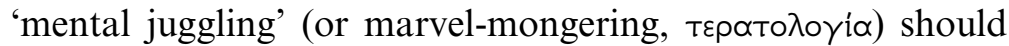
probably be understood as referring to (what we would now call) Presocratic philosophers, who had been associated with this strictly theoretical interpretation of philosophy (see also above). Contrary to the sophists, whose teaching was the result of an essentially pragmatic need for law court practices and who could thus not be rejected on the grounds of being detached from the actual pragmatic needs of society, Isocrates has elsewhere referred to Presocratic philosophers in a similar way to his description of the 'ancient sophists' here. $^{63}$ It seems, then, that Isocrates is consciously labeling proponents of a tradition of philosophy, which focuses primarily on theoretical speculation, as sophists, while at the same time inculcating a complete revision of the term to fit his own educational and philosophical paradigm. Isocrates argues that these sophists who call themselves (theoretical) philosophers have misled people about the true aims and use of philosophy, thus creating a misconception about philosophy as a superfluous practice unable to benefit society. It is, according to him, high time to reclaim the notion of philosophy from these sophists who thrive in paradoxical and unhelpful thoughts,

${ }^{63}$ In the Helen, Isocrates seems to consider (what we would call) Presocratic philosophers together with sophists. He starts his list of sophists with Protagoras (2: öotıs

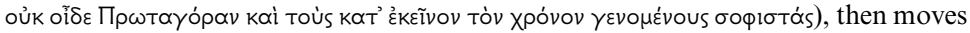
on to the philosophical works of Gorgias, Zeno and Melissus; the latter two of the list have become standard names in Presocratic philosophy. The entire group is

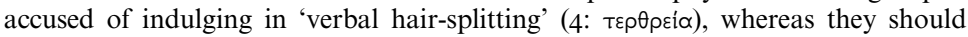
guide their students towards the truth and the practical affairs of government,

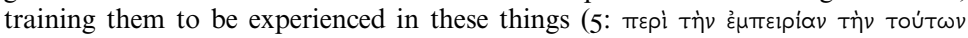

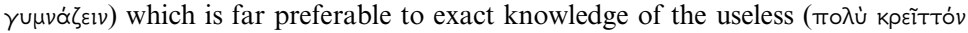

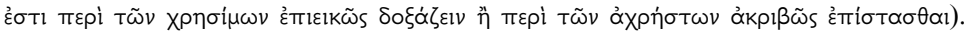
Furthermore, Eucken (1983), esp. 44-56, sees Isocrates' Helen as very closely engaged with the philosophical positions of Antisthenes, Plato and Socrates. 
and are negatively contrasted to Isocrates' pragmatic interpretation of proper philosophy. ${ }^{64}$

Isocrates' positive definition and exposition of philosophy is most clearly expressed in his Antidosis. Even though he has explained his understanding of the term in various previous passages of the work, by evoking parallels from physical training or talking about the different professions of his pupils to give an idea of his encompassing treatment of the subject, he comes to give a definition of philosophy in section 27I that is worth quoting in full:

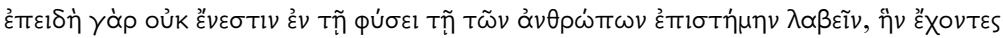

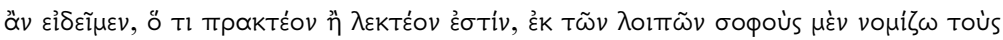

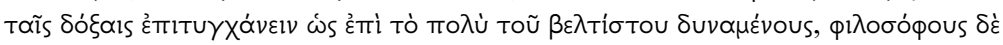

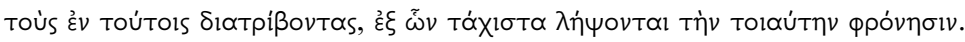

For since it is not in the nature of man to attain a science by the possession of which we can know positively what we should do or what we should say, in the next resort I hold that man to be wise who is able by his powers of conjecture to arrive generally at the best course, and I hold that man to be a philosopher who occupies himself with the studies from which he will most quickly gain that kind of insight.

In this one compressed sentence, Isocrates explains the fundamentals of his interpretation of philosophy in a way that is intelligible to different audiences, from the theoretical sophist to an active politician or layman. Isocrates argues that knowledge is unattainable for humans and thus that every kind of theoretical activity that aims to produce infallible and systematic knowledge is futile and unproductive. Even though he does not bring further evidence to bear in this passage, elsewhere in the work Isocrates invokes sophists (a group which also includes those called philosophers today, ${ }^{65}$ possibly also the Socratics) as a proof for this sentiment. According to Isocrates, sophists claim to work towards formulating fixed

${ }^{64}$ Most commentators on Isocrates do not take his claims to philosophy seriously and interpret Isocrates' discussion as focusing on rhetoric instead. This general reluctance to consider Isocrates in any way philosophically relevant is perhaps particularly surprising in Too (I995) and (2008), whose focus is unyieldingly fixed on Isocrates as a rhetorician. An exception is Schiappa (I999), I62-84.

${ }_{5}$ Cf. Kerferd (I950); Schiappa (I999), 67-82. 
principles and arguments that would result in systematic knowledge, but end up proposing solutions that are unacceptable and also in disagreement with each other: oi $\mu \dot{\varepsilon} v$ $\gamma \dot{\alpha} \rho$

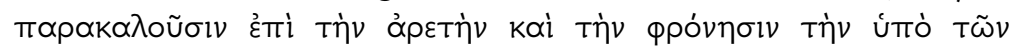

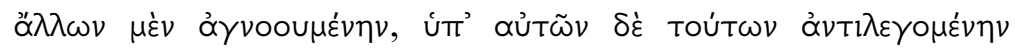
(Antidosis 84). Isocrates maintains in another passage of the work that it is not appropriate to 'call philosophy something that does not profit us in the present, either for (improving) our speaking or our actions' (266). Instead, he would call 'this kind of exercise gymnastics of the soul and a preparation for phil-

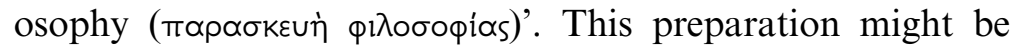
useful, as anything learned at school (266-7), to sharpen the minds and train the learning of students (265), but it should not become the sole object of their attention and students' minds should not 'be stranded on the speculations of the ancient sophists' (268), who make different claims about the ontological status of the world. The examples mentioned Empedocles, Ion, Alcmaeon, Parmenides, Melissus and Gorgias - are all from (what we now call) Presocratic philosophy and Isocrates describes them as a group that tried to render observations in the physical world to a select number of substances, ${ }^{66}$ and eventually engage in speculations about their interrelations through theoretical arguments. Isocrates rejects this tradition wholesale with his claim that this kind of knowledge is not accessible to human beings. Having made this statement and rejected the concept of philosophy as a strictly theoretical study relying on proofs, Isocrates automatically frees himself not only from the demands of this philosophical tradition, but also from any further necessity to provide more detailed or systematic argumentation to support his claims.

Instead, Isocrates argues that a true philosopher is someone who, having understood the limits of human mind, will turn his energies to studying good practice and widespread opinions

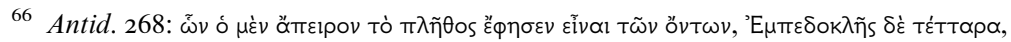

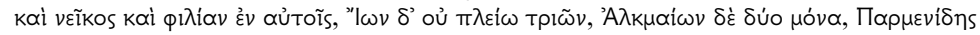

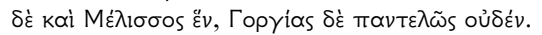


that have been verified over the course of human (Greek) history. ${ }^{67}$ Philosophers, as Isocrates claims in the passage quoted above, are those who are most experienced in this kind of study and are able to determine the best possible practice most frequently and quickly. How is this achieved without relying on theoretical arguments and sound methodologies? ${ }^{68}$ Isocrates gives three main methods that can be used: striving towards speaking well, persuading others, and a desire to seize

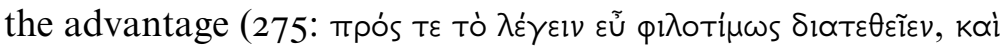

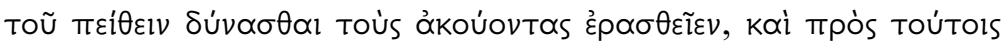

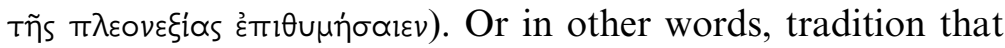
leads to forming a good moral character, which, in turn, works towards benefiting society. Isocrates explains all three aspects in detail. With regard to the first point, he argues that whenever someone has set their mind to speaking or writing honorable discourses these will be devoted 'to the welfare of man and our common good' (276). In this case, one will select actions and deeds of remarkable men and, by preparing the discourse, will thus profit oneself by becoming familiar with praiseworthy thoughts and actions (277). Isocrates argues that through this kind of training the man who is closely familiarized with his outstanding ancestors 'will feel their influence not only in the speech he has at hand, but also in other actions of his life' (277). Speaking well means, then, that by using models that have been proven by tradition to be valuable (no need to engage in theoretical discussion about these time-tested models) one tries to reach the level of these models through imitation. In other words, history and proven deeds will be used as criteria for preparing a discourse that meets the expectations of Isocratean philosophy: it will cultivate one's mind

${ }^{67} \mathrm{Cf}$. also Panathenaicus 32, where Isocrates explains what constitutes the 'educated' man.

${ }^{68}$ Cooper (I 985) summarizes (from an unabashedly Platonist perspective) many of the concerns that contemporary philosophers, heirs of the tradition of philosophy that follows Plato's conceptualization of philosophical pursuit, will inevitably have when trying to find philosophically satisfactory answers to this question in Isocrates. See also Halliwell (1997), who argues that Isocrates' thought remains disturbingly at the 'first order level' and shows a profound lack of self-examination. 
and, at the same time, provide role models for active emulation throughout one's life. ${ }^{69}$

The second point, persuasion, is discussed in relation to character. In an almost anti-Aristotelian fashion, ${ }^{70}$ Isocrates claims that 'only those fixed on philosophy have failed to

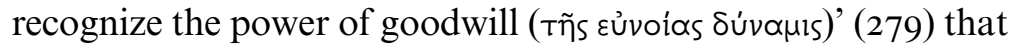
can be achieved through presenting a trustworthy and appealing character. ${ }^{71}$ Therefore, Isocrates concludes, 'the stronger a man's desire to persuade his hearers, the more

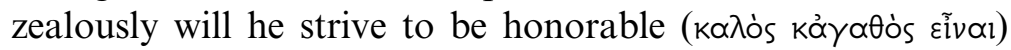
and well regarded by his fellow citizens' (278). The general pressure to have a good reputation which helps, when necessary, justify one's conduct, will provide the motivation needed to cultivate an overall honorable image of oneself. Furthermore, while all the theoretical elements of argumentation - probabilities, proofs and other kinds of persuasive

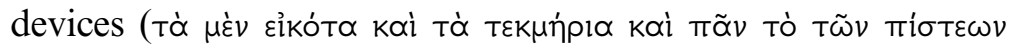
عĩठos) - only contribute to this one specific part of the case,

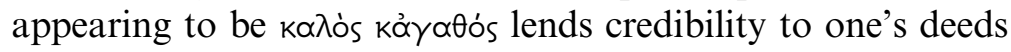
as much as to one's words (280). In this way Isocrates draws attention once again to his claim that training in successful self-presentation involves a training of character and intellectual abilities in such a way that will, eventually, lead to developing a virtuous character. In fact, elsewhere Isocrates also refers to his teaching as a broad training of the soul, ${ }^{72}$ or as an art of the mind, conceived as parallel to gymnastics, the instruction of one's body. ${ }^{73}$ Philosophy in this Isocratean sense seems to encompass a variety of other areas, and Isocrates explains how good training in astronomy, mathematics and geometry, to name but a few, might enhance the students'

${ }^{69}$ Cf. Batstone (1985), I07.

$7^{0}$ Aristotle argues in Rhetoric I356a that when persuasion occurs through character

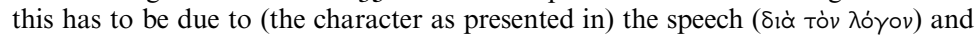
not through the preconceived idea of the speaker. Aristotle's position is, thus, the exact opposite to what Isocrates claims in this passage.

${ }^{71}$ See de Romilly (1958) for the political implications of Isocrates' use of züvola.

${ }^{72}$ In To Nicocles (5I), where he lists his teaching among his competitors to show that in a broad sense they all aim to give guidance about how to discipline the soul.

73 Antidosis (18I, I83). 
potential when they arrive at philosophy as the final goal of their educational training (Antidosis 26I). ${ }^{74}$ Note that Isocrates is always careful to evoke philosophy in educational settings and as an intellectual activity that serves a wider purpose of cultivating a 'proper' citizen. Philosophy is not really a goal in itself. ${ }^{75}$

The breadth of Isocrates' philosophia is also on display when he talks about his teaching methods. Isocrates suggests that his students might have multiple areas of specialization depending on their natural endowments and that in his school everyone can freely pursue different career paths and get proper support from the teacher who is going to enhance their knowledge and abilities in these different fields (Antidosis I86-8). ${ }^{76}$ In other words, contrary to a specialized philosophical school which concentrates on developing theoretical arguments about, say, the ontological status of the world, Isocrates' school trains the students in a wide variety of specializations, thus cultivating their minds and abilities more generally, as well as giving a concrete focus on their chosen field of study. Furthermore, it seems that Isocrates not only endorses multiple specializations for students, but regards philosophy as giving rise to multiple cultural and political institutions. This is stated in his Panegyricus, where Isocrates discusses various festivals of Greece and argues that philosophy is really the source for Athenian cultural supremacy:

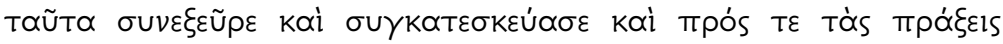

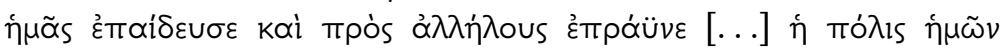
$\kappa \propto T \varepsilon \delta \delta \varepsilon 1 \xi \varepsilon v$ (47). On the one hand, this appears to be a polemical

${ }^{74}$ Philosophy seems, then, to be simultaneously the final goal of education as well as the actual practice of acculturation.

75 In this sense, I believe Isocrates is talking about something completely different than what Schiappa (I995) suggests when he tries to rehabilitate Isocrates' position in the canon of philosophy by referring to him as a representative of (philosophical) pragmatism.

${ }^{76}$ This could be supported by the surprising variety of political sentiments of Isocrates' students who do not conform in their allegiance to either democratic or aristocratic/oligarchic structures. See Harding (1973), I39. This approach seems to have resonated among later interpreters of Isocrates. See, for example, Cicero $D e$ orat. 3.9.35: discipulos dissimiles inter se ac tamen laudandos, cum ad cuiusque naturam institutio doctoris accommodaretur. 
claim, suggesting that previous traditions of philosophy (the Presocratics and/or earlier sophists) do not amount to proper philosophy. On the other hand, Isocrates is in this passage once more reinforcing the image of his philosophical project as the first comprehensive and all-encompassing training of the mind, one that must be seen in close relation to contributions made to the polis more generally. To push this thought further, it might be argued that Isocrates' philosophy remains deliberately a rather loose and undefined concept, and Isocrates shows no willingness to develop strict logical structures of thought or methodology that would compel all students to come to the same kind of results or state of mind.

Perhaps Isocrates' rejection of the rhetorical handbook tradition could be regarded as another side to the same argument about the pitfalls of applying fixed structures and/or rules of thought to a creative process such as learning. Given the previous discussion of Isocrates' philosophy, which is best conceived as a broad intellectual practice that makes a virtue out of the relative vagueness of the concept, it is easy to see why Isocrates would disapprove of the practice of writing and using technical handbooks for educational purposes. ${ }^{77}$ Isocrates makes this clear in his programmatic work Against the Sophists, where he criticizes teachers 'who have themselves failed to notice that they are bringing a fixed art as an example for creative process ( pares the art of using letters to the art of discourse $(\log o i)$ : the first is a fixed and unchangeable process where 'we continually and invariably use the same letters for the same purposes', whereas in discourses 'what has been said by one speaker is not equally useful for the speaker who comes after him' (I2). Furthermore, Isocrates expresses strong reservations about the ability to teach virtue or, more generally, to simply turn any willing student to virtue and philosophy. According to him,

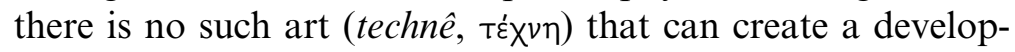
ment towards virtue and justice in 'depraved natures' (2 I: Toĩs

77 Cf. Bons (I996), I I-I3. 


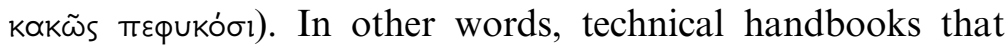
depict teaching and learning as a straightforward matter, where the student will improve simply by memorizing and following the rules provided in these books, are misleading and can hardly deliver what they boast to be able to do: to create experts or educated men from all their students. There are multiple references to Isocrates' aversion to the handbook tradition in his works, even though they are less explicit than his statements in Against the Sophists and Antidosis. ${ }^{78}$

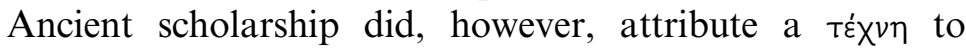
Isocrates and, despite the relatively widely held view among modern scholars that Isocrates did not participate in the handbook tradition, this position has been recently challenged. ${ }^{79} \mathrm{It}$ is true that Barwick, who argued against the Isocratean $\tau^{\prime} \times \nu \eta$, was forced, rather uncomfortably, to admit several stages of misunderstanding among ancient theorists (including Cicero and Quintilian) in order to maintain his point and at the same time give a plausible rationale for the existence of ancient accounts of Isocrates' $\tau \dot{\chi} \chi \nu \eta .^{80}$ The main thrust of his argument is based on the fact that $\tau \dot{x} \chi \nu \eta$ in the fourth century BCE could mean both a 'handbook' and a 'polished speech', and that the later understanding of ${ }^{\prime} \varepsilon \dot{x} \nu \eta$ in a strictly technical sense created a confusion among rhetoricians, who misread a passage from

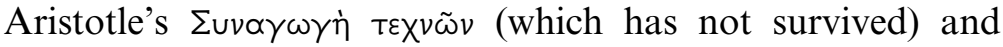
assumed that Isocrates also wrote a $\tau \varepsilon \dot{x} \chi \eta$ (even though no actual work survives). Papillon challenged this view and proposed viewing Isocrates as the inventor of 'hypodeictic discourse' that he explains as 'joining narration with argument through praise by comparison', and Isocrates' тย́x $\nu \eta$ as innovatively consisting of longer examples and a technical commentary. ${ }^{81}$ The most recent 'reconstruction' of an Isocratean $\tau \varepsilon \dot{x} \chi \eta$ has been put forward by Walker. ${ }^{82}$ Walker's admittedly

$7^{8}$ E.g. To Nicocles 28, Helen 65, On the peace 4, Antidosis 274.

79 The evidence is collected in Radermacher (195I), I53-63. Ancient references are summarized and discussed in Barwick (I963), who also gives a useful overview of the history of this question, and Walker (2011), 57-68. Both scholars arrive at completely opposite conclusions.

${ }^{80}$ Barwick (I963), 50. ${ }^{81}$ Papillon (I995), I59. ${ }^{82}$ Walker (20II). 
speculative work argues, among other things, that Isocrates' TÉx $\eta$ was very similar to the Rhetoric to Alexander and that it also became a sort of ' $U r$-handbook' for all future sophistic or

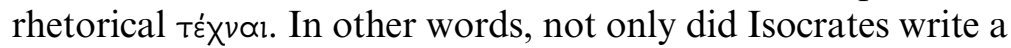
$\tau \varepsilon \dot{x} \vee \eta$, this work also became foundational for the subsequent rhetorical handbook tradition. ${ }^{83}$ Against Walker's extremely speculative account, I would like to make two points. Firstly, if Isocrates were indeed the founding father of the rhetorical handbook tradition, we would surely expect to hear more about that from our ancient sources. In fact, authorities in the field seem to question this attribution (e.g. Quintilian Inst. 2.I5.4: si tamen re vera ars quae circumfertur eius est). Hence, it could not have occupied such a central position in the rhetorical handbook tradition that Walker envisions if nothing at all was known about this work from relatively early on in the reception history. Secondly, contrary to what Walker suggests, one of the main characteristics of Isocrates that emerges is his uniqueness and dissimilarity from other (contemporary) teachers. This sense of difference is already articulated in the Phaedrus, where Socrates suggests that Isocrates is different from Lysias and the like, who could perhaps be grouped together with those writing handbooks and showing cleverness in little speeches like those that Phaedrus delivers in the dialogue. Indeed, in the handbook passage of the dialogue (266d-7d), Isocrates is not mentioned, whereas several others are mentioned as explicitly having written technai. Looking at the evidence we have about Isocrates' $\tau \varepsilon \dot{x} \chi \eta \eta$, it seems fairly clear that his contemporaries do not associate him with a rhetorical handbook tradition, and that this is something that becomes more prominent in later stages of his reception. ${ }^{84}$

83 Walker (20II), 90.

${ }^{84}$ Roochnik (I996) examines the notion of 'techne' in philosophical tradition (mainly Plato) and proposes two ways to conceptualize this notion in ancient works: one would be the strict handbook approach $\left(\right.$ techne $\left._{1}\right)$ and another a more loose but difficult to express approach (techne $e_{2}$ ). He analyzes Isocrates' use of this term and concludes that Isocrates 'offers a techne ${ }_{2}$, a kind of teachable knowledge that makes none of the hard and fast claims of a techne, ' (288). This is possible, but perhaps rendered somewhat dubious by the fact that Isocrates himself makes no references to having ever produced such a work and, as has been persuasively 
The third argument about how to achieve Isocratean philosophy (Antidosis 275, quoted above) concerns the notion of advantage or gain $(\pi \lambda \varepsilon \circ v \varepsilon \xi i \alpha)$. Isocrates considers this notion to be the most difficult of the points raised, because he has to argue against the widespread opinion according to which advantage is something achieved at the expense of others, either by robbing them or by doing other evil things $(28 \mathrm{I}){ }^{85}$ According to Isocrates, however, advantage in its true sense is applicable only to men "who are the most righteous and most faithful in their devotions'. These men are also rewarded with advantage by their excellent associates and fellows. Why is it, all of a sudden, that common knowledge is actually not trustworthy and that there is a need to redefine the notion 'advantage'? Indeed, Isocrates' entire methodology seems to depend on the general trust in public opinion and widely held views. Isocrates realizes this problem and argues that there is a general misconception in Athens with regard to language and terminology used to denote certain activities and people. Meanings are turned upside-down, Isocrates claims, and buffoons capable of mocking and mimicking rather than men of excellence are called 'gifted' (عủфurĩs, 285). Tracing these changes back to the so-called ancient sophists enables Isocrates to suggest that in reality he does not disagree with the general public, but with those 'philosophers' who have unhelpfully discredited the idea of 'advantage', which used to function as a positive term in the context of any intellectual activity. $^{86}$

We arrive here at what appears to be an explicit confrontation with Socrates and his teaching. It is a central characteristic of Socratic teaching to closely scrutinize one's reliance on, and appreciation of, external characteristics such as wealth and reputation regarded as goals in themselves (e.g. Apology

argued before, his corpus stands out by the amount of internal references made to his work within his own work. Why would Isocrates fail to mention a more programmatic work on his teaching principles if he had indeed authored one?

${ }_{55}$ See also Antidosis 275, Nicocles 2, Peace 28-35.

86 This includes also an appraisal of the concept of wealth, for instance, that he claims has fallen into discredit amongst his contemporaries (Antidosis I59-60). 
3ob2-3). In the course of examining the true meanings of these characteristics, Socrates often ended up rethinking these terms in such a way that they acquired a meaning contrary to their original and literal sense: reputation ( $\delta$ ó $\xi \alpha)$ becomes mere appearance, the maxim 'help friends and hurt enemies' is turned upside-down, and so on. ${ }^{87}$ Isocrates takes issue with this approach and aims to return to the original or traditional meanings of these concepts and claims that his teaching will get the youth into the habit of striving towards advantage in relation to themselves and the country as a whole, and to do so in very concrete and practical terms. The challenge of the fundamental principles of Socratic teaching is not of secondary importance for Isocrates. In fact, rather than criticizing his contemporary intellectuals individually (Antisthenes, Plato, Aristotle, etc.) it could be argued instead that Isocrates treats them rather as a derivative or second-order group of Socratics, thus suggesting that Isocrates' most profound opponent, and one Isocrates is most committed to challenging in his works, is Socrates - the Athenian philosopher-teacher par excellence.

87 This is an oversimplification of the function of definitions in Plato's dialogues. See

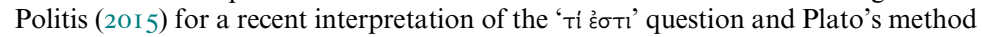
of inquiry in the early dialogues. 


\section{ISOCRATES ON SOCRATES}

While the biographical tradition associates Isocrates' intellectual formation most frequently with Gorgias, Prodicus and Theramenes, there is also another, much later and more dubious, tradition that connects Isocrates to Socrates. Despite the confident claim in the Anonymous Life of Isocrates, which

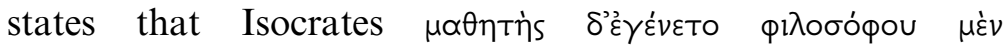
$\Sigma \omega$ kpótous ('became the student of Socrates the philosopher'), ${ }^{\mathrm{I}}$ and a couple of anecdotes, describing Isocrates utterly distressed about the death of Socrates to the extent of wearing mourning clothes for a year, the association between Socrates and Isocrates is of late origin and of little plausibility. ${ }^{2}$ However, the suggestion that there was some sort of intellectual association between the two men seems to carry irresistible attraction and it has never ceased to have prominent supporters. $^{3}$

Their association surely owes much to the reading of Isocrates' Antidosis together with Plato's Phaedrus and to noticing Isocrates' only mention of Socrates in his Busiris. Whether or not the two actually met is a wild speculation and in itself not a very relevant question for this inquiry. It is surely true, however, that Socrates' trial and execution had a long-lasting impact on Athens and it is highly probable that devising a career in education and laying claims to philosophy just immediately after such a watershed moment must have

\footnotetext{
I Mandilaras (2003), I.2 I I.

${ }^{2}$ See Klaus Ries' excellent discussion of the details of this tradition (I959), I-8.

3 One of the most prominent and vocal defenders of this association was George Kennedy in his account of Isocrates (I963), I74-203. Others make this assumption mostly in passing, e.g. Janko (2006), 58 who writes that Isocrates was Socrates' pupil, or McCoy (2007), 9 who uncritically assumes that Isocrates was a 'follower of Socrates' and a student of Gorgias.
} 
forced Isocrates to think hard about the role of teachers and intellectuals in Athenian society. Although it was held among many (if not most) contemporaries that Socrates' death was unfair and undeserved - and therefore it was (and perhaps still is) probably unwise to criticize Socrates for an educated audience - Socrates' behavior at the trial and his (lack of?) ability to defend himself have nevertheless been a subject of debate and interpretation. ${ }^{4}$ I believe that we should look at Isocrates, though clearly a non-Socratic thinker, also in this particular context. While most scholars regard Isocrates as a staunch rival of Plato, Aristotle and other Socratics, ${ }^{5}$ it is productive to regard Isocrates together with his contemporaries as trying to negotiate the Socratic legacy while developing his own unique approach to education and philosophy. ${ }^{6}$ This perspective will show that Isocrates' reflection of Socrates was more combative and critical than what has thus far been proposed.

Before Isocrates opens his school in early fourth-century Athens, we hear from another philosophy school in Athens that is active in 423 BCE - Socrates' 'Thinkery' (or Phrontistêrion) from Aristophanes' Clouds. Granted that this is a comedy and not an actual school (nor actual Socrates) that is portrayed in the play, this idea of Socrates as school master and student magnet seems to have resonated well after his death. ${ }^{7}$ Indeed, it is curious that of all the philosophical schools in Athens that we know emerged from the early fourth century onwards, Isocrates' was the only one not tracing its origins back to Socrates. ${ }^{8}$ This tells us two things: first, Socrates' influence on his followers seems to have been such that it inspired later schools to be founded with a focus

${ }^{4}$ See also Cartledge (2009), 76-90.

5 See e.g. Eucken (I983); Nightingale (1995); Haskins (2004); Wareh (2012); Muir (2019).

${ }^{6}$ In fact, Isocrates repeatedly diagnoses the cultural milieu of his contemporaries by reference to predecessors. See e.g. Isoc. Against the Sophists I9-2I.

7 The clearest expression of the lasting impact of Aristophanes' portrayal of Socrates is in Plato's Apology I8a-I9c where Socrates himself laments the impression that the Clouds has made on the Athenians.

${ }^{8}$ Clarke, forgetting Isocrates, maintains that 'the later philosophical schools, with the exception of the Epicurean, all derived from [Socrates]' (I97I), 58. Though see now Hessler (2018) on Socrates' influence on Epicurus and Epicurean philosophy. 
specifically on professionalization of philosophy, politics and education. ${ }^{9}$ Second, as far as we can tell, Isocrates was the only advocate for professional schools who shows us another way of conceiving higher education in Athens. It is plausible, then, that when Isocrates discusses/critiques philosophers and the philosophical tradition, Socrates (rather than any individual Socratic) is the overwhelming and underlying 'martyr' of philosophy and education that he needs to grapple with. Why indeed did he not, unlike all other heads of philosophy schools, become a Socratic?

It is an understatement to say that Isocrates disagreed with Socrates and with Socrates-inspired philosophical schools. The tradition itself was in development and Isocrates proposed, as discussed above, a fundamentally different kind of concept for a philosophical school. This school was predicated upon the principles of sophisticated rhetoric, persuasion and advantage (discussed above). The urgency with which Isocrates attacks Socratic philosophers and the courage he had to challenge Socrates as the fountainhead of what had started to become a standard conception of philosophy schools are best understood as political. While Isocrates promoted in his work public life and preparation for political participation in the city's governance, often specifically drawing attention to students who had excelled in relevant fields, Socratic dialogues underscore the importance of self-knowledge and promote a private study of true virtues in life. Isocrates' Antidosis is a good test case for their relationship.

It has been occasionally noted that Isocrates' Antidosis is much indebted to Plato's Apology. ${ }^{\text {Io }}$ A careful reader will

\footnotetext{
9 See Ostwald and Lynch (I994), 594-5 on the way various Socratic schools traced their origins to the historical Socrates. Having emphasized the fact that Socrates exercised some kind of impact on his followers that inspired them towards founding their own philosophical schools, it seems equally true, as emphasized by BoysStones and Rowe (2013), viii that this should probably be regarded as a side-effect rather than primary focus or aim of the Socratics, and that they were primarily geared towards horizontal conversation with each other rather than vertical institution-building.

Iо Too (I995), I92-3; Too (2008), 24-6; Nightingale (I995), chap. I; Ober (I998), 260-3; Ober (2004); Hunter (20I2), I I 7.
} 


\section{Isocrates on Socrates}

quickly notice, however, that in this work Isocrates subtly constructs an image of himself as an educator who is more effective and useful for Athens than Socrates had been. In one section, Isocrates discusses the role of education in shaping successful newer-generation politicians and orators in Athens and subtly draws attention to the work he himself is doing at his school. When he warns the jurors to not make a wrong decision of convicting him, he says that he has surpassed everyone else in providing Athens an education in intellect

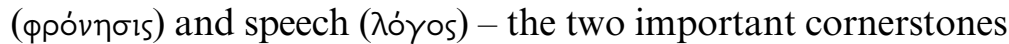
in the Athenian way of life that have brought the city its international renown and success (Ant. 29I-5). In other words, Isocrates' hard work in his school has enabled Athens to stand out internationally as the teacher of the rest of the world. ${ }^{\mathrm{II}}$

While Socrates of the Socratic dialogues revealed the underlying ignorance and complacency of his fellow Athenians that they actually do not know what they profess to know Isocrates takes a different path and praises his fellow Athenians for already having outdone other Greeks in education. Athenians are the leaders of the world in education and this is due to the work teachers in Athens have been doing so successfully. There could not be a starker contrast. The Socratics and Plato in particular tell a story of Socrates' encounters with the polis as one of attempts and failures, some more, some less ridiculous, but altogether it seems fair to say that Socrates' interlocutors (at least in our extant Socratic dialogues) are shown to be full of confidence, even though deeper conversations reveal them to be ignorant and incapable of dealing with criticism. Socrates keeps throughout the dialogues a distance from his interlocutors and thus a distance from Athens and its institutions. ${ }^{\mathrm{I} 2}$ This distance is predicated

${ }^{11}$ Antid. 295: 'For you must not lose sight of the fact that our city is looked upon as having become the teacher of all able orators and teachers of oratory' ( $x \rho \eta \dot{\eta} \gamma \dot{\alpha} \rho \mu \eta \delta \dot{\varepsilon}$

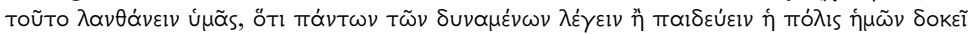
$\gamma \varepsilon \gamma \varepsilon v \tilde{\eta} \sigma \theta \alpha l \delta 1 \delta \alpha \dot{\sigma} \sigma \alpha \lambda \circ \varsigma)$.

${ }^{12}$ Socrates' conversation partners often claim expertise and/or authority in fields that are of particular importance to Athenian democracy: Nicias and Laches represent the military, Euthyphro claims authority on religion, Gorgias on rhetoric, Ion on 
on freedom that Socrates seems to enjoy, a freedom to scrutinize and criticize institutions and people who do not live up to their own convictions. We are not allowed to forget, however, that it was also this city that ended up executing Socrates.

Isocrates paints a rather different image of his fellow Athenians. Even though there are problems in the jurisprudential system that Isocrates addresses in the first pages of his Antidosis, Athenians are generally cast as wiser than the rest of Greece, better educated and with appreciation for culture and education. There are some malicious characters who have brought the charges against Isocrates ('some sophists', Lysimachus Antidosis 2, I4), but rather than being pervasive in Athenian society these are the outliers. There is of course a hidden suggestion behind this portrayal of Athens, namely that Isocrates himself had an important role in shaping this superior Athens, that his school had in no small way contributed to the outstanding success of Athens. Furthermore, Isocrates seems to assimilate his own image as a successful teacher and a head of school with the international reputation of Athens as a teacher ( $\delta 1 \delta \alpha \dot{\sigma} \sigma \alpha \lambda \circ \varsigma)$ of the Greek world. Isocrates and Athens have started to look alike - Isocrates has become Athens.

Another point of difference between Isocrates and Socrates is, obviously, philosophy itself and how one ought to practice it. In what counts perhaps as the most programmatic passage in the Isocratean corpus, Antidosis 26I-9 argues that astronomy, geometry and eristic dialogues are in themselves not harmful and as such benefit students as any training of the mind would (266), but they should not be called philosophy and they are useless as a preparation for real life. Therefore, these disciplines should not be practised too long nor be taken too seriously. This argument resembles another similar claim

musical education, etc. Beversluis (2000) offers a sympathetic reading of Socrates' interlocutors in Plato's early dialogues and divides them into three categories: young men, established professionals and wealthy employers (28-9). Those of the latter two categories (experts and businessmen) are generally approached as being able to represent a particular field or institution (in a broad sense of the word). 
made by Callicles in Plato's Gorgias, ${ }^{\mathrm{I} 3}$ except that Isocrates seems far less concerned with the personal fates of individuals than with the future of Athens more generally. ${ }^{\mathrm{I}}$ According to Isocrates, the Socratic quest for knowledge turns the youth from acting towards the wellbeing of the city towards prioritizing individual contemplation of personal virtues and happiness, thus depriving the city of educated and bright leaders. Isocrates' concern for the usefulness of philosophy to Athens constitutes one of the pervading themes of Antidosis and this theme will also be, as shown below, his primary departure from Socrates and his followers.

Isocrates talks about success and worldly rewards of his profession in the Antidosis (28I-5) where he lists advantage or gain $(\pi \lambda \varepsilon \circ \nu \varepsilon \xi i \alpha)$ as one of the cornerstones of his philosophy. Isocrates argues that there is a general misconception in Athens with regard to language and terminology used to denote certain activities and people. Meanings have been turned upside-down, Isocrates claims, and buffoons capable of mocking and mimicking rather than men of excellence are called 'gifted' ( so-called ancient sophists enables Isocrates to suggest that it is not really the general public, but rather the so-called 'philosophers' who have unhelpfully discredited the idea of advantage, which used to function as a positive term in the context of any intellectual activity. Most importantly, Isocrates is upset that wealth has recently, among his contemporaries, fallen into disrepute (Antidosis I59-60), and unfairly so.

I believe we arrive here at what appears to be an explicit confrontation with Socrates and his image as a teacher and philosopher. It is a central characteristic of Socratic teaching to closely scrutinize one's reliance on, and appreciation of,

${ }^{13} \mathrm{Pl}$. Gorgias 485e-6d where Callicles claims that philosophy, while a valuable part of liberal education, is unworthy and a waste of time for a serious adult.

${ }^{14}$ In Plato's dialogue there is of course a deep irony behind Callicles' words, which predict Socrates' death at the hands of Athenians. The tone driving Isocrates' treatment of philosophy emphasizes one's commitments to the city and so his worry seems to be primarily this: how to make sure that all talented young and wealthy Athenians end up fostering the polis? He seems to think that engaging in theoretical pursuits (philosophy) would keep some of the bright minds away. 
external characteristics such as wealth and reputation and challenge these as goals in themselves. ${ }^{\text {I5 }}$ Socrates' search for definitions often challenged the original or common meaning of a notion and aimed to demonstrate that things (or hopes, beliefs, desires) are not always what they appear on the surface or what the tradition handed down to us has had us believe. Through his critical lens on the political and social structures at place in Athens, Socrates has built a distance between the observer and the object so as to better contemplate matters at hand and reach a more objective and timeless decision. ${ }^{16}$ The move is away from the moment and political context towards contemplating important questions of ethics in a timeless space. ${ }^{17}$ The philosopher who is capable of following this quest ought to be independent and free from pressures from society in order to live that kind of critical life prescribed by Socrates. This intellectual freedom is an important reason why Socrates never charged fees. ${ }^{\text {I }}{ }^{\text {As }}$ Blank notices, the distinction between sophists and philosophers tended to be made on the basis of whether or not they

${ }^{15}$ E.g. Pl. Apology 30b2-3; see also Boys-Stones and Rowe (2013), chap. 2 for Socratics more generally. Antisthenes (Xen. Symp. 4.34-44) is sometimes taken as the most important testimonium for Socrates' (and, by extension, the Socratic circle's) views on wealth.

${ }^{16}$ This is not to say that Plato's Socrates is particularly invested in criticizing Athenian institutions, but rather that his quest for truth and knowledge is always already intertwined with thinking through critically our inherited and predetermined positions that pertain to governance and to city politics more generally. Furthermore, the kind of distance that we are talking about here does not mean that Socrates was not himself involved in matters of the state: he had allegedly distinguished himself in battle (and thus completed compulsory military service) and had served as a juror. However, the fact that he had fulfilled the basic criteria of Athenian citizenship does not mean that he was involved in (promoting) Athenian institutions in any deeper way.

${ }^{17}$ Obviously references to and implicit suggestions regarding the contemporary moment remain pervasive throughout the dialogues, but Socrates is overwhelmingly portrayed as somehow outside the usual social norms, as prioritizing the more abstract vision over the concrete decision. Schofield $(2006,20)$ talks about Socrates' 'quietist activism'.

${ }^{18}$ Despite the opposite suggestion in Aristophanes' Clouds, other contemporary theatrical evidence confirms the image that Socrates did not charge fees and was poor: Eupolis fr. $35^{2}$ Kock, Ameipsas fr 9 Kock; see Blank (I985), 7 for further discussion. 
charged fees for their activity. ${ }^{19}$ Otherwise, Socrates argues, he would have to talk to those who pay him and would therefore not be free to pursue his path of questioning as he chooses to. ${ }^{20}$

Isocrates sees things differently. ${ }^{21}$ According to him, everyone does everything for the sake of either pleasure, gain or honor. $^{22}$ This, he says, is a fact and teachers who are preparing students to become leaders in the city or to simply manage their affairs cannot and should not downplay the importance of these three motivations. In other words, Isocrates seems to regard these three as legitimate and justified goals for one's actions. He himself talks often about his reputation, thus giving the idea that to be well regarded by one's fellow Athenians is of great importance to him and thus also a valid concern for any Athenian. Unlike Socrates, who discourages his interlocutors from following the so-called external motivations, urging them to continuously search for truth and happiness, Isocrates acknowledges the relevance of pleasure, gain and honor in the existing political and economic system and is determined to highlight the potential of higher education as a direct path to achieving these goals. Coming after Socrates and reflecting on his provocative views of education, Isocrates might appear as a conservative advocating for traditional societal norms. ${ }^{23}$ As such, he may not seem to bring much

${ }_{19}$ Blank (1985), I with references to Xenophon Cyn. I3.8 ff. and Aristotle Soph. el. I.I, I65a22.

${ }^{20}$ Xenophon Memorabilia I.2.6, I.6.5, Apology I6; Plato Theaetetus I50c-Ib. Plato critiques the sophists who have to teach whoever pays them: Prot. $3 \mathrm{I}_{3} \mathrm{~d} 5$, Euth. 27Id3, Meno $70 \mathrm{~b}_{2}$ and 9rb2, Hippias Maj. $282 \mathrm{c} 4$.

${ }^{21}$ An argument has been made, most recently by Blank (20I4), that Isocrates might not have charged fees from his Athenian students, but only from those coming overseas. I find this suggestion quite implausible, also because it would be hard to explain why Isocrates would then choose not to mention it.

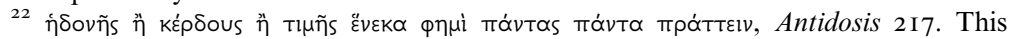
contrasts Plato's 'categorization of actual and non-ideal political communities into those motivated by pleasure (democracy, Rep. $557 \mathrm{~d}$ and $559 \mathrm{~b}-\mathrm{d}$ ), wealth (oligarchy at Rep. 55Ia) and honor (timocracy at Rep. 548c)'. Too (2008), I97.

${ }^{23}$ De Romilly (1954) discusses Isocrates as a moderate in his contemporary political landscape; see also Bringmann ( 1965 ), esp. 83. Of more recent commentators, Too (I995), I03-I 2 associates Isocrates explicitly with conservative thought, but (unlike de Romilly) provides no further clarifications as to what this term might mean in 
new to the ongoing discussion. As someone, however, trying to introduce (for the first time) institutionalized professional higher education to the intellectual and political landscape of Athens, his emphasis on demands for schools to cultivate the political elite of the city makes Isocrates' position stand out from the rest. By making financial demands, Isocrates reminds his students that his school participates in the economy of the city, that it is not an autonomous self-absorbed entity somewhere in the outskirts of Athens, ${ }^{24}$ but rather an integral part of the city's ongoing development.

Given the potential costs of running a professionalized institution of higher education, managing such an enterprise must require fees higher than what we hear were asked by the itinerant sophists. It is no surprise, then, that Isocrates comes back to the issue of money again and again throughout his writings. ${ }^{25}$ One of the most direct engagements with this topic is in his Antidosis, where after discussing the wealth (or lack thereof) of Gorgias, Isocrates turns to discussing the changing intellectual climate when it comes to charging fees for one's professional activity (I59-60). Isocrates explains that when he started out his business he was full of hope to recover the lost fortunes of his heritage and gain prominence through his hard work and education. Now, however, he finds himself surprisingly in a position where his foreign students who have brought him much financial support are continuously holding him in high honor, whereas Athenians on whom Isocrates has spent his resources are the ones to bring him on trial on the charge of being (too) wealthy. ${ }^{26}$ These references to the

the fourth-century BCE context. See also Poulakos and Depew, 'Introduction' to their co-edited Isocrates and Civic Education (2004), which also makes pervasive associations between Isocrates and conservative politics (in the US?) without making any effort to explain the relevance of this political terminology to the fourth-century BCE context.

${ }^{24}$ While we have a rather good sense of the location of Plato's Academy at the outskirts of Athens and of other philosophers, as far as I know we are not as well informed about the location of Isocrates' school.

${ }^{25}$ Examples: Antidosis 155, 240; Areopagiticus 3 I-4; Against the Sophists 3.

${ }^{26}$ In another revealing passage from his early Against the Sophists, Isocrates admonishes the sophists not for charging fees, but for charging too little for the great promises in education that they make (Against the Sophists 3: 'although they set 


\section{Isocrates on Socrates}

financial side of the 'education business' (and there are many more scattered around his works) are certainly indicative of Isocrates' vision of the field: money and fame matter, they reveal the place one occupies in the real economy of the city and it would be at the peril of dooming education and philosophy to irrelevance to deny that. Holding such a position sets Isocrates in direct conflict with Socrates and his followers, and thus the entire mainstream of philosophical schools that trace themselves back to Socrates.

Despite his explicitly critical reception of Socrates, Isocrates never explicitly confronts Socrates, though he does mention him once. In the Busiris Isocrates criticizes the work of Polycrates who had written two paradoxical discourses: a praise of Busiris and an accusation speech against Socrates. Even though Isocrates then goes on to rewrite the praise for Busiris, ${ }^{27}$ he argues against Polycrates not because one ought not to accuse Socrates, but rather because his accusation speech looked more like praise.

Niall Livingstone has argued that Polycrates wrote the accusation speech against Socrates primarily because he regarded Socrates as a hero of his profession and therefore someone very hard for any educator to attack. ${ }^{28}$ Given that in this work Isocrates clearly conveys a very negative opinion of Polycrates, it might look obvious to assume that Isocrates is defending Socrates and, thus, that his relationship to him is one of admiration. ${ }^{29}$ Indeed, he chooses to offer a proper

themselves up as masters and dispensers of goods so precious, they are not ashamed of asking for them a price of three or four minae!'). See also Plato's Sophist 234a7 and Apology 20a-b for a similarly critical attitude. Most ancient sources challenge the view that sophists earned little and there certainly seems to have been a commonplace understanding that such education was expensive and unaffordable for the average Athenian (see e.g. Socrates' reflections on it during his youth in Laches I 86c). For a more thorough discussion, see Blank (I985), part I.

${ }^{27}$ This is probably an explicitly provocative maneuver from Isocrates. By that time, defense speeches for Socrates had become standard rhetorical exercises and served as a way to display one's excellence. By bringing up this reference and then disappointing the reader with offering a discourse on a different - more valuable? topic, Isocrates is playing with generic expectations and downplaying the valorization of Socrates.

${ }^{28}$ Livingstone (200I), 36.

29 This seems to be also what Livingstone (200I), 38 proposes. 
praise of Busiris rather than a 'correct' accusation of Socrates! However, it is also plausible that attacks such as those leveled against Socrates by Anytus, Meletus and Polycrates (even though all on different levels and probably with different motivations) were in Isocrates' view so serious attacks against the position of intellectuals and teachers in Athens that regardless of the individual differences and disagreements, it was a matter of urgency that they be refuted tout court. ${ }^{30}$ But more specifically, it is striking that Isocrates' criticism of Polycrates revolved around the figure of Alcibiades: Isocrates claims that Polycrates has falsely given the ever-talented Alcibiades to be a student of Socrates. Most Socratic philosophers thought long and hard about how to distance Alcibiades from Socrates and how best to address the claim that Socrates was responsible for the damage that Alcibiades inflicted on Athens. Isocrates instead embraces the excellence of Alcibiades and claims that Socrates was never his teacher in the first place, thus effectively belittling the influence Socrates as a teacher had on Athenian politics. ${ }^{3 \mathrm{I}}$ Isocrates' claim might be best understood as a twist on the paradoxical subject itself, ${ }^{32}$ but either way it is hardly supportive of Socrates as a venerated teacher and role model.

As suggested before, Socrates' trial plays a fundamental role for our understanding of Isocrates' Antidosis, which is arguably one of the most multilayered fourth-century engagements with Socrates' trial that we have. This work is clearly set in competitive dialogue with many other contemporary literaryphilosophical works that reflect on this watershed moment, but more than anything else, it seems that the Antidosis is imbued with a competitive attitude towards Socrates and his philosophical/educational heritage. ${ }^{33}$ Isocrates had also participated in a

$3^{30}$ It is also possible that by the mid fourth century an accusation against Socrates would no longer have been particularly fashionable given Socrates' re-evaluation as a paragon philosopher, teacher and citizen. See above and Zanker (1995).

${ }^{31}$ Isocrates offers praise of Alcibiades also in On the Team of Horses (I6).

${ }^{32}$ If it was common knowledge that Socrates was Alcibiades' teacher, then Isocrates' claim would do exactly what paradoxical writings aimed at: take a common subject and turn it on its head.

33 The possibility that Isocrates is fashioning himself as the 'new' Socrates is proposed, but quickly rejected, by Haskins (2004), 39. Others, too, seem to make a nod 
court trial that he - similarly to Socrates - lost. ${ }^{34}$ As Socrates in Plato's Apology, Isocrates imagines the real reason behind his failure at the trial to lie in fundamental misunderstandings that have arisen around his school and his personality. Yet, it would be dangerous for Isocrates to sound too much like Socrates, to suggest that his influence in the city has been primarily negative, that he has not made any political impact and - above all - that engaging in higher education inevitably means taking distance from the political life of the city. The pervading ideas of the Antidosis are, therefore, inspired by the desire to demonstrate the relevance of his school and philosophy to Athens and, thereby, implicitly criticize the core of what Socrates - the head of school - was standing for. Thus we see Isocrates who is hopeful that the jury will eventually recognize the truth about him (28, I69-70), confirm his importance to the cultural milieu of Athens and pay their due respect. ${ }^{35}$ It is curious that Isocrates had explicitly decided to side with his audience and listeners, being confident that his words will make a difference. This is yet another instance where Isocrates consciously adopts an opposite view to Socrates, envisioning himself to be an effective teacher and educator in Athens in contrast to Socrates. Indeed, Socrates may have been a teacher of sorts in Athens, but he was not a teacher of Athenians nor useful for the city. Isocrates, instead, aims to be both.

Finally, there may also have been some urgency in Isocrates' perceived need for a new vision for higher education and its role in the city. As some studies point out, there were hesitant attitudes towards wealthy aristocratic Athenians after the Peloponnesian war that seem to have resulted in the

towards this interpretation (e.g. Blank 20I4), but they never posit a competitive relationship between the two. It is always Isocrates who admires and attempts to emulate Socrates the teacher.

${ }^{34}$ It is also possible that the story about his previous court trial for an antidosis 'exchange' process was a fiction. If indeed it was a fiction, one could easily see the benefits of inserting it in his narrative. It serves the purpose of showing Isocrates as very wealthy (enough to be challenged for an antidosis), without actually saying it openly.

35 Even though at some sections of the speech (e.g. I 54) Isocrates addresses different members of the audience - much like Socrates in Plato's Apology - he also says that he will not rest until he has convinced everyone of the truth about him (I96-7). 
continuous decrease of active political elite running the city. ${ }^{36}$ By the end of the fourth century вCE, Aristotle's Politics and the Aristotelian Constitution of the Athenians both describe contemporary Athens as the most radical form of democracy, arguing that citizens and decrees rather than laws rule the city. ${ }^{37}$ Further, Claire Taylor has drawn attention to comparative evidence from the fifth and fourth centuries that suggests that the participation and influence of wealthy elite in Athens had significantly declined in the fourth century вСЕ. ${ }^{38}$ In this context, we might look at Isocrates' political discourses as aiming at popularizing his school among the upper-middleand high-class Athenian citizens and, no less importantly, as attempts to cultivate their preparation for a political career.

If indeed there was a perception that the political elite had lost its influence and importance in Athenian politics, Isocrates' discourses seem to suggest two things: first, by challenging Socrates as the fountainhead of contemporary philosophical schools that promote the pursuit of knowledge and truth in isolation from active day-to-day life in the city, Isocrates is drawing attention to the increased danger that this kind of philosophical education will turn Athenian leadership even more apathetic to contemporary politics and thus further reduce the influence of the elite and educated leadership in Athens. In other words, Athenian educated elite should look to Isocrates rather than Socrates for a proper guidance in reaching a truly accomplished civic life. ${ }^{39}$ Secondly, Athens in her complex political context of the fourth century BCE cannot really afford to lose the voice of the educated (upper-class) Athenian and therefore other philosophical schools should be held to the task of preparing and advocating political careers

${ }^{6}$ Sinclair (1988), 43.

37 Arist. Pol. I274a7-I I, Ath. Pol. 4I.2. For discussion, see Ober (I998), 98.

$3^{8}$ Taylor (2007), 89 .

39 Isocrates is here quite possibly challenging the entire Socratic tradition of philosophy. Nightingale (2004) mentions Isocrates as the most prominent proponent of socalled 'pragmatic philosophy', but since she never mentions other less prominent ones it is possible that she too would view Isocrates as the only prominent educator who runs against the mainstream Socratic view that prioritizes theoria over practice. 
Isocrates on Socrates

for the educated (and wealthy) Athenians. ${ }^{40}$ Therefore, Isocrates' challenge of Socrates as the paragon citizen and exemplary teacher of Athenians might not have been motivated simply by hopes for personal glory (though that should not be ruled out in the case of Isocrates), but was also - or even primarily - seen as a result of contemporary political necessity for anyone who cared for the future of the stability of the Athenian polis.

$4^{\circ}$ For information about the contemporary political struggles, see e.g. Hansen (I983), Sinclair (I988), Ober (I998), Osborne (2000), Taylor (2007). Isocrates himself happily demonstrates his success in preparing students for successful political careers. Primary example he uses is the famous Athenian general Timotheus. 


\section{CONTEMPORARY REFLECTIONS ON ISOCRATES AND HIS ROLE IN RHETORIC AND PHILOSOPHY}

Other than bare (and rare) name droppings, Isocrates is not explicitly mentioned or discussed by his contemporary writers and philosophers. This is not unusual for fourth-century BCE literary culture and does not mean that writer-philosophers were engaged in serious discussions only with the famous sophists and philosophers from the past. Quite the contrary, references in the works of fifth/fourth-century authors to their (mostly anonymous) critics and readers suggest an intense literary landscape and display a wide repertoire of solutions that are offered to shared concerns about the newest changes in politics, philosophy and education. It is plausible that suppressing the names of one's rivals was a standard way to play down their importance and increase one's own standing. Thus, in order to better understand Isocrates' sentiments regarding the intellectual climate of fourth-century вCE Athens, and the way his self-fashioned image resonated within this context, it is worthwhile to look at writers close to his time, with whom he might have been in dialogue and who make references to his work.

\section{I Alcidamas}

An important figure for our understanding of fourth-century BCE conceptions of written and spoken speech, and relationships between rhetoric, sophistry and philosophy, Alcidamas and his Against Those Who Write Written Speeches, or Against Sophists (henceforth Sophists) is an important source for understanding the wider intellectual environment of Isocrates. ${ }^{\mathrm{I}}$

\footnotetext{
' Alcidamas' relationship with Isocrates, especially their relative chronology and the contrasting positions of their works, has been an object of several studies. See most 
There is a strong ancient tradition according to which both Alcidamas and Isocrates were treated as pupils of Gorgias. ${ }^{2}$ Despite the fact that Isocrates only has critical comments to make about Gorgias, ${ }^{3}$ modern scholarship too is sometimes overly fascinated with establishing continuity of thought among ancient thinkers. ${ }^{4}$ Too has rightly questioned this uncritical approach to Isocratean apprenticeship with Gorgias. ${ }^{5}$ Given our lack of any direct evidence about it, we should rely on what Isocrates himself has to say about Gorgias and the latter's importance to his work. Hence, it seems very strange indeed to think that Isocrates singled out Gorgias from other sophists and saw him as his teacher in any meaningful sense. It is surely true, however, that Gorgias was an important (even inspirational) figure for thinking about higher education in Athens, and insofar as both Alcidamas and Isocrates are part of that tradition, it is no wonder that we'll find similarities and differences in their positions. ${ }^{6}$

Other than the superficial connection through Gorgias, the majority of scholars interested in the links between Isocrates and Alcidamas have focused on the chronological relationship of Alcidamas' work to Isocrates' Against the Sophists. It has

recently O'Sullivan (I992), chap. 2 and Mariß (2002), 26-55 who gives a useful summary and discussion of the scholarship on the relationship between Isocrates and Alcidamas. Citations of Alcidamas' fragments follow Mariß (2002).

${ }^{2}$ For the tradition on Alcidamas and Gorgias, see O'Sullivan (I992), 33-40. Following ancient biographers, most commentators on Isocrates also see him one way or another as the pupil of Gorgias. See, for example, Blass (I868), ii, I4; Norlin (I966), i, xii; Marrou (I965), I23; Kennedy (I963), I74-5.

3 Gorgias is explicitly mentioned only three times in the Isocratean corpus: twice in the Antidosis (155-6, 268) and once in Helen (3).

${ }^{4}$ Indeed, a recent commentator suggests, for example, that their differences stem from developing different aspects of Gorgias into two distinct 'poetic' prose styles: 'Alcidamas followed the strange $\dot{\varepsilon} \kappa \lambda \circ \gamma \eta$ ' of his master, while Isocrates tamed his extravagant $\sigma u ́ v \theta \varepsilon \sigma ı s . '$ O’Sullivan (I992), 58 (cf. also 40).

5 Too (I995), 235-9.

${ }^{6}$ Cf. Steidle (I952), 285. I do not agree with an overly nuanced reading of Friemann (I990), 308 who argues that rather than attacking each other, Alcidamas and Isocrates both appear to attack an altogether different position, i.e. they both are concerned with those who write in simple style and call themselves teachers of rhetoric. For the exact opposite conclusion, see Eucken (I983), I23. Both Alcidamas and Isocrates do have fundamental disagreements about how education should be transmitted and cultivated (through writing or orally) - it is not simply a matter of style. 
been suggested that Alcidamas' Sophists is a direct attack against Isocrates (his programmatic Against the Sophists in particular) and his school. ${ }^{7}$ Whatever the chronology, these texts indicate that Isocrates and Alcidamas advocated opposing views on what a proper rhetorical or philosophical education should consist of, and this disagreement touches the very core of their respective educational practices. Alcidamas enters the debate by defining it in terms of written versus spoken discourse, and advocates the latter as an appropriate aim for

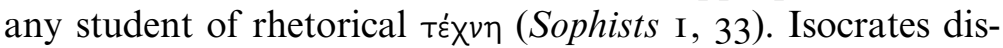
tinguishes between a polished/good and an ignorant/bad composition, and seems to allow both written and spoken discourses to qualify for either category (i.e. of good or bad composition). ${ }^{8}$ Yet Isocrates also argues that a hallmark of good and wide learning is the ability to excel in written discourses, for they are, due to the high expectations of precision and argument, more difficult to compose satisfactorily (e.g. Panegyricus II-I2, Antidosis 49). Isocrates and Alcidamas agree, however, that both written and spoken discourse are, generally speaking, part of a wider paideia; they disagree over what role each should play in education and in rhetoric more widely.

We have, admittedly, a rather minimal idea of Alcidamas' educational practice, but his Sophists suggests that according to him the whole art of rhetoric is best studied by way of learning to speak ex tempore (I). This seems to mean memorizing the few crucial points one aims to make in a speech and otherwise improvising the rest. It is not entirely clear how this technique is put to practice in a schoolroom, but such shortcomings in detailed information might also stem from the narrow scope of his treatise: Alcidamas' accusation speech

7 Different strands of interpretation are most recently discussed in Mariß (2002), 26-55. Along with O'Sullivan (I992), she takes a more skeptical view towards attempts to reconstruct the relative chronology between Alcidamas and Isocrates. This is also the point of departure for the present discussion.

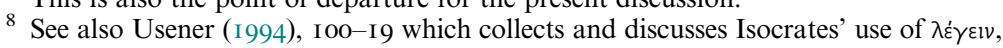
үрópsıv (and their derivatives). She concludes that Isocrates employs both notions to describe his own works and his activity as a writer/author. 


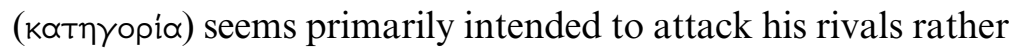
than to provide details about his own school. It is clear throughout the text that Alcidamas is solely concerned with rhetoric and he identifies this as an art of public speaking (тo $\left.\lambda \varepsilon^{\prime} \gamma \varepsilon v\right)$. All six occurrences of the root ${ }^{*} \rho \eta$ in Sophists refer to either the practice or practitioner of rhetoric as either speaking or speaker. ${ }^{9}$ Alcidamas seems to understand this art as separate from philosophy, even though the distinction between the two is not explicit in this work. ${ }^{\text {IO }}$ Based on our previous discussion about Isocrates' terminology, Alcidamas is very similar to Isocrates. Contrary to the latter, however, Alcidamas does not explicitly proclaim to teach philosophy.

Isocrates' rejection of spoken discourse as the primary basis for education becomes one of the definitive hallmarks of his work, and his advocacy of written discourses as providing the best foundation in education makes him stand out in the fourth-century $\mathrm{BCE}$ intellectual scene. It is indicative in this context that one of the few actual descriptions of a teaching situation in Isocrates, his Panathenaicus (264-6), shows Isocrates especially uncomfortable about public performance. In this passage, Isocrates argues that he has produced highly eloquent speakers in his school (despite his emphasis on writing skills), but also indicates that a spoken debate is too confrontational, emotional, and perhaps too similar to eristics, to be constructive. Stylistic differences between Alcidamas and Isocrates might indeed reflect their respective views on rhetoric and on its way of functioning. ${ }^{\text {I I }}$ Isocrates' meticulously polished 'written' style is perhaps intentionally lacking in the ability to stir emotions and manipulate the audience, something that is promoted by Alcidamas - and rightly so - as the key to success in public performances. In other words, we might be justified in regarding Isocrates' turning away from

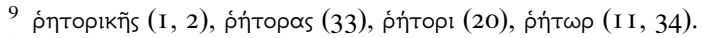

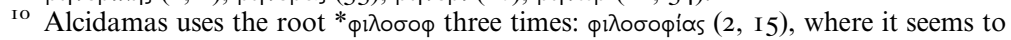

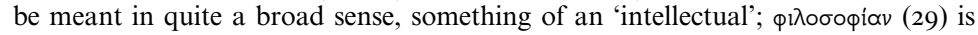

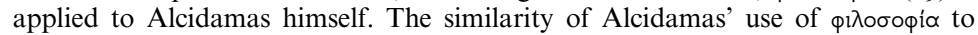
Isocrates' is pointed out in Muir (200I), 4I and Mariß (2002), 97-9.

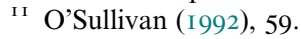


the performative qualities of speech, which were highly advocated by the sophists (and Alcidamas), towards the less spontaneous and meticulous prose as a response to the debates about the moral quality of rhetoric. Isocrates' written style aimed to be the result of scrupulous training and deeper learning, which would elevate the level of discussion and prevent his students from scoring 'cheap points' by appealing to the irrational and/or emotional expectations of the audience. ${ }^{\mathrm{I} 2}$ After all, it is undisputed that Isocrates was deeply concerned with the moral status of rhetorical teaching, and this might explain his appropriation of 'philosophy' as an allencompassing $\pi \alpha 1 \delta \varepsilon i \alpha$ that strives to help its practitioners

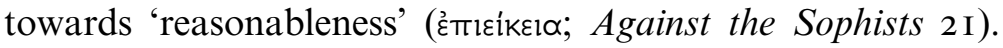
In that sense, whether Alcidamas intended to oppose Isocrates specifically or not (and it is more likely that he intended to encompass in his criticism everyone who promotes education through writing, including Isocrates), they do end up occupying opposing positions and, as such, offer valuable perspectives on each others' arguments. Isocrates emerges from Alcidamas' criticisms as a teacher who fails to prepare students for success in the courts, whose writing lacks in emotions and who, as a consequence, is not able to move his audience.

\subsection{Plato's Isocrates}

Plato's engagement with Isocrates is complex and has been the subject of substantial scholarly controversy. There are two explicit references to Isocrates in the corpus Platonicum: there is Socrates' famous prophecy concerning Isocrates in the Phaedrus (278e-9b), and a passing reference in the Thirteenth Letter to some of Isocrates' students (36oc). ${ }^{\mathrm{I}}$ In addition,

${ }^{12}$ Isocrates' style is referred to as 'sober' in Cole (I99I), I28; on Isocrates' definition of philosophy as having an 'almost heroic vapidity' see Wardy (I996), 96.

${ }^{13}$ In the pseudo-Platonic letter, the link to Isocrates becomes very loose: Helicon is said to have been associated with the students of Isocrates (I3.36oc). Other than providing another useful source for understanding how the Isocrateans might have worked as a group, there is not much direct relevance to the present discussion of the reception of Isocrates in Plato. 
there are passages in Plato's dialogues, in Euthydemus (304d$6 \mathrm{~d})$ and Theaetetus (I72c-7b), where Isocrates' name is not mentioned but which have been interpreted either as responses to Isocrates or at least as criticisms of intellectual practices that greatly resemble those of Isocrates. ${ }^{\mathrm{I} 4}$ Finally, there is an entire dialogue of Plato, the Gorgias, which focuses on politics and rhetoric and where views rather similar to that of Isocrates are subjected to substantial criticism. Let us take a closer look at Plato's references to Isocrates and examine the extent to which this engagement played an important role in shaping Isocrates' subsequent reception.

The most explicit reference to Isocrates in Plato's corpus comes at the end of the Phaedrus, where - almost as an afterthought - Phaedrus reminds Socrates of his friend

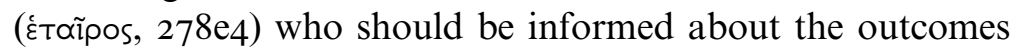
of their discussion on rhetoric. Even though Socrates' response 'which one?' (Tiva Toũtov) suggests that the association between himself and Isocrates comes to him as a surprise, the fact that he does not refute this connection nevertheless sets a positive tone to the relationship as portrayed in the passage.

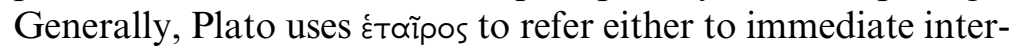
locutors of, or simply to people close to, Socrates. ${ }^{15}$ In fact, later in the tradition غं ๔ĩpos was also understood as a byword for Socrates' students, and this particular passage is clearly the source for later claims that Isocrates was Socrates' pupil. ${ }^{\text {I6 }}$ Regardless of the neutral or even borderline-encouraging connotation of the word here, Socrates' account of Isocrates has been taken by most interpreters to be ironic in its intent, thus encouraging scholars to look for further evidence of the differences between Plato and Isocrates that might demonstrate more clearly that Plato's arguments on rhetoric and false

${ }^{14}$ There are many attempts at more precise Quellenforschung on the relationship between Plato and Isocrates. A landmark publication on this subject is Eucken (I983). Recently, see also Wareh (20I2) for a different methodological approach to the question.

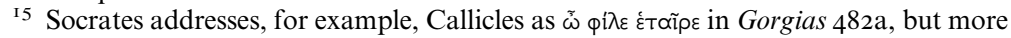

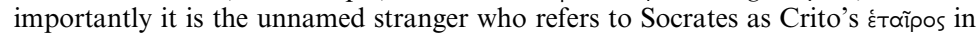
Euthydemus (305a), analyzed below.

I6 Nails (2002), I80. 
philosophy are explicitly targeted at Isocrates. Isocrates' works appear just too dissimilar to Plato's conception of philosophy and Plato is often read as a fundamentally non-compromising author on philosophical method - to accept any kind of positive interpretation of their relationship through this passage. ${ }^{17}$ Indeed, it is quite difficult to read this passage of the Phaedrus without at least considering an ironical attitude: the two important thinkers were contemporaries and opened philosophical schools in Athens around the same time, schools that offered completely different understandings of higher education and philosophical excellence. Perhaps philosophically most significant is their different treatment of knowledge and opinion. Howland offers a compelling discussion on the difference and rivalry between Plato and Isocrates by comparing specific passages from the Phaedrus and Isocrates' Helen. In Phaedrus 262c, Socrates argues that the orator has to use definitions to arrive at knowledge of the topic and that it is not enough to work with opinions, for without systematic understanding of the matter at hand it is impossible to produce the expected result consistently. In his Helen (5), however, Isocrates argues that pupils should be instructed in practical affairs, 'bearing in mind that likely conjecture about useful

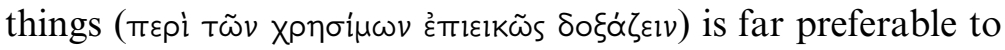

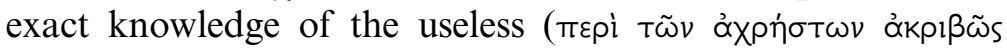
$\varepsilon \pi i \sigma \tau \alpha \sigma \theta \alpha)$, and that to be a little superior in important things is of greater worth than to be pre-eminent in petty things that are without value for living'. Isocrates claims that in some matters it is possible to reach a state of knowledge, but that these areas are so remote from human life and interests that it is actually not worthwhile to dedicate one's life to studying them. It is possible to achieve a level of confidence, however, in areas which do pertain to human interests, but this is attained primarily through experience ( $\dot{ }_{\mu \pi t \varepsilon i p i \alpha)}$ rather than theoretical

${ }^{17}$ See for example Howland (1937), I 52 who argues that the 'whole dialogue must be considered primarily as a direct and comprehensive attack on the educational system of Isocrates'. The particular target in Howland's view is Isocrates' Helen. 
discussion. This experience will not result in absolute knowledge and the ability to predict the right course of action in every possible circumstance, but it does boost one's skills in coping with unexpected situations in the best possible way in most cases. They both use the language of knowledge versus opinion, thus clearly indicating that they are participating in the same debate though advocating opposing positions. It seems straightforward to then conclude that the two must have been each others' fiercest rivals. And yet, why would Plato suggest such ambivalence about Isocrates at the end of the Phaedrus if indeed they were in every possible way each other's worst enemies?

Another, and in my view more plausible, reading of Plato's mention of Isocrates in the Phaedrus emerges once we take seriously the sheer number of references to education and to rhetorical teachers in particular in the dialogue. Leaving aside the poets (Homer, Stesichorus, Sappho, Anacreon, Sophocles), whose frequent mention in the dialogue is interesting in its own right, Socrates brings up Lysias, 'wise men' offering rationalizing accounts of myths (229c4), Simmias the Theban (242b3), Gorgias, Thrasymachus, Theodorus (26Ic2; Thrasymachus also 27Ia4), a representative Laconian critic (260e5), Zeno (26Id5), Theodorus, Evenus, Gorgias, Tisias, Prodicus, Hippias, Polus, Licymnius, Protagoras (266d4-7e5; Tisias longer discussed also 273a5-4a4), Adrastus (269a4), Pericles and Anaxagoras (269e2-70a6), and finally Isocrates (278e4). With the possible exception of Pericles/Anaxagoras and Isocrates, all other references to (rhetorical) teachers are overtly disparaging, and Lysias, treated here as speechwriter and teacher, seems to have become by the end of the dialogue the byword for the kind of rhetoric that ought to be rejected, explicitly, without hesitation. By contrast, Phaedrus evokes Isocrates at the end as a curious case ('what shall we say he is?'), though introducing him as 'beautiful' (koגós) already puts us in a positive mindset. Socrates fulfils Phaedrus' cautious questioning about Isocrates when he confirms that the latter is not indeed to be classified together with all the rest represented by Lysias, prophesying that he will be important and that there 
is 'some' philosophy in this young man. Finally, Socrates suggests that he himself will deliver the content of this current conversation to his 'favorite' ( $\pi \propto 1 \delta$ ikoĩs, 279b2), much as Phaedrus should inform his favorite Lysias. Rhetorical education is divided, in this last section of the Phaedrus, into two: there are those many who operate like Lysias, and then there is Isocrates, who stands out from the rest by offering 'some philosophy' and growth to his students. Socrates unashamedly sides rather with Isocrates though this is not to say that he agrees with the latter. Isocrates still needs to hear the content of this conversation, about the tools and goals of rhetoric and its relationship to philosophy. Significant differences between Socrates/Plato and Isocrates ought not to be downplayed, sure, though setting this passage in the broader context of rhetorical teaching available in Athens both at the time and during Plato's time, strongly suggests that Isocrates is sincerely, if relatively to the particular context, ${ }^{\mathrm{I} 8}$ praised for the (somewhat philosophical) kind of education that he promotes in Athens. ${ }^{19}$ As Socrates says, Isocrates is naturally capable beyond the speeches of Lysias, but also has a nobler êthos, character or ethics (279a4-5). This êthos and Isocrates' attention to sound moral education in Athens are precisely what elevate and distinguish him from politicians like Callicles and sophists like Thrasymachus, whose positions are in some respects not very far from those of Isocrates.

${ }^{18}$ Erbse (I97I) makes a similar argument, though he refers to Isocrates consistently as an orator/rhetor or as a teacher of rhetoric and speech. I hope to have shown by now that Isocrates could be legitimately called a philosopher or thinker and I think this is not irrelevant to our rethinking of Plato's praise of Isocrates. The fact that Isocrates emphasizes philosophy and does not conceive of himself strictly as a teacher of rhetoric is precisely the reason why he ought to be understood as having been mentioned by Plato in this dialogue as a positive role model for rhetoric. See also Laplace (I995) for a comparison between Plato's and Isocrates' criticisms of logographoi and rhetoric.

${ }^{19}$ It is not surprising, then, that Eucken (I983), who offers perhaps the most comprehensive argument about the rivalry between Plato and Isocrates, does not focus on this passage and chooses to find controversies and direct attacks on each other's work elsewhere in the Platonic corpus. Some problems in Eucken's valuable, if not always convincing, Quellenforschung are highlighted in Hudson-Williams (I985). 
A somewhat comparable image of Isocrates emerges from the concluding section of Plato's Euthydemus (304d-6d) with an important difference that Isocrates is not mentioned by name. ${ }^{20}$ Even if some inconsistencies remain in the 'caricature' of Isocrates, ${ }^{21}$ Plato introduces in this section a critique of a particular type of intellectual that is in a broad sense compatible with Isocrates: this is a man who partakes in political life to some extent but does not participate in court proceedings

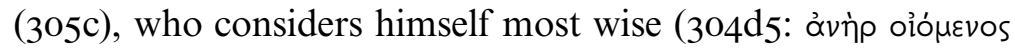

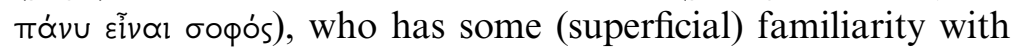
politics and philosophy, but does not know any of these sub-

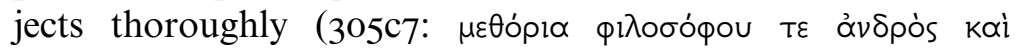

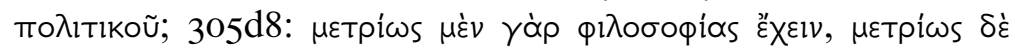

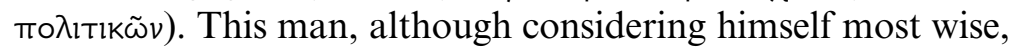
is unable to confront sophists like Euthydemus and Dionysodorus in public debates $\left(305 \mathrm{~d} 5^{-7}\right)$, and is not honest about his publicly visible inability. Even if this passage is not meant to criticize Isocrates exclusively, it does seem to map rather well onto the previous analysis of Isocrates in the Phaedrus and is in agreement with many characteristics that Isocrates himself uses to introduce his philosophia and to criticize his rivals. Most striking in this description is the use of the

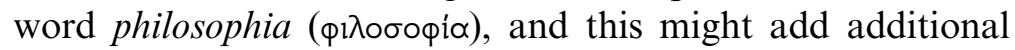
weight to the suggestion that it is Isocrates and his appropriation of the term 'philosophy' that are the explicit object of discussion here. ${ }^{22}$

Crito describes the discussion he had with a person who witnessed Socrates' exchange with Euthydemus and Dionysodorus. Despite initially seeming to praise the show

${ }^{20}$ Most commentators on the dialogue suggest this: Gifford (I905), I 8-20; Hawtrey (I98I), I90; Guthrie (I986), 282-3. As well there are numerous discussions on the relationship between Isocrates and Plato more generally: e.g. Ries (I959), Eucken (1983), and more recently Michelini (2000), Palpacelli (2009), 220-6 and Sermamoglou-Soulmaidi (20 I4), I43-53.

${ }^{21}$ For example the fact that the critic is associated by Crito at first with forensic

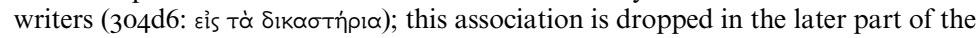
discussion $(305 \mathrm{c})$.

${ }^{22}$ I differ here in some significant details from the analysis of SermamoglouSoulmaidi (20I4), I5I, whose evaluation of Isocrates' notion of philosophy is heavily informed by, and openly dependent on, Plato. 
(304e), the stranger, when asked what he himself learned from them, retorts and says that there was nothing to learn, but (presumably) simply to enjoy the debate: they showed 'merely the sort of stuff that you may hear such people babbling about at any time - making an inconsequent ado about matters of no

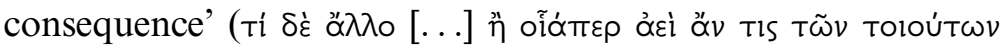

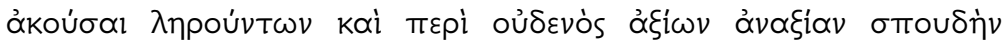
$\pi \circ{ }^{\prime}(\mu \varepsilon v \omega v)$. It seems, then, that the stranger is upset about the fact that in this debate unimportant matters were treated as if they had serious and relevant consequences. Crito's reply is itself problematic and highly provocative: 'but surely ... phil-

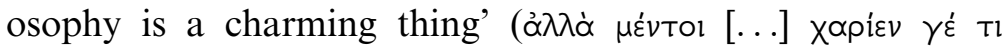

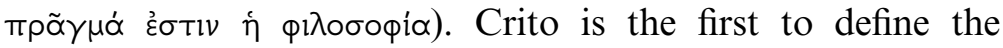
exchange between Socrates and the brothers as philosophy and, furthermore, to declare it to be charming regardless of the potential dangers that the stranger had highlighted. The stranger reiterates that (whatever Crito means by) philosophy

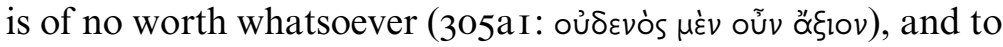
demonstrate this he mentions how Socrates, who agreed to take part in such a debate, made a laughing-stock out of himself, for 'the business itself and the people who follow it

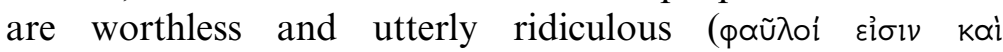
$\kappa \propto \tau \propto \gamma \varepsilon \dot{\varepsilon} \lambda \sigma \tau \sigma)$ )'. The anxiety about appearing ridiculous and the energetic attempts to associate oneself with serious and important things certainly evoke the image of Isocrates as the candidate for the stranger in this passage.

After having heard Crito's summary of their exchange, Socrates offers an analysis of an intellectual type: Prodicus had allegedly called such people somewhere in-between phil-

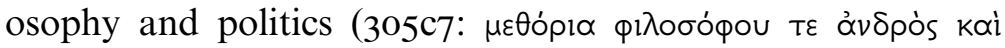

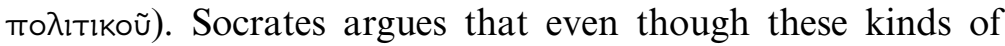
people are only 'moderately versed in philosophy and moderately too in politics' (305d8), and cannot thus claim to know the subjects in the depth necessary, still one 'ought to recognize

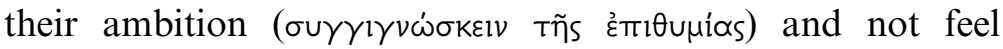
annoyed with them', for one should applaud 'anyone who says

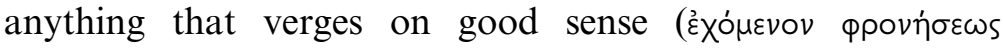
$\pi \rho \tilde{\alpha} \gamma \mu \alpha)$, and labors steadily and manfully in its pursuit' 
(306c6-di). Without any further elaboration, Socrates suggests here that while these people are not fully entitled to

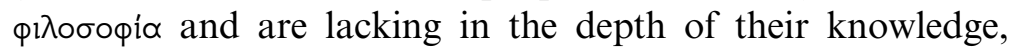
there is nevertheless something valuable in their pursuits in that they have good intuitions and ideally cultivate some of this also in their students or followers.

Coming as it does at the end of the dialogue, one cannot help but draw parallels to the Phaedrus, which suggested - in a rather comparable way - that there is 'some (kind of) philosophy' (tis $\phi i \lambda_{\circ \sigma o} \phi_{i \alpha} \alpha$ ) in Isocrates and predicted he would grow beyond his current rhetorical studies towards philosophy proper. Surely there were other practitioners of philosophy or proponents of education in contemporary Athens who could have been included in this characterization. However, the position of this observation at the end of the dialogue and the language used to describe the stranger (calling himself most wise, advocating against too deep engagement with philosophy, etc.) do seem to fit perfectly with Isocrates in particular. Isocrates seems to have been exemplary during his time and has certainly remained a unique case study of philosophy and rhetoric for contemporary readers. Hence, it does seem reasonable to consider Isocrates as an intended recipient of this evaluation and to be applauded over some of their other contemporary rivals. $^{23}$ This almost benign rejection of Isocrates as a second-rate (or third-rate in this passage) thinker might have had a less devastating effect on the reception of Isocrates than, for example, Socrates' portrayal of the 'immoral sophists', such as Callicles and Thrasymachus. Sketching out a more or less acceptable alternative to his own philosophical project, Plato seems to become an influential source for subsequent attempts to conceptualize and revive Isocratean philosophy. While the Phaedrus was surely a prominent place for Isocrates' rehabilitation as a student of Socrates and a positive role model for philosophical rhetoric, an

${ }^{23}$ Socrates' positive comments are often forgotten; paradigmatic is Sudhaus' reaction (I889), 53: 'Dass die Schlussepisode gegen Isokrates geht, wird jetzt wohl Niemand mehr bezweifeln.' 
attitude that seems particularly prominent in the works of Dionysius of Halicarnassus of the first century BCE, the Euthydemus further confirms this image of Isocrates but also indicates briefly the shortcomings of Isocratean philosophy.

This explicit mention of Isocrates at the end of the Phaedrus and potential references to Isocrates in the Euthydemus have inspired critics to launch into a wider examination of other dialogues by Plato in order to find support for their interpretation of Isocrates as one of the main rivals of Plato. Some scholars have regarded, for example, the digression about the philosopher in Plato's Theaetetus ( $172 \mathrm{c}-7 \mathrm{~b})$ as a critique of Isocrates. Eucken argues that the digression in Theaetetus is to be regarded as Plato's critique of the 'rhetorical man' (rhetorischer Mensch) more generally and should be regarded not as an ad hominem attack on Isocrates, but as an attack on an image of the intellectual that, however, encompasses the essential features of Isocratean philosophy/education. ${ }^{24}$ Even though Socrates draws a marked dichotomy between forensic speakers and philosophers, and Isocrates can be regarded among the former group only at a significant stretch, ${ }^{25}$ some of the fundamental characteristics of the two types of men as portrayed by Socrates - it has been argued - do map out the central disagreements between Isocrates and Plato. While Isocrates focuses on the 'here and now', Socrates emphasizes the triviality of sense perceptions and of life embedded in political or oratorical activity. For Socrates' leading

${ }^{24}$ Eucken (1983), 75, 276-8I.

${ }^{25}$ Isocrates himself denies having written forensic speeches, though he surely did and five have been preserved in his corpus. However, there are aspects in Socrates' description of the 'orators' which would be difficult at first sight to connect with Isocrates. For instance, the idea of lacking in time that characterizes orators under the pressure of courtroom conventions and the inability to pursue a topic properly can hardly characterize Isocrates who took, according to himself, at least ten years to complete a speech (Panegyricus), and appears to emphasize the thoroughness in his studies contrary to the practice of other sophists. Isocrates is hostile towards courtroom oratory and denies his involvement in this practice during his youth. Nevertheless, it needs to be pointed out that Isocrates' students were, highly likely, to pursue careers in public offices, law courts and so on. Hence, even if not a critique of Isocrates' person per se, Isocrates' philosophical school would have cultivated characteristics that emerge in the 'orator' in contrast to the values of the 'philosopher cohort'. 


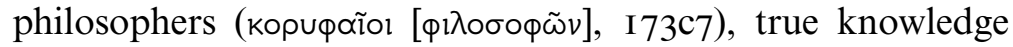
and wisdom lie in contemplation of the eternal and in aiming to be united with the divine as soon as possible (I76a8-bi). Isocrates, as demonstrated above, does not believe in the human capacity to achieve systematic and abstract knowledge of things worth knowing about, thus acknowledging beliefs ( $\left.\delta \xi_{\xi} \alpha\right)$ as the closest one can get to (practical) wisdom. These beliefs will inevitably depend on all kinds of stimuli coming from the world around us and thus are fundamentally rooted in our environment and context.

Next to the epistemological disagreements, ${ }^{26}$ another important divergence between Plato and Isocrates, or the respective images of philosophers that they would advocate, goes back to the notion of 'ridiculousness'. In fact, Socrates' digression in Theaetetus $172 \mathrm{c} 4-6$ is inspired by the recognition that philosophers appear 'laughable' ( $\gamma \varepsilon \lambda$ олоs) to others around them: 'how natural it is that those who have spent a long time in the study of philosophy appear ridiculous ( $\gamma \varepsilon \lambda$ ĩol $\phi \alpha i v o v \tau \alpha$ ) when they enter the courts of law as speakers (ṕnтopes)'. Socrates describes this ridiculous appearance as a necessary characteristic of a philosopher who spends all her time contemplating things that lie beyond her physical experience of the world. ${ }^{27}$ Isocrates, quite to the contrary, is keen to establish authority, a sense of seriousness and relevance to his educational methods. According to him, philosophy is what can be considered useful, and anyone who appears ridiculous in pragmatic affairs will have misunderstood the ultimate goals of philosophy (e.g. Helen 4-6). In his Antidosis, for example, Isocrates has his associate explain the difference between himself and the 'showing-off sophists'. The latter are sometimes ridiculed ( $\kappa \alpha \tau \propto \gamma \varepsilon \lambda \tilde{\alpha} \nu)$ and sometimes praised by the auditors,

${ }^{26}$ Note that the disagreement between Plato and Isocrates is not over the difference between knowledge and belief, but about their usefulness. The belief/knowledge distinction is implicitly maintained by Isocrates.

${ }^{27}$ It is perhaps relevant that at the end of the Phaedrus (277e3-8e2) Socrates suggests that one ought not to take written texts too seriously and, in fact, it would be ridiculous indeed if one did so. Now if we ought to see a rebuke of Isocrates anywhere in the Phaedrus it might be in this sentence, for it is hard to imagine an author who takes his writings more seriously than Isocrates. 
whereas Isocrates is not (I47-8). Sophists are associated multiple times with the most ridiculous situations (ö $\delta \dot{\varepsilon} \pi \alpha \dot{v} \tau \omega \nu$

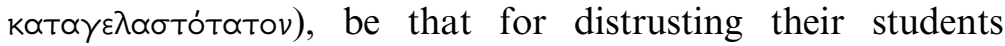
(Against the Sophists 5), or for trying to convince with implausible arguments (and not by deeds) that they have relevant things to say about political knowledge (Helen 9). Isocrates is also concerned for Athens appearing ridiculous if his views on logoi and education are neglected (Antidosis 297). ${ }^{28}$ Finally, in a passage of the Archidamus, Isocrates demonstrates perhaps his strongest stance on ridicule: he states that it is preferable to suffer annihilation rather than derision

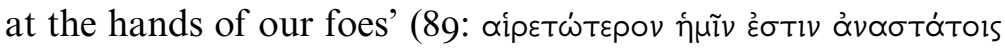

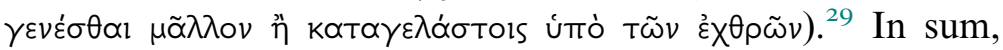
Isocrates agrees with Plato that hypothetical theorizing as described in this digression will inevitably lead to the 'ridiculous state' of the philosopher, but while this is something Plato accepts as a side-effect, Isocrates views it as an ultimate failure of the profession.

Epistemologically and emotionally, therefore, the views put forth in this digression seem to position Socrates/Plato and Isocrates on opposing axes and in direct and fierce antagonism. However, the drama of the dialogue is more complicated than that. The fact that all quests for knowledge end in aporiai, ${ }^{30}$ that there is no mention of the forms and recollection, and the presence of the digression in the middle of the dialogue which seems to have little to do with other themes of the dialogue, ${ }^{3 \mathrm{I}}$ have kept commentators on their toes. Indeed, as has been noticed before, next to expressing a rather exaggerated view of orators or law court officials, this passage of the

${ }^{28}$ Other passages where Isocrates warns against appearing ridiculous: Archidamus 37, 84, Busiris 3I, Helen 46, To Philip IoI, Panegyricus I69, I76, Trapezitikus 21, Antidosis 56.

29 The idea of derision as the ultimate tool of humiliation is also suggested in On the Peace I49.

${ }^{30}$ Of course, the aporetic nature of the dialogue does not mean that an account of knowledge cannot or has not been given in the Theaetetus. Cf. Bostock (I988), esp. 272-4; Sedley (2004), I78-8I.

31 McDowell, for example, has described the digression as containing material 'which in a modern book might be served by footnotes or an appendix' (I973, I74). 
Theaetetus also provides a caricatured depiction of philosophers to the effect that it is highly dubious that Socrates actually endorses this way of life any more than that of the orators. Indeed, the philosophers are described as oblivious to life happening around them, unaware of politics, of customs and laws, of feasts and trials, and most importantly, the philosopher 'doesn't even know that he doesn't know all these things' (I73eI). This can hardly be a positive characterization of philosophers. In the end, it is Socrates rather than the idealized leaders of philosophy (корupqĩol) who is occupying the position of a truly desirable middle measure, having a grasp - as much as striving towards achieving knowledge of the things in the world. ${ }^{32}$ Hence, if we are to locate Isocrates somewhere in this digression, it seems that he resembles the position of Socrates more than he does that of the orators. Even if he did have an early career as speechwriter, he has made a name for himself and gathered reputation rather as a teacher and head of a philosophy school. Isocrates is very negative about orators and other writers of political speeches (except for himself, of course) and recognizes the place for theoretical knowledge, even though he strongly advocates using theoretical philosophy as a tool for intelligent participation in the city's politics. In other words, within the crude distinction between orators and philosophers, Socrates and Isocrates seem closer to each other than they seem to either of the extremes. Hence, this passage can hardly be taken as a criticism of Isocrates, and even less so as an explicit critique of the Isocratean school. If anything, it seems to recognize the importance of a school like that of Isocrates, which is trying to find a middle way between the two highly problematic extremes.

Finally, there is Plato's Gorgias. Some see this dialogue as Plato's school-founding manifesto, written as a response to Isocrates' Against the Sophists, which has in turn been taken to be a manifesto for Isocrates' newly opened school. ${ }^{33}$ One of

\footnotetext{
32 Rue (I993). See also Sedley (2004), 65-74. $\quad 33$ Eucken (I983), 38-43.
} 
the chief reasons for this position is the discussion over tuition fees, for which Socrates (Plato) criticizes the sophists and, implicitly, Isocrates. Eucken maintains that this debate shows most clearly the way schooling was regarded by Plato and, being critically opposed to the views of Isocrates, he argues mistakenly in my view - that 'Die Akademie wird so gesehen gegen Isocrates gegründet'. ${ }^{34}$ While we know that Isocrates charged tuition fees, like the sophists, it does not necessarily follow that Plato's dialogue was directed solely against Isocrates and his practice. Be that as it may, stronger arguments of anti-Isocratean sentiments can perhaps be found in the knowledge versus belief discussion. This is developed in the first part of the dialogue in the exchange between Socrates and Gorgias. By having introduced a distinction between know-

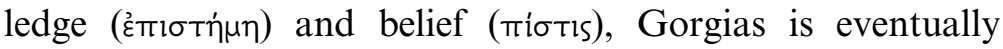
forced to agree with the following definition of rhetoric

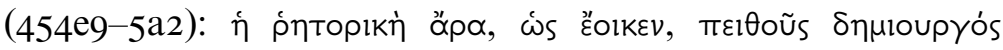

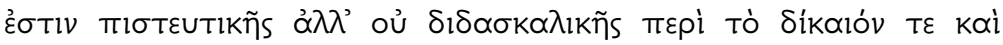

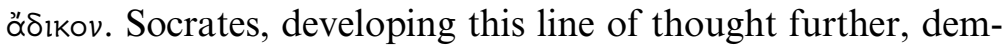
onstrates that Gorgias' conception of rhetoric might end up having serious and contradictory moral implications. Gorgias, who advocated at the beginning of the dialogue a neutral concept of rhetoric $(456 \mathrm{c}-7 \mathrm{c})$, is forced to accept by the end of the discussion that 'it is impossible for the rhetorician to use his rhetoric unjustly or wish to do wrong' (46Ia5-7), thus admitting a contradiction to his views on rhetoric. What is relevant for the Isocratean context is the way in which Socrates develops the argument from the distinction between knowledge and belief into a question about the moral foundations of rhetoric. ${ }^{35}$ Isocrates would, however, insist that he would not be able to teach morally depraved students in the first place. Overall, his insistence on the moral aspects of his logoi seems strong enough to make us suspect that as much as the image of Gorgias might have been associated with that of

34 Eucken (I983), 4I.

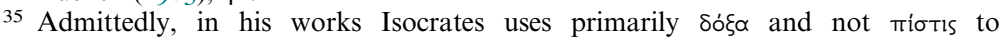
express 'opinion'. 
Isocrates (through a potential teacher-student link), Isocrates could hardly have been conceived as the object of criticisms expressed in this passage.

Perhaps more than in previous passages, Isocrates has sometimes been associated with the views of Callicles at the later stages of the dialogue, where the latter argues that philosophy should be pursued only as a training of the young, but that grown men should abandon this and get involved with 'real' politics. $^{36}$ There are some textual markers that indicate that reference is made indeed to a position rather close to the one advocated in the Euthydemus and having similarities with the way Isocrates fashions himself and is portrayed by his contemporaries. ${ }^{37}$ Callicles introduces the argument from nature and claims that laws are made in favor of the weak and for their protection against the strong $\left(483 \mathrm{~b} 4-\mathrm{c}_{2}\right)$. Socrates would be able to understand this position if he would only abandon philosophy and pass to greater things (484c4-5). For 'philosophy is a charming thing ( $\chi \propto p i \varepsilon v)$ if a man has to do with it

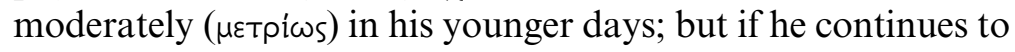
spend his time on it too long, it is ruin to any man' (484c5-8). There are many verbal references here to the last part of the Euthydemus and therefore the connection to Isocrates - if indeed he is to be identified among the recipients of Socrates' 'mediocre thinker' in that passage - springs immediately to mind. The description that follows this claim closely approximates the characterization of true philosophers in the Theaetetus section analyzed above, where Socrates mentioned elements that positively define the philosopher (ignorance of 'worldly matters', ridiculousness in private and public gatherings), but in this passage Callicles intends these features to be anything but complimentary to the profession. According to

${ }^{36}$ E.g. Irwin (1995), 95.

37 It is surprising that more has not been made in recent scholarship of their potential similarity. Rossetti (2018), 282 expresses the same sentiment when he briefly notes the resemblance of the views of Isocrates and Callicles, but in his analysis of Socrates and contemporary philosophy decides to completely neglect Isocrates and his potential contributions. The most detailed discussion of their relationship is still Sudhaus (I889), 55-60. 
him, philosophizing in excess makes one 'ignorant (ämeipov) of

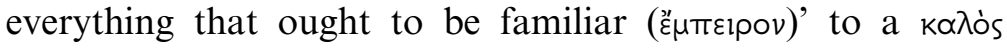
kớyatós (484c9-d2): they are ignorant of the laws of their city, of the terms of negotiation in private and public affairs, of human pleasures and desires. As a consequence, this business

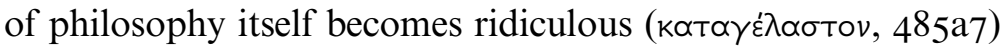
and those practising it seem to Callicles most similar to those

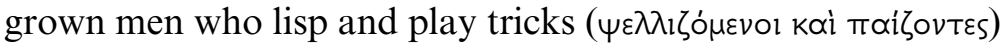
like children (485 bI-2). Both activities, philosophizing and playing, are acceptable as a stage in one's educational training, but not appropriate in advanced age with increased responsibility and experience. Comparing philosophy to frivolous tricks also resembles the way in which Isocrates rejected theoretical philosophy as irrelevant and useless activity for example in his Helen (4-6). There is indeed a sense of anxiety about appearing ridiculous and useless that informs both Callicles' and Isocrates' views on what true philosophy ought to be about.

First off, however, Callicles is characterized as an aspiring as well as promising politician and not as a teacher or even a sophist proper. ${ }^{38}$ This is an important difference, for if indeed Plato intended his readers to recognize Isocrates in the figure of Callicles, the portrayal of Callicles as an active and vocal politician in this dialogue would make any such explicit link impossible. ${ }^{39}$ If anything, we might wonder whether Callicles could stand for a potential student of Isocrates rather than Isocrates himself. ${ }^{40}$ This is a tempting avenue for two

${ }^{38}$ It is interesting that of all influential characters created in Plato's dialogues, that of Callicles is perhaps among the most enigmatic. We do not know anything about Callicles beyond this dialogue, and the lack of historical context has invited scholars to see other contemporary rivals as speaking through this character. See Dodds (I959), I2-I4 for a more detailed discussion of the historical context and scholarship around Callicles.

39 Dodds (I959), I2 highlights the incomparable dynamism and energy in Isocrates and Callicles (as portrayed in Plato) and thus rejects Sudhaus' speculation to see Isocrates behind Callicles as absurd. It must be said, however, that Dodds' opinion, whether correct or not, rests on his preconceptions about Isocrates as 'respectable and unadventurous', which are not supported by any evidence and longer discussion.

$4^{4}$ As far as I can tell, this idea has been proposed before only by Gotschlich (I87I), 4 who claims that 'in Kallikles sei recht eigentlich ein aus der Isokrateischen Schule hervorgegangener politischer Redner gezeichnet'. 
reasons: first because of the overt similarity of some ideas presented by Callicles in the dialogue, and secondly because of the sympathy and respectful treatment Callicles receives from Socrates despite supporting positions completely opposed to him. Despite the emotional turmoil portrayed in the dialogue it is worth noting that Socrates maintains throughout a respectful tone to Callicles and considers him the best conversational partner due to his sufficient education, frankness and goodwill towards Socrates (487a-8bi). At the end of the dialogue, Socrates laments that they both have fallen far back in education (doing philosophy moderately evidently has important drawbacks). He then invites Callicles to abandon his previous guide to life and instead to join in with Socrates in the quest for proper understanding of justice and excellence in life and death (527e). Much as Socrates had shown goodwill and understanding towards Isocrates in the Phaedrus and, arguably also, in the Euthydemus, Callicles is depicted as a promising young person with potential to embark on the right path. Socrates' criticism, among other matters, seems to be directed at the superficiality of his education and thought and, as such, we could read from their encounter an implicit criticism of any school that leaves education incomplete while giving its students an impression of having reached some level of maturity of thought. In other words, in comparison with his peers, Callicles stands out in a positive way as a somewhat educated and passionate conversation partner. However, his schooling has not been thorough enough to render him capable of following and fully participating in a philosophical discussion.

This may be a more general criticism of some philosophical schools at the time, though based on our knowledge of the various authors and educational institutions the only real candidate for this kind of criticism is the Isocratean school. Such a review that emphasizes both the positive and negative traits of an Isocratean education is in line with the way Plato's Phaedrus and the Euthydemus engage with Isocrates and his influence in Athens. Unlike many commentators, therefore, I regard the portrayal of Isocrates in Plato to be rather positive though with important caveats. While Isocrates is to be 
applauded for turning young men to philosophy in a broad sense, for cultivating youth who would appreciate notions like virtue and tradition, justice and excellence, he is also to be criticized for the incomplete philosophical program offered in his school. In the end, despite some central disagreements between Plato and Isocrates on philosophical education, they probably share more in terms of their views of intellectual life than either of them does with some of the more radical sophists.

\subsection{Isocrates and Aristotle}

We can say frustratingly little with confidence about the relationship between Isocrates and Aristotle, despite the increasing scholarly interest in their interaction. ${ }^{4 \mathrm{I}}$ Isocrates himself makes no reference to Aristotle, but there are two works by Aristotle that seem to engage with Isocrates: the Protrepticus and the Rhetoric..$^{42}$ Looking at the portrayal of Isocrates in the latter is straightforward and requires no explanation, for Isocrates is mentioned there by name and is the most frequently quoted contemporary in the whole work. Seeing an Isocratean connection in the Protrepticus is more speculative and requires further comment. I will start with the Protrepticus as much as it has been taken to be the earlier of the two.

${ }^{41}$ E.g. recent work by Haskins (2004), Hutchinson and Johnson (2005), Wareh (20I2), Collins II (20I5).

42 There have also been hypotheses based on FGrHist I026 F34 (= Diogenes of Laertius 2.55) that Aristotle wrote an early dialogue Gryllus in which he allegedly attacked Isocrates (who is also credited with a eulogy of Gryllus) as the chief opponent to academia and representative of contemporary rhetoric. As Too (I995), I 2 reminds us, there is no further information about Isocrates having written a work titled Gryllus and the association with Aristotle is also very weak. See a longer discussion of this fragment in Bollansée (I999b), II A5. It has to be said, however, that the supposed controversy between Aristotle and Isocrates, mentioned in Bollansée, does not rest on any actual evidence, but on the general (misguided) assumption that the two were bitter rivals. This view will be examined here in more detail. 
The history of recovering Aristotle's Protrepticus is full of scholarly controversy, and all these debates have now received a new dimension in the forthcoming edition by Hutchinson and Johnson. ${ }^{43}$ Even though the Protrepticus was proposed for a while to have been composed as a speech, in an Isocratean manner, reading of ancient biographical information together with Cicero's Hortensius has shifted scholarly opinion towards a dialogue form. ${ }^{44}$ Hutchinson and Johnson go further than that and argue that this dialogue featured three interlocutors: Aristotle himself, Isocrates and Heracleides Ponticus. ${ }^{45}$ Whether or not such hypothetical reconstruction is to be trusted, Isocrates has been considered by most scholars to constitute a crucial background to our understanding of Aristotle's Protrepticus, both in terms of its content and format. ${ }^{46}$ Indeed, the writing of a protreptic work, irrespective of where it belongs in Aristotle's composition, ${ }^{47}$ means that Aristotle was actively engaged with the educational rivalry in Athens, much as most

43 More detailed overviews of the scholarship can be found in Düring (I96I), who gives a good overview of the scholarship from I957-6I; Rabinowitz (I957), although negative in its conclusions, gives a good account of the scholarship prior to I957. Most recently, Hutchinson and Johnson (2005) provide a helpful overview of the scholarship from I96I onwards. The most up-to-date information about their reconstruction of the work is collected as a webpage: www.protrepticus.info. For references to the Protrepticus I use Gigon (1987) together with Hutchinson and Johnson (20I5).

44 This conclusion is to be preferred mainly due to external evidence: in the lists of Aristotle's works, the Protrepticus was mentioned among dialogues; Cicero's Hortensius was (highly likely) a protreptic dialogue which allegedly took its cue from Aristotle (and assumedly from his Protrepticus in particular). A good discussion of Cicero's thoughts on the dialogue form is Schofield (2008), 74-84. See also Hirzel (I895), 276 and Gottschalk (I980), 9 with further bibliography and references to ancient evidence.

45 On the dialogue form of Heracleides Ponticus, see Fox (2009). As far as I can tell, there is no actual evidence of the names of these three in any of the fragments that we have and the attribution of speakers is purely speculative based on the views detected in the fragments. I would therefore be very cautious about any grand claims like those in the unpublished essay (but published and available on the website) that maintains that the Protrepticus was written as a response to Isocrates' Antidosis (I).

${ }^{6}$ Schneeweiss (2005), 235-6 n. 227.

47 Many have speculated that it belongs to Aristotle's early works when he was still part of the Academy. E.g. Jaeger (1948), 54; Berti (1997), 402. Most recently, see van der Meeren (20II), xxii-xxxi. 
philosophers probably were. Unfortunately, we can only speculate about the role Isocrates might have explicitly played in this work.

Since we cannot say much about the generic category of the Protrepticus nor be sure whether Isocrates was explicitly mentioned in the work, I will confine the following brief analysis to looking at some of the generally agreed views advocated in this work and contrast them to Isocrates, in order to see if Isocrates could indeed have been regarded as a recipient of Aristotle's criticism of philosophical education in Athens.

The first point of comparison emerges in the formal address of the Protrepticus, which - according to Stobaeus - appears to have been to Themison, a king of Cyprus. ${ }^{48}$ There is almost no information about Themison and one can only assume that he must have been a man of importance in Cyprus if Aristotle decided to address him in the Protrepticus. ${ }^{49}$ As Jaeger has pointed out, it is somewhat paradoxical that a work which aims to encourage pupils to take up a theoretical life (Bios $\theta \varepsilon \omega \rho \eta \tau \imath k o ́ s)$, or a life of contemplation (as contrasted to the 'practical' life of Isocrates), is eventually addressed to a political actor ('the man of deeds'). ${ }^{50}$ Indeed, this address would be easily conceivable in the case of Isocrates who exhorts his audience to practical philosophy, but it seems less appropriate for the purposes of Aristotle's Protrepticus. But it could have also been a more generic trait of protreptic works that often address an individual with the aim of engaging and exhorting a wider audience to take up philosophy. ${ }^{5 \mathrm{I}} \mathrm{A}$ similar approach is apparent also in Isocrates' 'Cyprian orations', which, although

$4^{8}$ Stobaeus, Ecl. IV.32.2 I (frag. 54 Gigon). The Protrepticus was 'addressed' rather than 'dedicated' to Themison. See Jaeger (I948), 56.

49 Chroust (I973), II9-25 reviews the ancient evidence for Themison and concludes that 'it is well-nigh impossible to identify this Themison'.

5o Jaeger (I948), 55-6. Chroust (I973) interprets this paradox in the light of political rivalry between Isocrates and Aristotle.

${ }^{51}$ Surprisingly little has been done with regard to ancient protreptic discourses. For a general overview, see Jordan (I986). A more detailed overview of ancient evidence for the protreptic genre is provided in Slings (1995) and van der Meeren (2002) and (20II). Collins II (20I5) is the most recent discussion of Plato, Aristotle and Isocrates on protreptic genre, but adds little new to the existing literature on the topic. 
probably intended to be read by the wider public, are addressed to a particular person and the exhortation to philosophy closely follows the individual development of character. Overall, however, Isocrates' use of a personal address stands out from the comparison with Aristotle's Protrepticus as more developed and incorporated into the speech. In Aristotle's Protrepticus, Themison and his royal status do not seem to play any larger role in the work, contrary to Isocrates' To Nicocles where the personal address serves to give a raison d'etre for the work. In fact, compared to other (protreptic) examples - Plato's Euthydemus or Isocrates' Cyprian orations - Aristotle's Protrepticus appears as the most $a$-personal: aside from the address, the main body of the text (or what has been suggested to constitute the main text) appears to contain general arguments and discussions on the nature of philosophy and the aims of 'good life' more generally, rather than engaging itself with concrete examples or individuals in particular.

The wider philosophical controversy between Isocrates and Aristotle concerns the 'usefulness' of philosophy. Isocrates dismisses in his discourses (e.g. Antidosis 26I, Helen 3) the idea that philosophy should be identified with strictly theoretical pursuits, and attempts to establish and popularize his own understanding of philosophy as a practically oriented broader educational framework. According to him, a wise man is someone who is 'able by his powers of conjecture to arrive generally at the best course', and a philosopher a person 'who occupies himself with the studies from which he will most

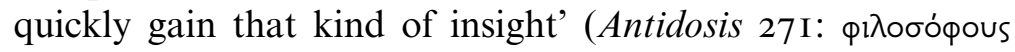

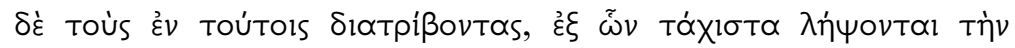

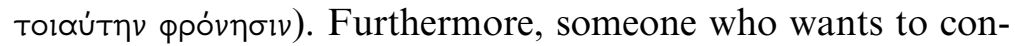
tribute to society should 'banish utterly from their interests

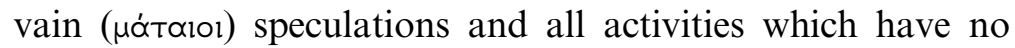
bearing on our lives' (Antidosis 269). Wilms argues that behind Isocrates' understanding of philosophy is the wider cultural

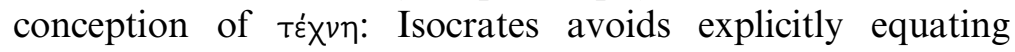

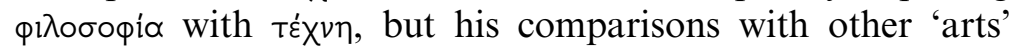
(e.g. medicine) indicate that he views the acquiring of 


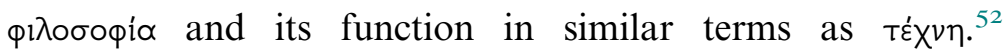
Hutchinson and Johnson claim to be able to recognize this Isocratean position in fragment 74. I of the Protrepticus, which exhibits a comparable position to the Antidosis passage above, renouncing a practice that is interested in 'goods themselves' without being able to make use of them.

Aristotle's Protrepticus appears to promote two central aspects of philosophy: firstly, arguably in response to the Isocratean pragmatic view of philosophy that limits 'good things' only to those that have instrumental value, Aristotle argues that there are things which are truly good and worth pursuing for their own sake (fr. 73.6I). ${ }^{53}$ Furthermore, access to these fundamental 'goods' (that are then the basis for other arts and skills) is granted to philosophers alone (fr. 73.67-8). ${ }^{54}$ Isocrates, who values education and philosophy above other pursuits, would probably not challenge the idea that access to fundamental 'goods' is the purview of philosophers, even if we should probably think here of the Isocratean kind of philosopher in particular. Isocrates might also agree with the fact that some things are worth pursuing for their own sake, though he might disagree that we should see philosophy as a thing rather than as a tool towards better governance. Secondly, Aristotle argues that philosophy is what makes us truly human: since the function of the soul is thinking, those who fulfil this function are more alive and fulfil the 'human condition' more than those who do not dedicate themselves to philosophy (fr. 73.72). In addition to this, the tradition has preserved a famous and clever argument from the Protrepticus, which, however, is not cited by Iamblichus in his Protrepticus.

\footnotetext{
52 Wilms (I995).

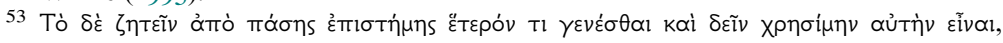

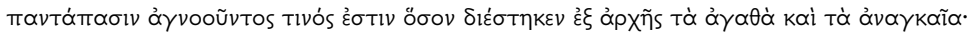

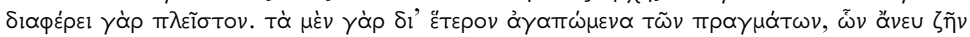

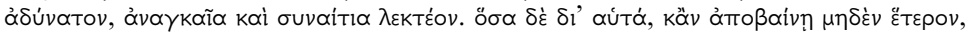

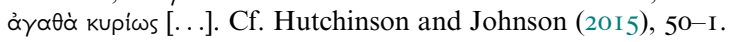

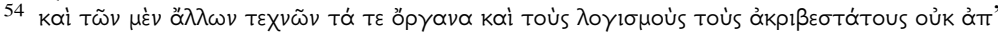

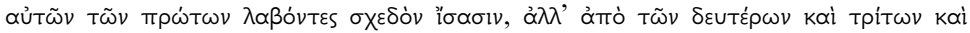

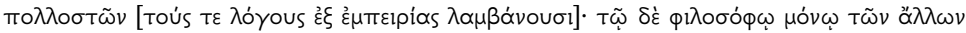

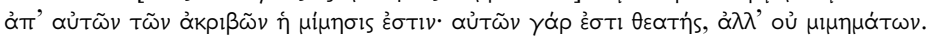


According to this argument, if anyone claims that philosophy should not be studied they are in a self-refuting position, for in order to argue for this point they are already using the tools of philosophy and are, thus, automatically committed

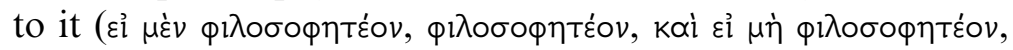

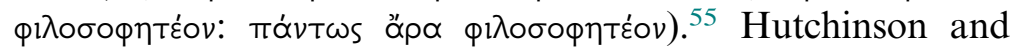
Johnson suggest that this might have been Aristotle's reply to Isocrates in the dialogue, but this is not entirely persuasive.

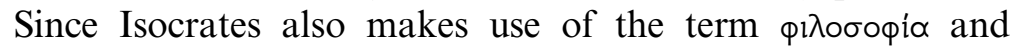
appropriates it to his own school of thought, the power of the argument is diminished as Isocrates would not deny (on a very general level) that 'one ought to philosophize'. Isocrates would reject the view that philosophizing ought to be understood as a theoretical pursuit. In other words, if we should speak of the Protrepticus as a response, at least on some levels, to Isocrates, it remains unclear from any of those central claims of the work how and why they ought to be read as a direct attack on Isocrates. On the face of it, it seems to make better sense to understand Aristotle's Protrepticus in a broader Athenian educational and political context as a work that has no time to spend on criticizing fellow philosophy rivals on smaller disagreements and hidden remarks, and instead as a manifesto that is focused on the bigger picture: how to draw students to philosophy more generally (rather than to politics, medicine, craftmanship and so on) and thus improve general morality and education in the city as a whole. ${ }^{56}$

55 The evidence for this argument is preserved in Lactantius Divine Institutes 3.I6.396b, Clement of Alexandria Miscellanies 6.I8.5, Alexander of Aphrodisias Commentary on Aristotle's Topics (at II.3 I Ioa2), Sextus Empiricus Against the Logicians II, Iamblichus' Letter to Sopater on Dialectic (cited in Stobaios Anthology II.2.6), Olympiodorus Commentary on Plato's Alcibiades II9a-2od, Elias Prolegomena to Philosophy (3.17-23 Busse), David Prolegomena to Philosophy (9.2-I2 Busse). For an analytical discussion of this argument see Castagnoli (2010), I 87-97.

${ }^{56}$ Hutchinson and Johnson (2005), I96-7 argue that Aristotle's Protrepticus was one of his most widely read philosophical-programmatic works. It is odd indeed not to find in ancient commentators any other reference to Isocrates' involvement in the work. If it did feature Isocrates as a character, it certainly does not seem to have had a negative impact on Isocrates' popularity in subsequent reception. Overall, I find it rather implausible that Aristotle even intended with his Protrepticus a more 


\section{Aristotle's Rhetoric}

Isocrates' role in Aristotle's Rhetoric is at once simple and complex. He is the most often quoted contemporary individual in the work, ${ }^{57}$ and this is relevant even if only in suggesting that Aristotle was familiar with Isocrates' works and felt comfortable exhibiting his acquaintance with the latter. At the same time, the Rhetoric displays no deeper engagement with Isocratean thought and philosophy - all quotations are restricted to examples of his style and argumentation without any hint about the way in which Isocratean philosophy might be positioned in the context of Aristotle's own views. ${ }^{58}$ It is therefore tempting to conclude that Aristotle intends to treat Isocrates solely as a stylistic figure who has no relevant rhetorical, philosophical or educational innovations that would prompt Aristotle's response in the context of his philosophical discussion of rhetoric. ${ }^{59}$

Isocrates is explicitly mentioned in twelve passages of the Rhetoric, ${ }^{60}$ but there are also numerous implicit references to and paraphrases of Isocrates' work. ${ }^{61}$ None of these passages discusses or even briefly mentions Isocratean philosophy or educational theory. In none of the direct references to Isocrates does Aristotle take a polemical attitude to Isocrates. Quite the contrary, Aristotle evokes examples from Isocrates' works when he needs to explain different aspects of rhetorical

technical and overt criticism of Isocrates. Moreover, one should also be careful when taking Cicero (and his Hortensius, for example) as an informative source about the possible generic outlook of Aristotle's Protrepticus, for the context of philosophical exhortation is very different in fourth-century BCE Athens and firstcentury BCE Rome. I hope to address this topic elsewhere in more depth.

57 Cf. Benoit (I990), 252. In fact, as far as I can tell, Isocrates is the second (only after Socrates) most frequently mentioned author in the whole work.

${ }^{58}$ References to Aristotle's Rhetoric follow Kassel (I976). Translations are adapted from Kennedy (I99I).

59 Dow (2015) seems to share this view, though he does not elaborate on the possible influence of Isocrates for Aristotle's Rhetoric and confines his argument to a brief footnote, where he suggests that Gorgias, Thrasymachus (i.e. the sophists) and Plato appear more likely inspirations for the Rhetoric than Isocrates.

6o I368a20, I392biI, I399a2, I399bio, I408bi5, I4IIa29, I4I2b6, I4I4b27, I4I4b33, I4I8a3I, I4I8a34, I4I8b26.

6r Veteikis (20II), 3. He claims that Aristotle makes around forty references to Isocrates in his Rhetoric. 
compositions and topics. As these passages show, Isocrates is referred to in all books, but most often in the third book which is dedicated generally to style. Intriguingly, there is one passage with a direct reference to Isocrates which seems to have a sarcastic undertone. When describing the differences between deliberative and forensic oratory, Aristotle claims that the former is more difficult because there are fewer 'tricks' one can use and appeal to. Yet, when at a loss 'one must do as the

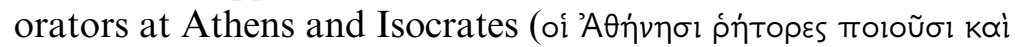

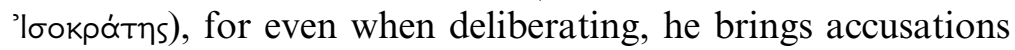
against the Lacedaemonians' (I4I8a29-3I). It is worth pointing out that Aristotle mentions Isocrates together with Athenian orators, but also keeps him separated from that group ('as the Athenian orators and also Isocrates'), suggesting thus that he does not properly belong in that group either. Indeed, Isocrates seems to remain somewhere in-between various categories and Aristotle himself does not appear to have a very defined opinion about Isocrates. It may be a coincidence that Isocrates is mentioned so frequently as a source for stylistic examples in Aristotle's Rhetoric, but it certainly seems that he was not relevant or provocative enough for Aristotle's philosophical enterprises. Based on the little evidence we have, perhaps it is most wise to conclude that Aristotle remained uninterested in Isocrates' philosophy though he might have considered him excellent enough to be used as an example in the context of argumentation and composition.

Two relatively recent accounts of the relationship between Aristotle and Isocrates have proposed opposing explanations for the state of our scarce evidence of Isocrates in Aristotle. Haskins has interpreted this move by Aristotle as minimizing 'the political importance and timeliness of Isocrates' writings by tearing them into stylistically interesting but ultimately decontextualized fragments'. ${ }^{6}$ Admittedly, the emphasis Isocrates lays on the stylistic aspects of his work certainly gives good ground for Aristotle to make such a categorization.

${ }^{62}$ Haskins (2004), 78. 
At the same time, Haskins' arguments from our lack of evidence are purely speculations. Indeed, the fact that Isocrates has no place in Aristotle's other works might simply suggest that Isocrates is either not taken seriously as a philosophical rival or that his conception of philosophy, popular as it may have been, is simply uninteresting for Aristotle. One might entertain the fascinating position, as Haskins does, that Aristotle had a larger goal in mind when writing Isocrates out of the history of philosophy, to actively discredit him, but there is no real evidence that would support such a speculative interpretation and, as such, it will be cast aside until further evidence should emerge. Wareh, on the other hand, is another extreme and offers a far more sympathetic engagement between Aristotle and Isocrates than he can substantiate with evidence. ${ }^{63}$ In an inspiring as much as frustrating inquiry into the mutual influences between Aristotle, Isocrates and their respective schools, Wareh suggests that many central insights of Aristotelian ethics and politics can be traced back to the 'Isocratean' challenges and insights in contemporary philosophical debates. As appealing as this view may sound, there is little evidence to prove, for example, that what Wareh treats as strictly 'Isocratean' may not have been simply a commonly shared view, a substratum of a broader debate, that thus emerges in the works of both. ${ }^{64}$ These speculations must, too, be abandoned until further information should arise on the relationship between Aristotle and Isocrates.

Yet even without suggesting that Aristotle wrote Isocrates deliberately out of philosophy (as we now understand it), it is nevertheless plausible that Isocrates would have received in later reception a more serious consideration (including in modern scholarship!) had Aristotle explicitly discussed his

63 Wareh (2012).

64 There are several other criticisms that could be voiced against Wareh's study. In particular, the lack of clarity of the argument and sometimes misleading use of source texts is frustrating enough to prevent more serious engagement with the otherwise valuable provocation in Isocratean scholarship. The discussion of Isocrates' students and school is, nevertheless, very valuable. For a generally positive evaluation of this book, see Edwards (2013). 
views on philosophy and rhetoric in his works. Aristotle, who remains in many respects a highly valuable pillar for our understanding of the philosophical canon, who collects arguments and fragments of pre-Socratics that have otherwise been lost, seems (for whatever reason) not to have found in Isocrates a productive conversational partner. This very fact may indeed have shaped the reception of Isocrates and fixed his position somewhere between philosophy and rhetoric. Not quite philosopher, because he is not mentioned in the philosophical canon, but not quite rhetorician, because his works and activity could not be categorized under any of the three main branches of rhetoric as defined by Aristotle: deliberative, epideictic and judicial. On the other hand, this in-betweenness has enabled Isocrates also to be considered, from time to time, a legitimate philosopher who ought to belong in the philosophical canon and whose views of the practical side of philosophy offer a refreshing opportunity to access philosophy without getting bogged down too deep into the difficult terminology of some philosophical schools. In fact, the silence of Aristotle and praiseful attitude of Plato's Phaedrus probably encouraged rather than hindered the spread of Isocrates' works and influence in Greece and, later on, from Greece to Rome. In other words, Plato's overtly positive praise in the Phaedrus and hidden criticisms in the Euthydemus and Gorgias, together with Aristotle's neglect of Isocrates, paved the way for the emergence of Isocrates as an alternative teacher of philosophy, who was oriented towards the practical and who emphasized the responsibility of elite members in society to maintain the wellbeing of the political community. 
PART II

CREATING THE ANCIENT RHETORICAL TRADITION: DIONYSIUS OF HALICARNASSUS IN ROME 
FROM ATHENS TO ROME: LYSIAS, ISOCRATES AND THE TRANSMISSION OF GREEK RHETORIC AND PHILOSOPHY

Dionysius of Halicarnassus was a close reader of Plato and his engagement with the Phaedrus occupies an important position in his rhetorical essays and in his treatment of Lysias and Isocrates in particular. Between Plato and Dionysius, however, were three centuries of thinking and writing about rhetoric, compiling and commenting on the works of Attic orators, speechwriters, philosophers. Hence, before looking at Dionysius of Halicarnassus' rhetorical essays, a brief overview of the reception of Lysias and Isocrates in the centuries between Plato and Dionysius is in order, so as to gain a good insight into the background for Dionysius' work and to better assess his contributions to ancient rhetorical theory. ${ }^{\text {I }}$ The following overview will proceed roughly along chronological lines, focusing primarily on more substantial evidence on Lysias and Isocrates that we have from Ps. Demetrius, Philodemus and Cicero.

\section{I Post-Fourth-Century BCE and Hellenistic Receptions of Lysias and Isocrates}

Lysias and Isocrates had very different fates in post-fourthcentury and Hellenistic rhetorical criticism: on Lysias we know very little and have few papyri from that period, whereas Isocrates seems to loom large in common perception about Hellenistic education, philosophy and rhetoric. ${ }^{2}$ Research into

${ }^{\mathrm{I}}$ For a recent acknowledgement of the need for a more thorough examination of the Hellenistic context for Dionysius' work, see the 'Introduction' to de Jonge and Hunter (20I8), 23.

${ }^{2}$ E.g. Jebb (I876a), I6 who calls him the 'prophet of Hellenism'; Burk (I923), 204. 
Hellenistic oratory and rhetoric is growing, but it is also a complicated field due to lack of evidence on rhetorical activity from that period. ${ }^{3}$ Polybius, of course, is a major source for Hellenistic history and speechwriting, but he by no means aims to record rhetorical theory and does not mention Lysias and Isocrates in his work. ${ }^{4}$

\section{Lysias}

Even though Diogenes Laertius' records suggest that Lysias (and his family) had a relatively lively afterlife in Academic circles (see above, Chapter I.2.), we know very little about the reception of his works and persona from the fourth century to the first century вСE. We do have papyri of Lysias' corpus, but they are very few and in general offer inferior readings in comparison to the existing manuscript tradition. ${ }^{5}$ With the exception of the treatise by Ps. Demetrius (more below), whose dating is continuously controversial, Lysias seems to disappear almost completely from our records after the fourth century ВCE. Indeed, before his renaissance in the first century BCE there are only two relatively obscure references by Peripatetic philosophers to a Lysias that may potentially have something to do with the famous Lysias of the fourth century BCE. Clearchus of Soloi, a disciple and close confidant of Aristotle, uses the name 'Lysias' for a character in his dialogue On Sleep (Пврi ümvou), but the significance of this choice of name, and in fact the overall interpretation of Lysias in the dialogue, remain unclear. ${ }^{6}$ The second Peripatetic to mention

3 See most recently Kremmydas and Tempest (2013) with bibliography.

${ }^{4}$ Wooten (1974) argued that there was an overwhelming influence of Demosthenes during the Hellenistic period that could be discovered from close reading of Polybius' works. Kremmydas (20I3), I6o has recently challenged this view. Looking at Polybius' references to Demosthenes, it is striking, however, that most passages refute Demosthenes' position on Philip. The name Isocrates is mentioned three times in the Histories (in 3I.33.5.5, 32.2.5.I and 32.3.6.I), but Polybius' discussion indicates that he seems to have had some other Isocrates, a certain

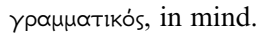

5 Carey (2007), x; Indelli (2000).

6 The relevant section is in fragment 8, lines I9-25 in Tsitsiridis (2013). 


\section{Post-Fourth-Century Receptions}

Lysias is Ariston of Ceus, ${ }^{7}$ who deals with the character type

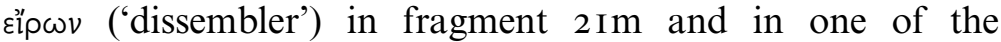
examples uses both Phaedrus and Lysias. There is clearly a strong Platonic influence lurking behind this passage, as in most (Peripatetic) treatises of this particular character type, ${ }^{8}$ and commentators have found parallels for this character depiction in Plato's Gorgias, Phaedrus and Euthydemus. In any case, it is difficult to say what significance this reference has, other than to show that Lysias - and the Platonic portrayal of Lysias in particular - might have had a relatively interesting afterlife in philosophical circles, of which we know, unfortunately, frustratingly little.

\section{Isocrates}

The reception of Isocrates in that same period is a completely different matter. Even though none of the works of his students have survived and we do not have other works that offer direct engagement with Isocrates' writings, we can suppose a relatively broad Isocratic influence from the fact that we have many papyri from this period, indicating that he must have been widely read at least in Hellenistic Egypt. ${ }^{9}$ We also hear from various secondary sources about the importance of his school and the success of his students. Isocrates' influence on the Hellenistic period, and particularly on Hellenistic historiography, has been a very controversial topic, which in itself is not the focus of this overview. However, in the course of revisiting some of the sources, it will emerge that Isocrates

$7 \mathrm{I}$ am following the numeration and the text from the newest edition of Ariston in Fortenbaugh and White (2006).

8 There was a strong tradition of equating Socrates with elp $\omega v$. For a more thorough discussion of this character type, see Knögel (I933), 34-9.

9 See also Morgan (I998), 99 for Isocrates' important presence in schooltext papyri. In schools, Isocrates seems more widely read than Plato, Herodotus and Thucydides, thus remaining the only more 'theoretical' figure in the list that also includes Homer, Euripides, Demosthenes and Menander (see 97). Kremmydas (2013), I50-4 persuasively argues for seeing Isocrates as an important influence in Hellenistic forensic and epideictic oratory. Given the few theoretical works on rhetoric at the time, it is indeed plausible, as Kremmydas argues, that rhetorical education was achieved primarily through imitation. 
seems to have been less influential than he appears, for example, in the account of Werner Jaeger, ${ }^{\text {IO }}$ and at the same time more influential than argued by some contemporary historians. ${ }^{\text {II }}$

From the scattered evidence, it seems that we can speak of Isocrates' influence in four main areas: (I) theater, (2) historiography, (3) language and style, and (4) political philosophy.

The most problematic of these four categories is Isocrates' connection to the first, the tragedians: there is a tradition according to which Astydamas and Theodectes, the foremost tragedians of the fourth century BCE, were pupils of Isocrates. ${ }^{\mathrm{I} 2}$ The evidence that Xanthakis-Karamanos invokes in support of her claim that 'Isocrates [...] seems to provide a link between rhetorical development and fourth-century dramatic poetry' relies entirely on the Suda and on a comparison with, and stylistic evaluation of, the fragmentary evidence of the contemporary dramatists. ${ }^{13}$ This is not entirely persuasive: the later tradition in literary criticism that was motivated to identify teacher-pupil relationships among earlier writers might well have imposed this framework and created a thematical link between the writers without much concern for historical reality. Hence, the importance and influence of Isocrates on tragedy cannot be maintained with much confidence.

One seems to be on firmer ground in historiography. ${ }^{\mathrm{I}}$ Debates on this issue focus on the so-called Isocratean school of history, and argue that Theopompus (of Chios) and Ephorus, who were apparently writing in Isocratean style, were not only instructed by Isocrates to write history, but also told what kind of history they should write. ${ }^{15}$ Furthermore,

Io Jaeger (1945), 46: 'Today as of old, Isocrates has, like Plato, his admirers and exponents; and there is no doubt that since the Renaissance he has exercised a far greater influence on the educational methods of humanism than any other Greek or Roman teacher.'

I My reading of Isocrates' influence on Hellenistic thought comes very close to a recent evaluation of Isocrates in historiography by Marincola (20I4).

${ }^{12}$ Xanthakis-Karamanos (1979), and (I980), 60-I; more recently Hall (2013).

${ }^{13}$ Xanthakis-Karamanos (I980), 60-I, where the teacher-pupil relationship is supported by references to Suda (s.vv.) $\propto 4264, \propto 4556, \theta$ I3 8 .

${ }^{14} \mathrm{Jebb}$ (1876a), I3 and 72 makes very confident claims about this association.

15 E.g. Laqueur (I9I I), 345; Cartledge (I987), 67. 
even though none of their works actually survive, some scholars have gone on to suggest that both Theopompus and Ephorus wrote a moralizing history which was imbued with rhetorical decorations and distortions of historical truths, thus following what some have taken to encapsulate 'Isocratean' ideology. ${ }^{16}$ Recent scholarship has, rightly, pointed to the extremely scarce evidence to support these broad claims and has questioned whether Isocrates had any associations with history writing at all. ${ }^{17}$ Indeed, Isocrates never wrote history himself nor can we glean from his writings any programmatic views about historiography. As Marincola has rightly emphasized in a recent article, however, history itself was an important topic for Isocrates and provided material and inspiration for his teachings and writings. ${ }^{18}$ Given that Isocrates had regarded his school as an educational center that prepared students for careers in a variety of different fields, such may well have been also his reception and influence on later writers. In other words, even though he did not author works of history himself, his philosophy, attention to writing, traditions and cultural memory might well have been very inspirational for historians.

In any case, even if we reject the view that Theopompus and Ephorus were exercising Isocratean political thought or philosophy in their histories, this does not change the fact that they were perceived already in antiquity as part of the Isocratean school and that almost all our existing evidence on Isocrates from the fourth and the third centuries connects the Isocratean school (whatever this might mean) overwhelmingly with historians: a fragment of Callisthenes of Olynthus (Fr. 44.2-5 FGrH I24) recounts Isocrates' failed attempt to call for peace in the latter's letter to Philip. Two of Ephorus' fragments, preserved in the lexicon of Harpocration, mention Isocrates, and are used as a source for explaining (or providing an

${ }^{16}$ Cicero and Dionysius of Halicarnassus seem to associate history writing with Isocrates' school mostly due to the Isocratean style that was apparently imitated by both writers (Theopompus and Ephorus). Cf. D. H. Letter to Pompeius 6, Cicero De oratore 2.13.57, Quintilian I0.I.74.

${ }^{17}$ Flower (1994), contra Natoli (2004). $\quad{ }^{18}$ Marincola (2014). 
exegesis of) certain Isocratean words. ${ }^{19}$ The testimonia of Anaximenes, the rhetorician and historian who has been considered as the author of the Rhetoric to Alexander, ${ }^{20}$ refer to an engagement with Isocrates' work, but we do not have any explicit mention of Isocrates in Anaximenes' fragments nor in the rhetorical treatise that has come down under his name. ${ }^{2 \mathrm{I}}$ Philochorus, another important fourth-century historian of Athens and a source for Dionysius of Halicarnassus, refers in his fragments to Isocrates and recounts, among other things, a story about Plato rejecting the opportunity to have a statue erected in his honor in the manner of Isocrates. ${ }^{22}$ Finally we have Demetrius of Phalerum, a philosopher and a historian, date Isocrates' death in a fragment. ${ }^{23}$ Much later, Dionysius of Halicarnassus connects Timaeus (late fourth- and thirdcentury $\mathrm{BCE}$ historian) with Isocrates and counts him among the many unsuccessful imitators of Isocratean style. ${ }^{24}$ All those brief snippets taken together highlight Isocrates' role as a teacher (rather than simply stylist or rhetorician) and, in the case of Philochorus, as head of a philosophy school rivaling the famous ones by Plato and Aristotle.

The third and second centuries $\mathrm{BCE}$, despite providing even patchier information about Isocrates, boast two important sources that indicate the importance of Isocrates for the period: Hermippus of Smyrna (or the Callimachean), a grammarian and a historian, who was mostly known for his work on ancient biographical tradition, ${ }^{25}$ and Hieronymus, the philosopher. Athenaeus, Dionysius of Halicarnassus and Harpocration all claim that Hermippus wrote books about Isocrates and, importantly, a separate book On the Pupils of

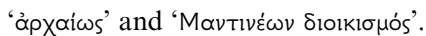

${ }^{20}$ Against his authorship, see Chiron (2002).

${ }^{21}$ Even though there are no explicit references to Isocrates, Chiron (2002) has argued in his edition of the Rhetoric to Alexander that there are strong Isocratean influences ('global influence') in the work (cxxxi-cxlviii).

22 The fragment is preserved as $\mathrm{FGrH}_{32} 8 \mathrm{~F}_{59}$. The background of this anecdote is surely a later perception of school rivalries in Athens, but quite possibly also the anecdote about Lysias offering a speech for Socrates who then rejects it as not fitting. A good recent commentary on this fragment is Harding (2008), I 55-7.

${ }^{23}$ Mandilaras (2003), I.258-9. $\quad{ }^{24}$ D. H. Deinarchus 8.

${ }^{25}$ Hermippus of Smyrna is quoted after Bollansée (I999a).
} 
Isocrates. ${ }^{26}$ A recent commentator on Hermippus has suggested that the 'Hermippean material was firmly entrenched in the literary tradition concerning the fourth-century rhetoricians' and that 'more of it may be thought to persist, albeit completely anonymously, in the still extant works'. Bollansée points out an important detail - that Hermippean material plays a crucial role in the establishment of the tradition of Isocrates' numerous and important pupils. ${ }^{27}$ As Cooper and Bollansée have both argued, Hermippus' approach to Isocrates was similar to the way he aimed to create a biographical continuity between philosophers through the idea of $\delta ı \alpha \delta \circ \chi \eta$ (succession). ${ }^{28}$ Hermippus seems to have applied the same approach to Isocrates and other contemporary orators/ rhetoricians. Or perhaps it is worth considering the possibility that Hermippus had not, contrary to what Bollansée and Cooper suggest, treated Isocrates as a rhetorician, but rather as a philosopher-rhetorician? Such a reading would indeed offer a better explanation for two important things: first, his attempt to create a professional heir and succession for Isocrates would make sense as a comparison to other philosophers and teachers (it might have been felt to be a badly needed desideratum), and second, this would help better explain why he does not really mention orators in his works. Hermippus mentions Demosthenes, for example, only in fragments preserved in the book on Isocrates' pupils, and there does not seem to have been a separate treatise on him.

Engels has discussed in greater detail the school of Isocrates and concludes that based on our current information it is difficult to find any clear-cut political, rhetorical or even generic link that would connect all those names who have been

${ }^{26}$ FGrHist I026 Ti4a (= Athenaeus I3.592d), Ti4b (= Hypothesis of Isocrates speech two), Ti5a (= Dionysius of Halicarnassus Isaeus I.2) Ti5b (= Harpocration in Suda I 620 s.v. Isaios), TI5c (= Athenaeus 8.342c), TI5d (= Athenaeus I0.45IE). Bollansée (I999a), 2I argues that the first book on Isocrates was probably written in one book, but that the second was probably published in three books.

27 Bollansée (I999a), 85.

${ }^{28}$ Engels (2003), I 83 n. 30 suggests that Hermippus inherits from Phainias the method of organizing the treatise on Isocrates' students around the idea of succession. 
listed among Isocrates' students. ${ }^{29}$ If we take seriously the ending of Isocrates' Panathenaicus, which stages a dialogue with one of his students who holds evidently different political views from Isocrates himself (I2.200-65), we might wonder why should we expect Isocrates' students to exhibit similar political belonging, especially in the context of political turmoils and the geographical breadth of the Hellenistic empire. ${ }^{30}$ Cooper and Bollansée have both instead suggested that Hermippus' motivation for emphasizing Isocrates and creating the idea of rhetorical 'succession' might have been entirely detached from the political/philosophical implications of rhetoric, and was purely an idea to map the history of Attic prose and its development. ${ }^{3 \mathrm{I}}$ For this, I find little evidence, especially since all preceding snippets and fragments on the reception of Isocrates in the fourth and post fourth century BCE have pointed clearly to his appreciation as a teacher and head of a philosophical school. Excellence of prose and emphasis on writing were definitely an important part of Isocratean education and seem to have remained so also in the reception of his work and influence in later periods. However, given the wide spread of his works, our evidence does not seem to support the claim that Isocrates became valued for Hermippus simply as a stylist of Attic prose.

Hieronymus of Rhodes offers us another perspective on the reception of Isocrates in the third century BCE. A philosopher, he is also interested in rhetoric and criticizes Isocrates for his style which makes his speeches ineffective in delivery. ${ }^{32}$ Mirhady has suggested that this fragment also contains an implicit criticism of Isocrates' pedagogical work. Indeed, even

29 Engels (2003), I92-3.

30 This would also apply for Isocrates' immediate students, for he was known to have taught also outside Athens and for a politically very diverse audience.

${ }^{31}$ Cooper (1992); Bollansée (I999a), 89-93.

32 A recent discussion of Hieronymus' engagement with Isocrates is Mirhady (2004), who argues that Hieronymus' condemnation of Isocrates' style had an important Nachleben in the works of Dionysius of Halicarnassus and, possibly, also in Philodemus. Hieronymus talks about Isocrates in fragment 38A-B (White), collected in Fortenbaugh and White (2004). Dionysius of Halicarnassus discusses Hieronymus in On Isocrates I3. 
if Isocrates was loud and clear about not having engaged in forensic speechwriting, ${ }^{33}$ his famous works are nevertheless composed as speeches. Furthermore, if Kremmydas' argument is to be followed that rhetorical education at the time was probably based primarily on imitation, ${ }^{34}$ it is easy to see why Isocrates - one of the most widely read authors of the Hellenistic period - would be criticized. In any case, Hieronymus' interest in Isocrates seems to be further evidence that suggests that Isocrates might have been a far more important focus for the third-century theoreticians for oratory and rhetoric than other famous fourth-century practitioners of rhetoric/oratory (e.g. Demosthenes). Hieronymus' complaints that Isocrates' work is not fitting for imitation also seems to suggest a context where advocates of Isocrates' writing would perhaps argue the other way around and aim to compose speeches for delivery that are inspired by Isocratean prose. One might speculate that because of the wide readership that Isocrates' works enjoyed, it is possible that he also started to become increasingly valued for providing a paradigm of a kind of oratorical style. A style that is sophisticated, complex and difficult to access and imitate without advanced school instruction. In other words, Isocrates, the teacher and philosopher, may have started to occupy a place in people's minds within the canon of Attic oratory and taken as a representative of style. Most of first-century BCE criticism, starting with Dionysius of Halicarnassus, will work very hard to rectify this misunderstanding of Isocrates as an example of style and bring back his contributions to philosophy and education.

Lastly, an area where Isocrates might have been of importance is the discourse of kingship and its implications for political philosophy. However, even if the debates about different ways of life - the contemplative versus the practical - still seem to have had some currency in philosophical discourses after Aristotle (e.g. Cicero Att II.I6.3), it is not clear whether

33 This is of course false, for we have his early forensic speeches. What Isocrates means is that his reputation came from his teaching and philosophy career.

34 Kremmydas (2013), I52. 
Isocrates was in any way considered part of the debate. Isocrates is mentioned by two fourth-century BCE philosophers, Praxiphanes and Speusippus. Praxiphanes is reported to have written a work that depicts Plato (ó фìóoopos) as a

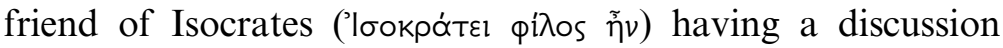
about poetry in Plato's country house, and thus thematizing the intriguing relationship between Isocrates and Plato. ${ }^{35}$ Speusippus' letter to Philip II is overtly hostile against the Isocratean school and propagandistic in favor of Plato. The context of its writing has been debated, ${ }^{36}$ but it is clear that the writer of this letter had Isocrates' To Philip in mind and, with an aim to diminish Isocrates' importance in Philip's court, also serves as good evidence for the political influence of Isocrates and his school at the end of the fourth century BCE. In other words, Isocrates was seen as a legitimate rival by Academic philosophers and we can thus infer that he had a politically appealing vision of philosophy to offer to rulers.

Scholarly evaluation of Isocrates' possible contributions to political philosophy (as to philosophy more generally) has been harsh. With regard to the later Hellenistic period, for example, Schofield argues that most of what we know of the Hellenistic discourse on kingship seems to have very little philosophical ambition and that the almost total absence of information about the contents of the works written on this topic at that period suggests 'that a Stoic or Epicurean work on kingship was not the place to look for major or distinctive statements on issues of philosophical importance, but only for variations on stock themes inherited from To Nicocles and similar writings' ${ }^{37}$ Isocrates seems to have been an important role model for those writing on kingship, and Schofield's discussion of Aristeas and Philodemus confirms this: according to him, the few sources that we do have discussing kingship show resemblance to the Isocratean To Nicocles, in that they map out the duties of a king and mention various spheres of

\footnotetext{
35 Fr. I I in Wehrli (1969), 96.

${ }^{36}$ The most recent, and persuasive, account is Natoli (2004).

37 Schofield (I999), 743.
} 
regal conduct or interest, but offer neither theoretical discussion of the different forms of government and their comparative merits, nor any defense of kingship as the best institution. Indeed, given the fact that Isocrates' works are so richly attested in papyri (in particular his To Demonicus, To Nicocles and Nicocles), ${ }^{38}$ thus indicating that he was very widely read across the Hellenistic empire, we would expect that Isocrates was influential for Hellenistic thinking about monarchy. However, while we see that he was read, our scarce evidence from that period does not indicate that Isocrates had also inspired theoretical engagement with political philosophy. ${ }^{39}$

Given the extremely volatile political environment after Alexander and the emergence of rather unstable Hellenistic kingdoms, ${ }^{40}$ it is perhaps not altogether surprising that the works of Isocrates (and especially those with a focus on kingship, like To Nicocles) would find particularly wide readership. What exactly were the contexts in which Isocrates was read and whether or how it translated to other aspects of the sociocultural milieu in the Hellenistic world, is very hard to tell. It is tempting to think that Isocrates' appeal rested in his advocacy of panhellenic unity that was based on a mobile understanding of education: through paideia, everybody could become cultured Greeks, and therefore members of the elite. But it is also possible that due to his wide appeal on a pedagogic and ideological level, Isocrates was read in some quarters as a paradigm for prose writing and, as a consequence, that his style of writing may have been imitated in schools. If so, this would explain the fierce opposition we see in later literary critics and rhetorical theorists to the influence of Isocrates. Even though his style of writing (and philosophy) was never intended as a sample of public speech, he seems to have found

${ }^{38}$ See here the extremely valuable collection of Isocrates' papyri with commentaries in Adorno et al. (2008).

39 For a recent interesting contribution to Isocrates' influence on Hellenistic and Roman writers, in particular on the importance of Isocrates' shaping of Athenian ideology, see Canevaro and Gray (2018).

40 Walbank (I98I), chap. 2. 
followers and imitators precisely in those quarters. The result was probably pretentious prose that was looked down upon by later teachers of rhetoric and philosophy.

\subsection{Ps. Demetrius on Lysias and Isocrates}

Before we come to the first-century BCE criticism, there is one final important source for the reception of Lysias and Isocrates to discuss - Pseudo-Demetrius. The general and growing consensus about Ps. Demetrius' On Style is that it was written sometime in the second or the first century BCE, thus preceding Dionysius of Halicarnassus, ${ }^{4 \mathrm{I}}$ and that it presents us with a unique resource for post-Aristotelian stylistic criticism and rhetoric. Scholars have already paid attention to the similarities of various linguistic theories in the works of Dionysius and Ps. Demetrius, ${ }^{42}$ but there has not been comparable interest in looking at their use of rhetoricians. Both Lysias and Isocrates have a place in this work and in both cases Ps. Demetrius' discussion sheds valuable light on the critical ideas about these writers that were probably floating around between the fourth and first centuries BCE. It is important to bear in mind that when Ps. Demetrius uses ancient authors as examples of certain styles, he does not divide the styles between the writers, as we will see in Dionysius of Halicarnassus, but instead draws examples for one particular style from a variety of different authors. Ancient authors, in Ps. Demetrius' conception, rarely write in only one style, but often display features of a variety of different modes of writing.

\section{Ps. Demetrius on Lysias}

Ps. Demetrius mentions Lysias explicitly in three passages: first, in the introduction to the elegant style and charm

4I Chiron (2002); de Jonge (2008), 40; Innes (I 995), 3 I 2-2 I. Of recent commentators, Marini (2007) is an exception and argues for a date in the first century BCE. Her arguments have been contested, persuasively in my view, by de Jonge (2009).

${ }^{42}$ See especially de Jonge (2008), who points throughout his discussion to similarities and differences between Ps. Demetrius' and Dionysius' views of language and composition. 
(xópls, §I28), second in relation to plain style (§I90), and thirdly in the discussion about wit (\$262). I will briefly review these references in more detail.

Paragraphs I28-89 of Ps. Demetrius' On Style tackle the elegant ( $\gamma \lambda \alpha$ qupós) style, which he describes as speech with

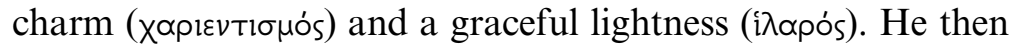
continues the discussion by referring explicitly to charm (xópls), rather than the elegant ( $\gamma \lambda \alpha$ pupós) style, and goes on to divide $x$ ópıs into two larger categories: the poetic $x \alpha$ óp,

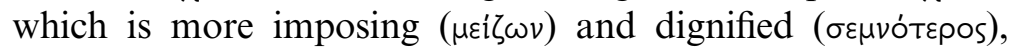
and a more ordinary xópls, which is closer to comedy and resembles jests $(\sigma \kappa \tilde{\omega} \mu \mu \alpha) .{ }^{43}$ Lysias is evoked as an example of the latter kind and Ps. Demetrius quotes a few examples from Lysias to illustrate the 'comic' $x$ '́pis. ${ }^{44}$ The critic is eager to pin down further what he means by xápls and distinguishes

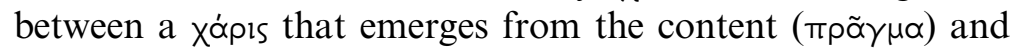
that which results from style ( $\lambda \dot{\varepsilon} \xi 1 \varsigma)$. The examples of the content that give rise to xópıs are marriage songs and 'everything

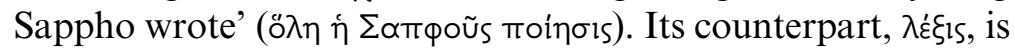
expressed less explicitly. The examples seem to suggest that there are two kinds of stylistic devices an author can use to create charm: first, personification (I33), and secondly, the use of contrasting tone, so as to add a lighter pitch to an otherwise gloomy topic (I34). Ps. Demetrius considers the latter to be the

43 Grube (I96I), 52-6 suggests that the notion of Xópis might connect Ps. Demetrius with Demetrius of Phaleron, who, according to Diogenes of Laertius, had written

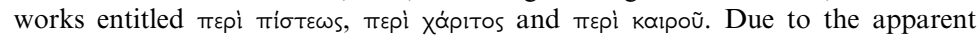
overlap of critical terminology it is quite plausible indeed that these critics might have been relatively close in time. The actual dating of Ps. Demetrius is not really essential for my argument, for most recent discussions indicate that Ps. Demetrius is best understood as having participated in the critical context in which Dionysius' essays were written, whether belonging chronologically to the literary culture before Dionysius and thus illustrating the preceding ideas to which we see him responding, or showing a contemporary perspective on the ideas that were also formative for Dionysius - in both cases Ps. Demetrius provides a useful perspective against which to evaluate Dionysius' essays and contributions to rhetorical theory and criticism.

44 One of the examples quoted here is also evoked, with minor changes, in the later

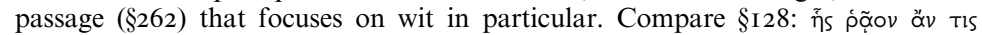

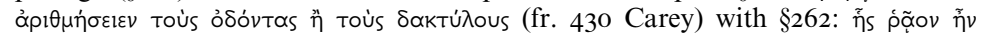

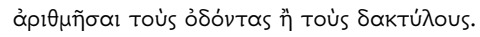




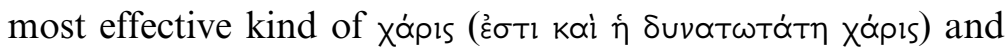
one which most depends on the writer ( $\left.\mu \alpha \dot{\alpha} \lambda_{1 \sigma \tau \alpha} \varepsilon \dot{\varepsilon} \nu \tilde{\omega} \lambda \lambda^{\prime} \gamma \sigma \nu \tau \imath\right)$, for it requires skill to demonstrate that in a topic 'hostile to

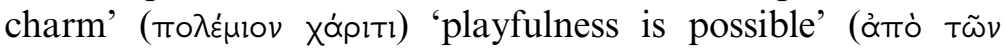

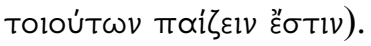

Within Ps. Demetrius' discussion of xápls, Lysias' writings seem to belong to the type of xópis that is created through style rather than the subject matter (as in Sappho). Even though it is never spelled out explicitly, Lysias might also be counted among those writers whom Ps. Demetrius praises for being able to create a lighter tone in somber topics (the example he uses is drawn from Homer), for even with all the seriousness of the forensic genre, Lysias' speeches also demonstrate that it tolerates some lightness and wit. Ps. Demetrius, having categorized the various usages of xópls in literary criticism, goes on to dedicate most of the discussion of the elegant style to schematizing ways in which xápis can be created in literature. What is curious, however, is that despite having initially introduced Lysias among the first authors in the context of xópis, Lysias is not mentioned in any of the following examination of different kinds of xápıs. He simply seems to prefer to use Xenophon and Plato (for prose), Sappho (for lyric poetry) and Sophron and Aristophanes (for mime and comedy). It might be, but this is difficult to say with more certainty, that Ps. Demetrius' tepid interest in Lysias reflects the contemporary perception of the importance of this orator for literary criticism and rhetoric, where he was popular enough to be mentioned briefly as an example of xópls, but had not yet become as securely connected with the 'canon' of classical writers or as exclusively associated with xópis as we see in Dionysius below.

In §igo Ps. Demetrius briefly quotes an example from Lysias' speech On the Murder of Eratosthenes (Lysias I), but does not discuss the speechwriter again in the context of plain style. His examples of plain style are taken from Homer, Xenophon and Plato. Lysias is mentioned one more time, in $\$ 262$, where he discusses how an element of playfulness, otherwise associated with the elegant style, can actually contribute 
to the forceful style. The example Ps. Demetrius uses is the same he used in the first Lysias passage when he discussed the elegant style. In itself this is not surprising, for the playful element that Ps. Demetrius is concerned with here is the same he was discussing in the context of elegant style earlier. Overall, despite the fact that Lysias plays a minor role in Ps. Demetrius' work, we can nevertheless glean from his discussion, however brief, that Lysias is associated primarily with wit and simplicity. Given the influence of Lysias on later literary criticism and in particular for his influence on plain style, it is important to notice that the speechwriter's own charm was probably not much appreciated in the centuries before the first century BCE.

\section{Ps. Demetrius on Isocrates}

Ps. Demetrius serves as a valuable intermediary source also for the reception of Isocrates, who is mentioned explicitly in four passages: ${ }^{45}$

I In §I 2, when he discusses two different kinds of period, he refers to

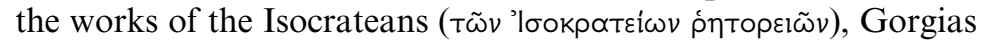
and Alcidamas as examples for the compacted style (

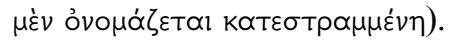

45 Ps. Demetrius' lack of interest in Lysias and Isocrates is apparent when the few references made to these orators are compared to the number of instances where Plato and Aristotle are discussed in the work. Overall, Ps. Demetrius explicitly evokes Plato seventeen and Aristotle twenty-one times in On Style. Passages from Plato are used to exemplify many different stylistic features throughout the spectrum of the different styles (Plato is referred to in $\$ 5, \S 37, \S 5 \mathrm{I}, \S 56, \S 80, \S \mathrm{I} 8 \mathrm{I}, \S_{\mathrm{I}} 83$, §205, §2 I 8, §228, §234, §266, §288 (twice), §290 (twice), §297). Ps. Demetrius refers to his Republic (5.2, 205.2), Phaedo (288.I), Protagoras (2 I 8.I), Menexenus (266.I), and apparently also to the Platonic letters $(228.5,234.5)$ which he seems to consider, along with Aristotle's, as the best examples of the epistolary genre. In addition to using Aristotle as an example for style (especially in chapters on letter writing, \$\$223-35), Aristotle is also used in On Style to systematize and structure the work as a whole (Ps. Demetrius refers to Aristotle explicitly in §I I, §28, §29, §34,

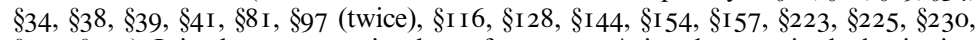
$\$ 233, \S 234)$. It is, thus, no surprise that references to Aristotle occur in the beginning of a theme (e.g. in $\$ 38$ which starts the topic of 'grand style') or throughout to guide the discussion and focus it on specific points (e.g. in §I I when defining the period). Thus, Plato and Aristotle are used as theoretical guidelines to good stylistic writing, and are regarded as practical models for students. 
2 In $\$ 29$, which focuses on assonance and brings as examples the antitheses of Isocrates and Gorgias, who make use of assonance for imposing grandeur on the composition.

3 In $\S 68$, where he discusses an element otherwise considered as the trademark of Isocratean prose, the avoidance of hiatus. He claims that there are two extremes, Isocrates and his followers who avoid

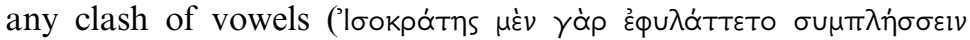

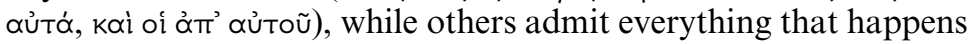

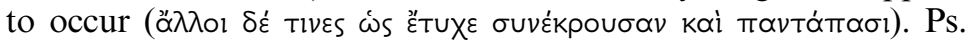
Demetrius advises his reader, in an unsurprising move coming from a Peripatetic sympathizer, to follow the middle way.

4 Hiatus is also the reason Isocrates is mentioned once more in this work. In \$299 Ps. Demetrius claims that 'smoothness of composition, of the kind particularly used by the Isocrateans (oi 'a $\pi^{\prime}$ 'lookpótous), who avoid any clash of vowels, is not well suited to

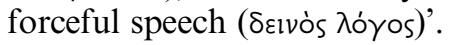

What is perhaps striking in Ps. Demetrius' discussion of Isocrates in On Style is that he is often mentioned either as a member of a stylistic movement/trend (together with Gorgias and Alcidamas) or associated with a group of followers, the Isocrateans. This group will be discussed in more detail in the following chapter on Philodemus, who refers to them relatively frequently. Compared to Philodemus, their presence is clearly less marked in Ps. Demetrius, but these few instances in On Style suggest that Isocrates seems to have had devoted and vocal followers, whether the author has in mind immediate students of Isocrates or later followers who identified themselves as the 'Isocrateans'. ${ }^{46}$ Ps. Demetrius' use of Isocrates also suggests that, whatever his reception in philosophical circles, Isocrates also accumulated following, either for his general style or its specific features (hiatus, sentence structure), in stylistic and rhetorical circles.

Overall, despite the fact that Ps. Demetrius has clearly only lukewarm interest in Lysias and Isocrates, On Style nevertheless casts an interesting perspective on the two writers. For the first time we see Lysias associated in a programmatic work on

${ }^{46}$ I do not think we can tell from the way Ps. Demetrius discusses the 'Isocrateans' whether he has Isocrates' pupils and contemporaries or later followers in mind, or indeed both. 
rhetorical style with plain style, charm and wit, and Isocrates linked strongly to literary stylists, showing that his writings were probably increasingly used, at least in some quarters, as examples of an oratorical style to be imitated. Aside from the reception of Lysias and Isocrates, however, Ps. Demetrius' use of critical terminology - as we will see in the following chapter - is very close to that of Dionysius of Halicarnassus. ${ }^{47}$

\subsection{The Reception of Lysias and Isocrates in Cicero and Philodemus}

Philodemus and Cicero were both prolific writers whose works reveal a great deal about their intellectual environment and enable us to access sources not otherwise available to us. They were both active around the same time (from early to mid first century BCE) and we know that Cicero was at least familiar with Philodemus' works as he alludes to him in his In Pisonem (70). ${ }^{48}$ Despite Philodemus' Epicureanism, which Cicero opposes, he receives a more positive treatment from Cicero for his engagement with rhetoric, a topic otherwise spurned by the 'orthodox' Epicureans. ${ }^{49}$ The following discussion will be focused strictly on the treatment of Lysias and Isocrates in the context of their works. We will be looking mainly at Philodemus' On Rhetoric and Cicero's Orator, Brutus and De oratore..$^{50}$

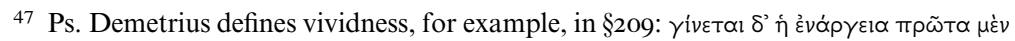

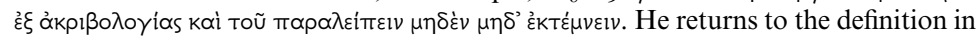

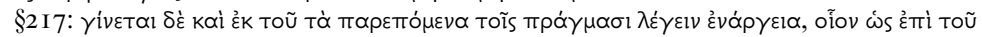

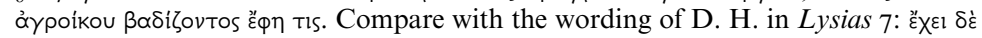

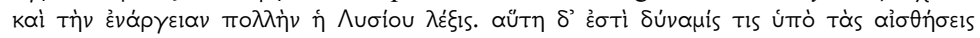

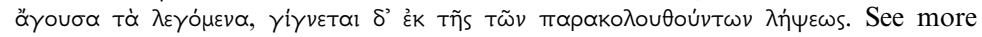
below in next chapter.

${ }^{48}$ Gigante (I995), 29-38 more generally on Cicero and Philodemus. Gaines (200I) puts forth an interesting argument in favor of seeing a close intellectual connection between Cicero and Philodemus; Wisse (200I) is, however, more convincing in his reply and cautions us about some of the details of Gaines' suggestion.

49 Cf. Griffin (200I), 96 for caveats in reading too much into Cicero's praise of Philodemus. A celebrated treatment of the Epicurean attitudes to politics is Momigliano (I94I). More recent accounts are Roskam (2007) and Fish (20II).

5o The Rhetoric is one of the best preserved and most secure texts of Philodemus, and the standard critical edition is still Sudhaus (I896). Dorandi (I990) is a helpful 


\section{Philodemus and Isocrates}

Despite making several references to Isocrates, Philodemus' On Rhetoric and the role of Isocrates in that work have not elicited much scholarly discussion. ${ }^{51}$ The most extensive and by now almost canonical treatment of this topic is an article by Hubbell from I9I6, which argues that there was something of an 'Isocratean revival' in early first-century BCE philosophy and criticism and that Philodemus' numerous references to Isocrates in On Rhetoric are critically replying to this newly found fascination for the orator. ${ }^{52}$ In Hubbell's thesis, Isocrates is treated by Philodemus as a stylist and an exponent of sophistical rhetoric (more on this term below), a field that according to the Epicurean is incapable of preparing the young for a successful career in public and private life. Hence, studying Isocrates is a waste of time for those interested in such matters. This interpretation has provided the backbone of most (if not all) scholarly approaches to this topic: Isocrates is exclusively viewed as a stylist whose influence - Philodemus allegedly argues - on education is (or ought to be) negligible. There are, however, some problems with this interpretation. First, there is a question about sophistic rhetoric as an only rhetorical art form, and second, Hubbell may not be representing the popularity of Isocratean works and education adequately so that a better understanding of the context might also shed new light on the complicated textual fragments.

overview of the potential content of the individual books of the Rhetoric and the distribution of papyri within the books. There are several relatively recent discussions on new papyri, individual rolls and interpretations of specific passages of the Rhetoric (e.g. Erbì (20I2) with bibliography), without challenging the broad outline of the work explained by Dorandi (I990) or the text as established by Sudhaus (I896).

5I The following section has greatly benefited from conversations with David Blank and I'm extremely grateful for his patience and generosity with which he endured my cross-examination on Philodemus' possible engagement with Isocrates and Aristotle. All remaining errors are mine only.

${ }^{52}$ Hubbell's central thesis has been further elaborated, but not substantially challenged, by Indelli (I994) and Di Matteo (I997). In Philodemus' other works, Isocrates is mentioned as an influence on Andromenides in his On Poems I. See Janko (2000), I48-5I. Andromenides was, according to Janko, most probably a Peripatetic even though he appears to have been influenced by Isocrates ( $\mathrm{F}$ I8 of Andromenides is allegedly taken from Isocrates' Panegyricus Io). 
Let us first start, however, with laying down some groundwork of what we know about rhetoric among the Epicureans and in Philodemus in particular.

According to the Epicurean tradition, the philosopher should avoid getting involved with public life, and thus also with the study of rhetoric for the purposes of public life. ${ }^{53}$ Epicurus' own relationship to rhetoric is open to speculation, ${ }^{54}$ though it is clear from Philodemus that some Epicureans regarded rhetorical training to be beneficial for the philosopher 'as an aid to literary composition'. ${ }^{55}$ Epicurean rhetoric has sometimes been divided into three separate categories, sophistical (бофıбтıкท́), rhetorical or judicial (

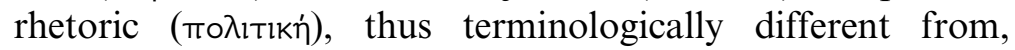
though thematically similar to, the tripartite Aristotelian division into epideictic, forensic and deliberative rhetoric. ${ }^{56}$ A closer examination of Philodemus' Rhetoric makes this claim unsustainable: Philodemus does not think that rhetoric can be meaningfully divided into three genres. ${ }^{57}$ Instead, we ought to regard these three categories as differences in 'rhetorical speaking' and not strictly as three separate genres of rhetoric. ${ }^{58}$ The more fundamental difference emerges rather between art and non-art, between the goals of the types of rhetorical speaking (i.e. persuasion or instruction).

Whatever the disagreements otherwise, most critics agree that Philodemus treats only sophistical rhetoric as an art, ${ }^{59}$

53 On Epicurean views of politics, see for example Scholz (I998), 25 I-3 I4 and Brown (2009) with further bibliography.

54 DeWitt (I954), 47 goes as far as to suggest that Epicurus himself might have been a teacher of rhetoric.

55 Hubbell (I9I6), 4II.

${ }^{56}$ Hubbell (I9I6), 409. It is not entirely clear from Hubbell's discussion what is exactly the distinction between the Aristotelian and Epicurean scheme of three types of rhetoric. Hubbell seems to treat it as a mere difference in terminology rather than content, and translates the Epicurean terms back into the more familiar Aristotelian ones (e.g. in sentences like 'бофıбтn's means an epideictic orator', 409).

57 For example, Rhet. IIa, PHerc. I674 col. $58.8 \mathrm{ff} . \quad 5^{8}$ Gaines (2003).

59 Philodemus himself records (in Books I and 2 of the Rhetoric) the various (and fierce) disagreements on this topic among the Epicureans themselves, all of whom draw their arguments from first-generation Epicureans. Philodemus' argument against Epicurean opponents teaching in Cos and Rhodes is detailed in IIb, PHerc I672. 
for it is the only form of rhetoric that is following certain principles of composition which apply to the majority of cases, and which produces 'a result that is beyond the power of those who have not studied it'. ${ }^{60}$ In the first book of the Rhetoric, Philodemus says that 'sophistic rhetoric is an art ( $\tau \varepsilon \times \chi \eta)$ concerned with display pieces ( $\left.\varepsilon_{\pi} \_\varepsilon i \xi \varepsilon 1 \zeta\right)$ ' (Sudhaus I: I 22.29). In other words, sophistic rhetoric seems rather similar to what we would call (after Aristotle) epideictic oratory. For Epicureans it is the only form of rhetoric that is a proper $\tau \dot{\varepsilon} \times \nu \eta$ and thus the only kind of rhetoric that could be actually studied. Both judicial and political rhetoric are used in the context of politics and they both depend mostly on practice and experience. ${ }^{61}$ Hence, since neither of the two is based on general rules that we can all have access to, they cannot be studied. Indeed, Philodemus argues that the ability 'to speak in assembly and court comes from practice and observation of political events' (Sudhaus I:I2 I XXI.35-XXII.7). ${ }^{62}$ In other words, these two categories, 'artistic' rhetoric and 'political' rhetoric, do not overlap in their usage or practice, because they have fundamentally different structures and different goals. Hence, an aspiring politician or public figure should not be advised to attend a rhetorical school, for example, because it will only educate him in the art of sophistical rhetoric which encompasses (what some might call) philosophy, literature, composition and language. The rhetorical schools will not, however, be able to prepare the young for 'real life' debates and affairs in politics. $^{63}$

It is less clear what exactly is the proper domain relevant to sophistic rhetoric. Given that it requires a grasp of some set of

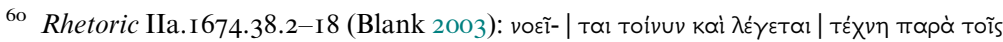

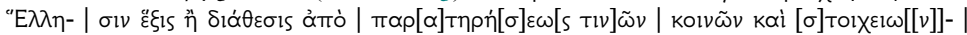

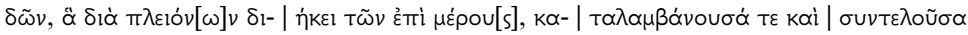

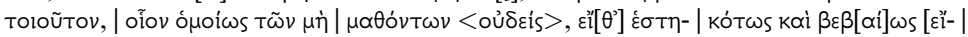

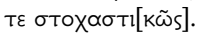

6I Gaines (2003), 2I7 with further discussion.

${ }^{62}$ Unfortunately I have not been able to access Federica Nicolardi's new 2018 edition of the first Book of the Rhetoric (covering Sudhaus I: I-I2).

${ }^{63}$ Hubbell is assuming that this is the entire ambition of an Isocratean school, that is to produce politicians and public speakers. 
general principles related to thought and composition, and given that it seems to be understood primarily in connection with praise and blame, ${ }^{64}$ it is possible that we ought to think here beyond simple display speeches and instead consider the possibility that the associated discipline we should be thinking of is philosophy. ${ }^{65}$ This suggestion is strengthened by the fact that Philodemus himself had apparently composed a book on praise, ${ }^{66}$ though we do not know more about the content of this work. Whatever the implications of this possibility for Epicurean philosophy, it is surely true that a somewhat more positive evaluation of sophistic rhetoric in the context of philosophy might also cast a different light on Philodemus' treatment of Isocrates, who seems to be explicitly associated with sophistic rhetoric and is mentioned several times throughout the work.

Philodemus argues, for example, that Isocrates' works reveal themselves to have been composed 'not without method' (oủ- $\mid k$ ả $\mu \varepsilon] \theta o ́ \delta \omega \varsigma$ ), ${ }^{67}$ and that he must have possessed some kind of knowledge even though he himself denies it. ${ }^{68}$

${ }^{64}$ Sudhaus I:2 I7 and I:2I3-I4.

${ }^{65}$ Gaines (2003), 2 I 7. The same is carefully suggested by Blank (2009), 233.

${ }^{66}$ Sudhaus I:2 I9.

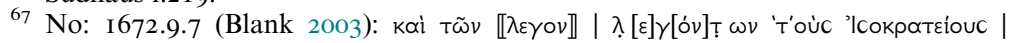

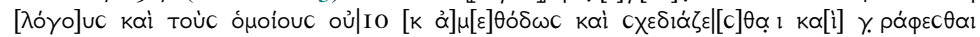

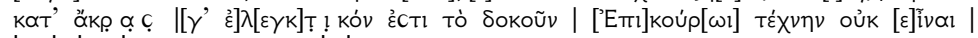

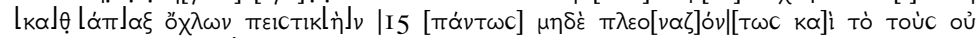

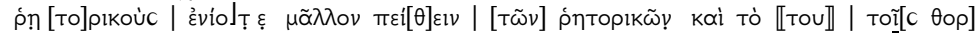

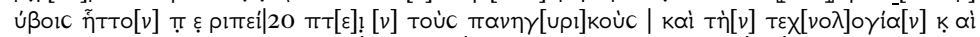

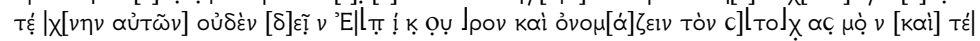
$25[x v \eta v]$. Cf. Sudhaus I.I27 XXVII.23, which seems to express a similar idea.

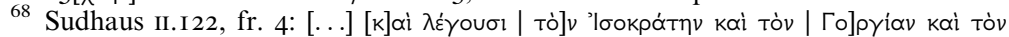

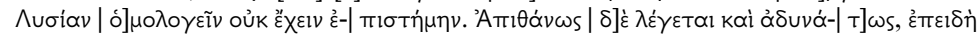

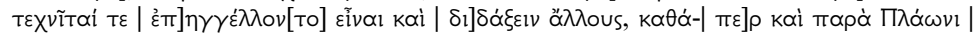

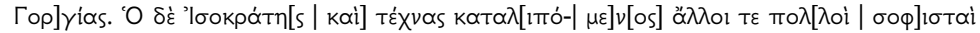

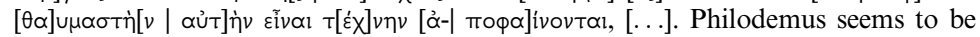
talking here of knowledge in a different sense (i.e. knowledge of composition and methods of writing) than what Isocrates had claimed in the Antidosis (I85) not to possess (i.e. detailed knowledge of things in the world, especially those that end up being of little relevance to actual everyday life). It is also interesting that Philodemus claims Isocrates wrote technical treatises. This is a very controversial claim and it was argued above that it is indeed very unlikely that Isocrates would have written technical treatises on rhetoric or philosophy, at least in his mature period. It may be possible that he wrote technical treatises around the same time he was active as a logographos. 
Isocrates is hence understood as a practitioner of sophistic rhetoric and he is in some passages also explicitly called a sophist, contrasted to orators and statesmen like Pericles, Demosthenes and Lycurgus (Sudhaus II.97.Io and II.233. I I). Here we need to bear in mind that the term 'sophists' may have had a somewhat broader application for Epicureans and Stoics than simply evoking the group of fifth-century intellectuals we know from Plato. Indeed, for Epicureans sophists are any kind of intellectual opponents, both within and outside the Garden. ${ }^{69}$ They are therefore credited with philosophically challenging arguments, which might nevertheless be (and mostly are) wrong and have to be refuted. However, sophists are philosophical opponents to Epicureans and as such associated with things more important than mere oratory. Isocrates is referred to as a sophist in just these circumstances and contrasted in a few passages to representatives of other philosophical schools.

In the fourth book of the Rhetoric (Sudhaus I.I47-8 Col. II), for example, Philodemus appears to say that the term 'philosophy' used in Isocratean discourses denotes a broader sense of intellectual pursuit, and as such stands in contrast to the narrower practice of philosophy we find among the Peripatetics and the Stoics. ${ }^{70}$ Furthermore, when discussing

${ }^{69}$ Diogenes Laertius I0.26 refers to disagreements among Epicureans, where some (Epicureans) are called sophists by 'true Epicureans'. See also Long (2018), who persuasively argues for a more sophisticated influence of sophistic thought on Epicurean political philosophy than thus far granted.

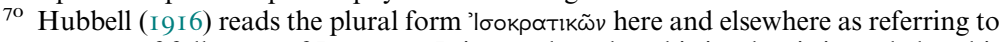
a group of followers of Isocrates. It is not clear that this is what is intended and it also overtly contradicts a passage elsewhere in Philodemus (Sudhaus I.I53.I4), where he says that either no one at all or two or three were disposed in a similar

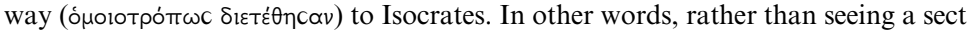
of Isocrateans suddenly emerging and occupying an important place in Philodemus' discussion, I think it is safer to assume that plural forms refer to the works of Isocrates, that he had been treated as an authority on questions of educational aspects of philosophy and rhetoric continuously since the fourth century BCE and as such is an expected personality to be discussed by Philodemus on the topic. I want to thank Stephen Halliwell for his helpful suggestions about Philodemus and the supposed 'Isocrateans' and David Blank for his insights on the matter.

The idea that the term 'philosophy' has gotten too narrow in philosophical schools has found support also in later writers, who were on the fringe of 
the famous anecdote about how Aristotle got involved with rhetoric (as a response to Isocrates, whose dominance in the field he wanted to crush), Philodemus comments that unlike Aristotle who stooped down from philosophy to rhetoric, Isocrates at least moved on to things more important and

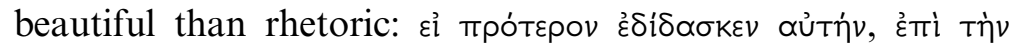

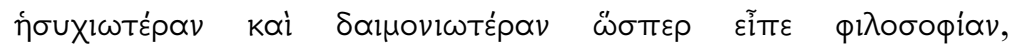

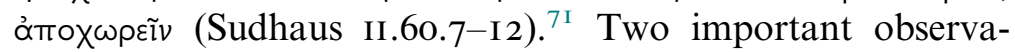
tions are in order. First, even though one might get the sense from this and other references to Isocrates that the latter might have been recognized by Philodemus (and perhaps also by some other Epicureans) as a philosopher, we should approach such suggestions with caution. Isocrates never was a 'proper' philosopher in Epicurean/Philodemean terms and thus remains an opponent (and a sophist) to true Epicureans. However, he is contrasted here positively to Aristotle and hence regarded as someone who possessed an art and had some business with philosophy and someone who might have had at least the good intuition of recognizing philosophy (even

philosophy and rhetoric. See, for example, Cicero (De oratore III. 6o) and the notion of 'true philosophy' in D. H.'s Isocrates.

${ }^{71}$ See also Di Matteo (1997). In Blank (2003) the new version of this text section attributes this line as referring to Aristotle: 'If he taught rhetoric before, he could later retire to philosophy, which he called "more peaceful" and "more divine" (30).

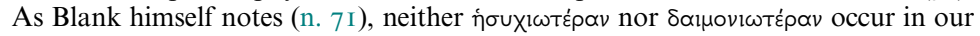
extant corpus of Aristotle, though it might have (as Blank suggests) have been used in the Protrepticus. In this form, they do not seem to appear in Isocrates either. In our conversation, David Blank has pointed out to me that the following section of the text seems to refer to Aristotle (as subject) and that it would on this ground make more sense to make him also the subject of the sentence under question. This is a difficult matter to decide and as far as I can see at the moment (without having had the opportunity to look at the fragment), Isocrates may still be referred to here for two reasons. First, Isocrates narrates himself the way he has come to write his philosophical works and seems to suggest in some of his narratives that he has progressed into philosophical activity and has explicitly stayed away from the political or overtly oratorical activity. We do not find such direct engagement with this topic in Aristotle. Secondly, as suggested below, I think Plato's Phaedrus might have been an important influence on, and authority for, Philodemus' apparent preference for Isocrates (and the narrative of his progressing to philosophy) over Aristotle. I hasten to say that this means nothing about Philodemus' views of Isocrates and I do not think that Isocrates would qualify for Philodemus as a philosopher. However, it might have been sweet for Philodemus to criticize Aristotle (with the use of his former teacher Plato) by suggesting that even his most fierce enemy, Isocrates, was more philosophical than Aristotle. 
if this was not the true Epicurean philosophy)..$^{72}$ Perhaps the most plausible and least committed reading of this section would be something like this: Philodemus really focuses here on attacking Aristotle and for that, it was convenient to use Isocrates, who had been cast in the history of the philosophical and rhetorical tradition as his fiercest opponent, as more philosophical than Aristotle. The emphasis, therefore, was probably not on Isocrates being a philosopher, but rather that Aristotle was so non-philosophical that even Isocrates was more of a philosopher than Aristotle. Secondly, it is very plausible that a comparison involving Isocrates with another intellectual and philosopher (here Aristotle) that concludes favorably to the former is explicitly drawing on the final part of Plato's Phaedrus. This complements well the previous reading: even though recognizing that Isocrates was not a 'proper' philosopher, he does linger at the fringes of the philosophical tradition and thus has 'some' philosophy and there is 'some' merit to his works. Predicting his progress to philosophy, as Socrates does in the Phaedrus, seems to have become a particularly poignant aspect in the reception of Isocrates. Hence, it is rather plausible that Philodemus is drawing, rather cleverly, on the authority of Plato's Phaedrus to play the figure of Isocrates (as more consistently committed to philosophy) against Aristotle who is attacked fiercely throughout the book. This may mean many different things, but perhaps most

72 That much is granted also by Sudhaus (I893), 56I ('Philodem erkennt ihn [Isocrates] ausdrücklich als Philosophen an') whose authoritative description of this passage has remained instrumental for later evaluations of Isocrates' treatment by Epicureans. Sudhaus' argument is taken over and elaborated, for example, in Hubbell (I9I6), 407-8. They both argue that Isocrates receives a devastating assessment by Philodemus, because by denying sophistic rhetoric legitimate application in the political sphere, Isocrates' ambitions to educate future political leaders are demonstrated to have been fundamentally false. Isocrates might have disagreed with the assumption lurking behind Hubbell and Sudhaus, namely that his school prepared young people only for a political career, and would have probably argued that he trained his students for a variety of careers, or more precisely, for the kinds of careers they were best fitted for. This all does not mean, of course, that Philodemus did not criticize Isocrates. For the purposes of my argument, however, I only want to highlight that Philodemus seems to have considered Isocrates relevant as a philosopher of rhetoric and education and not simply a stylist and prose writer, as Hubbell in particular seems to insist. 
importantly for the present discussion this passage indicates that - unsurprisingly - Plato's Phaedrus has remained an important reference text for conversations about the true meaning and application of rhetoric. Furthermore, the Platonic image of Isocrates who is progressing to philosophy and thus has more relevant contributions to make to rhetoric and philosophy is emerging from those much later accounts of Isocrates, thus maintaining a continuity of his presence in philosophical conversations about philosophical and rhetorical education.

While Hubbell suggests that Philodemus' engagement with Isocrates indicates a resurgence of his importance in the first century BCE, we have thus far seen that Isocrates' presence in Hellenistic education seems to have been ubiquitous. It is of course true that we have lacunose evidence of rhetorical theory from the Hellenistic period and cannot say much with certainty about the importance and relevance of Isocrates' work for the more theoretical engagements with philosophy and rhetoric in that period. However, the abundance of Isocratean papyri from Hellenistic Egypt strongly bolster the possibility that he was widely read, if not highly inspirational for theorists and philosophers, in the periods leading up to his explicit emergence in rhetorical criticism in the first century BCE. Even though Isocrates was surely not a mainstream thinker to be discussed in philosophical schools in the context of metaphysics or epistemology, it is likely that he demanded attention in the context of rhetoric and education more generally. If that is true, then Philodemus (and other Epicureans) are not simply grappling with a new emerging group of Isocrateans, but rather engaging with an important authority on the question of rhetoric and its function in philosophical education.

\section{Cicero and Isocrates}

On the Roman side of the debate we find Cicero, who has already been mentioned as a possible supporter of some of Isocrates' views and their appeal for a broader understanding 
of philosophy. Cicero's interest in and use of Isocrates as a source for his own philosophical/rhetorical program has proven to be a difficult topic to tackle because, despite several apparent thematic affinities in their work and Cicero's occasional praise of Isocrates as a master and teacher of eloquence, Cicero's works contain very few direct indications or explicit statements that he was drawing in any substantial way on Isocrates' philosophy. ${ }^{73}$ This has led scholars to suppose that the praise of Isocrates in some passages of Cicero's work is intended to evoke Cicero's debt to Isocrates as his model of style and prose writing. ${ }^{74}$ Laughton and Weische have rightly drawn attention to the fact that in passages where Cicero mentions Isocrates, his writings and style are not really admired as models for 'real' (courtroom) oratory. ${ }^{75}$ Instead, Isocrates is primarily revered as a teacher (magister) of rhetoric or educator of aspiring public intellectuals. ${ }^{76}$ Indeed, the idea of merging rhetoric and philosophy into one mutually supportive discipline seems to characterize, in a very broad sense, the preoccupations and intellectual program of both Cicero and Isocrates. Cicero's De oratore (but also his De republica), a work inspired (in his own words) by Aristotle and Isocrates, ${ }^{77}$ is perhaps one of the most ambitious

${ }^{73}$ Cf. Solmsen (I94Ia) and (I94Ib) for a critical assessment of our abilities to conclude anything more certain about the Isocratean tradition of rhetoric.

74 E.g. Jebb (I876a), 73, Sandys (I885), xxii, Blass (I892), 2I2-I3. Hubbell (I9I3), I 7-40 collects and discusses the passages where Cicero mentions Isocrates. Hubbell's work is also one of the first attempts to look at the Isocratean influence in Cicero's thought rather than style.

75 Laughton (I96I), Weische (I972), I65. In one instance, Cicero explicitly claims to have written a work in Isocratean style: Cicero writes to Atticus that he had written a commentary (commentarium) in Isocratean style (i.e. using his 'perfume-box') mixed with some Aristotelian features (Letter to Atticus II.I.I). The context seems to suggest, as Laughton argues, that Cicero emphasizes this aspect precisely because of the uniqueness of the composition rather than reflecting on his usual writing practices. Posidonius was apparently so put off by this style of writing that he did not want to write on the same subject himself.

${ }^{76}$ E.g. in De oratore II.Io where Isocrates is referred to as pater eloquentiae (also III.59), or later in Brutus (32) where the Isocratean school came to be regarded as the house of eloquence of all Greece. This last idea is also repeated in Orator (42).

77 Ad familiares I.9.23. Fantham (2004), I6-I7 points out that this particular letter, written in 54 BCE just after having finished De oratore, was 'almost certainly circulated to a wider readership and serves as a political apologia'. Thus Cicero's 
examples of this endeavor. Regardless of the similarities in the broad outline of their programs, the comparison between Cicero and Isocrates falls apart as soon as one sets out to examine their works in more detail. Cicero neither acknowledges Isocrates' influence upon his philosophical thought nor does he tell us more precisely where in the outlook of his works the Isocratean inspiration might lie. I argue that this incongruity is mainly due to Cicero's own philosophical affiliation with Academic skepticism that operated with a very specific understanding of the notion of philosophy and left little room for an Isocratean broader definition of the concept, however it may have otherwise fitted Cicero's own philosophical, rhetorical and political agendas. Cicero does acknowledge the 'pre-Socratic' broad notion of philosophy, when he writes in De oratore that

is eis qui haec quae nos nunc quaerimus tractarent, agerent, docerent, cum nomine appellarentur uno quod omnis rerum optimarum cognitio atque in eis exercitatio philosophia nominaretur, hoc commune nomen eripuit, sapienterque sentiendi et ornate dicendi scientiam re cohaerentis disputationibus suis separavit. (III.60)

the people who discussed, practiced, and taught the subjects and activities we are now examining bore one and the same name (because knowledge of the most important things as well as practical involvement in them was, as a whole, called philosophy), but he robbed them of this shared title. And in his discussions he split apart the knowledge of forming wise opinions and of speaking with distinction, two things that are, in fact, tightly linked..$^{78}$

I take this passage to be, on the one hand, a reference to the general aim and ideal of Cicero's program of joining the disciplines of philosophy and rhetoric, and on the other, a reflection on the contemporary challenges to traditional interpretations of philosophy with its implications for the perception of the wise and honorable men in society. Cicero cannot go back to the fourth century BCE and ignore the way philosophy had since become institutionalized and used in the context

mention of his two influences, Aristotle and Isocrates, functioned more like an open manifesto about the philosophical and rhetorical outlook of his program.

${ }^{78}$ I follow here the translation and comments in May and Wisse (200I). 
of philosophical schools and education. Thus, whenever Cicero mentions philosophy, he is talking from the perspective of his own philosophical affiliation - Academic skepticism. The fact that Cicero is not simply a neutral historian of philosophy, but rather affiliated with, and trying to prove his importance within, a specific philosophical institution also means that on a philosophical level there remains a significant distance between him and Isocrates.

It has been noticed in scholarship before that Isocrates' importance, however great it may have been for his earlier approach to rhetoric and philosophy, seems to decrease in Cicero's later works as he becomes more and more involved with institutionalized philosophy. ${ }^{79}$ And indeed, when it comes to identifying his prime influences, Cicero says in the Orator, one of his last works dedicated to rhetoric from 46 BCE: 'I confess that whatever ability I possess as an orator comes, not from the workshops of the rhetoricians, but from the spacious grounds of the Academy. Here indeed is the field for manifold and varied debate, which was first trodden by the feet of Plato' (I 2: fateor me oratorem, si modo sim aut etiam quicumque sim, non ex rhetorum officinis, sed ex Academiae spatiis exstitisse. Illa enim sunt curricula multiplicium variorumque sermonum, in quibus Platonis primum sunt impressa vestigia). Despite the important position of Demosthenes and Isocrates in this work, ${ }^{80}$ Cicero makes it clear from the beginning that his biggest debt and intellectual affiliation remains to the Academic school. As Cicero's own admission shows, his appreciation for Isocrates requires most defense among his fellow intellectuals (Or. 40). As a stylist, Isocrates' works are not appropriate for public performance; as a philosopher he remains outside all existing respectable schools and is not part

79 Too (I995), 237 discusses one aspect of Cicero's changed approach to Isocrates and sees his increased detachment from him exemplified in the former's association of Isocrates with Gorgias. Gildenhard (2007), I 53-4 notices this change in terms of Cicero's conscious (political) move to prioritize philosophy over oratory in his later works.

${ }^{80}$ See the recent excellent analysis of this work, and the position of Isocrates and Demosthenes in particular, in Dugan (2005), chap. four. 
of the philosophical canon proper. To bolster his own confidence in relying on Isocrates for inspiration for rhetorical education and - in particular - for the idea of writing, Cicero turns to an undoubted authority: Plato's Phaedrus. ${ }^{81}$ Cicero quotes the last sections of Plato's dialogue (from 279a), where Socrates utters the famous prophecy that Isocrates will aspire, once he grows up, to greater things (than the Lysianic rhetoric), 'for nature has implanted philosophy in the man's mind' (4I: inest enim natura philosophia in huius viri mente quaedam). ${ }^{82}$ Cicero claims to be following Socrates and Plato in having a high regard for Isocrates and he argues that while the epideictic rhetoric (epidicticum genus), which Isocrates is presumably taken to represent, is not appropriate in real-life rhetoric (42), it is an important step in rhetorical education, because 'eloquence receives nourishment from this until it later takes on color and strength by itself' (42: sed quod educat huius nutrimentis eloquentia ipsa se postea colorat et roborat; cf. 37-8). Hence, while Isocrates is not to be followed and emulated by fully developed orators or statesmen, he remains an important cornerstone and signifies a particular stage in the rhetorical-philosophical education.

${ }^{81}$ With regard to the general influence of Plato's Phaedrus on Cicero, Görler (I988) argues that this dialogue is an important subtext for the first book of De oratore. It may be that one of the reasons for Cicero's particular interest in the Phaedrus at that time, i.e. in the 5OS BCE, was its subject matter - rhetoric and its relationship with philosophy. Indeed, this interest in the Phaedrus at that period seems to be paralleled, as one might expect, with the importance of Plato's Gorgias, which expresses arguments against rhetoric that elicited response from anyone seriously interested in the position of rhetoric in society. This view finds support also in Quintilian (Inst. 2.XV.29), who uses Phaedrus as a source for a positive definition of rhetoric. Phaedrus is evoked twice in Cicero's late works for its philosophical contribution: in Tusc. Disp. I.53 Cicero mentions the immortality of the soul from Socrates' palinode as an inspiration for his views on the soul expressed in $D e$ republica; in De finibus II.4 Socrates' first speech in the Phaedrus is invoked as an example for organizing and commencing a serious philosophical argument. There are several references to Phaedrus also in Cicero's Orator (I4, 39, 4I), but as I will be suggesting below, there is probably a different reason for the use of the Phaedrus in this particular work.

${ }^{82}$ Contrary to many modern critics, Cicero reads the praise in this passage literally: he reminds his readers that Plato wrote this prophecy when Isocrates was already in the middle of his career and claims that Plato, a contemporary and a critic of all rhetoricians, admires of all rhetoricians only him, Isocrates (hunc miratur unum). 
There is also the political dimension. Cicero might have found Isocrates, among others, an interesting model for the 'deep' political layer of rhetoric and oratory. Since Isocrates was himself not active as a politician, but makes it clear through his works that he exercised significant impact on Athenian politics through his teaching and discourses, he remains a fascinating example for anyone struggling to assert themselves overtly in a public and political context. Isocrates' political encomia of princes and men of power might have been particularly instructive in this context. ${ }^{83}$ Indeed, the proximity to power that this kind of writing suggests might have been particularly seductive to Cicero when banned from active political life and confined to observing and commenting on contemporary politics without being able to intervene in any other way than through his writings. ${ }^{84}$ However, since Cicero does not explicitly talk about Isocrates' influences on the political considerations of his career, these observations though attractive - are bound to remain speculative. In the end, the overwhelming sense we get from Cicero is that despite the wide appeal and attraction of Isocrates, he was strongly enough opposed among Cicero's intellectual circle as a legitimate predecessor and inspiration, that Cicero (in his careful progress in philosophical circles) did not feel confident enough to take upon himself a defense of Isocrates.

What we see, in sum, from the two important critics of the earlier part of first-century BCE Rome is that Isocrates continued to be talked about among critics and philosophers of rhetoric. Both Cicero and Philodemus speak of Isocrates in positive terms and react against critics who think either too little or too much of the rhetorician. In framing their respective views on Isocrates, they both refer back (Cicero explicitly and Philodemus implicitly) to Plato's assessment of Isocrates in

${ }^{83}$ Weische (I972), I65-6 argues that this is where Isocrates' real influence on Cicero ought to be examined. Rosillo López (2010) discusses Cicero's writing to rulers from the perspective of the loser.

${ }^{84}$ Gildenhard (2007), 5I n. I84 makes a compelling argument about how Cicero conceived writing philosophy as an active engagement with his contemporary politics. 
comparison with Lysias: Isocrates has potential for philosophy though he is not there yet. As we will see below, the Atticist movement will re-evaluate the debate about classical rhetoric and the role of Isocrates and Lysias in it. While Lysias will gain dominance for the first time after a long period of dormancy, Isocrates continues to be championed as providing a crucial theoretical axis for the interpretation and application of Greek rhetoric.

\section{Philodemus and Cicero on Lysias}

While Isocrates looms large in Philodemus' discussion of rhetoric and education, Lysias occupies by contrast a negligible position in the Rhetoric. He is mentioned only once (Sudhaus II.I22.3) alongside Gorgias and Isocrates, where Philodemus argues that all these three have a method or possess an 'art' in writing. ${ }^{85}$ Philodemus' choice of the three is intriguing, but given that the overall context of the passage is sophistic rhetoric, it is very plausible that Lysias figures in the list for his funeral oration. ${ }^{86}$ Lysias did not merit more attention as a representative of sophistic rhetoric, because other than the funeral oration he was associated neither with epideictic speeches nor with teaching or education more generally. He was a representative of courtroom oratory and, as such, not relevant for Philodemus' discussion of rhetoric as an art. The lack of further references to Lysias in Philodemus' work suggests not only that Lysias (contrary to Isocrates) was not a particularly relevant writer for Philodemus, but also that he was not prominent within the critical circle at the time when

85 In other fragmentary works of Philodemus, the name Lysias occurs in his Socratica, 5.XXII.30 (Acosta Méndez and Angeli 1992), but clearly refers to the characteristic way Socrates is depicted in Plato's dialogues communicating with his interlocutors.

${ }^{86}$ Ancient authorities regarded the 'Eroticus' in Plato's Phaedrus as a genuinely Lysianic work, though given Socrates' ruthless analysis of this speech, revealing the lack of method used by Lysias, it is rather unlikely that Philodemus would have thought of this speech as an example of artful display of sophistic rhetoric. We know that Lysias 2 (funeral oration) was a very popular speech also during the Hellenistic period and it is therefore most plausible to take the inclusion of Lysias in this list as a tribute to the popularity of that work. 
Philodemus was writing. ${ }^{87}$ As a forensic or political writer, Philodemus clearly preferred Demosthenes, who was characterized as the true proponent of political rhetoric, a rhetoric that is not an art ( argued that the image of Demosthenes was consciously shaped

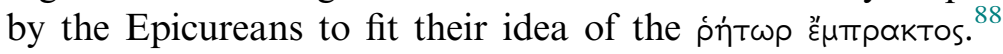
This concept was probably developed in a polemical confrontation with the Peripatetics, who had long attempted to discredit Demosthenes and downplay his skills as an excellent orator. ${ }^{89}$ Since ultimately the Epicureans were not interested in political speeches and they seem to pay attention to Isocrates as a representative of sophistic rhetoric only in so far as it is an art that might be relevant for philosophy, it also explains well why they would discard Lysias for having been relevant to neither the practical nor the theoretical domain of rhetoric that they were interested in.

Neither is Lysias a prominent figure in Cicero, at least not before the Atticist polemic explodes in critical circles sometime in the earlier part of the first century BCE..$^{\circ}$ The Atticist movement seems therefore to constitute a clear shift in the reception of Lysias. Indeed, from that moment onwards Lysias becomes once again the representative of style and of a kind of rhetoric that is concerned with (simple) style and persuasion.

Cicero might have imitated Lysias' speeches in his own early work, but due to the large number of Lysianic fragments and speeches that were probably available to Cicero, it would be in any case impossible to determine more precisely where and

${ }^{87}$ Philodemus has proven to be a valuable source for recording the views of other critics and thus for mapping the broader intellectual environment he was participating in. For Philodemus as a source for the so-called kritikoi, for example, see Schenkeveld (I968), Porter (I995) and Janko (2000), I20-89.

${ }^{88}$ Erbì (2008).

${ }^{89}$ Demosthenes seems to have been the battleground for rhetoric and politics in the first century BCE. I hope to address this topic at greater length elsewhere.

90 A good discussion of the Atticist and classicist movements is Gelzer (I979); for a more recent discussion of the beginnings of the Atticist movement in particular see Wisse (I995) and (200I). Cicero's position is persuasively discussed in Wisse (I995) who argues that the Atticist movement had essentially Roman origins. 
how Lysias was emulated. ${ }^{91}$ Cicero's later appreciation for Lysias is directly related to the trends of contemporary literary criticism and especially to the rise of the Atticists who had apparently condemned Cicero's elaborate prose, comparing it with the simple Lysianic style that reigned supreme in these circles. This provoked Cicero's response, and his discussion of Lysias in the Brutus and Orator, works which are our primary sources for the Atticist criticism, is rather polemical. Cicero is quick to praise Lysias' style, but his expressed admiration is often followed by comments or comparisons which hinder Lysias' emergence as a single and unique representative of the Attic style. In the Brutus, for example, Lysias is acclaimed as a 'writer of extraordinary refinement and elegance, whom you might almost venture to call a perfect orator' (35: egregie subtilis scriptor atque elegans, quem iam prope audeas oratorem perfectum dicere), only to be reminded in the next sentence that 'the perfect orator and the one who lacks absolutely nothing you would without hesitation name Demosthenes' (nam plane quidem perfectum et quoi nihil admodum desit Demosthenem facile dixeris). ${ }^{92}$ This passage, which continues to point out Lysias' excellent qualities, shows also Cicero's own fine compositional skill and boasts a highly rhetorical sentence structure, full of double negatives (e.g. nihil acute inveniri potuit [...] quod ille non viderit, etc.).

Perhaps the most striking analysis of Lysias' writing style follows his comparison with Cato (Brutus 63-4), where Lysias' style is described by reference to the human body: Cicero establishes first that Lysias, like Cato, is sharp (acutus), fine (elegans), witty (facetus) and brief (brevis), and then turns to his followers who 'cultivate a lean rather than a copious habit of body' (qui non tam habitus corporis opimos quam gracilitates consectentur), and admire slenderness (tenuitas ipsa delectat). Lysias' style as a whole is more of a meagre type (verum est

9I Weische (I972), I64 argues that Lysias' simple style was probably useful for Cicero in constructing specific sections of speeches (e.g. narrations or digressions), but that he was not a model that Cicero would follow consistently throughout a speech. Cf. Hubbell (I966). Though plausible, this is bound to remain a speculation.

${ }^{92}$ Cf. Orator I Io. 
certe genere toto strigosior) and his admirers delight in this slightness (qui hac ipsa eius subtilitate admodum gaudeant). ${ }^{93}$ This develops and adds another layer to the ancient reception, starting from Plato's Phaedrus, of Lysias' writings as witty, simple and persuasive. ${ }^{94}$ It is plausible that in this description Cicero's attitude to Lysias is somewhat preconditioned by the proximity of this language of Lysianic smallness and slenderness with Hellenistic literature and its emphasis on the small and fine ( $\lambda \varepsilon \pi \tau$ rós $)$ - attributes of the Callimachean poetics that Cicero viewed with contempt. ${ }^{95}$

Cicero makes two further interesting comparisons that are worth spelling out in this context. In the Brutus, Cicero points out that Lysias started out his career with (theoretical) writings on rhetoric (48: Lysiam primo profiteri solitum artem esse dicendi), but upon realizing the superiority of Theodorus, he abandoned the art (artem removisse). Cicero says he is relying in his report on Aristotle, but it must have been one of his lost works, for we do not find any such statements in Aristotle's existing corpus. ${ }^{96}$ Either way, Cicero's reliance on Aristotle shows that the latter also seems to have corroborated the view (analyzed in Chapter I) of Lysias as an 'anti-theorist' or as someone inept for abstract or theoretical thought. He makes another illuminating comparison in his Orator. when discussing the role of humor in oratory, Cicero concedes that

93 With this vocabulary of thinness and finesse, which is here associated with Lysias and contrasted to the powerful and heavy (gravis), the latter of which is presumably conceived as a characteristic of the style Cicero is trying to cultivate, Cicero seems to be trying to assimilate Lysias with the representatives of Hellenistic literature and their emphasis on the small and fine ( (I979), 28.

94 It is true, of course, that the 'Eroticus' is ruthlessly mocked for its structure and content, but even though it fails as a real philosophical argument, Phaedrus' own perception of the speech indicates that it was successful and persuasive as a piece of rhetorical or paradoxical argument.

95 On Cicero's views of Hellenistic poetry and Callimachus, see Knox (20I I). For the reception and use of Hellenistic literature in Rome more generally, see the discussions in G. O. Hutchinson (I988), 277-354, Cameron (1995), 454-83, and Hunter (2006). J. I. Porter (20II) offers an intriguing discussion of $\lambda \varepsilon \pi т$ tótns in Hellenistic aesthetics.

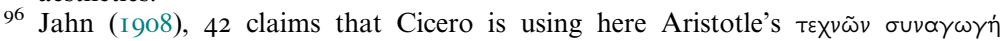
(fr. I25 Gigon). 
'whatever is witty and wholesome in speech is peculiar to the Athenian orators' (90: quoniam quicquid est salsum aut salubre in oration id proprium Atticorum est) and plays the Greek orators against each other according to this characteristic. Lysias is mentioned first as having enough of wittiness, Hyperides is judged to be equal to Lysias, but Demades as having excelled them all. Demosthenes 'is not witty so much as humorous' (non tam dicax fuit quam facetus). Cicero explains: being witty requires sharper talent (acrioris ingeni), being humorous 'greater art' (maioris artis). This statement places Cicero at the center of the $\phi u ̛ \sigma ı / \tau \varepsilon x \nu \eta$ debate that Peripatetics and Epicureans were having about the orators and Demosthenes in particular. Cicero associates Demosthenes

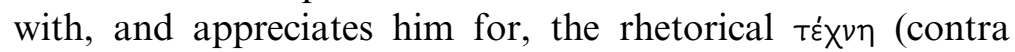
Epicureans), while Lysias is evoked as an example of talent and admired both by the Atticists and Cicero for his wit. The previous discussion on Philodemus indicated exactly the reverse: Lysias (and his funeral oration in particular) was an example of art, whereas Demosthenes was an example of talent and experience. What does that mean? Besides making comments about Attic orators, these passages also indicate that the tradition of rhetoric and its classical representatives were all conceived as useful political tools that were now being reinterpreted and used by critics and philosophers for their own different agendas. Rhetoric had thus far not developed a stabilized and solid tradition that would have fixated the interpretation of the orators in a specific framework. Indeed, Plato's Phaedrus had thus far offered some thoughts about how to think about orators and speechwriters, but the firstcentury $\mathrm{BCE}$ critics and philosophers were now eagerly starting to create that missing theoretical axis for rhetorical education that would incorporate orators and teachers of rhetoric that had become so meaningful for the subsequent constructions of Greek identity and culture.

It is clear that in the Roman context, too, more is at stake than simply the right kind of style. It is about cultural capital. When Cicero turns to discuss the Atticists' preferences, his tone is particularly critical, even if his admiration for Lysias 
is the more straightforward. In his Brutus Cicero accuses the Atticists of having willfully chosen one example, Lysias, from a variety of different and equally illustrious examples of Attic eloquence. According to Cicero, these Atticists regard meagreness, dryness and general poverty, provided it has polish, urbanity and fineness, as the characteristics of Attic style (285). Yet there are more examples of Attic writing than simply Lysias. In the Orator, Cicero argues that the Atticists champion the man who 'speaks in rough and unpolished style, provided only that he does so elegantly (eleganter) and plainly (enucleate)' (28). He questions again their grounds for considering this style the only one appropriately labeled as Attic. Cicero turns to Lysias and agrees that 'the Attic manner of speech belonged to Lysias, that most charming (venustissimus) and exquisite (politissimus) writer (who could deny it?)' (29), but adds that Lysias should not be praised for his plain and unadorned style, but rather for the fact that 'he has nothing strange (insolens) or wanting in taste (ineptus)'. This is clever and exemplifies well Cicero's general aim to demonstrate that the Atticists have not sufficiently understood their own principles and models that they advocate.

Plato's Phaedrus is explicitly present in Cicero's thinking through the rhetorical canon and his own relationship to the orators. Within the context of the Atticist controversy and having to defend his own writing, Cicero must have particularly enjoyed invoking the passage from Plato's Phaedrus, which compares Isocrates with Lysias. Despite its explicit aim to champion Isocrates as an important figure for rhetorical teaching, ${ }^{97}$ we might perhaps notice a victorious undertone in Cicero's translation of the Phaedrus (Orator 4I: 'He seems to me to possess greater talent than to be judged by the standard of Lysias' speeches'; [Isocrates] maiore mihi ingenio videtur esse quam ut cum orationibus Lysiae comparetur),

97 As far as I can tell, the ironical reading of Isocrates in the Phaedrus is not ancient. Plato's praise seems to have been understood as genuine and Cicero's own detailed discussion of that scene (Orator 4I-2) indicates that we can set aside as irrelevant for the time being the possibility that Plato might have been ironical in his comment on Isocrates.

I 74 
which enables him to appeal to Plato as an authority for his praise of Isocrates and, implicitly, for his lower regard of Lysias. It also seems to work particularly well for Cicero that Lysias, the model for plain Attic style, had apparently also been an inspiration for Hegesias of Magnesia, the 'chief' representative of the Asianist style, who was deeply despised by the Atticists. Cicero does not miss the opportunity to point this out in his Orator (226), as if to suggest that following one extreme (the Lysianic plain style) might inevitably lead to advocating the other extreme (the Asianist style). Cicero indicates, therefore, that Lysias was a rather more nuanced representative of rhetoric and with the authority of Plato (and Plato's Phaedrus in particular) he implicitly indicates some possible issues in Lysias' thought that may be relevant for those who are completely taken by the writer.

As we saw also in the case of Isocrates, Plato's Phaedrus offers itself as a crucial authoritative text for conceptualizing ancient Greek rhetoric and negotiating the position of its participants (Lysias and Isocrates) for a contemporary audience. Despite the messiness of the tradition, as long as philosophers and critics are drawing on this influential dialogue, we are never too far from constructing a view of rhetoric through the two opposing sides: the Lysianic and the Isocratean. While Isocrates seems to have had a strong hold in education and rhetoric from the fourth century $\mathrm{BCE}$ onwards, he was certainly not a mainstream philosopher and, as such, his views on philosophy and rhetoric did not gain currency in the tradition of Greek philosophy that was transmitted primarily through various philosophical schools. Lysias on the other hand seems to have been preserved in the fringes of rhetorical tradition largely due to his epideictic speech (funeral oration) and his presence in Plato's Phaedrus. In other words, by the time we come to Dionysius of Halicarnassus, the larger framework of the rhetorical tradition is heavily drawing on that Platonic dialogue, even if the specific roles of Lysias and Isocrates in it are not always conceptually clear or well understood. 


\section{DIONYSIUS OF HALICARNASSUS ON LYSIAS, RHETORIC AND STYLE}

\section{I Context and Contemporaries}

Dionysius of Halicarnassus says just enough about himself to allow us to date him with confidence to the last part of the first century вСE. In the preface to his monumental work on the

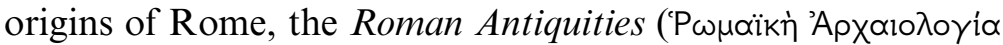
I.7.2), Dionysius writes that he arrived in Rome after the Battle of Actium either in late 30 or early 29 BCE and settled there to learn Latin, to familiarize himself with Roman literary culture, and write the history of Rome. ${ }^{\mathrm{I}}$ What he does not tell us, but what has been assumed from his literary activity, is that in Rome he 'also practiced as a teacher of rhetoric', and perhaps even 'kept an open school'. 2 Hence, next to this magnum opus of Roman history, Dionysius was engaged with rhetoric and literary studies and as evidence for this activity we have his essays on ancient orators and literary criticism. ${ }^{3}$ It is these critical works in particular that will constitute the focus of the following, and in many ways culminating, chapters of this book. Altogether, ten shorter essays and treatises have come to us: five essays on ancient orators (Lysias, Isocrates, Isaeus, Demosthenes, Dinarchus) with a preface to the work On the Ancient Orators, ${ }^{4}$ an essay on Thucydides, a treatise on

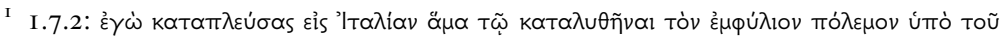

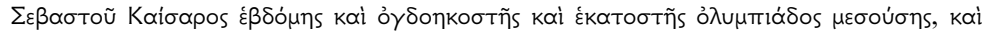

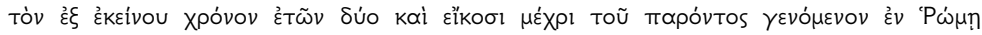

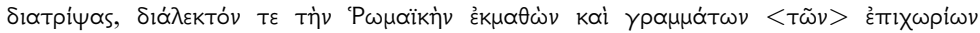

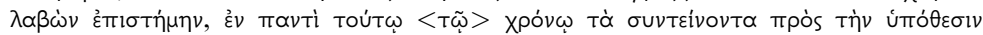

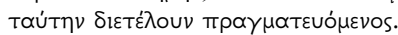

2 Bonner (I939), 2. Egger (I902), 7 rightly draws attention to the fact that we have no actual evidence that Dionysius had a school.

3 A general introduction to Dionysius' critical essays is Bonner (I939) and Usher (I974).

${ }^{4}$ Dionysius' essay on Dinarchus was part of a later project, as he himself writes in Dinarchus (I.I).

I 76 
literary composition (De compositione verborum), and finally three letters (two letters to Ammaius and one to Gnaeus Pompeius). The relative chronology of these works, as well as their relation to his Antiquities, is uncertain and scholars have contended over the probable order of his oeuvre. ${ }^{5}$ To an extent we can rely here on Dionysius' own words at the end of the preface to On the Ancient Orators (4.5), where he introduces his project:

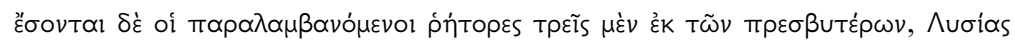

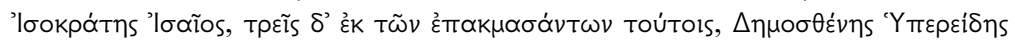

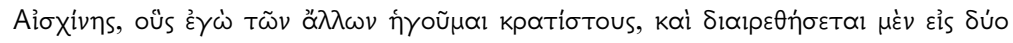

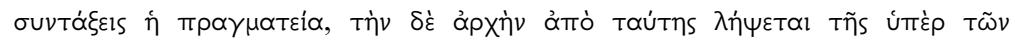

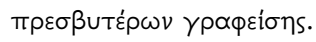

The orators to be compared will be three from the earlier generation, Lysias, Isocrates and Isaeus, and three from those who flourished after these, Demosthenes, Hyperides and Aeschines, whom I consider to be best of others. This work will be divided into two parts, the first dealing with the writings of the older orators.

As Usher notices, there are plenty of cross-references between these works to confirm that this was the order in which Dionysius wrote at least the first three essays. ${ }^{6}$ With other essays we tread a more problematic ground: the longer but incomplete essay Demosthenes has been considered as part of the same project (On the Ancient Orators), ${ }^{7}$ but the apparent inconsistencies within the work have brought some scholars to consider it either as an independent and separate work on Demosthenes, ${ }^{8}$ or as consisting of two separate treatises, Demosthenes I (I-33) and II (34-58) respectively. ${ }^{9}$ For the

5 E.g. Roberts (I90I), 6; Bonner (I939), $38 . \quad{ }^{6}$ Usher (I974), xxiii.

7 E.g. Usher (I974), xxiii; Bonner (I939), 3I-3. ${ }_{8}^{8}$ Tukey (I909).

9 Aujac (I988), I6-24. van Wyk Cronjé (I986), I23-33 argues that the work comprised four (rather than two) parts. It has to be said that the second part of the work is somewhat similar to Dionysius' De compositione verborum $(\mathrm{CV})$, which in turn makes references back to Demosthenes 5-7. According to the standard interpretation of their relationship, Dionysius had interrupted his work on Demosthenes in order to write his essay $C V$ (e.g. Kim 20I4, 37I n. 38). Recently, however, de Jonge (2008), 22-3 has proposed an appealing solution, namely that Dionysius might have been 'working on the two treatises at the same time', and this solution might best explain the difficulties relating to both texts. 


\section{Dionysius of Halicarnassus on Lysias}

present purpose, the question of the relative chronology and relationship between Dionysius' Demosthenes and $C V$ is relevant in as far as it may shed light on the development of Dionysius' thought and methodology through his use of critical terminology. ${ }^{\text {IO }}$ The general consensus, which will be challenged in this chapter, sees 'a clear evolution in Dionysius' critical methods, which become more sophisticated in his later works'. ${ }^{\text {II }}$ According to this view, Dionysius' rhetorical works belong to the last period of his activity and they have been understood as a natural result of Dionysius' long career and work in Rome, where it is highly likely that his interaction with peers contributed to this intellectual development. ${ }^{\text {I2 }}$ As will be argued below, Dionysius' rhetorical treatises offer us instead an insight into a developed understanding of the Attic orators from their first instalment (On Lysias) onwards. Thus, instead of seeing the essays progressing from one orator to another as an advancement of the critical competences of the author, it appears much more appropriate to view the progress from the perspective of a potential student. Dionysius emerges, then, as a writer and a teacher who is much more sensitive to the interests and abilities of his students than perhaps granted thus far.

Many more debates around Dionysius' critical works concern his intellectual circle, which could tell us something about the nature of his essays as well as their intended audience and circumstance for delivery. ${ }^{\mathrm{I} 3}$ Unfortunately, the evidence is very scarce. However, even though most of the personages Dionysius mentions in his work are unknown to us, ${ }^{\mathrm{I} 4}$ the various names themselves indicate a possibly mixed Greek-Roman

Io The chronology of Dionysius' critical works and the way it reflects on the development of his critical acumen are the focus of Bonner (1939), Lebel (I973) and Damon (I99I).

II De Jonge (2008), 2I. $\quad$ I2 Schenkeveld (I983), 69.

${ }^{13}$ For different positions on Dionysius' audience, see Bowersock (I965), I3 I; Gabba (I982), 79-80; Schultze (I986); and most recently (and persuasively) de Jonge and Hunter (20I8), 32-3.

${ }^{14}$ There are important exceptions, such as Quintus Aelius Tubero. Bonner (I939), 4-5. For Tubero, see Cornell (2013).

I 78 


\section{Context and Contemporaries}

audience. ${ }^{\mathrm{I}}$ Within the deeply polarizing debates about the intended readers and audience of Dionysius' works, a careful assessment of the existing evidence seems to confirm that Dionysius wrote for readers of elite status who had competent Greek, regardless of their ethnic background and citizenship. ${ }^{16}$ In any case, the fact that Dionysius had Roman students, ${ }^{17}$ for whom Greek was desirable and within reach, also suggests that he was well informed about the contemporary educational setting in Rome, sensitive to the needs of his students and had a positive reputation, enough to appear attractive to them.

Dionysius' intellectual network is as fascinating as it is complicated. ${ }^{18}$ It would be wonderful to know more about other scholars and intellectuals Dionysius met, and read, and exchanged his ideas with. Unfortunately, a lot of that information will have to remain speculative. Yet, from his commitment to history and rhetoric and from what he tells us about his migration to Rome in the beginning of the Antiquities, we can assume that he was well read in Roman history, knew the works of the orators (especially Cicero) and was familiar with the poetic and rhetorical criticism of Roman intellectuals. ${ }^{\text {I9 }}$ Within this network there is one person in particular that deserves heightened attention in the context of this present

${ }^{15}$ It is unclear, for example, whether Ammaeus, the recipient of two of Dionysius' letters and the preface to On the Ancient Orators, was Greek or Roman (Hidber I 996, 7). Equally unclear is the identity of Cn. Pompeius Geminus. Dionysius' student Metilius Rufus, however, was a Roman as was Q. Aelius Tubero, a historian, lawyer and the addressee of Dionysius' On Thucydides. See more in Bowersock (I965), Hidber (I996), de Jonge (2008), 26-8.

16 'Introduction' in de Jonge and Hunter (2018), 32-3. See also Luraghi (2003) on the addressees of his historical works and Weaire (2005) of the rhetorical ones.

${ }^{17}$ From the little information we have about Dionysius' teaching environment, we know that at least one of his students came from a Roman elite family (De comp. 20). Bonner (I939), 2 thinks it likely that Dionysius had a school of rhetoric and taught for a fee; Schultze (I986), I23-4 is more skeptical. For a balanced account in-between the two positions, see Weaire (2005).

${ }^{18}$ Unlike the concept of a 'circle' which Wisse (I995), 78-80 has shown to carry associations with patronage, I will use 'network' to refer to Dionysius' intellectual environment more generally. For a thorough and persuasive analysis of the classicizing aspects of Dionysius' community-creation, see Wiater (20I I), chap. 5.I.

I9 See, for example, de Jonge (2008). 
discussion - Caecilius of Caleacte. ${ }^{20}$ As far as we can tell, Caecilius was writing both history and literary criticism. ${ }^{2 \mathrm{I}} \mathrm{He}$ seems to have also made use of the comparative method in literary criticism, synkrisis, which is well on display also in Dionysius' writings, and which might have been regarded as an innovation over traditional criticism. ${ }^{22}$ Some scholars have argued that Caecilius was the creator of the canon of ten orators, ${ }^{23}$ though given the very sparse information we have on Caecilius' work, this argument has not won universal acceptance and at this stage will have to remain a speculation. Finally, in his works on literary criticism Caecilius appears to have been particularly invested in the Atticist-Asianist controversy and the Suda attributes several works to Caecilius that may have treated this subject from different perspectives. ${ }^{24}$ There is one more important aspect to mention here in relation to the relevance of Caecilius' criticism of Dionysius. Namely, Caecilius was credited by Ps. Longinus with championing Lysias as the supreme Attic stylist. Despite the fact that the Suda does not list a work of Caecilius explicitly focusing on Lysias, Ps. Longinus tells us that Caecilius had written several works on Lysias, and points out that in these ( $\dot{\varepsilon} \nu$ Toĩs úmè

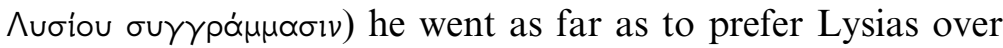

${ }^{20}$ On Caecilius, see also Kennedy (I972), 364-9; O'Sullivan (I997) on Caecilius as the originator of the canon of ten orators; Heath (1998) on Caecilius as a source for Photius; and Innes (2002) with de Jonge (20I2) on Caecilius and Ps. Longinus. For a recent edition, see Woerther (2015) who also provides an insightful introduction to the critic in context (cf. Woerther 2013 on editing Caecilius' fragments).

${ }^{21}$ Roberts (I897), 303-4.

22 Bonner (I 939), 9-IO. On synkrisis see Focke (I 923) and now also de Jonge (2018a) on the comparison between Cicero and Demosthenes among ancient literary critics.

${ }^{23}$ O'Sullivan (I997) is among the few modern scholars who have argued in favor of seeing Caecilius as the originator of the canon of ten orators. Most have remained skeptical about our ability to say anything more affirmative about Caecilius' role in canon-making. See most recently Woerther (2015), xxxii, and Matijašić (20I8), 27.

${ }^{24}$ From his works that are unmistakably concerned with the Asianist-Atticist contro-

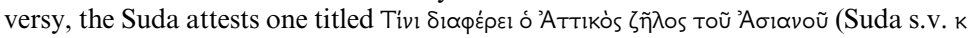
I I65 and Ofenloch fr. 6). It may well be (so Roberts I897, 304), however, that a

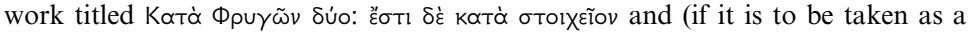

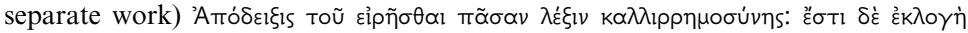

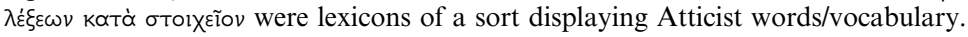
See also Kennedy (I972), 364-9. 


\section{Context and Contemporaries}

Plato. $^{25}$ It is very plausible that Ps. Longinus had misrepresented Caecilius' critical position on this matter, especially

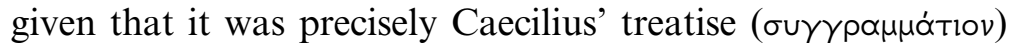
on the sublime which prompted Ps. Longinus - or so he claims - to write his work as a response to him (On the Sublime I.I). In other words, Caecilius' role in the whole of On the Sublime is one of an intellectual foil against which Ps. Longinus expresses his own views on the topic. That Caecilius might have had a more nuanced position on Lysias is suggested by Photius, who tells us that Caecilius did not approve of Lysias' arrangement and found it lacking in power. ${ }^{26}$ Innes has argued convincingly that it is highly unlikely that Lysias was considered a model for sublimity in Caecilius' treatise on the subject, and that it is very probable that he regarded Demosthenes instead as most appropriate for this role. ${ }^{27} \mathrm{Be}$ that as it may, Caecilius surely demonstrated high regard for

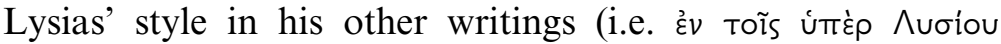

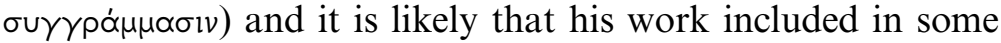
form a comparison between Lysias and Plato.

All the previous aspects indicate that Dionysius and Caecilius had much in common as regards their intellectual work. Indeed, given that the focus of their literary criticism has many points in common, scholars have long wondered whether they were rivals or friends. ${ }^{28}$ Dionysius refers to Caecilius explicitly in the Letter to Gn. Pompeius and calls

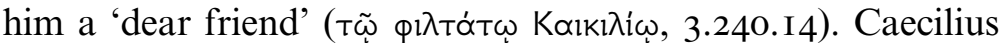
seems to be brought into the discussion as an authoritative critic whose agreement will further bolster Dionysius' divisive discussion about the comparison between Herodotus and

25 Ps. Longinus On the Sublime 32.8. Ps. Longinus' wording is very strong and highly emotional: 'he loved Lysias not even as he did himself, and at the same time he hated Plato and all his works more than he loved Lysias' (

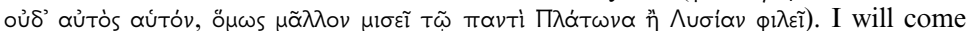
back to the recurring Lysias/Plato comparison below.

${ }^{26}$ Photius Bibliotheke 489aI3-17. Caecilius is here listed among the critics of Lysias, which suggests that his work on Lysias might have contained a more nuanced account of the orator than presented in Ps. Longinus.

${ }^{27}$ Innes (2002). $\quad{ }^{28}$ On this question, see further Bonner (I939), 6-IO. 


\section{Dionysius of Halicarnassus on Lysias}

Thucydides. ${ }^{29}$ This might as well just settle the discussion for now. Taking into consideration their shared views (on Lysias, Plato and Demosthenes) and methods (e.g. synkrisis), it is more likely that Caecilius was a friendly collaborator and an influence rather than a bitter rival.

What emerges from this previous discussion is that Dionysius was part of a busy intellectual network, which included many critics and historians who were invested in thinking about the ancient rhetorical tradition through classical Greek writers, playing them against each other and making them representatives of certain stylistic approaches that always also reflected political ideologies. Lysias' treatment in these contexts appears to have been particularly controversial and naturally invited critics to go back to that previous moment when Lysias' style and rhetorical contributions were subjected to intense commentary - Plato's Phaedrus. Formulating views about Lysias also meant critically engaging with Plato's Phaedrus. It is therefore not at all surprising that whenever critics of that period form a strong opinion about Lysias, they also ended up having strong views about Plato and Isocrates. ${ }^{30}$ Since Plato had in that dialogue posited the two figures at opposite ends of the rhetorical discourse (as much as they were at the opposite sides of the dialogue: Lysias in the beginning, Isocrates at the end), critics soon found themselves participating in this double axis of literary-critical analysis: Lysias and Isocrates required interpretation as representatives of opposing views of rhetoric, and Plato demanded response as an important predecessor in assessing their success and relevance to the contemporary moment. In the centuries between Plato and Dionysius, we have found sections and snippets from various writers,

29 If indeed Demosthenes was the most illustrious stylist also for Caecilius, then Dionysius' reference to the orator as an imitator (of sorts) of Thucydides surely softens his preceding criticism of the historian.

${ }^{30}$ Hunter (2OI2), I5I-84 is a must-read analysis of the ancient criticism of Plato's style and of the reception of Plato's Phaedrus. Hunter masterfully demonstrates how Plato's Phaedrus, which offered criticisms of Lysias and Isocrates, was soon in the critical tradition itself subjected to criticisms and assessments of its author's style. 
second-hand accounts and spurious fragments that have all individually supported an interpretation that regards Lysias and Isocrates as important (if not central) figures for the broader conceptualization of the rhetorical tradition. However, it is not until Dionysius of Halicarnassus and his classicizing ambition to rethink the preceding rhetorical tradition and appropriate it to the contemporary Roman context that we see a fully fledged engagement with the triad - Lysias, Isocrates and Plato - emerging.

Curiously, of all Dionysius' works, his critical essays on ancient orators (with the exception of his preface to On the Ancient Orators) and particularly his essays on Lysias, Isocrates and Isaeus, have received the least scholarly attention. ${ }^{3 \mathrm{I}}$ This is surprising, because Dionysius' programmatic approach to the rhetorical tradition, and his aim to map it out for his contemporaries that is on display from the preface onwards, invite us to follow his discussion from the beginning and not to skip any building block on the way. This chapter goes further than that and will examine the way in which his essays on Lysias and Isocrates function as the foundational base for Dionysius' creation of the rhetorical tradition.

\subsection{Dionysius and Lysias}

As Dionysius announces in the preface to On the Ancient Orators, Lysias is the first contribution to this larger project on ancient orators and historians that aims to benefit the general public with a worthy topic that has not been discussed

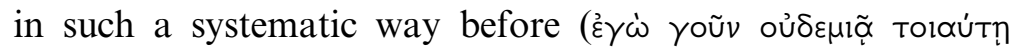

${ }^{31}$ I thus disagree with Wiater's (20 I I, I) evaluation of Dionysian scholarship when he says that '70 years after the publication of Bonner's treatise, Dionysius' linguistic and rhetorical theories seem to have been exhaustively explored'. It is true that there has been a significant interest in Dionysius' linguistic and rhetorical work and important work has been done on the De compositione verborum (esp. de Jonge 2008). However, his shorter essays on Attic orators have not received much focused attention and his engagement with individual orators has been rather unevenly discussed in recent scholarship. Wiater (201 I) himself goes on, of course, to offer detailed and insightful readings of the rhetorical essays in his overarching discussion of Dionysius' classicism. 


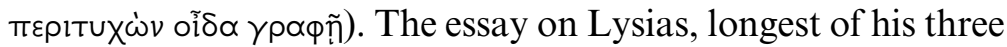
essays on the earlier generation of ancient orators, is roughly divided into two larger sections, the first dedicated to Dionysius' assessment of Lysias' speeches by reference to specific characteristics of Lysias' style, the second part analyzing examples from Lysias' speeches to sustain claims made in the first part. Additionally, the essay contains a very brief section on Lysias' biography with a short discussion of his dates. Usher points out that in this biographical section Dionysius is simply reproducing 'uncritically facts recorded by earlier biographers'. ${ }^{32}$ As we have seen before, however, Lysias was a rather hidden figure (also because of his profession as a speechwriter) already for earlier authors, so that recovering reliable biographical facts about his life was hard and existing accounts were mostly full of controversy. ${ }^{33}$ Either way, we are given only the very basic information about Lysias' life before Dionysius proceeds to discuss the orator's work and the literary qualities of his style.

As a brief side note, it is noteworthy that none of the speeches mentioned and discussed by Dionysius in this essay are those preserved to us by the manuscript tradition. Of the three speeches quoted at length in the second half of the essay, the first three sections of speech 32 (Against Diogeiton) are attested also in Syrianus' commentary on Hermogenes' Peri ideon (88.I5-89.I5), sections of speech 33 (Olympiacus) are preserved in Diodorus Siculus (I4.I09), Ps. Plutarch's Lives of Ten Orators (836d) and in Theon's Progymnasmata (63), and for speech 34 (On Preserving the Ancestral Constitution) Dionysius is our only source. This is perhaps not surprising if we remember that Dionysius had a very wide selection of

${ }^{32}$ Usher (1974), 2 I n. I. Usher draws attention here to another passage (First Letter to Ammaeus 3) where Dionysius explicitly mentions biographers on whom he relies for biographical accounts, in this particular case for Demosthenes and Aristotle.

33 Dionysius might have simply wanted to avoid getting involved in this discussion so as to keep the essay from expanding further. There is indeed a preoccupation with time and length in these first three essays, in a way that we do not find in the later works. Could this be taken to suggest something about the role of these orators in rhetorical teaching, where they might have been used to set the ground for further study? 
Lysianic speeches to choose from, so that his choice was understandably different from those who later put together the collection of Lysias' speeches. And yet it is still somewhat unexpected that the later tradition did not pick up the Lysianic speeches held in such high regard by Dionysius. One more aspect is worth mentioning here: namely, Dionysius' varying enthusiasm for the speeches he quotes in this essay. He furnishes all three speeches with a brief introduction, but only provides comments on the forensic one. The excerpts from the other two speeches are much shorter and are not accompanied with a single critical comment. This lack of close critical engagement with the speeches has led some scholars to argue that at the time Dionysius wrote Lysias his critical methodology was not yet developed to the heights we see in his later essays. We should also note, however, that Dionysius is consciously and openly prioritizing Lysias' forensic work over other genres (3.7.), so that the lack of engagement with his other speeches is an expected result of his fashioning of the image of Lysias as a forensic author.

Dionysius portrays an image of Lysias as an active and established writer in a variety of different genres. According to Dionysius, Lysias 'wrote many well-arranged speeches to the law courts and the council and the assembly, as well as

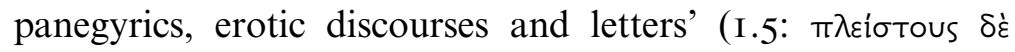

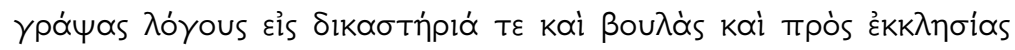

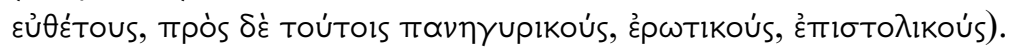
Dionysius continues: 'he overshadowed the fame of those orators who came before him and those who blossomed in his own time, leaving not many opportunities to improve for those to come in all these forms of writing, by Zeus not even in

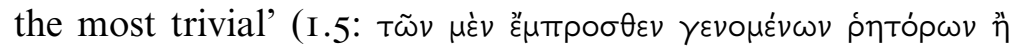

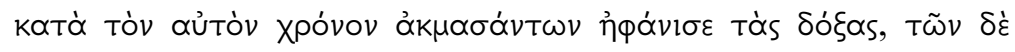

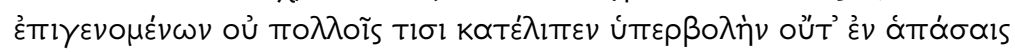

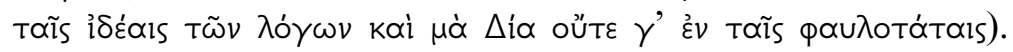
Lysias was, then, a well-rounded writer, accomplished in all genres, and yet Dionysius consistently emphasizes Lysias' excellence in court speeches and the most trivial matters

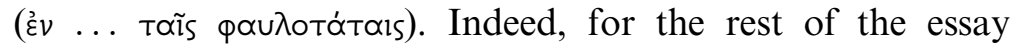


Dionysius leaves to one side, without further comment, 'his letters, his amatory discourses' and 'the other works which he wrote for amusement (3.7: $\mu \varepsilon \tau \dot{\alpha} \pi \alpha \_\delta \tilde{\alpha}_{s}$ है $\left.\gamma \rho \alpha \psi \varepsilon v\right)$ ', and focuses only on 'the serious speeches which he wrote for the law courts

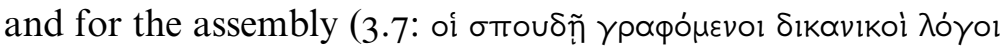

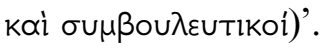

With regard to Dionysius' critical method, as far as we can tell from this essay, he seems to have been an eclectic, drawing from a variety of different critical approaches and not subscribing to any literary or philosophical school in particular. Indeed, not only does Dionysius follow the (Peripatetic) theory of virtues of style (more below), but throughout this essay he appears to make use of many different rhetorical theories and systems: he makes productive use of Theophrastus (6.I, I4.I), of Isocrates or, perhaps more appropriately, the followers of Isocrates (I6.5), and of older rhetorical handbooks (24. I-4). In doing so, Dionysius does not seem particularly concerned to stick to one specific system of virtues and to describe Lysias according to the terminology of a particular school. Instead, as he tells us at I0.3, he could name many more virtues of style, leaving it essentially open from where he is drawing his terminology and system. Or, when analyzing the introduction to Lysias' forensic speech (24.5-7), Dionysius' comments on its success are drawn from older rhetorical handbooks and he is not at all disturbed by the level of specificity and particularity that these handbooks seem to employ, ${ }^{34}$ even though their approach seems very different from the more abstract terminology that Dionysius uses to discuss Lysias' style in this essay.

Bonner, whose seminal work on Dionysius' critical essays examines the development of his critical method, has argued that Dionysius' early essays, of which Lysias is an example, display a less developed and sophisticated methodology and

${ }^{34}$ Dionysius reports that the handbooks recommend, among other things, the following: when the defendants in a case are relatives of the plaintiffs, they should not appear malicious or vexatious; to blame the charge and the lawsuit on the opponent; to claim that the wrongs committed were great and spell out specifically how to gain a jury's benevolence. 
critical discussion than what we see in his later treatises. ${ }^{35}$ Focusing strictly on the Peripatetic theory of the virtues of style, Bonner claims that Dionysius is simply reproducing in this essay the system of virtues that he had inherited from the previous tradition. He thus connects Lysias with the mechanical use of this system in the first books of On imitation, where Dionysius, as appears from the epitome of that work that has been preserved in Dionysius' letter to Gnaeus Pompeius, had made extensive use of the theory of the virtues of style. ${ }^{36}$ While it is undoubtedly true that Dionysius' critical discussion in the Lysias appears more simplistic compared to his examination of the following authors, this may also reflect the special position of Lysias in Dionysius' critical thought. Lysias becomes a point of reference and comparison for Dionysius in his examination of all subsequent orators. In that role, it is almost inevitable that Lysias himself is far less compared to others in that first essay with the consequence that Dionysius' essay Lysias contains the fewest comparative references. It will be argued below, however, that instead of merely reflecting an initial stage of Dionysius' critical thought, this essay seems to have been used by the author to establish a point of reference for, and a connection to, all his following essays. Thus, while in Bonner's reading Dionysius' critical thought only begins to emerge in the essay, from another perspective Dionysius' Lysias could be read as laying the groundwork for his intellectual project, a foundational work which provides the background for all his subsequent examinations of ancient orators.

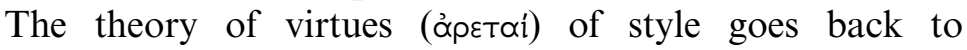
Aristotle's identification of one single virtue of style, clarity

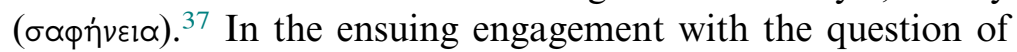

35 Bonner (I939), 39-48.

${ }^{6}$ Bonner (I939), 47. Bonner argues (37) that On Imitation was Dionysius' earliest work, because he brings up there the list of orators and refers to Lycurgus instead of Isaeus. Bonner claims that it is highly unlikely that he would have made this mistake (if mistake it is) had he already written the first instalment of his essays on the ancient orators and thus the essay on Isaeus.

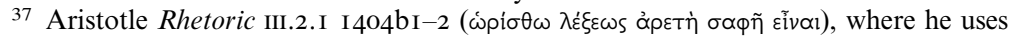

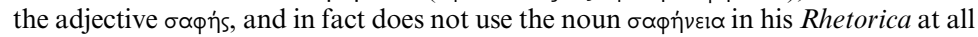

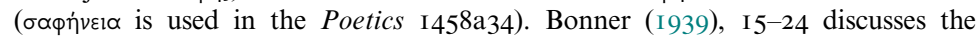




\section{Dionysius of Halicarnassus on Lysias}

style, Theophrastus had apparently broken down this virtue into four different virtues - purity of language ( $\dot{\varepsilon} \lambda \lambda \eta v 1 \sigma \mu o ́ s)$,

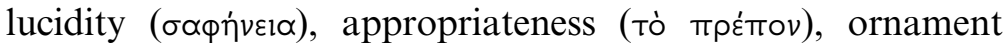

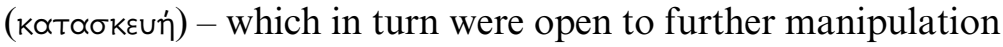
by different theorists, who added and/or omitted certain elements for their own particular purposes. That Dionysius is making use of a version of this system is clear from the lists of virtues that he provides in the essay on Lysias and, as Bonner points out, in his analysis of Herodotus and Thucydides in the epitome of On Imitation (3). Dionysius mentions this system explicitly in his later essay Thucydides (22.2-3), where he writes:

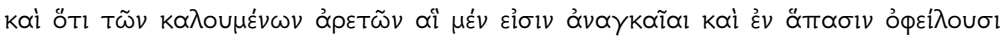

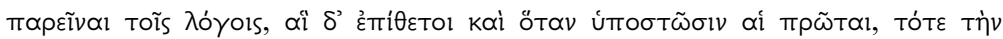

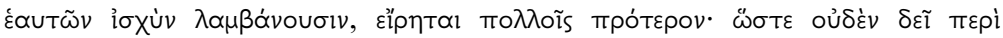

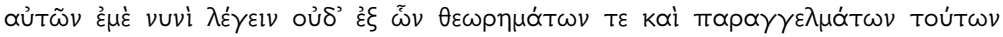

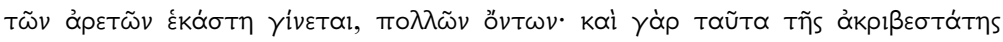

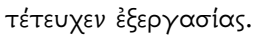

And some of the 'virtues' ascribed to style are essential, and should be present in all writing, while others are ancillary, and depend for their effect upon the presence of the essential virtues. All this has often been said before, so that it is unnecessary for me to speak of them now, or to discuss the many principles and rules on which these virtues are each founded; for these matters also have been the subject of precise and elaborate theorization.

In the letter to Gn. Pompeius, which Bonner posits in close proximity with Dionysius' Demosthenes and Thucydides, and which contains remnants of his (arguably) very early work $O n$ Imitation, Dionysius mentions this distinction between two different kinds of virtues again (3.I6-2I). He lists purity of

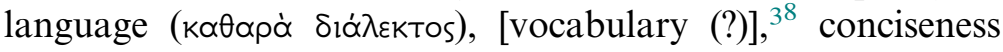

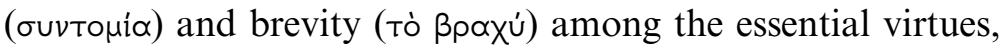
and vividness ( $\left.\varepsilon^{\prime} \alpha \dot{\alpha} \rho \gamma \varepsilon \_\right)$, imitation of character and emotions

development of the theory of virtues of style, and the following brief overview is indebted to his discussion there as well as to Schenkeveld (I964), 72-6, and Innes (I985).

${ }^{38}$ There appears to be a lacuna here; Usher $(1985,383$ n. 2) suggests it may have contained the element of vocabulary as distinct from dialect; cf. the reconstruction in Aujac (I992), 92 (Gnaeus Pompeius 3.I6). 


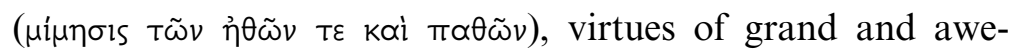

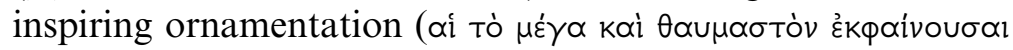

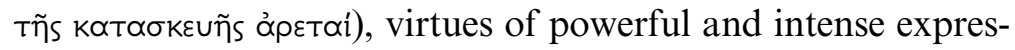

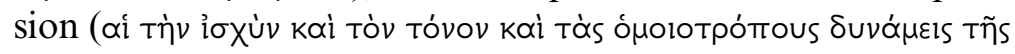

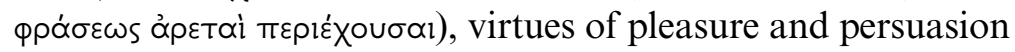
( lary virtues. Propriety is mentioned as altogether the most

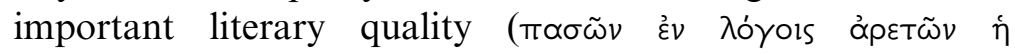

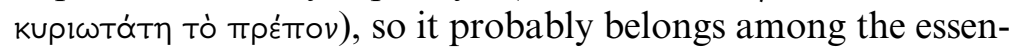
tial virtues. The main difference between these different virtues is that the 'essential' virtues have to be present in every speech, 'to make clear and manifest what one wishes to say, but they do nothing more'; the ancillary virtues have more influence

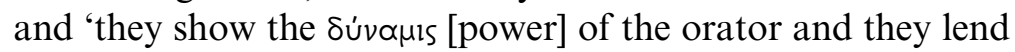
him his glory and fame'. ${ }^{39}$ Overall, however, this list gives the impression of being composed rather arbitrarily and depending heavily on specific authors, which probably results in the growing obscurity of the explanations of various 'virtues'. At any rate, there appears to be a pronounced difference in Dionysius' expression between the 'essential' and 'ancillary' virtues: the 'essential' elements are expressed in concise language, often as abstract concepts ( $\sigma \alpha \varphi \eta \dot{v} v \varepsilon 1 \alpha$ [clarity],

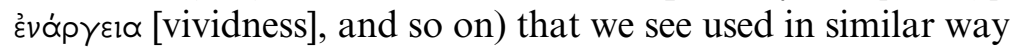
in both works (Thucydides and On Imitation), whereas the 'ancillary' virtues show more fluctuation depending on the specific author under discussion and the description of these virtues seems at times rather diffuse (e.g. đi tò $\mu \varepsilon \dot{\gamma} \alpha$ kai

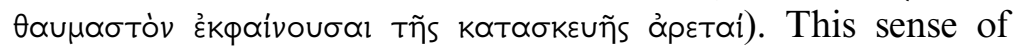
arbitrariness surrounding the 'ancillary' virtues is underscored by Dionysius' own comment at the end of the paragraph that he could provide many more examples and elements to distinguish the style of the historians, but he will save that for another opportune moment. ${ }^{40}$

Even though Dionysius does not mention the twofold division of the virtues of style into essential and ancillary

39 Schenkeveld (I964), 74. $\quad 4^{\circ}$ Letter to Gn. Pompeius 3.2 I. 


\section{Dionysius of Halicarnassus on Lysias}

explicitly in his Lysias, the proximity of the language and critical tools that Dionysius employs strongly suggests that the list he produces in this essay is indebted to that theory and connected to previously quoted passages from Dionysius' other works. ${ }^{4 I}$ The one significant difference between the virtues of style in Lysias and his Letter to Gn. Pompeius is that, compared to the latter, the former essay displays an almost definition-like distinction and treatment of the virtues: every virtue is mentioned in lucid and clear terminology, and the terms are often followed by brief explanations. The first part of the essay is largely structured around Dionysius' dis-

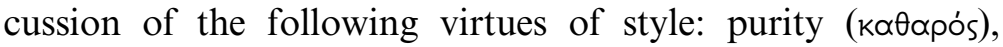

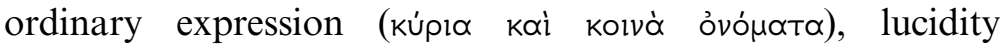

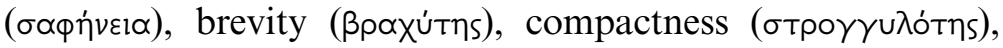

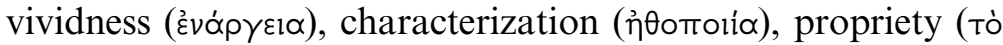

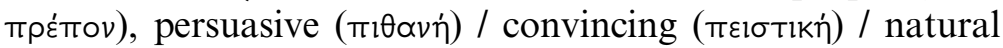

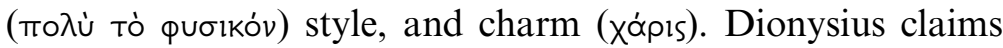
that he could mention many more relevant virtues of style, but that he will confine himself here to those mentioned. As this list clearly demonstrates, Dionysius uses, in contrast to many of the elements described in his Letter to Gn. Pompeius, a far clearer terminology which renders the discussion more structured. It should be remembered, of course, that Dionysius is here concerned with emphasizing stylistic characteristics of one author, Lysias, and that he is not engaged in comparative criticism as we see in his discussion of Herodotus and Thucydides. Whether or not this can be used to infer anything about the development of Dionysius' critical method, Dionysius' efforts to create a clear-cut critical vocabulary and method to analyze Lysias (and, by extension, all subsequent orators) have had a profound impact on later rhetorical criticism. And despite the fact that Dionysius does not mention explicitly the distinction between essential and ancillary virtues, the breakdown of the individual elements in this list seems to reveal that he is indeed following this principle.

4I Cf. Bonner (I939).

I90 
Of all Lysianic virtues Dionysius mentions purity, Lysias'

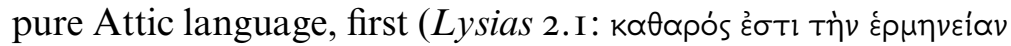
$\pi \alpha \dot{v u})$. In the context of the Atticist-Asianist controversy, putting this quality in such a prominent position, and ahead of the Peripatetic/Aristotelian 'lucidity' ( $\left.\sigma \alpha \varphi \eta^{\prime} v \varepsilon 1 \alpha\right)$, is certainly a significant move, indicating Dionysius' adherence to the classicizing attitude towards the past. ${ }^{42}$ Dionysius explicitly says that purity is 'the first and most important element in speeches'

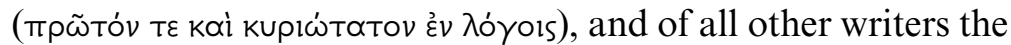
one closest to Lysias in this stylistic virtue was Isocrates. In other words, neither Plato nor Thucydides, and not even Demosthenes, is to be taken as a model for pure Attic prose. A similar Atticist-classicist background seems to lurk behind his second virtue, simplicity. In fact, Dionysius seems particularly concerned to spell out what this virtue really entails: Lysianic simplicity is deceptive, and the common words and language that he uses conceal a highly artistic prose. It is not simply everyday speech that Lysias reproduced in his speeches, ${ }^{43}$ but a highly sophisticated art of simplicity. In fact, proof of the artistic labor behind the effect of a simple and common expression is that of all the followers of Lysias it was Isocrates, this time the young Isocrates, famous for his elaborate style, who came closest to imitating Lysias' artistic and

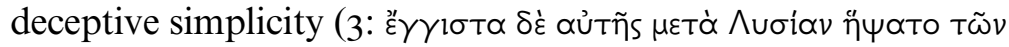

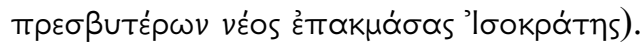

42 On Atticism, see Gelzer (I979), Gabba (I982), Hidber (I996), Porter (2006a), Kim (20I4). An excellent account of Dionysius' classicism and its relationship to Atticism is Wiater (20I I). Whether Atticism was originally a Roman or a Greek phenomenon is fiercely debated in scholarship. Hose (1999) offers an appealing solution: even if the movement itself grew out of a Roman context by Roman critics, the role models for Atticists as well as their rhetoric teachers had nevertheless been Greek. In other words, perhaps it is best to take this movement as a mixture of the two, the Roman and the Greek. More could be said about this topic, but I simply wanted to add here one more thought, which is that with Dionysius the question of Atticism comes up in dialect terms, which inevitably gives his account of Lysias and Isocrates as Atticists a rather different flavor from the one it had in Cicero.

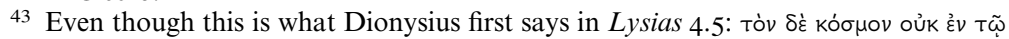

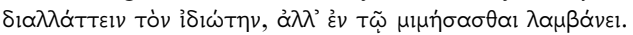




\section{Dionysius of Halicarnassus on Lysias}

Lucidity and brevity seem to conclude the list of essential virtues, for the next virtue - compactness - is already introduced in a slightly different manner. Instead of simply continuing to list further virtues, Dionysius stresses the distinctness of the next virtue, compactness, by saying 'after

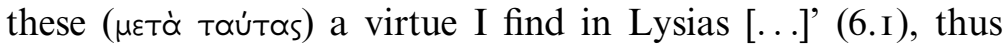
suggestively grouping together the previous four qualities and marking a new set of virtues. This virtue of style does not lend itself easily to a one-word summary: 'It is a manner of expression in which ideas are reduced to their essentials and

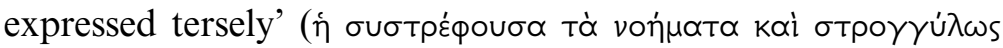

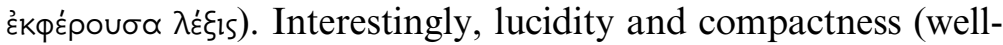
roundedness) are two elements that are also used to describe Lysias' style by Socrates in Plato's Phaedrus, where Socrates suggests that the only reason to admire the Lysianic speech is because 'all the expressions are clear and well rounded and

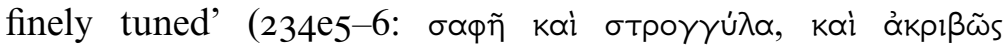

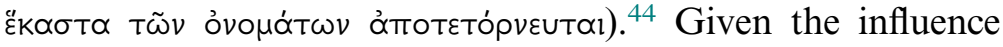
of the Phaedrus on the reception of Lysias from the fourth century onwards, it is surely no coincidence that these two elements have found such a strong presence in Dionysius' description of Lysias' virtues of style. As noted before, Dionysius is reading Plato's Phaedrus very closely and we witness here an implicit reference to the underlying importance of this dialogue for Dionysius' project. Indeed, he appears to be picking up the terminology of praise intended for Lysias (regardless of whether it was intended as such in the dialogue) and incorporates it to his own detailed analysis of Lysias' style. Making use of these two stylistic categories enables Dionysius to show himself as well informed of Lysianic criticism while at the same time demonstrating, by setting his own stylistic categories above those of Plato, the

${ }^{44}$ Whether or not Socrates' comments on Lysias' style are ironic (they surely are ironic with regard to the content and the overall success of Lysianic rhetoric), we find no evidence in ancient criticism that would suggest Socrates' analysis of Lysias and Isocrates would have been interpreted as anything but sincere assessments of their rhetoric. So too Dionysius, who seems to take Socrates' praise of Lysias' style here literally. 
importance of his own interpretation of Lysias over previous critics, and in particular over that of Plato.

The ancillary virtues in the list are selected to highlight Lysias' superiority in these elements over all other orators. In other words, for Dionysius' discussion these are specifically the Lysianic elements of style. Dionysius concludes the section on vividness ( $\varepsilon v \alpha \dot{\alpha} \rho \gamma_{\varepsilon l \alpha}$ ) by the following assessment of Lysias: 'He was the best of all the orators at observing human nature and ascribing to each type of person the appropriate emotions,

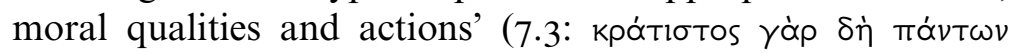

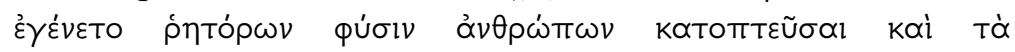

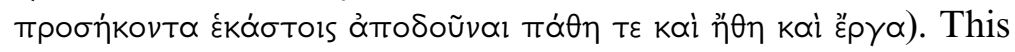
quality seems to be particularly fixed in the Peripatetic theory on virtues of style: it is alluded to in Aristotle's Rhetoric (III.II.I-4 I4IIb24-I2a9) and is defined in almost identical terms in Ps. Demetrius (209-IO). ${ }^{45}$

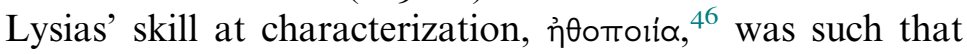
'anybody pursuing truthfulness $(\dot{\alpha} \lambda \hat{\eta} \theta \varepsilon 1 \alpha)$ and wishing to

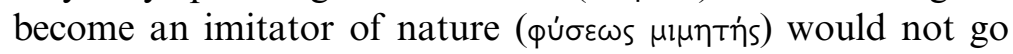
wrong in using Lysias' composition, for he will find nothing more truthful ( $\left.\alpha^{\prime} \lambda \eta \theta \varepsilon \sigma \tau \varepsilon \rho \alpha\right)$ than this' (8.7). Characterization is a particularly dense paragraph and it has also caused some scholarly debate: Dionysius' description has been read to suggest that Lysias' characters were created as general 'literary types', ${ }^{47}$ and this judgement has been contested as one-sided by those who see Lysias' speeches as displaying individual

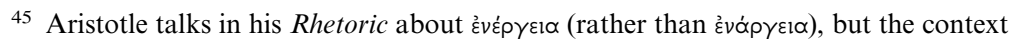
is similar: Aristotle aims to elucidate what it means to bring something 'before the

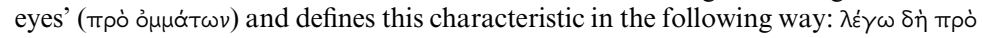

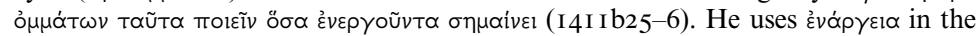
Poetics (I7 I455a22-6). A good discussion of their difference in Aristotle is Eden (I986), 7I-5.

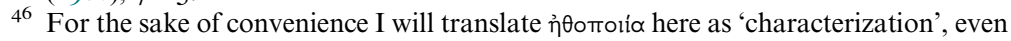
though a good case could be made for a more precise translation that would emphasize the moral qualities and normative connotations inherent in Dionysius' use of this notion.

47 See, for example, Bruns (I896), followed by Büchler (I936) and most recently Weissenberger (2003), 75. The advocates of 'individual characterization' in Lysias include most famously Usher (I965). I hope to address the topic of characterization and its use in Dionysius elsewhere. 
characterization. It is useful to remember that Dionysius is interested in identifying general features that his students can usefully imitate, which may explain his lack of engagement with what Usher labels Lysias' 'individual characterization'. In other words, the characteristics of specific historical individuals that may or may not be entirely unique to them are not really relevant for Dionysius' rhetorical interests. This section thus describes Lysias' achievement in characterization from the point of view of the general moral effect on the audience. ${ }^{48}$

In order to emphasize Lysias' character appropriations, Dionysius links Lysias' skill at characterization with the virtue of a simple and common style. That Dionysius aims to establish a link between the two virtues becomes clear when he writes that 'the impression ( $\chi \propto \alpha \alpha k T \eta \dot{\rho})$ of this harmonious [composition] seems to be somehow un-labored (åmoíntos)

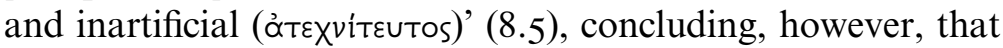
'it is more carefully composed than any work of art' (8.6: 'ُ॰

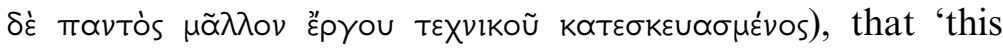

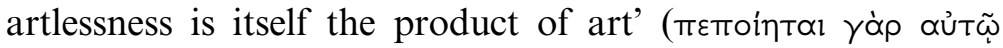
тоŨTo tò ớroíntov) and that 'it is in the very appearance of not having been composed with masterly skill that the clever-

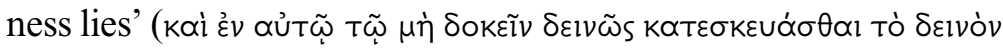
$\left.\varepsilon^{\prime \prime} \chi \varepsilon 1\right)$. This compares well with what he claimed a few passages before under the topic of 'common language/simplicity', namely that despite the apparent simplicity, Lysias 'is the most

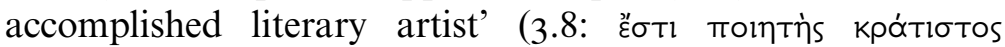
$\lambda o ́(\omega v)$. Dionysius' emphasis on this deceptive quality of Lysias' style, his cleverness, strongly resembles Phaedrus' judgement of Lysias in Plato's Phaedrus. When summarizing Lysias' approach to the topic of love in the speech, Phaedrus says: 'For Lysias has written on one of the beauties being tempted, though not by a lover, but this is just the clever thing about it: for he says that favors should be granted rather to the

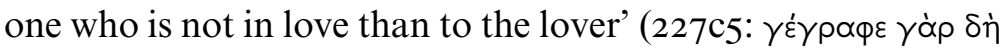

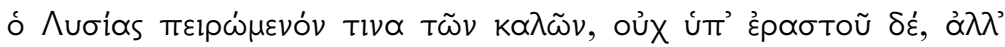

${ }^{48}$ Dionysius' apparently increasing interest in deception that he explores through the figure of Lysias is very curious in this educational and morally heightened context.

I94 


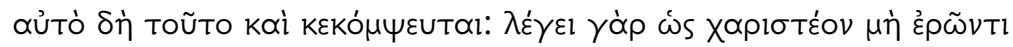
$\mu \tilde{\alpha} \lambda \lambda \circ \nu \ddot{\eta} \varepsilon \hat{\rho} \tilde{\omega} \nu \tau l)$. There is a kind of cleverness in Lysias' writing, a simple twist to a commonplace topic, or here a commonplace construction of participating characters, that makes him stand out. Shortly afterwards Phaedrus explicitly

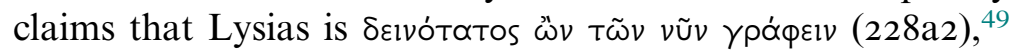
thus stressing a crucial characteristic to Lysias' success and appeal - his 'being $\delta \varepsilon v v o$ s' ${ }^{50}$ It is probably no coincidence that

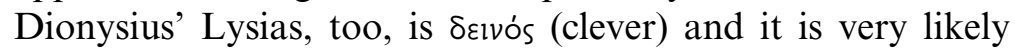
indeed that this concept of Lysias' cleverness has crept into Dionysius' discussion of Lysias' stylistic features through the Phaedrus. While Phaedrus' praise of Lysias is honest, there is no doubt that the dialogue as a whole aims to challenge the view of Lysias as an accomplished writer. As we noticed before, however, Dionysius does not raise the possibility of ironical reading and thus seems to take all praise of Lysias expressed in the dialogue matter-of-factly. Given his criticism of Plato's own style elsewhere, ${ }^{5 \mathrm{I}}$ however, it is also conceivable that by taking Phaedrus' praise of Lysias seriously Dionysius is implicitly undermining Plato's authority when it comes to stylistic recommendations, and is eager to show to his contemporaries and students his supremacy over the philosopher.

In any case, given what we know about the reception of Lysias and the continuous association of his speeches with successful character portraits, it is worth noting that of all the 'ancillary' virtues of Lysias, characterization and charm are the ones that receive fullest treatment and attention by Dionysius. Therefore, it must have been felt by Dionysius that these two features characterize Lysias' style particularly aptly and thus require a more elaborated discussion in the treatise.

49 This claim is reiterated by Dionysius in his Letter to Gn. Pompeius I. Io where he

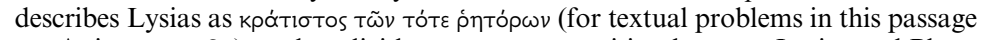
see Aujac I992, 8I), and explicitly stages a competition between Lysias and Plato.

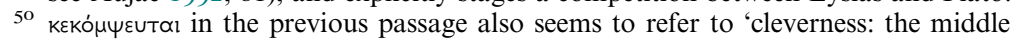

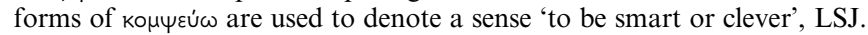

${ }^{51}$ E.g. Demosthenes 5.4-6, 28.6-7. See useful discussion in Hunter (20II), I5I-84, esp. I63-6. 


\section{Dionysius of Halicarnassus on Lysias}

Lysias' style has propriety, a virtue that Dionysius considers

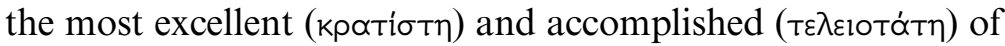
all virtues of style (9.I), but it is also one of the most general virtues mentioned in the list and one which does not emphasize Lysias' idiosyncrasy in any more detailed way. Given the

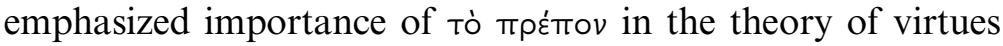
of style (cf. Thucydides 22), this is a virtue that Dionysius was probably compelled to mention in this context, even though there does not seem to be anything particularly Lysianic about it. This might explain Dionysius' choice of language and relative lack of praise of Lysias in this section. Paying mere lip service to Lysias' skill at persuasiveness and naturalness (which is apparently already common knowledge, Io.2), ${ }^{52}$ Dionysius rushes forward to one of the most enigmatic of Lysias' virtues - his charm ( xópis). To conclude his otherwise rather uniform list of virtues with a long digression on Lysianic charm is perhaps the most striking aspect of the essay, ${ }^{53}$ especially as Dionysius seems to use this notion as a way to explore the limits of criticism and artistic creation.

\subsection{Dionysius and Lysias' Charm ${ }^{54}$}

The description of charm (xópıs) in Dionysius' essay On Lysias extends over several chapters of the work and is the longest section dedicated to a single virtue of style. ${ }^{55} \mathrm{He}$ explains Lysias' charm in the following way: 'I will demonstrate one more virtue of this orator, which I consider to be his finest and most important quality, and the one above all which enables

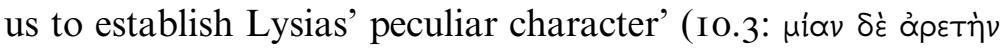

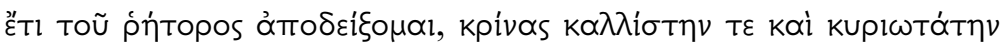

\footnotetext{
${ }^{52}$ Wiater (2OII), 3I6-I7 attributes more weight to this section and offers a persuasive analysis of the importance of Lysias' 'naturalness' as opposed to Platonic guise.

53 For Usher (I974), I 8-I9 this gives the entire essay a 'Janus-like quality, looking inwards to the earlier systems of the ancient rhetoricians, of Theophrastus and Hermagoras, and outwards to the later intuitive criticism of Dionysius in the $D e$ compositione verborum, and of the author of the treatise On the Sublime'.

${ }^{54}$ I have discussed elsewhere in more detail the development of the concept of Xópis and its use in literary criticism prior to, and in, Dionysius' work (Viidebaum 20I8).

55 Despite some hesitations, I will translate below the Greek xópıs as 'charm'.
} 


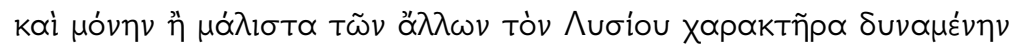
$\beta \varepsilon \beta \alpha 1 \tilde{\omega} \sigma \alpha l)$. Even though nobody else excelled him in xópıs, those who imitated it appeared superior to others because of this quality alone (Io.4). It is 'some sort of charm that blos-

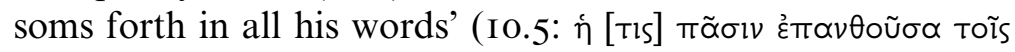
óvó $\mu \alpha \sigma l<\chi \alpha \dot{\alpha} 15>$ ) and it is 'something bigger than all words

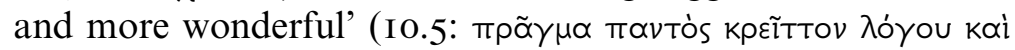

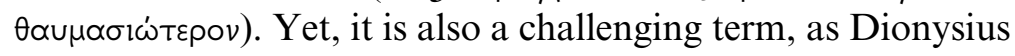
concedes when he says that it is very easy to see and it is to everyone, layman and expert alike, manifest, but it is most difficult to express in words, and not simple even for those with

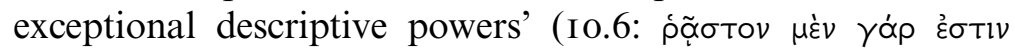

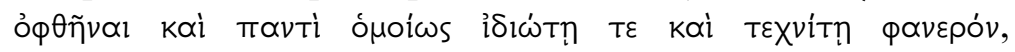

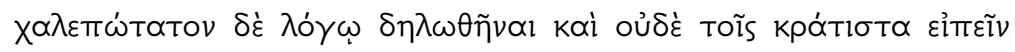

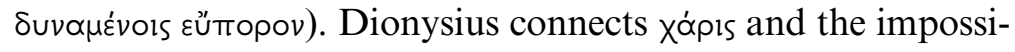
bility of determining in exact terms what it is with other difficult, but most productive, literary-critical terms, such as

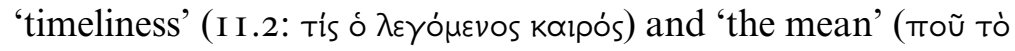
$\mu \varepsilon \dot{t}$ piov). In all these cases, 'it is with senses and not with reason

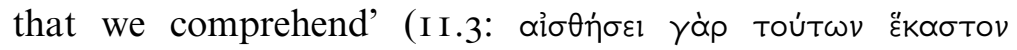

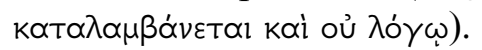

As attested in Philodemus, the term xápis had been used before by the so-called kritikoi in ways overlapping somewhat with Dionysius. Pausimachus (and by extension the whole group of the kritikoi) had argued that xópis appeals to the irrational in us and constitutes the core of any poetic aspiration. ${ }^{56}$ Dionysius also claims that xópıs is an irrational sensation and one that proves for him the most essential quality of Lysias. Beyond the obvious similarities, there are also substantial differences between the kritikoi and Dionysius on this matter. Firstly, Dionysius makes no attempt to actually understand xópis as comprising sounds and, if anything, he is clearly struggling to provide his readers with a clear definition of the concept. To be sure, Dionysius is emphasizing the centrality of

${ }^{56}$ Philodemus On Poems I.83.24-6 and I.89.I4-I6, quoted after the Janko (2000) edition. Gomperz restored 'pleasure' (Xópıv) in column Ioo from P. Herc. 994. col 6, 9-II. 
sense perception, but he is not clear which senses he has in mind (his examples range overall from aural sensations (music) to visual stimulations (painting and sculpture), or how the experience of this phenomenon could be broken down to smaller pieces (in a way similar to the kritikoi). Hence, Dionysius is reluctant to participate in the debate of whether it is sound or sense that should have primacy in oratorical compositions. Secondly, instead of focusing on one particular constituent of xápis (as the kritikoi do in prioritizing the aural perception of sounds), Dionysius concentrates almost exclusively on a specific author whom he considers to be the best learning-source for $\chi \alpha$ óp - Lysias.

Throughout the section we witness Dionysius working out his way closer towards an explanation of xópis. Since definitions and words are not much help, Dionysius turns to another art where senses are heavily involved - music. Borrowing from music teachers, who advise their pupils simply to cultivate their ear, which is the most accurate criterion

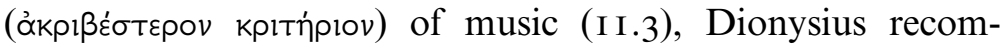
mends his students who wish to learn the nature of Lysias' xópls 'to train the instinctive feeling over a long time with

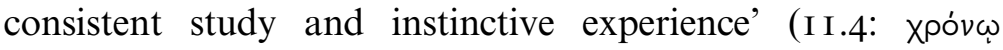

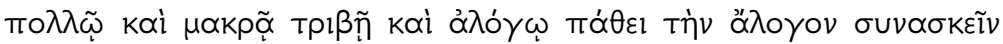
alo $\theta \eta \sigma i v)$. In other words, the first step towards a full appreciation of Lysias' mastery is to simply listen to and read numerous speeches by Lysias without making any attempt to critically discuss or otherwise engage with the work. This constant exposure to Lysianic style will form one's senses in such a way that will eventually lead to a uniform understanding of his particular style and make sure that any non-Lysianic feature will immediately stand out. ${ }^{57}$ How exactly this

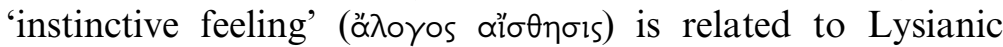
xópls, however, is not entirely clear. ${ }^{58}$ What emerges, however,

57 Dionysius' treatment of ä $\lambda$ oyos aï $\sigma \eta \eta \sigma ı s$ is discussed with conflicting conclusions by Schenkeveld (1975) and Damon (199I).

${ }^{8}$ One might also wonder whether Dionysius' method that he recommends for understanding Lysias' xópis could be meaningfully used to determine the qualities and idiosyncrasies of any author, and not just those of Lysias. Indeed, a passage 
is that this method, if that is the right way to call it, is associated with the universal impression of an author and his works, so that Dionysius associates Lysias' xópıs not so much with a particular virtue of style, but rather with the overall effect of his work. ${ }^{59}$

Looking for Dionysius' use of xópıs elsewhere, particularly in the comparisons between different orators, is helpful. It emerges, for example, that Lysias' speeches are compared to those of Isocrates explicitly as having 'lightness' and 'charm' (Isocrates 3.6). Juxtaposed to Isaeus, Lysias, by his simplicity

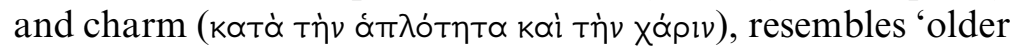
paintings which are worked in simple colors without any subtle blending of tints but clear in their outline, and thereby

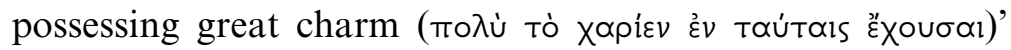
(Isaeus 4.I). From a passage in his Demosthenes (54.8), Dionysius seems to connect xápls with wit, just like Ps. Demetrius had done:

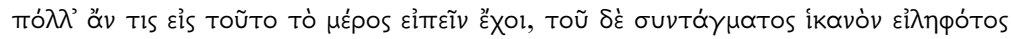

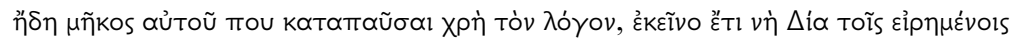

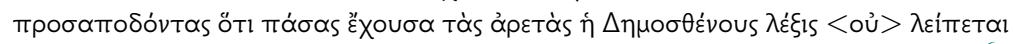

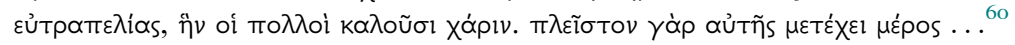

One could say many more things about this subject, but since the treatise itself is already long enough I had better finish my discussion. And yet this

from his essay on Demosthenes (Demosthenes 50.3) reveals that this is the case. Dionysius discusses the melodious composition of Demosthenes and recommends to those wishing to exactly understand Demosthenes' composition ( $\sigma \dot{v} v \theta \varepsilon \sigma 15$ ) to judge the most important and significant individual elements of the composition, the first being melody ( $\dot{\varepsilon} \mu \mu \dot{\varepsilon} \lambda \varepsilon 1 \alpha)$, the best means of judging which is the 'instinctive feeling' ( $\alpha \lambda \circ \gamma \circ \alpha_{\alpha}$ alo $\left.\theta \eta \sigma / s\right)$. Dionysius adds, however, that this requires much practice

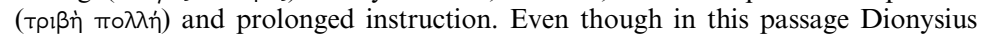
connects the 'instinctive feeling' more precisely with melody in style, thus giving his

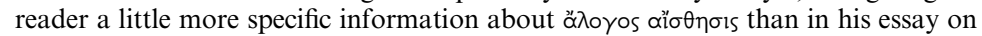
Lysias, its continued association with the aural aspects of style clearly suggests that Dionysius' thinking in the two works on the topic of 'instinctive feeling' is similar: Dionysius still considers the 'ear' a crucial sense for the evaluation of literary value and artistic success.

59 This overall effect of xópis could possibly be compared to what Aristotle and Theophrastus seem to have called tò í $\delta$. See Innes (1985), 256.

6o Usher (I974) prints the text without Reiske's addition of $<$ oủ $>$, which completely changes the interpretation of the passage. I follow here Aujac (I988) who adopts Reiske's addition, because Dionysius does not really hint anywhere else in his critical essays that Demosthenes did not have enough charm. 
point ought to be added to what has already been said, namely that Demosthenes' style with its many virtues also does not lack in wittiness, which many call charm. Largest part of that quality ...

Dionysius introduces here xópls as a synonym for $\varepsilon u ̉ \tau p \alpha \pi \varepsilon \lambda i \alpha$ and refers to the authority of 'the many' who have previously made this association. It is very unfortunate that the passage seems corrupt and breaks off at the end. I have adopted, with many hesitations, Aujac's interpretation over that of Usher and included <ou $>$ in the text to indicate that Demosthenes did not lack xápıs. It is, however, also possible that Dionysius concluded his discussion of Demosthenes with a brief reference to xópls and that in this context he would have ended the passage with a reference to Lysias, who has 'the largest chunk of this quality'. Seeing that Dionysius seems to reserve this quality primarily for Lysias, it would not be surprising if also in his discussion of Demosthenes' virtues and of his charm, Lysias would be used as a comparative force. ${ }^{61}$

Throughout Dionysius' critical essays, we are never offered a clear definition of xópı, a quality in which Lysias apparently overpowers everyone else and that seems to best stand for a summary term of Lysias' writing. Dionysius justifies his inability to define and better explain this concept by connecting it to the 'instinctive feeling' and associating it with other supremely important, but extremely difficult concepts of literary criticism. What emerges from this discussion is that for Dionysius xópls is somehow associated with the small, the commonplace and the witty. How exactly these associations work and how students could fruitfully imitate them, all that remains rather unclear. Yet, perhaps the difficulty in defining xópis served a purpose for Dionysius. In its social and educational context, it might have helped Dionysius to reassert the authority of rhetorical teaching and teachers, who will have sat down with their texts and trained their senses to recognize

${ }^{61}$ I regret that I do not have access to Costil (I949), on whose authority Aujac's interpretation seems to rely. There also appears to be a literary tradition that denies Demosthenes 'charm' and without Reiske's emendation of the text Dionysius appears to be flirting with that trend. 
different stylistic features characteristic of different authors. As a reflection of Dionysius' intellectual interests in criticism, Lysias' xópıs might underscore his fascination with these subtle means of persuasion and deception that manage to 'smuggle conviction unnoticed past the listener's senses' (Lysias I8.3:

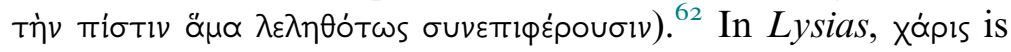
on several occasions mentioned in the company of or as a

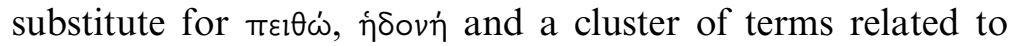
Aphrodite. When Dionysius points to the shortcomings of Lysias' style, for example, he writes that it does not have the capacity to 'force and compel his audience in the same way it is

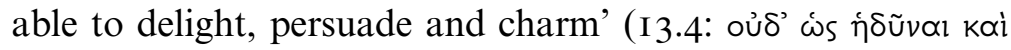

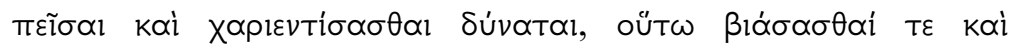

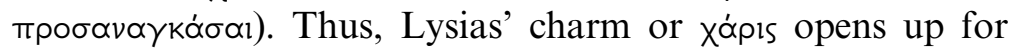
Dionysius and his students a way to see rhetoric as an amusing and delightful activity that is playfully exploring the murky waters of $\pi \varepsilon \imath \theta \dot{\omega}$ (persuasion) and deception.

\subsection{Lysias - a Greek Writer for Rome}

The sections that follow Dionysius' discussion of Lysias' charm ( $\chi \alpha$ '́p) are perhaps best summarized as 'Lysias the

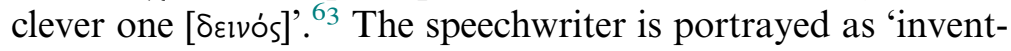

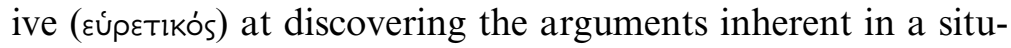
ation, not only those which any of us could discover, but also

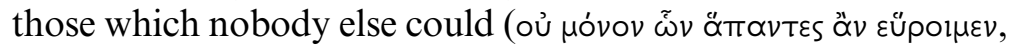

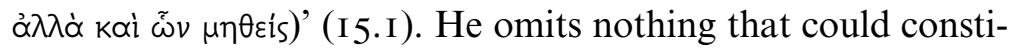

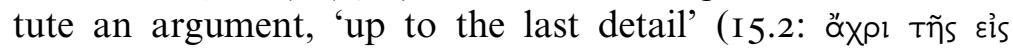

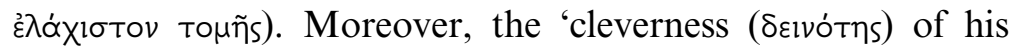
invention is best exemplified in those speeches in which there

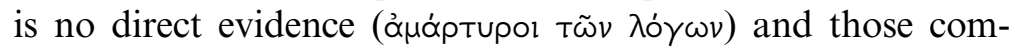

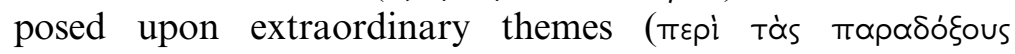

${ }^{62}$ Dionysius in the section quoted is talking about Lysias' narratives.

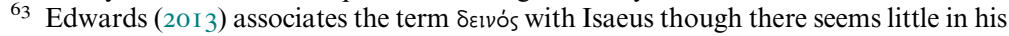
own analysis that would tie this particular concept together with Isaeus in particular (mostly Isaeus is treated, both by Dionysius and Edwards, as a frontrunner for

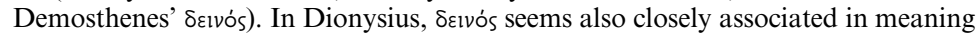
with 'sublime' (üพos); see more in Porter (2015), 395-6. 


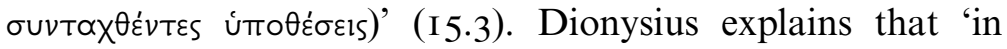
these he furnishes a great many excellent arguments and makes cases regarded by everyone else as hopeless and impossible seem easy and practicable' (I5.3). This cleverness finds its clearest expression on the forensic stage and Dionysius argues that 'in this type of oratory, he is more capable of speaking

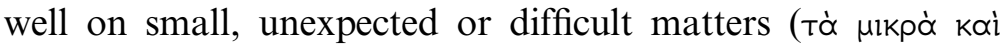

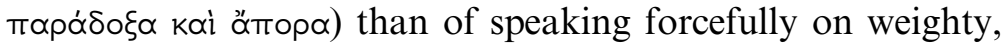
important or straightforward subjects' (I6.3). The fact that Dionysius fails to give any comments or analysis for the examples he cites from Lysias' ceremonial and deliberative speeches shows clearly that Dionysius' interests in Lysias' style are restricted to his forensic work. It might also be, even though Dionysius does not dwell much on this possibility, ${ }_{4}$ that Lysias' forensic speeches are most securely attributed to him in the tradition, whereas speeches from other genres had aroused questions about delivery and authorship. Be that as it may, Dionysius' Lysias is attractive for his ability to invent and twist arguments beyond one's imagination, for bringing unexpected and surprising solutions to complicated and impossible cases, and for talking about small everyday matters with a wide lay audience. These could have been characteristics that many young Romans and Dionysius' potential students might have found very attractive: here was an entertaining Greek author who would not put off students (and Romans?) with his philosophical gravity, ${ }^{65}$ and who at the same time has much to teach about 'playful intellectualism'.

That Dionysius was generally alert to the topic of appropriate audience and styles is clear from his essay Thucydides, where Dionysius comments on the complex style of Thucydides. In response to those who suggest that Thucydides 'can be read with understanding only by the

${ }^{64}$ As far as I see, Dionysius acknowledges the issue of Lysias' performances in a brief remark at paragraph 32 .

${ }^{65}$ It seems that the introductions of Cicero's work may be particularly relevant as reflecting the responses of his contemporary Romans to Greek culture and literature. See Baraz (2012) for a more detailed discussion. 
well-educated' (5I.I), Dionysius claims that 'in confining it to an extremely small minority of readers, they are removing from ordinary men's lives a necessary and universally useful

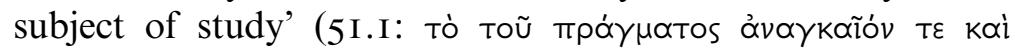

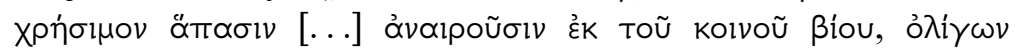

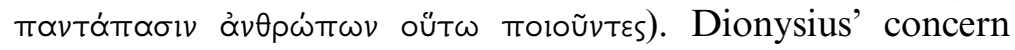
for the 'uneducated' reader is also strongly present in his

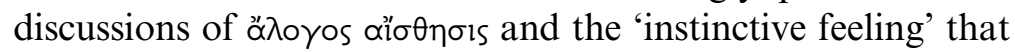
affects the critic and the non-critic alike. It seems fair to say, then, that Dionysius is in favor of clear and simple Attic prose; his criticisms of Thucydides and Isocrates, for example, point to their obscurity (Thucydides) or overly ornate style (Isocrates). It might not be too far-fetched to suggest, then, that this preference of simplicity and clarity also reflects Roman literary tastes and rhetorical education, ${ }^{66}$ and - if true could be interpreted as a confirmation of the above sentiment about the potential attractiveness of an author like Lysias for the Roman audience.

However, this conclusion might appear problematic when we look at what Dionysius explicitly tells us about his intellectual environment and his potential readership. In his $O n$ the Ancient Orators, which served as a broad (ideological) introduction to the critical essays on selected ancient orators, Dionysius claims that the changed appreciation of rhetoric is indebted to 'the fact that Rome was ruling the world' (3.I:

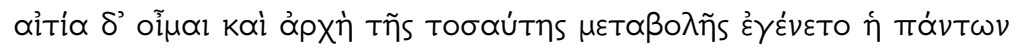

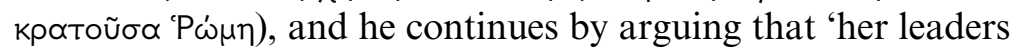
are chosen on merit, and administer the state according to the

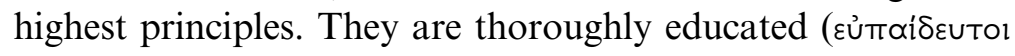

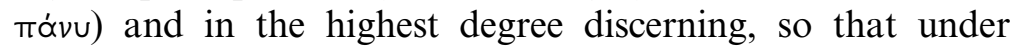
their ordering influence the sensible section of the population

${ }^{66}$ In Suetonius' Augustus (86.I), the emperor's stylistic preference is made clear: 'he cultivated a neat and sober style [...] his chief object was to deliver his thoughts with all possible perspicuity' (Genus eloquendi secutus est elegans et temperatum [...] praecipuamque curam duxit sensum animi quam apertissime exprimere). Hose (I999) emphasizes that Greek critics in Rome had Romans in mind as their intended audience and thus tailored their discourses to the particular tastes and expectations of the Roman setting. 


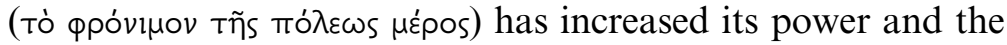
foolish have been compelled to behave rationally' (3.I). In other words, Dionysius claims that the level of education among the populace has risen in Rome and we can expect this to have a direct effect on Dionysius' evaluation of his students and readers. And indeed, Dionysius makes several gestures towards his imagined readership that support his high regard for their cultural education. In his essay Lysias, for example, he characterizes his audience as 'those knowing' or 'connoisseurs' (IO.I: દỉótes) and later on as 'well-educated and moder-

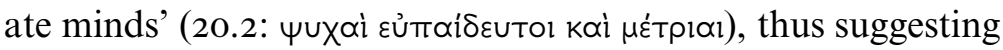
that he has high expectations for the intellectual capacity of his imagined readership. ${ }^{67}$ Yet perhaps these apparently conflicting views of Dionysius' intended audience are not necessarily mutually exclusive. Rome has already demonstrated her dislike for the ornate and excessive Greek style (On the Ancient

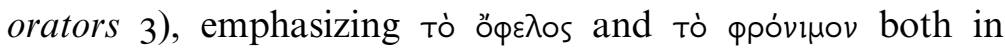
rhetoric and in style. Dionysius, building on this intellectual climate that prefers the simple over the complex, and the useful over the pleasurable, will thus find a favorable audience when commencing his critical essays with the Greek orator that most fulfils these conditions - Lysias. By proposing Lysias as the first role model for style, Dionysius is at the same time fashioning his audience as 'learned' men who already know that it is simplicity and effectiveness, the very virtues Dionysius ascribes to Lysias, that are to be valued highly in oratorical performance. In other words, Dionysius attracts the Roman elite reader to the Greek models by appealing to the virtues to which Romans are already committed and flattering them for having duly recognized these virtues thanks to their wide

${ }^{67}$ More parallels are collected in Hidber (I996), I20. Wiater (20II), 270-8 strictly emphasizes Dionysius' elitist approach to education and his readership and demonstrates its connections with his classicism. It is surely true, as Wiater maintains, that Dionysius' writings were addressed to the Roman elite, but we might not want to dismiss the possibility that the Roman elite was not as eagerly invested in classicism as Dionysius' rhetoric invites us to believe. Emphatically labeling one's audience as 'knowledgeable' and 'well-educated' might also have been used by Dionysius to flatter his readers and create a suggestive image for them that would be very difficult to reject. 
learning. Furthermore, if it is indeed true that Rome was suspicious of Greek intellectuals and philosophers and did not have high regard for their abstract argumentation and emphasis on theory, ${ }^{68}$ this might also show Dionysius' discus-

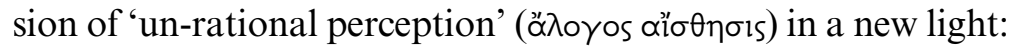
when Dionysius argues that the most important quality of Lysias' style is his charm (xópıs), which according to him depends on this kind of 'un-rational perception' (ä $\lambda$ oyos alo $\theta \eta \sigma 15)$ and cannot be understood through logical/abstract reasoning, Dionysius might in fact have put his finger on the Roman virtue of style par excellence. Even more than the emotion and power of a Demosthenes, this experience-based and sense-dependent charm that does not render itself amenable to theoretical discussion is what might have spoken most closely to the Roman oratorical practice. ${ }^{69}$ Hence, with his notion of 'charm' Dionysius appears to have given the Romans a useful critical tool with which to justify their high regard for Lysias and the kind of rhetoric that is associated with it. ${ }^{70}$

It has been briefly suggested by scholars before, ${ }^{71}$ but has not been followed up by any further examination, that Dionysius' essay on Lysias has a foundational role for Dionysius' criticism of the orators. This is particularly apparent in the first three essays of the project On the Ancient Orators, where essays on Isocrates and Isaeus are clearly

${ }^{68}$ Cicero has made this intellectual climate plain in his attempts to counter these accusations. He discussed this topic in depth in his lost Hortensius, but we see his continued engagement with this environment, for example, in his Tusculan Disputations (2.I). For thorough discussion of this passage, see Gildenhard (2007), I56-66. Griffin (I989), I 8-22 offers a fundamental analysis of the Roman suspicions about philosophy in public life, and a very helpful overview is provided recently by Baraz (20I2), I3-43.

${ }^{69}$ Cf. Gabba (1982), 48.

${ }^{70}$ I take Wisse's (I995) discussion of the Atticist movement as originating among the Romans as potentially strengthening my argument.

${ }^{71}$ E.g. Bonner (I 939), 27. Most recently Wiater (20 I I), 32 I ff. Wiater (20 I I), chap. 5 offers also a fascinating reading of Dionysius' complicated relationship to Plato and Platonists, and how Dionysius' treatment of Lysias is aimed to counter the stylistic observations of Platonists. In many ways his observations pave the way for the present discussion of the rivalry between Plato and Dionysius over the position of leading literary critic on rhetorical education. 


\section{Dionysius of Halicarnassus on Lysias}

written against the backdrop of Dionysius' work on Lysias, and the prominent presence of Lysias in Dionysius' critical work seems to be a strong indication that Lysias is used as a point of reference by Dionysius to develop and clarify his views on other orators.

Indeed, in Dionysius' essays on Isocrates and Isaeus, Lysias is clearly the central figure with whom both Isocrates and Isaeus are compared. In fact, both essays seem to reveal characteristics of Lysias as much as they tell us about the style of Isocrates and Isaeus. In the essay on Isocrates, for example, Dionysius runs quickly through the list of terms that he had

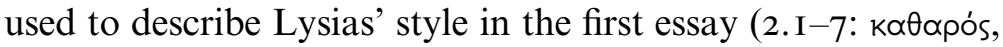

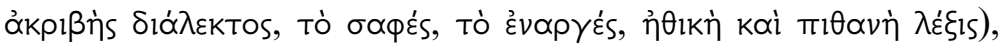
employs the same structure for discussion, and expands the list where Isocrates differs from Lysias (e.g. 2.4). Despite his appreciation of Isocrates' writings, Dionysius keeps coming back to Lysias as the point of departure for his discussion of style, and especially forensic style, throughout the essay. ${ }^{72}$ The same observations apply to Dionysius' essay on Isaeus. While Isaeus is positioned between and compared with both Lysias and Demosthenes, Dionysius' underlying comparative method follows the terminology that he had introduced in the first essay on Lysias: Isaeus' language is 'pure, precise, clear, standard, vivid and concise, and also persuasive, appropriate to the subject and suitable for law courts not less than that of Lysias'

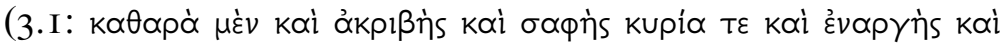

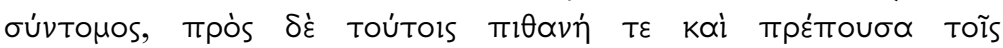

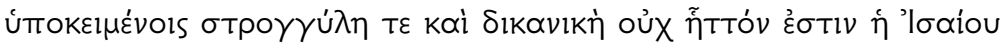
$\lambda \varepsilon^{\prime} \xi 15$ Tñs $\Lambda$ úiou). In his summary of the two orators Dionysius concludes, for example, that Isaeus aims more at artistic effect and forcefulness, while Lysias is more natural and charming

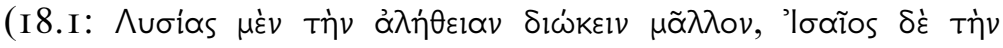

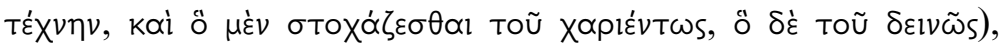
referring back to the characteristics introduced in his essay. These examples clearly show that the terminology and

${ }^{72}$ The whole discussion of style, for example, is summarized in paragraph io by a comparison with Lysias. 
language of comparison in these two essays require a close familiarity with Dionysius' essay on Lysias, where these features of style were first introduced and explained in more detail. His first essay, then, instead of showing undeveloped and uninteresting rhetorical criticism, might be better understood as a way for Dionysius to set the stage for the following critical discussions and to use the figure of Lysias, the most straightforward example of plain style, to shed light on the basic structure and critical language that he is going to adopt in his critical essays.

The critical language introduced in Dionysius' Lysias is also reflected, even though to a somewhat lesser extent, in his later work Demosthenes. Lysias is used as the representative of plain style and opposed to Thucydides who is the figure for grand style. When introducing Isocrates and the middle style, the main object of attention in this essay, Dionysius again makes productive use of Lysias and the characteristics of style introduced in Lysias to show how representatives of the middle style are able to make use both of the plain and the grand style. Isocrates' style, for example, is described as having the Lysianic purity (тò $k \alpha \theta \alpha \rho o ́ v$ ), clarity (тò åkpıßśs), use of

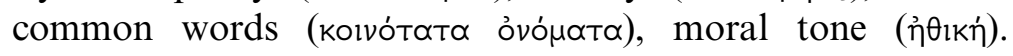
Furthermore, it is persuasive $(\pi \imath \theta \alpha v \eta)$, pleasant $(\dot{\eta} \delta \varepsilon \tilde{i} \alpha)$ and

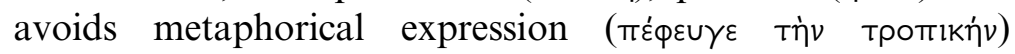
(4.I-2). Demosthenes' ability to write in a plain style is described with the same critical vocabulary familiar from Dionysius' previous essays. His forensic style is as pure

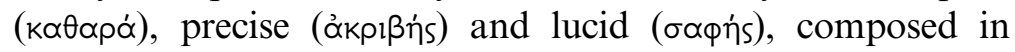
standard words ( of Lysias. It is also concise ( $\sigma \dot{v} v т о \mu о \varsigma)$, terse ( $\sigma т \rho о \gamma \gamma \dot{u} \lambda \eta)$, full of

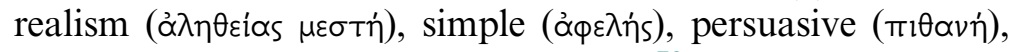
moral ( $\dot{\varepsilon} v \not \eta \theta \varepsilon l)$ and charming (Xópltes). ${ }^{73}$ In a later passage, Demosthenes' style is described as incorporating features of the plain style (tò бaфśs, tò koıvóv) where appropriate and the elements of the grand style when needed (34). In sum,

73 Demosthenes I3. I-2. 
Dionysius' discussion of Demosthenes' style is in certain respects drawing on the discussion of Lysias' style, and he is certainly making use of the same critical terminology in this later work.

Finally, Lysias and Dionysius' first critical essay Lysias have a prominent position in Dionysius' essay Dinarchus. In the beginning of the essay, Dionysius quotes the judgement of Dinarchus by another critic, Demetrius of Magnesia, who was active at the time of Cicero, thus a few decades before Dionysius. ${ }^{74}$ Demetrius appears to make use of a similar technical language to that we see in Dionysius: Dinarchus is described as persuasive, his diction portrays moral character in standard language, and is capable of arousing emotion. ${ }^{75} \mathrm{It}$ is curious that the first characteristic that Dionysius quotes from Demetrius' work is Dinarchus' charm which he compares

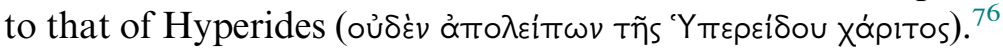
From this quotation, which is admittedly taken out of context and also intended to discredit the older critic, we get a sense that Demetrius considers xópıs a basic stylistic category, one that is easy to understand and does not require further explanation. Dionysius could not have disagreed more. Also, many orators are measured according to their xópis and this quality does not seem in any way connected (in Demetrius' quotation) to Lysias. It is perhaps not a surprise then that Dionysius finds fault with Demetrius and his approach to Dinarchus. Indeed, Dionysius is unhappy with Demetrius' criticism and complains that it is neither precise nor accurate; Demetrius has used the common critical terminology without contributing to the scholarship. ${ }^{77}$ Even though in what follows, Dionysius makes use of a very similar critical terminology, referring to terms like lucidity, naturalness, charm and animation, his

74 On Demetrius of Magnesia, see Mejer (I98I).

75 Dinarchus I.3:

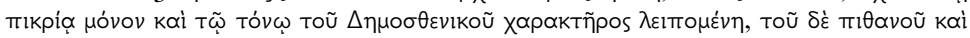

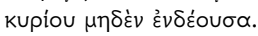

${ }^{76}$ It is worth noting that the occurrence of xópis in Demetrius' critical work on the orators indicates that a larger conversation occurred around that time on the concept of $x$ ópıs and its use in contemporary rhetoric.

77 Dinarchus 2.I. 
comparative criticism and close analysis of original passages make his judgement more systematic and informative. In passages where Dionysius introduces critical terminology, his early work on Lysias seems implicitly evoked for comparison and context. ${ }^{78}$ All in all, we notice a general trajectory of critical language from Dionysius' earliest critical essay on Lysias until his late essay on Dinarchus. This 'tool-kit' is enlarged throughout his numerous essays, but some of the most important features introduced in Dionysius' Lysias remain at the center stage of his critical outlook throughout his critical oeuvre.

This position runs somewhat counter to the arguments advanced by Bonner in his work on Dionysius' essays, where he aims to map out the development of Dionysius' critical method throughout his work on ancient orators. ${ }^{79}$ The evidence Bonner is drawing on, explicit examples from the essays where Dionysius adds new elements or elaborates on existing elements of his critical method, is clear and confirms Bonner's observations. It is surely true that Dionysius incorporates in the course of his writing new elements that show him as broadening his critical method and outlook. Yet, the fact that Dionysius' essays on the orators grow in sophistication as he emphasizes different elements in their styles might also be read to suggest that this was exactly what Dionysius' essays were meant to do from the start: Dionysius seems to invite us to follow the ever more complicated details of style and method as he works his way through the different authors, and thus asks us to build upon the knowledge we have acquired from reading the previous author and to apply and elaborate that on the subsequent authors he is discussing. The implicit crossreferences in his essays, as shown above for example in the essay on Dinarchus, seem to corroborate this conclusion. In fact, strategic thinking seems to be at the core of Dionysius' selection of the ancient orators: every figure enables him to pursue a different agenda and emphasize various aspects of

\footnotetext{
$7^{8}$ E.g. Dinarchus I.2, 6.2. 79 Bonner (I939), 23, I03.
} 


\section{Dionysius of Halicarnassus on Lysias}

Greek oratory and rhetoric that he perceived to be relevant to his Roman environment. ${ }^{80}$ While Lysias is the first in line and introduced as standard for style, Isocrates (as will be argued below) is important for giving the direction and moral boundaries for rhetoric. Isocrates also comes to stand for the teacher figure who serves as an intellectual for the community, effectively laying out Dionysius' own image as a teacher and critic in Rome, the cultural hub of the world. Isaeus is included as an intermediary between Lysias and Demosthenes, a teacher not of the city as a whole, but of the complete orator Demosthenes. $^{81}$

Lysias, then, is the earliest and the first orator treated in the collection, and he has therefore an important role to play in the whole project. Through this orator, Dionysius sketches out the terminology of style that he adopts for all following essays and introduces his critical method to rhetoric. The subsequent treatments of other orators will expand and modify, but not substantially change the outlook and critical 'tool-kit' introduced in that first essay. As such, Dionysius' critical essays seem to function almost like protreptics to literary and rhetorical criticism. ${ }^{82}$ Dionysius is guiding his reader towards a competence in literary and rhetorical criticism by feeding them with just enough information at each stop/essay to get a sense of increasing knowledge and understanding of the complicated field of rhetoric. And Lysias, the first author Dionysius discusses in detail, becomes a model of style against which all following orators are measured.

${ }^{80}$ In his manifesto On the Ancient Orators Dionysius also promises separate essays on Hyperides and Aeschines in addition to those on Lysias, Isocrates, Isaeus and Demosthenes, but these, it seems, were never written.

${ }^{81}$ On Isaeus, see also Edwards (2013).

${ }^{82}$ Wiater (20II), chap. 5 discusses Dionysius' criticism as dialogical and participatory, rightly drawing attention to the different voices that constitute his critical writing and to the cumulative effect of building a community that this style of writing will have on its readers. The point here is slightly different: Dionysius plans his critical essays to draw in students from the first essay onwards and to keep them going from the first to the last to get a full sense of his rhetorical program. Leigh's account (2004) on the preface of Quintilian 6 seems to work towards a similar argument. 
The inclusion of Isaeus over, say, Antiphon (the earliest Attic orator that we have evidence of ), may seem surprising. Indeed, it is curious that Dionysius decided not to include Antiphon in his list of orators, especially since this orator had been associated with forceful style before (Thuc. 8.68. I) and is credited by Dionysius elsewhere with innovative style (e.g. ad Amm. 2.3.). He would have been in a good position to claim a spot in his project. ${ }^{83}$ Dionysius asks himself this very question and responds, rather hesitantly, that Isaeus is admittedly only included for his alleged effect on Demosthenes (20.5: 'I think the seeds of genius [...] are present in this man', my emphasis). When Dionysius refers elsewhere, however, to the illustrious orators of that period, he readily substitutes Isaeus with Antiphon. So, for example, in his essay Thucydides, where he lists the three - Antiphon, Lysias and Isocrates (in that order) - as the 'leading orators of the day'

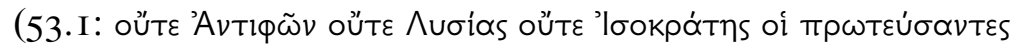

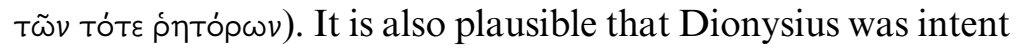
on commencing the project with Lysias and precisely for that reason did not want to include an older orator, Antiphon, who on a chronological basis would have had to precede Lysias and thus become the measure against which all following orators would be assessed. In order to create a neat chronological sequence and still keep Lysias in the first position, Dionysius decided to include Isaeus and leave out Antiphon.

There is something else about Lysias that might have been relevant for Dionysius: he was not an Athenian citizen. Though born and raised in Athens, Lysias was not and never seems to have become an Athenian citizen. ${ }^{84}$ In fact, he is the only non-Athenian orator included in the project $O n$ the

\footnotetext{
${ }^{83}$ See Usher's brief note about this (1974, I70).

${ }^{84}$ Thrasybulus' block grant of citizenship after the restoration of democracy in 403 BCE was very likely to have been blocked immediately by Archinus' graphe paranomon (prosecution for proposing an unconstitutional decree), thus giving no interim period for Lysias to resume citizenship, deliver speech I2 and then lose citizenship again. On Lysias' citizenship, see Todd (2007), I4-I6 with further bibliography.
} 


\section{Dionysius of Halicarnassus on Lysias}

Ancient Orators. $^{85}$ Therefore, in addition to what has already been said about Lysias' importance for Dionysius, it is worth considering the possibility that Lysias played such a crucial role in his critical essays also because he, like Dionysius himself, was not a citizen of the city (Athens/Rome) where he lived and reached his renown. Furthermore, Lysias' dedication to his 'host-city' Athens is widely on display in his twelfth speech, Against Eratosthenes, which is the only one in the corpus that can be confidently ascribed to Lysias himself (and as such the only non-logographic speech). To a large extent, the speech is staging a pronounced contrast between citizens and metics (under the Thirty), ${ }^{86}$ where the former have become the villains and a threat to the city and the latter (in particular Lysias and his family, of course) emerge as ultimate benefactors and restorers of Athenian democracy and its moral standard. ${ }^{87}$ The emphasis on the value of committed foreigners to the city is something that would have been relevant also to Dionysius and his fellow teachers, intellectuals and writers who hailed from the margins of the empire to contribute to the intellectual life of Rome. Whatever Dionysius' feelings towards Augustus and the political regime in Rome were at the time, ${ }^{88}$ his

${ }^{85}$ We ought not to forget, of course, that Dinarchus was a Corinthian, educated (like Lysias) in Athens, and is the subject of Dionysius' essay concerned primarily with ascription and authorship of the Demosthenic corpus. Dinarchus was not, however, included in Dionysius' project On the Ancient Orators and Dionysius admits himself (Din. I.I) that the addition of this orator has been something of an afterthought.

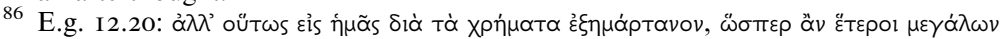

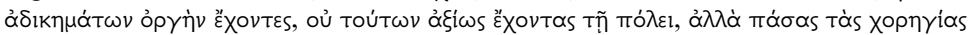

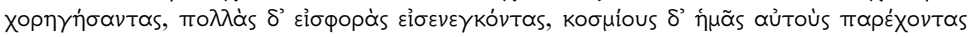

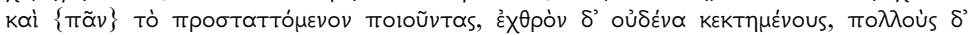

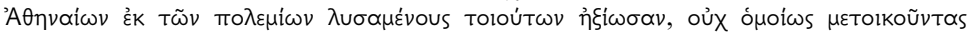

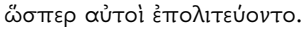

87 That the city has been hurt by its own citizens (and not by external forces or metics) is a frequent theme of the speech (I2.2: 'the defendants' hatred for their own city'; 39-40; 5I: 'this man treated the city as his enemy and your enemies as his friends'; 68, 78, 8I-2, 89, 92, 96, 99). The Thirty apparently had high moral goals (I 2.5: 'claiming they needed to cleanse the city of wrongdoers and redirect the remaining

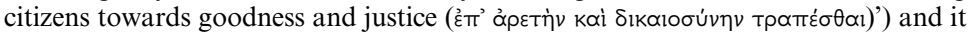
is the underlying goal of the speech to demonstrate the falsity of their moral enterprise.

${ }^{88}$ On Dionysius' political views towards Augustus, see Wiater (201 I), 206-I6, and most recently Pelling (20I8). 
Lysias - a Greek Writer for Rome

manifesto On the Ancient Orators clearly indicates a strong belief in Rome as the center of the world, and in himself as contributing to the flourishing of that city. Indeed, sometimes it takes a foreigner (Lysias/Dionysius) to restore and promote the values of the great city (Athens/Rome) ... 


\section{ISOCRATES AND PHILOSOPHY IN DIONYSIUS OF HALICARNASSUS' RHETORICAL WRITINGS}

We saw in the previous chapter that Lysias had a foundational role in Dionysius' critical work. Isocrates is another crucial pillar in Dionysius' rhetorical edifice, whose influence extends primarily to his treatment of the educational and philosophical components of rhetoric. Isocrates' importance for Dionysius has long been acknowledged and Dionysius himself is very explicit about it. He gives the clearest account of the Isocratean flavor of his program in his Isocrates, which is the second essay of the collection On the Ancient Orators. The structure of Isocrates is very similar to the previous work of the collection, Lysias, but in the course of the essay it becomes increasingly clear that Dionysius' emphasis and interest in the orator are visibly different from the stylistic concerns which were such a prominent feature of the first essay. ${ }^{\mathrm{I}}$ Dionysius sets up a new image of Isocrates, determined to show that he is not merely another orator on the list. We will see that Isocrates becomes a representative of the novel vision of education and rhetoric advocated by Dionysius and tailored to the particular political context of first-century BCE Rome.

On the one hand, it is clear from Isocrates' works, from the topics and the style in which they are treated, that he was not just another speechwriter. As we noticed before, his reception too, up until the first century $\mathrm{BCE}$, had primarily emphasized the political and philosophical aspects of his work, though the philosophical dimension had not received much detailed attention. He was primarily regarded as in opposition (and inferior)

\footnotetext{
I Bonner (I939) treats the two essays as fundamentally similar in structure and outlook, except that Isocrates falls short in some of the categories where Lysias excels. Bonner also points to the development of the critical method in this essay, where Dionysius goes into more depth in his analyses of the style of a particular author.
} 
to other philosophical schools. On the other hand, Isocrates had made significant contributions to writing and style, eventually also becoming firmly fixed in the canon of ten orators. ${ }^{2}$ Hence, despite his continued relevance for Greek paideia, Isocrates remained in-between rhetoric and philosophy and was - for all the reasons discussed in previous chapters - not a mainstream author, neither for the philosophers nor for the orators. One of the contributing reasons for such an assessment might have been Plato's Phaedrus, which also casts Isocrates famously as somewhere in-between rhetoric and philosophy. Similarly to his essay on Lysias, where Dionysius was in constant dialogue and competition with Plato's Phaedrus and its evaluation of Lysias' style, so too we see an underlying influence of the Phaedrus in Dionysius' essay on Isocrates. As a response to Plato and other critics, Dionysius' innovative approach to Isocrates lies in bringing him to the center of his rhetorical pedagogy and celebrating Isocrates' work as 'true philosophy'. His emphasis on the practical aspects of Isocrates' philosophy might also suggest that he was aiming to appeal to the tastes of his Roman students and readers.

\section{I Dionysius' On Isocrates}

Dionysius' essay on Isocrates is thematically divided into three parts: the long first chapter lays out Isocrates' life and summarizes his influence on rhetoric and philosophy, the second part (chapters 2-I4) reviews the stylistic and thematic strengths and weaknesses of Isocrates' discourses, and the third part (chapters I5-20) quotes and discusses two examples from Isocrates' speeches. The structure of the essay, then, is similar to Dionysius' previous essay Lysias and, furthermore, Lysias remains the most important figure of comparison for Dionysius' discussion of Isocrates throughout the essay.

\footnotetext{
2 On the notion of 'canon' (kav'sv), see Pfeiffer (I968), 207. For the canon of ten Attic orators, see Worthington (I994) and O'Sullivan (I997), who advocate a first-century BCE date. For earlier dates of the canon, see Smith (I995); for later dating, Douglas (I956).
} 
This supports a reading suggested above that the two works were intended to be complementary.

However, a few interesting details and divergences from Lysias immediately stand out in this essay. Firstly, compared to the biographical section of Dionysius' essay on Lysias, which was very brief and primarily focused on laying out the breadth of Lysias' writings, in this essay Dionysius takes time and space to inform the reader in more detail about Isocrates' life and teachings. It is not surprising that he relies in this section heavily on Isocrates' own writings, in which references to his position, career and mind-set abound. As Wiater notes, 'Dionysius adopts the self-image Isocrates created in his writings', ${ }^{3}$ and given the wealth of such information available, Dionysius appears to make use of this information as widely as possible. ${ }^{4}$ There might be, however, more to this biographical interest than first meets the eye. Isocrates' self-presentation is closely connected to his overarching message, repeatedly expressed in his discourses, that philosophy is not about theoretical quibbles and technical talk, but rather about making good decisions for the community and about how to reach those. Spending time on setting out in laudatory terms the kind of person, teacher and philosopher Isocrates was, is also time spent on preparing his readers for the kind of teaching and philosophy that Dionysius himself is striving towards. ${ }^{5}$ There is a marked contrast, therefore, with his evaluation of Lysias, who is expected to give the tone and perspective for a good rhetorical style. Isocrates and Dionysius will provide the substance.

From Isocrates' biographical details, Dionysius highlights the following as particularly important: his Athenian identity

3 Wiater (20I I), 68.

4 Some other examples where Dionysius makes use of Isocrates' own concepts or selfdescription to characterize the rhetorician are discussed in Too (I 995), 29-35, 76-7.

5 Cf. Wiater (20 I I), 7I. Dionysius' approach to Isocrates' biography seems to be thus connected with the importance of the lives of ancient (philosophical) authorities that start serving a separate function as educational models. To my knowledge, no other ancient author before Isocrates (and in fact very few after him, too) spends so much time in their works talking about themselves. I hope to address this topic elsewhere in more depth. 
and family background (I.I), early education and interests in philosophy and politics, his intellectual influences in both philosophy and politics (I.I-2), the important themes that characterize Isocrates' work (I.3), and the influence of his work in his own time (I.5). According to Dionysius, Isocrates was the first to turn rhetoric away from eristics and

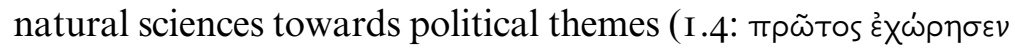

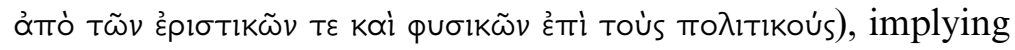
that Isocrates' approach was followed by later rhetoricians. Isocrates was an influential teacher and intellectual and his students were successful in a variety of fields (forensic orators, politicians, historians); Dionysius concludes that Isocrates had made his school a symbol of the Athenian polis (

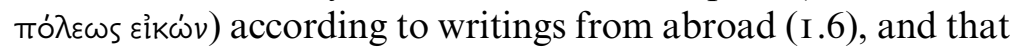
he was most successful in making money out of philosophy

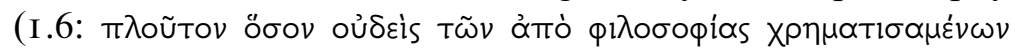

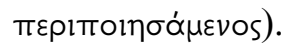

Many of these claims need unpacking and some of this explanatory work, especially in relation to Isocrates' contributions to conceptualizing Greek identity and its special appeal to Dionysius, has been undertaken in more recent scholarship. Hidber, for example, has recognized Isocrates' influence on Dionysius in the following areas: the use of antagonism between 'us' and 'them' (in Isocrates primarily shaped as a contrast between the Greeks and the barbarians), the idea of good education as being based on cultivating the ability to write good prose, and the idea of broad education as philosophy that prepares his followers/students for public life (political career). ${ }^{6}$ Wiater has mostly focused on Isocrates' influence on Dionysius' conception of the classical or classicizing identity. ${ }^{7}$ While the focus of these previous studies has been primarily on Dionysius' use of Isocrates for laying out his classicizing program, the aim of the following analysis is to look closely at the way in which Dionysius aims to create a coherent rhetorical tradition, where Isocrates is treated as a

\footnotetext{
6 Hidber (I996), 5I.

7 Wiater (2OII). This is also the primary topic of Goudriaan (I989).
} 
visionary tasked to lay out the ethical limitations and possibilities of rhetoric.

One cannot fail to notice Dionysius' downplaying of Isocrates' distinctive style in the essay. This is also noticeable from the fact that in the second part of the essay (2-I4), Dionysius spends only two chapters talking about style before turning to content. It is clear that Isocrates is important for Dionysius for what he says, but not how he says it. Isocrates famously advocated the idea that good prose is a sign of education or $\pi \alpha \delta \varepsilon i \alpha$, an idea that resonates strongly in Dionysius' writings. ${ }^{8}$ Yet, Dionysius' position on Isocrates' success in prose style is ambivalent: while acknowledging Isocrates' contribution to raising awareness of the importance of good written self-expression and making this idea one of the central points of his 'philosophical' school, Dionysius has at the same time few good words to say about Isocrates' own style. Chapter 2 of the essay, which is dedicated to a quick comparison between the styles of Lysias and Isocrates, presents Dionysius' criticisms of Isocrates' style: Isocrates' style is

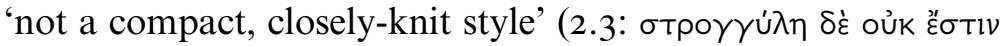

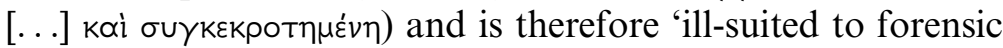

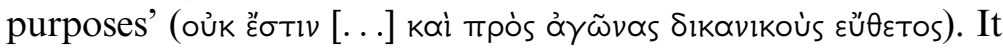

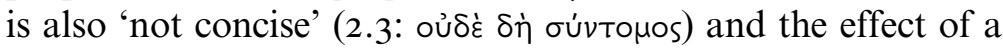
ceremonious and ornate dignity may at times be more attract-

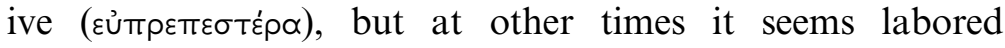

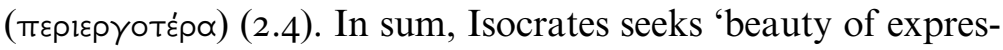
sion ( $\left.\varepsilon \mathcal{U}^{\varepsilon} \pi \varepsilon 1 \alpha\right)$ by every means, and aims to express himself in a

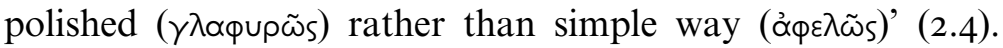
Finally, Isocrates uses the rounded period and strong rhythms (overusing the Gorgianic figures), all of which assimilate his prose to verse and thus render his work 'more suitable for

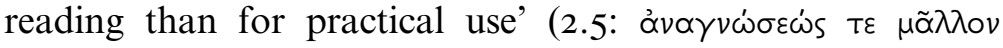

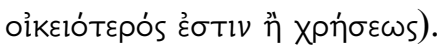

Dionysius' criticism of Isocrates' style is characteristic of Isocrates' reception (both ancient and modern) and 


\section{Dionysius' On Isocrates}

Dionysius points out that he is not the first to voice disapproval of Isocrates' prose. He introduces the views of previous critics in Chapter I3, just after having given a brief overview of his own criticisms of Isocrates' style, and claims that: 'This judgment of mine is not, of course, original: many earlier critics have held the same view regarding Isocrates' (I3.I:

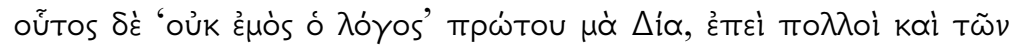

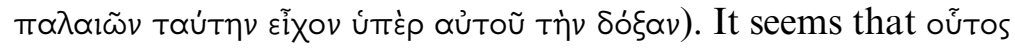
picks up a particular criticism of Isocrates' style and most probably is a reference to the unsuitability of Isocrates in an actual court or assembly hearing that Dionysius had discussed previously. ${ }^{9}$ That this is the case is confirmed by the quotations of critics that Dionysius introduces later on in the same chapter: Philonicus the grammarian complains that there is no accordance between the characters and their language (I3.2), Hieronymus the philosopher claims that Isocrates' speeches are unsuitable for declamation (I3.3), and many others critics hold similar views (I3.5). Dionysius agrees and evokes examples of Isocratean prose that confirm these opinions (I3.6). Even though Dionysius acknowledges the fact that Isocrates' speeches were not intended for public delivery in the courtroom (I.2), his occasionally scathing criticism of Isocrates' style betrays how tiresome his prose must have seemed to him as well. When introducing his own extended discussion of Isocratean style, Dionysius warns the reader to disregard Isocrates' overuse of stylistic features criticized above, because they will not be appropriate to imitate for court speeches, and advises them to focus instead on other qualities (тoĩs $\alpha$ $\lambda \lambda$ ors). Presumably he means the subject matter and how Isocrates 'shows that justice is superior to injustice not only on

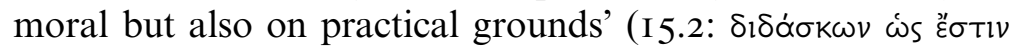

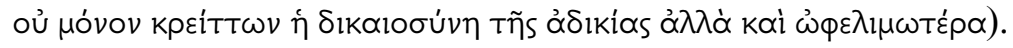
In short, critics who are looking for models in courtroom rhetoric have rightly advised against following Isocrates' style.

9 Goudriaan (1989), part I discusses the broader political background of the time and argues that due to the contemporary political scene Dionysius is more focused on assemblies and the courts. 
Dionysius suggests, however, that style and content can be kept apart and that Isocrates should be on everyone's minds for the latter aspect.

Is such a reading of Isocrates not undermining the unity of his teaching and thus misrepresenting his contribution? Indeed, Dionysius' criticism of an author who has championed the notion of kaipós as one of the driving forces of his philosophy, education and prose, for lacking in good judgement in the very things that he teaches (i.e. good prose) seems to require further explanation. To be sure, Isocrates' speeches convey the sense that his prose works are an expression of the content of his teachings, and that the two can hardly be separated. ${ }^{\text {IO }}$ That is, Isocrates' refined, carefully composed and long-winded sentences explicitly downplay the importance of an effective performative style and instead draw attention to the writerly character of his works. Isocrates, by emphasizing in his writing the very skills of good and sophisticated prose compositions and appreciating this ability as a sign of good paideia, which stands in the center of his educational program, makes no suggestion that one could distinguish his views on good prose from their content. Dionysius, however, appears not to see this problem; for him, Isocrates is essentially a ceremonial writer, whose writing will bear recitation at formal events or be studied privately (2.6): he does not belong in the courtroom and is

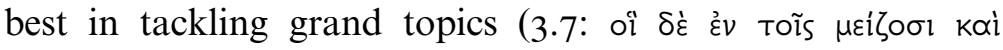

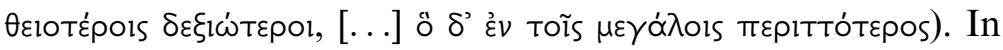
Dionysius' own words: 'most important is the scope of his discourses that he concentrated on and the nobility of the subjects upon which he chose to concentrate' (4.2: $\mu$ ó $\lambda_{1} \sigma \tau \alpha \delta$ '

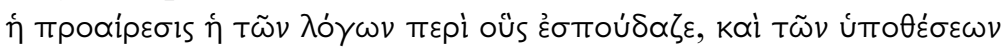

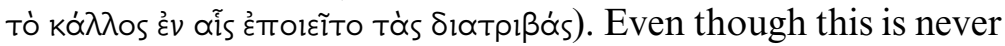
spelled out in his essays, Dionysius seems to regard a broader intellectual vision and good moral preparation essential for a successful demonstration of rhetorical mastery. In other words, Isocrates' words are not for imitation (nor were they

ro On the interconnectedness of Isocrates' prose and thought, see above, chapter 3.2. 


\section{Dionysius' On Isocrates}

so intended probably also for his own school in the fourth century $\mathrm{BCE}$ ), but for reflection and general improvement of character. In this sense, by constantly reminding his readers of the appropriate context for different kinds of rhetoric, Dionysius' distinction between Isocrates' style and philosophy seems more justified.

In sections 5 to 9 of the essay, Dionysius gives a list of the kinds of virtues or grand topics that one can find in Isocrates, with a brief summary of the speeches where he finds these notions advocated. In terms of the structure of the essay, this list is construed as a parallel to the kinds of stylistic virtues that Dionysius explored in his previous essay on Lysias. According to Dionysius, Isocrates' Panegyricus can be read as an exhort-

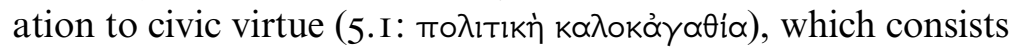

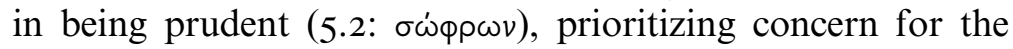
common good over personal advantage (5.2: oi $\gamma \varepsilon \tau \tilde{\omega} \nu \mu \dot{\varepsilon} v$

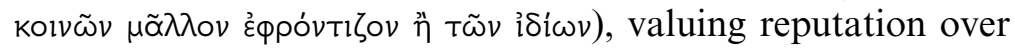

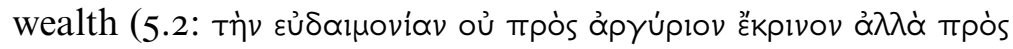

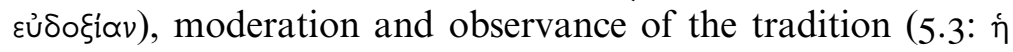

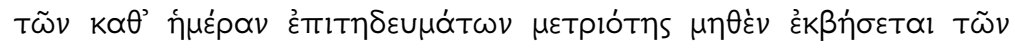
$\pi \alpha \tau \rho i \omega v)$, constructive spirit (5.4: $\pi \rho \circ \theta \cup \mu i \alpha)$, trustworthiness

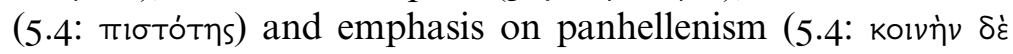

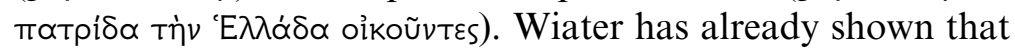
in summarizing the speech Dionysius is essentially relying on a very small selection of passages from that speech and has accommodated them to his own program as expressed in $O n$ the Ancient Orators, and that this is the method he adopts throughout the sections. II Isocrates' Letter to Philip should delight, according to Dionysius, anyone who is in a position of

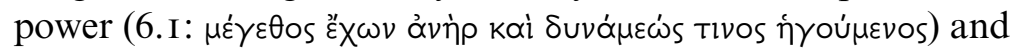
teach about the superiority of Greeks; his On the Peace should be read as an exhortation to justice and piety in international

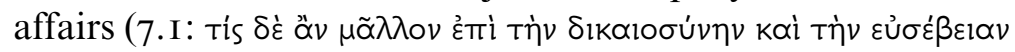

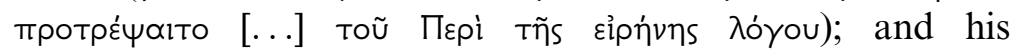
Areopagiticus as an encouragement to get responsibly involved

I Wiater (20II), 7I-4. 


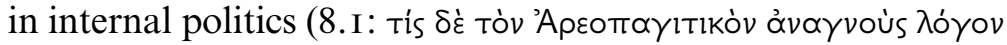

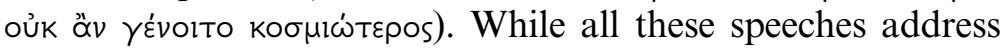
overlapping virtues that Dionysius mentions as the central theme of the Panegyricus, по of speeches also seems to characterize neatly and summarize Dionysius' interests: civic education (as portrayed in the Panegyricus), importance of Greek and Greekness (as expressed in the Letter to Philip), virtues involved in imperial politics (as laid out in On the Peace) and responsible civic action in internal politics (on the model of Areopagiticus). If this is a correct way to read Dionysius' priorities in introducing these speeches, then this is further evidence for reading Dionysius as deeply rooted in his contemporary political scene and tailoring his 'classicising identity' (in Wiater's words) to his Roman audience and their current political needs. ${ }^{\mathrm{I}}$

If indeed Dionysius is interested primarily in Isocrates' philosophy, why does he continue spending time on analyzing his style and criticizing it? Indeed, he is far more explicit about Isocrates' stylistic shortcomings than about laying out in more detail his philosophical content and rhetorical virtues. This could be related to what Damon suggests about Dionysius' critical methodology, that Dionysius' essays demonstrate the common asymmetry of judgement: it is far easier to describe the faults than to give as detailed an account of the virtues of a writer. ${ }^{\text {I3 }}$ But it might also be the case that Dionysius' 'failure' to go deeper in his explorations of the particular virtues of Isocrates' work stems from his programmatic lack of interest in the more theoretical discussions on education, oratory and philosophy, at least for the purposes of the project he had set himself in the preface to On the Ancient Orators. Instead, with his general and impressionistic praise of Isocrates, Dionysius gives his readers a rough idea of the kind of 'useful' philosophical

${ }^{12}$ Cf. Gabba (I982).

${ }^{13}$ Damon (I99I), 49-52. She applies this, rightly so, to stylistic criticism only and it is not obvious (in fact it seems counterintuitive) that the asymmetry of judgement would also apply to philosophical discussions. 
rhetoric he has in mind. ${ }^{\text {I4 }}$ It is not the kind based on theoretical discussions of abstract matters, but rather the kind which appears to bring about a change in the listener's character or mind-set simply by appealing to themes that are of seminal importance: war, peace, good life, education and so on. Interestingly, and perhaps not at all surprisingly, the impact that he seems to envision for this Isocratean philosophical rhetoric comes rather close to his ideas of Lysianic xópıs: through reading and studying of Isocrates' work one cannot but come to realize the importance of these virtues and - having internalized them - employ them in one's own political or writerly career. There is no need to linger on these virtues at great length (as there is no point in trying to get theoretical about how to achieve xópls) for this is something that seems to happen to the readers of Isocrates almost instantaneously: tís oủk å $v$ ývoolto (8.I)... Or at least, this is the effect Isocrates' works will have on well-instructed students who have been exposed to these topics for a prolonged time. These brief introductory expressions of admiration for Isocrates' discourses are well in line with Dionysius' rhetorical program in which he assigns primary attention to the imitation of classical models and rejects the view according to which one could gain rhetorical insight from technical workbooks on the topic alone. ${ }^{\mathrm{I} 5}$

Despite the fact that Dionysius eschews any more detailed engagement with philosophy, he refers to philosophy and related fields often enough to justify a further exploration into his philosophical commitments and positions. Isocrates is, after all, initially introduced in the biographical section as a

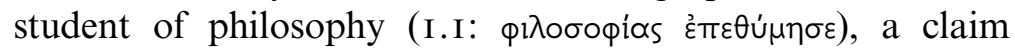
qualified in the next sentence by a reference to Isocrates' teachers, Prodicus, Gorgias and Tisias. The ancient philosophical tradition links these three figures primarily, or even solely, to rhetoric and sophistry rather than to philosophy, surely as a

${ }^{14}$ Of course, appealing to тo Xpírıov is the standard aim of the educational tradition, but it might have a particular ring in the Roman context and among the Roman audience who are notoriously suspicious of Greek philosophy and theory.

${ }^{15}$ Cf. Dionysius' First letter to Ammaios 2.3. Goudriaan (1989) describes Dionysius as a 'dynamic writer' (I4-I6) and claims that he distances himself from technocratic writings (I7). 
result (at least partly) of Plato's negative portrayal of sophists in his dialogues. ${ }^{16}$ When Dionysius calls Isocrates' training 'philosophical' and appeals as evidence for this claim to figures who have been employed by Plato precisely to specify what philosophy (as Plato construes it) is not, Dionysius appears to signal from very early on in the essay that his conception of rhetoric and philosophy will be provocatively different from that used in the philosophical schools. Furthermore, it is not a random list of sophist-philosophers that Dionysius refers to here. Indeed, when Dionysius constructs an intellectual ancestry for Isocrates' philosophical thought he is using three sophists who all have been traditionally linked with each other through a teacher-pupil relationship: Tisias was arguably Gorgias' teacher, ${ }^{17}$ and according to several ancient accounts Gorgias was a teacher of Prodicus. ${ }^{18}$ Ancient accounts that look back at the emergence of rhetoric and rhetorical theory consider Tisias one of the principal contributors (together with Corax) to this movement. ${ }^{19}$ By tracing his intellectual lineage all the way back to Tisias, ${ }^{20}$ Dionysius not only challenges the concept of philosophy, but he also creates a sense of a continuous school of thought around Isocrates, thus lending his ideas a more ancient and authoritative aura. It was well known that Isocrates had officially set up in Athens a school of philosophy, but - since it never had succession like the Academia and the Peripatos - it eventually died out as a school after the death of Isocrates. Dionysius here connects Isocrates to thinkers who were active before philosophy became a fixed concept and

${ }^{16}$ For attempts to recover the intellectual heritage of the sophists, see Kerferd (I98I) and de Romilly (I992).

${ }^{17}$ See further de Romilly (I992), 58-60.

${ }^{18}$ For a good overview of Prodicus' biographical data, with ancient testimonia, see Mayhew (20II). In the Suda, Prodicus is claimed to have been the student of Protagoras, but there is also a parallel tradition associating him with Gorgias. There is another interesting aspect sometimes emphasized in Prodicus' biographies, namely that he had a deep voice which made what he said quite unintelligible (Plato Protagoras 315c-I6a). As has been noted, this is ironic given that Prodicus was famous for his insistence on the clarity of words.

19 Cicero Brutus I2.46, attributing this view to Aristotle.

${ }^{20}$ Isocrates would of course not have been pleased about being fashioned as a pupil of these 'older sophists'; cf. Against the Sophists I9-20. 


\section{Dionysius' On Isocrates}

therefore reinforces the idea that Isocratean philosophy is 'true philosophy' because it goes back to the earliest thinkers in Greece.

It is also significant that Prodicus, Gorgias and Tisias were famously known for having gathered substantial wealth through their teachings. ${ }^{21}$ Plato is one of the main sources for this perception, but it is also confirmed by Isocrates who claims in his Antidosis ( I55), for example, that of all sophists Gorgias made most money from teaching. Be that as it may, by Dionysius' time it might have been commonplace to regard the activity of ancient sophists as a lucrative business, ${ }^{22}$ all of which makes it even more curious that Dionysius is evoking the trio with all their heavyweight sophistic connotations as philosophical teachers of Isocrates. Furthermore, Dionysius then goes on to say that Isocrates himself made most money

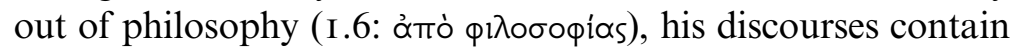

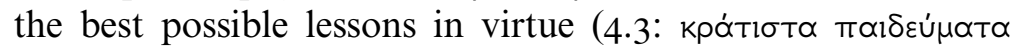

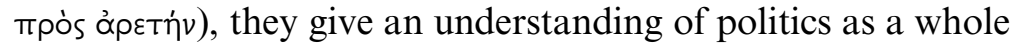

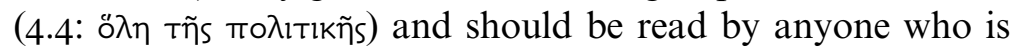

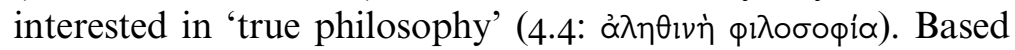
on this description, Dionysius appears as a careful reader of Isocrates and eager to amplify the provocation that the latter had introduced for his contemporary philosophical schools and intellectuals. ${ }^{23}$ We should also note that Dionysius never mentions Socrates as an influence on Isocrates. It may not be too far-fetched to suggest, then, that Dionysius reiterates Isocrates' challenge to contemporary educational models and scholastic philosophical schools.

There is another noteworthy aspect to Dionysius' mentioning precisely these three names as Isocrates' teachers rather than any other famous ancient rhetoricians. We have already

${ }^{21}$ Prodicus is credited, for example, in a scholium to Aristophanes' Clouds 36 Ia with having been the first to introduce a 'fifty-drachma epideictic speech' ( $\pi \rho \tilde{\omega}$ Tos $\delta \dot{\varepsilon}$

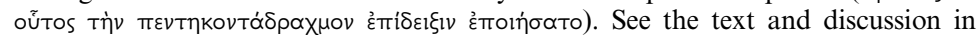
Mayhew (20II), 74. Isocrates also refers to these 'older sophists' as 'professors of

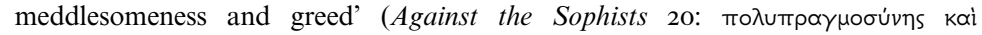

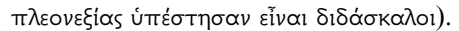

${ }^{22}$ It certainly seems to be the case by the time of Dio Chrysostom; cf. speech 54.

${ }^{23}$ For Isocrates' provocation to Socratic schools, see above, Chapter 4. 
noted the specifically anti-Platonic flavor of these first paragraphs of the essay, and this impression becomes even stronger if one considers that the only other place where these three names are evoked together is Plato's Phaedrus $(267 \mathrm{a}-\mathrm{b}) .{ }^{24}$ In this passage, Socrates gives a list of sophists who have composed handbooks of rhetoric and whom Phaedrus considers teachers of rhetoric. He then brings out (in mocking tone) in each case what are commonly perceived to be their contributions to rhetoric. Tisias and Gorgias are credited with the invention of giving more weight to probabilities over truth, of making the small appear great by the power of their words, and of having introduced 'conciseness of speech and measure-

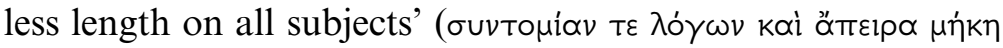

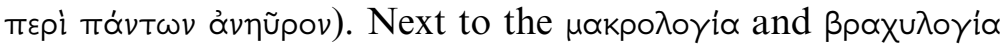
of Tisias and Gorgias, Prodicus is mentioned as an innovator

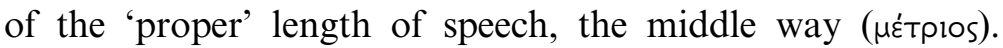
Socrates' sarcastic tone when listing the famous sophists who claimed to have made advances in the art of rhetoric leaves no doubt that this constitutes a re-evaluation of these writers. Indeed, somewhat later Socrates recategorizes them as contributors to the preliminaries of the art but not to art itself (268e-9a). When Dionysius maintains, in contrast, that Tisias, Gorgias and Prodicus taught Isocrates important philosophical insights (about rhetoric?), he goes not only against the standard philosophical tradition which had considered the trio sophists, but against this passage in the Phaedrus specifically. For while Dionysius suggests that (at least some of) the philosophical core of Isocrates' works goes back to his philosophical studies under Tisias, Gorgias and Prodicus, Plato denies them any place in the art of rhetoric, not to mention in philosophy.

Is it possible that Dionysius simply misunderstood the Phaedrus and is evoking it to support his interpretation even though the dialogue itself, when read closely, suggests a

${ }^{24}$ Gorgias and Prodicus are often referred to together (e.g. Meno 96d, Apology I9d), but there are very few references to Tisias, also outside of the Platonic corpus. 
different kind of reading? ${ }^{25}$ We have seen before that Dionysius opts for a superficial reading of the characters' claims and does not consider the possibility of irony (e.g. in the evaluation of Lysias or the praise of Isocrates at the end). This is possible, though I consider it rather unlikely. Dionysius' ambivalent attitude to Plato, particularly to the latter's competence as a stylist and a critic of style, suggests that Dionysius does have the ability to critically engage with the text. I think it is more likely that Dionysius goes against Plato and Plato's authority deliberately. This would bring about two possible reactions: for those who know their Plato, Dionysius appears a provocative author who is undertaking a criticism of the most influential text published thus far on the rhetorical tradition - the Phaedrus. For those who are not familiar with the complexities of the rhetorical and philosophical tradition (especially for Dionysius' students), Dionysius appears to reinforce ideas presented there and is thus able to demonstrate his intimacy with the characters and terminological details of this powerful dialogue.

All in all, Plato's Phaedrus appears to frame Dionysius' discussion of Lysias and Isocrates and it is certainly a work with which Dionysius is closely, if antagonistically, in dialogue. ${ }^{26}$ That Dionysius is a close reader of Plato's Phaedrus, and emphatically regards Isocrates as the representative of 'true philosophy', prompts further questions about his conception of philosophy and the way it is treated elsewhere in his critical works. In On the Ancient Orators, for example, Dionysius describes the overall motivations for his critical project and suggests there that the work is intended primarily for 'those

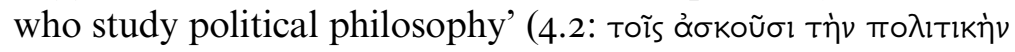
$\left.\phi \imath \lambda \circ \sigma \circ \varphi^{\prime} \alpha v\right)$. We will briefly investigate what exactly that means and to what extent Isocrates is a guiding figure for such 'political philosophy' throughout Dionysius' critical works.

${ }^{25}$ I would like to thank Harvey Yunis for prompting me with this important question.

${ }^{26}$ This is, of course, also clear from Dionysius' use of the Phaedrus in his essay on Demosthenes. 


\subsection{Dionysius on True Rhetoric, True Philosophy and True Isocrates}

With regard to his views on rhetoric and philosophy, Dionysius does not seem to be a follower of any one particular philosophical school. Instead, it has been argued that Dionysius draws on a variety of philosophical schools, such as the Stoics (especially in grammar), Peripatetics and that he has a close familiarity with Plato. ${ }^{27}$ In his essay on Isocrates, Dionysius provocatively associates his interests in Isocrates with what he calls 'true' philosophy (4.4: $\left.\alpha^{\lambda} \lambda \eta \theta_{\imath} v \dot{\eta} \phi i \lambda \circ \sigma \circ \phi^{\prime} \alpha\right)$. This section should probably be read side-by-side with the opening sections of On the Ancient Orators,

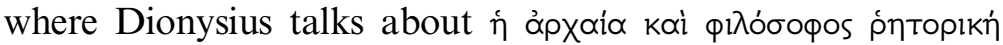
(I.2) - an ancient philosophical rhetoric - which, given the intense debates of the fourth century ВСЕ (at least as recorded in Plato, Isocrates and Aristotle) on the complicated relationship between philosophy and rhetoric, might seem rather controversial, or at least require further explanation. As mentioned above, this combination of philosophy and rhetoric vividly evokes Plato's views on this matter in the Phaedrus which has already been suggested to play a more general and in a way fundamental role in evaluating the aims of Dionysius' critical essays. Dionysius does seem to take up Plato's challenge of developing a 'philosophical rhetoric', but, instead of joining rhetoric with (Platonic) metaphysics, Dionysius weaves political and ethical philosophy into current practices of rhetoric. Indeed, there is something deeply un-Platonic in Dionysius' understanding of this kind of philosophical rhetoric as the starting point, rather than a distant and perhaps unachievable goal (as in the Phaedrus), of a rhetorical or philosophical enterprise. While the Phaedrus begins with rhetoric and moves slowly to a different, philosophical, conception of the art, Dionysius proposes philosophical rhetoric almost as a generally understood or common notion requiring no further explanation.

${ }^{27}$ See de Jonge (2008) on Dionysius' engagement with the Stoics, and Bonner (I938), Wooten (I994) and Fortenbaugh (2005), I4-I7 on Dionysius' Peripatetic inclinations. Plato is, after Demosthenes, the second most quoted name in Dionysius' oeuvre. 
Another controversial, and arguably anti-Platonic, aspect that Dionysius brings up in relation to Isocrates and his practice of philosophy is money. ${ }^{28}$ This topic was briefly touched upon above in the analysis of Dionysius' use of Tisias, Gorgias and Prodicus as Isocrates' philosophical models. It seems that ever since Plato's dialogues, where sophists' lucrative practice of 'selling education' was subjected to profound criticism with long-lasting effect on subsequent generations, ${ }^{29}$ material wealth had been strongly disassociated from (teaching) philosophy. Amongst different philosophical schools, Isocrates had always been the exception who did not criticize his contemporary sophists for taking money, but suggested that they were taking too little! ${ }^{30}$ To judge by the way in which Dionysius emphasizes and applauds Isocrates' financial success through his philosophical activities, it is clear that Dionysius has a rather un-Platonic position on this aspect of education and philosophy, and he openly turns to Isocrates, Plato's rival, as a model for an intellectual as well as a financial success story. ${ }^{3 \mathrm{I}}$ But what exactly does this emphasis on financial success mean in the context of Dionysius' essays? Perhaps nothing less than challenging the position and role of philosophy in his contemporary environment and, through the figure of Isocrates, sketching out another way to see philosophy as practical and meaningful for the social and political surroundings. Hence, Dionysius does not turn to Socrates when in search of alternatives, for Socrates is claimed as the fountainhead for most philosophical schools of the time, but rather to Isocrates. In fact, Dionysius mentions Socrates only as a character in Plato's dialogues, or makes use of 'Socratic' as a generic term for writers of Socratic dialogues ( $\Sigma \omega \mathrm{kp \alpha t \imath koi}$ $\lambda o ́(0)$ ). ${ }^{32}$ Dionysius does not refer to Socrates' engagement

${ }^{28}$ On Isocrates' relationship to money and philosophy, see above, Chapter 4.

${ }^{29}$ Perhaps most famously in Plato's Sophist 223a.

${ }^{30}$ E.g. Isocrates' Against the Sophists 3-6.

${ }^{31}$ Cf. Letter to Gn. Pompeius for Dionysius' further critical remarks on and engagement with Plato.

32 Socrates as a character in Plato's Phaedrus: Demosthenes 7. For references to and discussions of Socratic writings see, for example, Demosthenes 6 and 23 (Plato the Socratic), $C V$ Io (Xenophon) and I6 (Plato the Socratic), and Thucydides 5I. 
with Athenians or his influence on moral philosophy. Moreover, it seems that the image of the impoverished Socrates that became an important inspiration for the conception of a (true) philosopher carries little weight with Dionysius, whose turn to Isocrates, one of the wealthiest Athenians of the time, clearly signals a highly polemical attitude towards this kind of philosophical tradition. Dionysius is instead attracted to Isocrates who stands for an intellectual who values rhetorical education with its emphasis on language and writing, who has a stake in politics and considers active participation in actual decision-making as one's civic duty, and finally who has a respectable standing in society due to ample financial means, thus giving intellectuals the (political) authority needed to promote culture and education. This image of a rich Isocrates might have struck the wealthy Roman patrons as an attractive model of an intellectual. Indeed, these are the same patrons who would presumably send their offspring to be taught by Dionysius.

In his critical essays, however, Dionysius is cautious with terminology, and it might seem as if his references to philosophy do not bear out this provocative reading sketched out above. Looking at Dionysius' (explicit) engagement with the

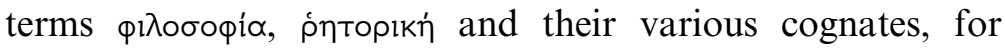
example, it appears that despite the fact that Dionysius claims Isocrates to be the proponent of 'true philosophy' ( $\alpha \lambda \eta \theta_{i v} \dot{\eta}$ $\left.\phi i \lambda \circ \sigma \circ \phi^{\prime} \alpha\right)$, in his essay Isocrates he most often describes him

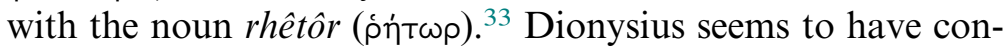
sidered $\rho \eta \dot{\tau} \omega \rho$ the most appropriate label for Isocrates, as he uses this often (as a stylistic device) to avoid repeating Isocrates' name (e.g. 8. I, 9. I, 20.5). In fact, the word 'philoso-

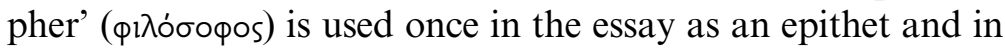
this case to denote somebody else: in Chapter I3 where Dionysius introduces the positions of previous critics on the style of Isocrates, he claims that Hieronymus the philosopher

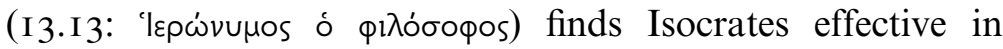

33 E.g. 3.7 (twice), 4.4 (twice), 8.I, 9.I, I5.I, 20.5. 
True Rhetoric, True Philosophy and True Isocrates

reading but unsuccessful when delivered. What is interesting about this sentence, aside from its comparison with Isocrates, is the reference to a philosopher who is actually reading Isocrates' works and assessing them on the grounds of their 'performability'. In the same essay, on another occasion, Dionysius goes as far as to contrast Isocrates with philosophers. When commenting on Isocrates' speech Archidamus, Dionysius claims: 'I would certainly say that Isocrates was giving this advice not only to the Spartans but also to other Greeks; and for all men it is much more effective advice than that given by all those philosophers who make virtue and

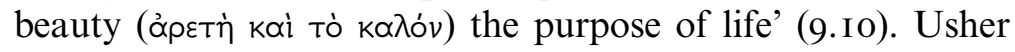

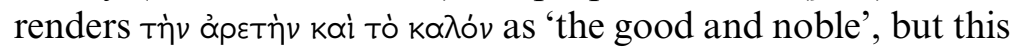
might obscure Dionysius' point. For Dionysius is presumably not saying that Isocrates is uninterested in 'the good' as the goal of life; he seems instead interested in drawing attention to the distinction between the immediate and pragmatic on the one hand, and the general and valuable in itself on the other. $\mathrm{He}$ is praising Isocrates for giving clear pragmatic advice to the Spartans and everyone on how to act in particular circumstances, and Dionysius suggests that in these circumstances (when decisions regarding war are made) this kind of advice is to be preferred to the more general and vague discussions of the philosophers. This comparison gives us significant information about Dionysius' opinion of philosophers, and gives some hints about why Isocrates is not associated with the фı $\lambda$ óooфor. ${ }^{34}$ The so-called philosophers are simply useless characters and calling Isocrates by that name would obscure his potential contributions.

Yet, while Isocrates himself is not awarded the 'title' of a

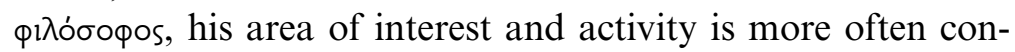
sidered by Dionysius as philosophy. We see this shifting focus, for example, in the very first chapter of the essay, where Isocrates is described as being attracted to the study of phil-

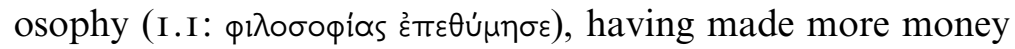

${ }^{34}$ Isocrates the rhetor is also contrasted to Plato the Socratic philosopher in Demosthenes 3.2. 


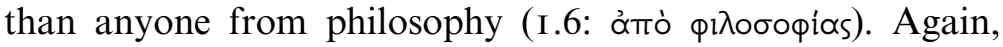
Dionysius suggests that anyone interested in 'true philosophy'

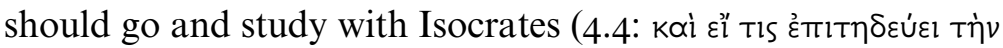

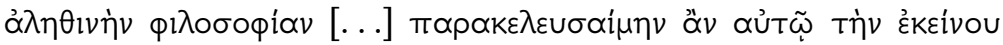

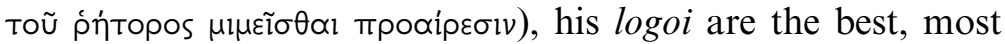

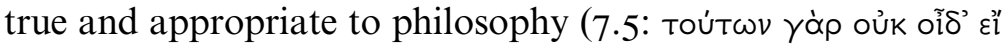

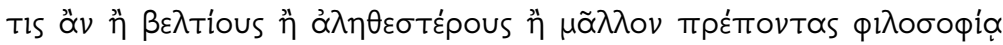

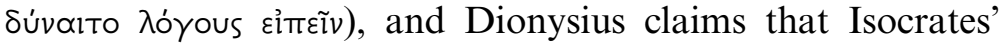
'philosophical purpose' is superior to everyone else's (I 2.2: tò

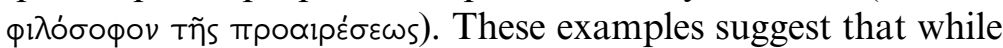
Dionysius deliberately avoids calling Isocrates a philosopher, he is at the same time happy to refer to Isocrates' activity and works as philosophy. This is in line with Isocrates' own conception of his practice, for he too avoided openly calling himself a philosopher, and instead made claims about philosophy. ${ }^{35}$

But what does Dionysius mean when he talks about 'true philosophy'? What kind of opposition is he setting up with this insistent emphasis on 'true' (as opposed to 'false'?) philosophy? Is 'true' here simply another way to say 'better' or 'more accurate'? Dionysius makes no attempt to clarify this usage and, interestingly, in his preface to On the Ancient Orators he

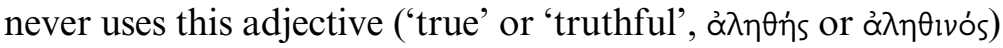
to characterize the subject of his work, 'the ancient and philo-

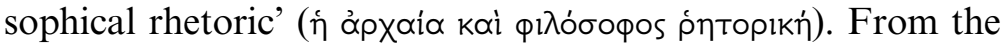
previous discussion, however, it seems clear that 'true philosophy' is a polemical term and intended to be opposed to some other, previous, conceptualizations of philosophy. What exactly Dionysius intended with this opposition we cannot know for sure, but it is highly plausible that Dionysius contrasts his notion of philosophy with that put forth by philosophical schools which laid primary emphasis on theoretical contemplation and presupposed theoretical foundation as the

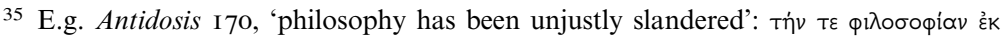

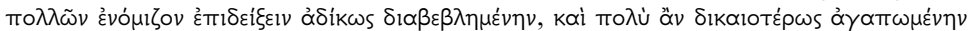

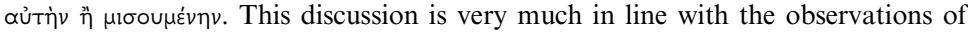
Hunter (20I2), I I8. 
basis for any form of action. Dionysius, who advocates in his critical works a view of judgements as having both rational and irrational components, ${ }^{36}$ must therefore regard this kind of (anti-theoretical) philosophy as 'more true' to human nature, as it also takes into account human actions that cannot be logically reasoned or accounted for. In this sense, Isocrates' denial of the possibility for human knowledge with its wider implications for any kind of theoretical activity could well be seen as parallel to, or an inspiration for, Dionysius' 'true' philosophy.

It has to be taken into account that Isocrates and his pupils were operating in a very different environment from that of Dionysius, and that the semantic fields of the notions 'philosophy' and 'philosopher' were more fluid and less theorized in fourth-century BCE Athens when compared to first-century BCE Rome. ${ }^{37}$ By Dionysius' time, philosophical schools had been running for about three hundred years, each making specific claims about philosophy and what it means to be a 'professional' philosopher. Moreover, often the direction and specific interests pursued in a philosophical school were determined by the lead 'professional' scholarch: e.g. with Arcesilaus the Academy became skeptic, with Antiochus of Ascalon the Academy became eclectic, Chrysippus developed Stoic logic and is famously claimed to be responsible for the existence of the Stoa, and so on. ${ }^{38}$ The notion of a 'philosopher' had thus become associated with a professional thinker who worked within a specific philosophical tradition and was in constant conversation with a rather narrow circle of similar-minded people. Despite their potentially conflicting positions, members of different philosophical schools would nevertheless call their

36 See more on this below.

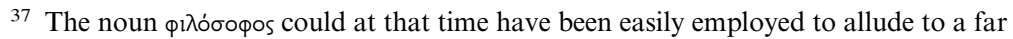
broader range of meanings (e.g. 'wise man', 'lover of wisdom' etc.) and Isocrates' use of this terminology, discussed above, is testament to this observation. A quick comparison with Plato, however, reveals that the latter uses the noun very frequently to refer to a 'professional' philosopher (e.g. Phaedo 63e ff., Theaetetus I64c9, Sophist 2 I6c6 etc.).

${ }^{38}$ For an overview of the contributions of various Hellenistic philosophers to the philosophical tradition, see Long (I986). 
opponents 'philosophers', because they share some basic understanding about the profession, about how philosophy is fundamentally done, and this was often a direct result of sharing philosophical authorities across schools (e.g. Socrates was considered a foundational figure for the Cynics, Stoics and Academics).

In his critical essays where Dionysius addresses Roman intellectuals, many of whom would have studied or been familiar with the philosophical schools, Dionysius is cautious and avoids going against the standard philosophical terminology. This is understandable: in order to be taken seriously as a teacher, he had to exhibit familiarity with the relevant terminology, especially on matters that were tangentially relevant but not directly the focus of his writing. Indeed, as his First letter to Ammaeus suggests, Dionysius was well aware of the prominent members of established philosophical schools, and was willing to engage with them on issues that concerned him. In such situations, Dionysius had to demonstrate himself as competent in current debates and capable of engaging in constructive conversation. This was not the appropriate place, in other words, to start questioning the meaning of philosophy itself. When, however, Dionysius discusses Isocrates and the philosophical underpinnings of his own views on rhetoric, he is clearly in a better position to offer a more provocative vision of the field and to challenge the existing philosophical establishment. And even in his essay on Isocrates, where he explicitly promotes 'true philosophy', he actually only implicitly goes against the standard philosophical tradition, ${ }^{39}$ for ultimately the aim of the whole project was to provide students with rhetorical models for imitation and not an extended debate about the true meaning and application of philosophy. Isocrates is singled out as offering philosophical perspective and inspiration for students of rhetoric, but a closer analysis of how to actually read Isocrates and interpret his work seems to

39 In I3.3 he makes a reference to Hieronymus the philosopher, thus indicating that he is very much comfortable, even in the essay on Isocrates, in applying the term philosophy in a traditional sense. 
fall unfortunately outside Dionysius' objectives. Elsewhere, when reviewing different orators and reflecting on the views of various other critics, Dionysius follows the widely shared and traditional sense of philosophers and makes no reference to 'true philosophy'.

Hence, where Dionysius operates as a literary critic, he makes a clear distinction between rhetoric and philosophy and their respective aims and methods. In fact, a clear example of Dionysius' distinct use of the notions rhetoric and philosophy is his First letter to Ammaeus (FLA), which explicitly contrasts both professions: the philosopher Aristotle and the orator Demosthenes. ${ }^{40}$ This is a fascinating and frustrating work at the same time: it raises important questions regarding the relationship between rhetoric and philosophy, but (even less than his essay on Isocrates) does not aim to discuss them more thoroughly and ends up being solely interested in establishing a strict chronology between the works of Aristotle and Demosthenes. ${ }^{4 \mathrm{I}}$ The first couple of chapters of FLA promise, however, something quite exciting: Dionysius finds the view that Demosthenes might have used Aristotle's Rhetoric to compose his speeches at first ridiculous, but realizing that this argument is brought forward by a respectable Peripatetic, ${ }^{42}$ he writes this letter to demonstrate the falsity of this account and prevent the philosopher from publishing his views (FLA I.23). Dionysius is worried that if this view becomes more widespread, people might start thinking that all the precepts of rhetoric are comprehended in the Peripatetic philosophy (2.3):

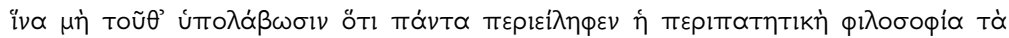

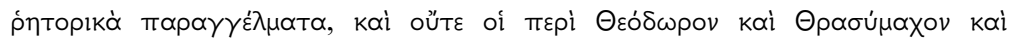

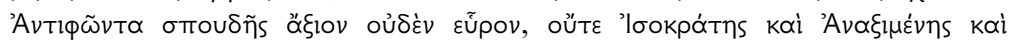

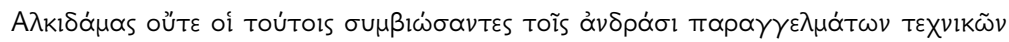

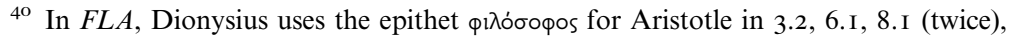
9.I, II.2, I2.I, I2.2, I2.4, I2.6; in 7.2 and the very last paragraph of the FLA he highlights a clear contrast between Aristotle the philosopher and Demosthenes the orator.

${ }^{4 \mathrm{I}}$ Roberts (I90I), I6I-3 has summarized the letter, for example, in a chronological table.

${ }^{42}$ Wooten (I994), I 2 I-2 argues it might be Andronicus of Rhodes. 


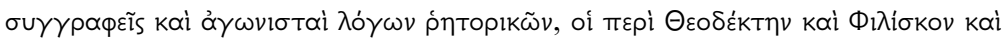

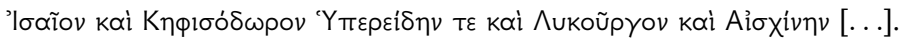

So that they would not suppose that all the precepts of rhetoric are comprehended in the Peripatetic philosophy, and that nothing important has been discovered by Theodorus, Thrasymachus, Antiphon and their associates; nor by Isocrates, Anaximenes, Alcidamas or those of their contemporaries who composed rhetorical handbooks and engaged in oratorical contests: Theodectes, Philiscus, Isaeus, Cephisodorus, Hyperides, Lycurgus and Aeschines [...].

In other words, the Peripatetic tradition might be an important source for rhetorical technique, but this is only one among many useful sources one could turn to. Even the best orators of the fourth century (e.g. Demosthenes) knew this and chose eclectically between various models (2.3) - a technique Dionysius recommends and highlights as the purpose of his writing the critical essays (Ant Or. 4).

Interestingly, however, Dionysius does not base his claims about the relationship between Demosthenes and Aristotle on their different views of the rhetorical art. Rather, Dionysius seems to suggest that while it is certain that Demosthenes could not have read Aristotle's Rhetoric, the latter could have based his Rhetoric on the speeches of Demosthenes and of other orators ( FLA I2). Even though Dionysius' extended discussion of the matter might initially suggest otherwise, it is not simply a matter of chronology, of who managed to write down their insights on rhetoric first. Rather, Dionysius might be making here a more general point about studying rhetoric: it does not suffice to read theoretical instructions about how to write/perform speeches, but rather it is important to explore the actual practice and study the performed speeches of orators, much like Demosthenes had to do. ${ }^{43}$ Aristotle's theoretical explorations, although helpful, can only go to a certain extent in helping the student of oratory; and even then, it is still necessary to become intimately acquainted with the actual speeches of those orators who are regarded as the best. In other words, there is something important to be learned from

43 Assuming that his alleged associations with Isocrates and Isaeus are accurate. 
mimesis that cannot be found in the theoretical discussions of the 'philosophers'. The letter is frustrating, however, because it seems to imply this interpretation, but does not explicitly state it. Why? Dionysius keeps constantly going back to various chronological evidence, bringing little proofs from Demosthenes and Aristotle's Rhetoric that would prove that the influence could not have been from the philosopher to the orator. It seems likely that the literary historian has taken over the literary critic at this point, and rather than fleshing out a more general account about why any such comparison between a theoretical text on rhetoric and actual speeches makes little sense, Dionysius continues to exhibit his command of the historical material.

The uselessness of philosophers for rhetorical instruction is also expressed in Dionysius' De compositio verborum (CV). There, Dionysius looks at Stoic philosophers as potentially useful sources for principles governing composition. ${ }^{44}$ This discussion is prefaced by a reference to Chrysippus, the famous head of the Stoa of the third century BCE, whose writings on (what may appear to be) similar topics demonstrate clearly to Dionysius that the Stoic is inept in arranging his compositions: 'of writers who have been judged worthy of renown or distinction, none has written treatises on logic with more precision, and none has published discourses which are worse specimens of composition'. ${ }^{45}$ And Chrysippus is just one example, the tip of the iceberg. While admitting that Chrysippus approaches the topic from a strictly logical perspective, Dionysius is nevertheless eager to find out whether there is anything in Stoic examination of the topic that might be of use for someone interested in composition. He answers this, unsurprisingly, with the negative. Despite the similarity of the titles of their works ${ }^{46}-$ and to

44 For a more in-depth discussion of Dionysius' relationship to Stoicism, especially in his $C V$, see de Jonge (2008). The present passage is analyzed at Io8-I I and 274-6.

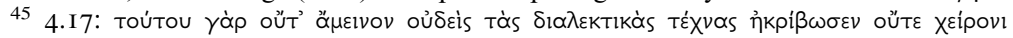

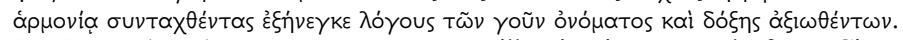

46 De Jonge (2008), 275 n. 98 quotes an illuminating example from Cicero's De oratore 2.6I, where Antonius expresses a similar frustration to Dionysius regarding the misleading book titles of (some) philosophical works. 
give an example Dionysius quotes the title of Chrysippus' work

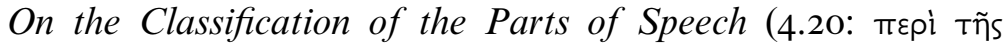

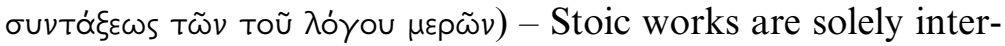
ested in logical investigations ${ }^{47}$ which examine categories of propositions, whether they are true or false, possible or impossible, admissible or variable, ambiguous and so forth (4.2 I). Dionysius concludes that they 'contribute nothing helpful or useful to civil oratory, at least as far as the attractiveness and beauty of style are concerned, which should be the aim of composition'. ${ }^{48}$ In other words, Stoic philosophers, even when they discuss a topic of interest to those concerned with composition, focus solely on the logical and highly abstract side of the question and, in so doing, they fail to say anything practically relevant on the subject. In contrast to the Stoic philosophers

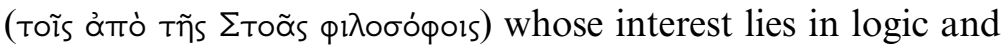
theoretical speculations, Dionysius is explicitly associating him-

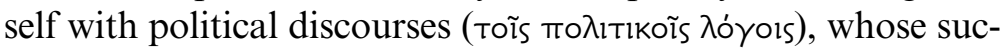
cess in composition is measured in terms of pleasure and beauty of style. Here we see, then, the opposition between philosophy as a purely theoretical pursuit and Dionysius' practice-driven conception of politikoi logoi fully set out. ${ }^{49}$

Yet, while distancing himself from 'theoretical philosophers', Dionysius commends philosophers' critical attitude to their peers and authorities, and he proposes to also employ their constructive approach to literary criticism. In his essay on Thucydides, Dionysius spends some time explaining his motivations behind writing an extended critique of Thucydides.

47 This is problematic and no Stoic would agree with this characterization.

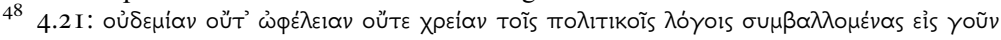

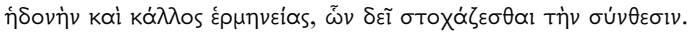

49 Goudriaan's (I989) discussion of Dionysius' politikos logos is perhaps the most idiosyncratic: he traces the ancestor for Dionysius' usage of the notion to Plato's Laws and argues that it is Plato's system of musical education that underlies Dionysius' description of the functioning of style in the politikos logos. Goudriaan admits, however, that Dionysius makes a particular use of this Platonic model and calls it 'a kind of reduced transcendentalism' (694). He furthermore seems to associate Dionysius' classicism with Plato. In the light of the present discussion here and Dionysius' explicit preference of Isocrates over the metaphysics of Plato, Goudriaan's suggestion appears extremely far-fetched and not sufficiently supported by what Dionysius actually says. 
He already assumes that his views will be met with hostility by some of the readers, and evokes philosophers as examples of constructive criticism and of a method of critique that, instead of stifling the discussion, provokes a further search for truth: Aristotle, Dionysius says, criticized his teacher Plato, who in turn tried to prove his predecessors Parmenides, Protagoras and Zeno wrong (3.4). As Dionysius remarks, nobody criticizes these authors for disagreeing with their predecessors or previous authorities, 'for it is recognized that the goal of philosophical studies is the discovery of truth by which the purpose of life is revealed'. ${ }^{\circ}$ But if this is the case with philosophers and it is widely agreed that the search for truth might in time prove previous proponents wrong, 'why should one censure those who have taken up describing an author's individual style when they do not ascribe to it all the qualities allowed to it by earlier critics, even those which it does not possess?. ${ }^{\text {I }}$ Despite the differences in topic, Dionysius assumes that literary critics share the same commitment to truth that characterizes philosophers, and thus they should also adopt the same method of constructive criticism that has been accepted for, and was widely used by, the philosophers. ${ }^{52}$

When he proposes that literary critics 'borrow' a useful method from the philosophers, Dionysius clearly sides with the critics and not with philosophers. At the same time, the beginning of the essay contains perhaps more references to philosophy and to his own engagement with it than what we see elsewhere in Dionysius' work. He casually mentions that he had in fact written a polemical work on political philosophy

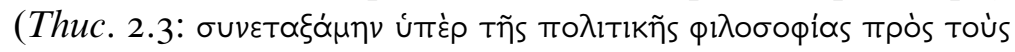

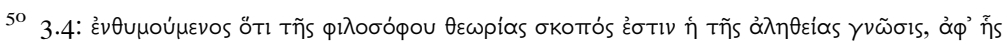

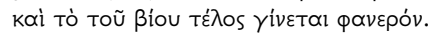

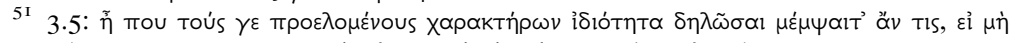

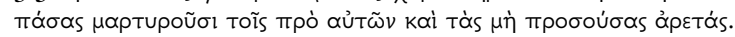

52 There is of course a significant difference that Dionysius neglects: contrary to those philosophers who critique their predecessors who tackled the same topics as they do, what Dionysius will be criticizing in Thucydides or Plato, for example, is not really their contributions to their respective sciences (history or philosophy), but something that had not been identified as their primary goal - style and effective use of language. 


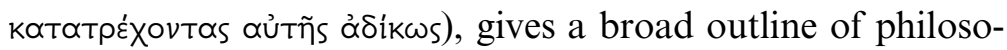
phy, its aims and methods, and finally offers a definition of the

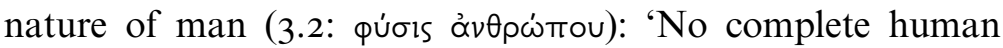
being has the self-sufficiency to be infallible in either word or deed: the best is the man who hits the mark most often, and misses it least. ${ }^{53}$ Even though this definition is offered as a justification for the following close analysis of Thucydides' style and simply suggests that everybody makes mistakes, including Thucydides, the tone and underlying idea are relevant to what Dionysius elsewhere says about philosophy.

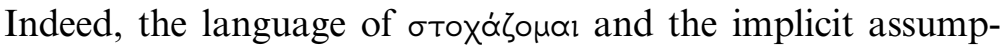
tion of this passage that there is no abstract universal knowledge that would be attainable for human beings, which would enable them to attain truth or knowledge through contemplation and help them avoid making mistakes, has strong resemblances to the Isocratean concept of (the unattainability of ) knowledge and the consequent possibilities for the pursuit of philosophy. ${ }^{54}$ Also, it is probably no coincidence that Dionysius' views on philosophy emerge in the two essays Isocrates and Thucydides, for it is in the first where he establishes the philosophical underpinnings of the rhetorical tradition, and in the second where he places his own critical activity, both in the rhetorical and historical writings, under close scrutiny. Self-criticism and the discourse of apology is used to a powerful effect in Isocrates' Antidosis, and the beginning of Dionysius' Thucydides is in its spirit very similar to that Isocratean discourse. Here too Dionysius refers to his potentially hostile audience (2.2), offers a brief overview of his critical activity (2.3) and uses the language of deciding (2.4: кpiveıv), as in a court case.

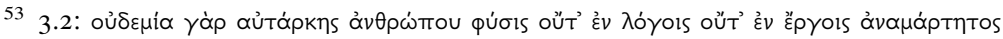

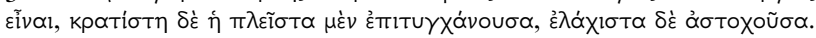

54 Isocrates uses this notion several times in his Panathenaicus (30, 26I, 27I), but also

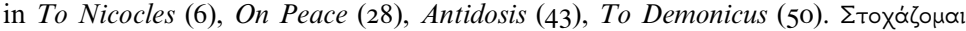
and its cognates also play a central role in identifying the valid method in rhetorical discourse in Aristotle's Rhetoric (e.g. I355a I 7, I36ob5, I362a I5, I395bio, I406a I6, I4IOb35, I4I5b28, I4I9bi6). 
True Rhetoric, True Philosophy and True Isocrates

This divide between theoretical and practical knowledge that seems to distance Dionysius from the philosophers, and at the same time enables him to label his own intellectual pursuit as philosophy in the wake of Isocrates, is closely connected to his views about critical judgement. Dionysius famously claims in a passage of his essay on Thucydides that there are two kinds of literary judgement, one that everyone can access and make use of, since it is based on irrational sensations and feelings that literary works arouse (4.3: $\tau \tilde{\omega} \nu \tau \varepsilon \delta l^{\prime}$

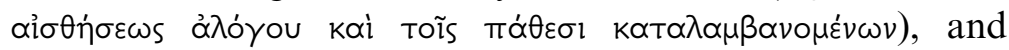
another that is characterized as expert knowledge and theoretical. The former comprises, in Dionysius' words, 'the faculties which all forms of art aim to stimulate and are the reason for

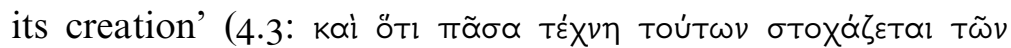

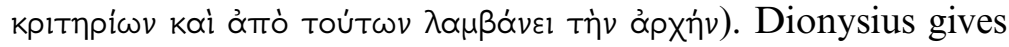
an example of this kind of sensation-based irrational judgement in action when he describes the impact of Isocrates' discourses on himself (Demosthenes 22.I):

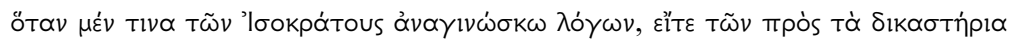

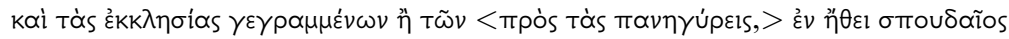

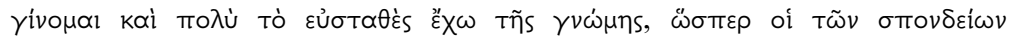

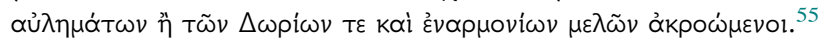

Whenever I read a speech of Isocrates, whether it be forensic, political (or epideictic), I become serious and feel a great tranquillity of mind, like those listening to libation-music played on reed-pipes or to Dorian or enharmonic melodies.

Dionysius then brings in a comparison with Demosthenes, but what is more relevant for the present discussion is that he prefaces these comparisons with a brief suggestion that the feelings he describes are not uniquely his own, but rather

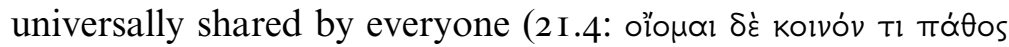

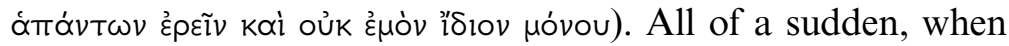
describing a universal mátos, this irrational sensation which Dionysius outlined in Thucydides starts looking less irrational

55 I am not following here Aujac's unnecessary emendation of $\dot{\varepsilon} \nu ~ \eta ै \theta \varepsilon l$ (transmitted in the manuscripts) to $\tau \dot{\alpha} \ddot{\eta} \theta \eta$, despite the parallel he cites from Isocrates 4.3 ( $\dot{\alpha} \lambda \lambda \dot{\alpha}$ k $\alpha \dot{i}$

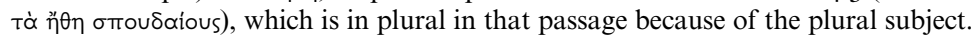




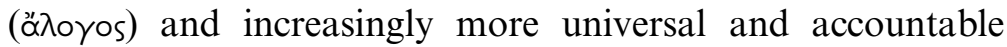

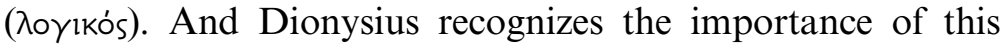
shift, for a good critic and teacher is, presumably, someone who has both trained his (irrational) senses and is up to date with the best means of explanation. ${ }^{56}$ It seems, however, that there is no qualitative difference between the layman operating

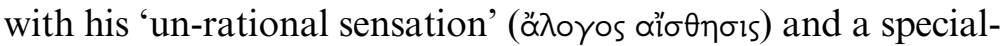

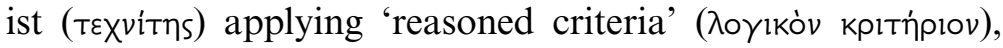
but merely a quantitative one: the critic will have consciously cultivated his senses and abilities to describe, write down and explain the aesthetic effects of prose for students. Here again, Dionysius seems to reject pure abstract theoretical rules (like in a textbook) that can be simply imposed on oratorical practice; instead, an expert is someone who has accumulated these sensations and organized them in groups of patterns himself (much like Dionysius shows us how to do in his critical essays) that might be helpful in guiding the sensations of the students, without trying to provide a metaphysical or abstract explanation of these phenomena. In other words, just as Isocrates said (Helen 5): of important things likely conjecture is preferable to exact knowledge of the useless.

Thus far it has been emphasized that Dionysius is deeply inspired by Isocrates' politico-philosophical program. Yet, when Dionysius decides to fashion his discourse as a politikos $\log o s$, and in so doing consciously invokes the Isocratean model, he also appears to take precautions in order to make sure that he will not be taken for yet another Isocratean stylist. Isocrates and his followers had long attracted negative attention from critics and Dionysius makes several references to this group in his essays: in $C V$ (I9.I3) he refers more generally to the style of composition used by Isocrates and his followers

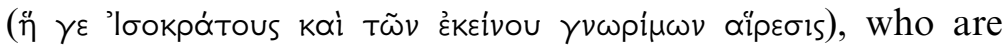
introduced as an example of a rather unsuccessful application of the principle of variation and change in their compositions. In Isaeus (I9.4), Dionysius gives a list of famous pupils of

${ }^{56}$ A helpful discussion of Dionysius' use of the two evaluative criteria, tò ä $\lambda$ oyov tĩs

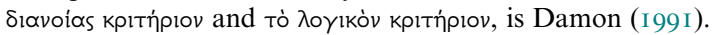


Isocrates who cannot, however, be compared with the genius of Isocrates. ${ }^{57}$ Indeed, there are clear tensions between the originator and the copyist or imitator that Dionysius hints at in the last quotation, and these are further explored in his Dinarchus. There Dionysius is primarily interested in establishing useful guidelines for differentiating between authors and confirming or rejecting authorship of ancient writings. The main focus is on Dinarchus, whose varied and heterogeneous style is compared to the imitators of Isocrates who also display many similarities but also important differences from the works of Isocrates. ${ }^{58}$ In a later passage (8), Dionysius discloses explicitly the pitfalls of closely imitating an author. Examples are drawn more generally from the followers of Plato, Thucydides, Hyperides, Isocrates and Demosthenes, but we will focus here on the Isocrateans. The trouble with the Isocrateans, and in particular with their style, is that it became

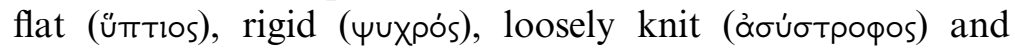

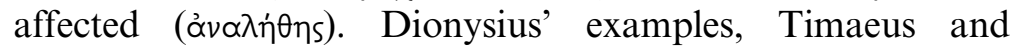
Psaon, are historians (a third name mentioned, Sosigenes, is otherwise unknown), whose Isocratean style Dionysius strongly disapproves of. As a historian, as well as a literary critic and a rhetorician, Dionysius goes to quite a length to return to this topic in various essays and make clear that he is not one of the 'Isocratean-type' historians, or a promoter of their interpretation of the importance of Isocrates. In other words, by overtly distancing himself from previous proponents of Isocrates, Dionysius is careful to make sure that his treatment of the famous educator and rhetorician breaks new ground in the overall appreciation of Isocrates, and establishes him as an authority in the philosophical sphere of rhetoric.

It is by now clear that Plato's Phaedrus lies in important ways behind Dionysius' assessment of Lysias and Isocrates in his critical essays and, more generally, that this dialogue

57 The superiority of Isocrates over his imitators and followers is also explicitly mentioned in $C V$ I9.I3.

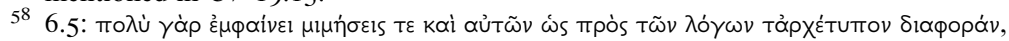

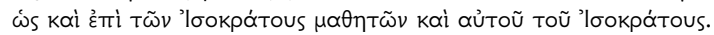


deeply informs Dionysius' treatment of the ancient rhetorical tradition. The portrayal of an Isocrates with lots of philosophical potential, as contrasted to the clever and persuasive Lysias, is obviously indebted to the Phaedrus. While Plato's discussion of the orators is also ironical or even outright critical, Dionysius picks up none of the criticisms of the two and has no ear for Socratic irony. Is Dionysius simply misreading the dialogue, or could we see here Dionysius' more critical engagement with Plato? The latter option seems more plausible. Dionysius' systematic reinterpretation of Isocrates and Lysias, combined with his ambivalent attitude to Plato (especially as a critic of style) and his ambition to put together a comprehensive account of the rhetorical tradition, all suggests that Dionysius probably entertained a competitive attitude to Plato. While the latter had had a strong impact on the reception of Lysias and Isocrates, Dionysius was to counterbalance that with his own interpretation of the two orators as constitutive pillars of the rhetorical art: Lysias as a legitimate model for style and Isocrates as the path-breaking visionary in education and philosophy. In other words, Dionysius not only follows and promotes Isocrates' philosophy, as has been suggested many times before, but he creates the image of a 'true Isocrates' that he then brilliantly casts as an underlying philosophical feature of his own program. In some circles, Dionysius' interpretation of the two rhetors prevails, in others, that of Plato. For us, however, all these four writers present the sine qua non of the ancient rhetorical tradition. 


\section{BIBLIOGRAPHY}

Abbenes, J. G. J., S. R. Slings and I. Sluiter (eds.) (I995) Greek Literary Theory after Aristotle: A Collection of Papers in Honour of D.M. Schenkeveld. Amsterdam: VU University Press.

Acosta Méndez, E. and A. Angeli (I992) Filodemo: Testimonianze su Socrate. Naples: Bibliopolis.

Acosta-Hughes, B., L. Lehnus and S. Stephens (eds.) (20I I) Brill's Companion to Callimachus. Leiden: Brill.

Adorno, F., G. Bastianini, A. Carlini, F. Decleva Caizzi, M. S. Funghi, D. Manetti, M. Manfredi, F. Montanari and D. Sedley (eds.) (2008) Corpus dei papiri filosofici greci e latini I.2 (Galenus-Isocrates). 2 vols. Florence: Olschki Editore.

Alexiou, E. (2000) 'Enkomion, Biographie und die 'unbeweglichen Statuen': $\mathrm{Zu}$ Isocrates Euagoras 73-76 und Plutarch Perikles I-2' - Classica et mediaevalia (5I), I03-I7.

(20I0) Der Euagoras des Isocrates. New York: De Gruyter.

Algra, K., J. Barnes, J. Mansfeld and M. Schofield (eds.) (I999) The Cambridge History of Hellenistic Philosophy. Cambridge University Press.

Arnim, H. F. A. von (i898) Leben und Werke des Dio von Prusa. Berlin: Weidmann.

Aujac, G. (ed. and trans.) (1978) Denys d'Halicarnasse: Opuscules rhétoriques, Tome I: Les orateurs antiques. Paris: Les Belles Lettres.

(1988) Denys d'Halicarnasse: Opuscules rhétoriques, Tome 2: Démosthène. Paris: Les Belles Lettres.

(I99I) Denys d'Halicarnasse: Opuscules rhétoriques, Tome 4: Thucydide; Seconde lettre à Ammée. Paris: Les Belles Lettres.

(1992) Denys d'Halicarnasse: Opuscules rhétoriques, Tome 5: L'imitation (fragments, épitomé); Première lettre à Ammée; Lettre à Pompée Géminos; Dinarque. Paris: Les Belles Lettres.

Aujac, G. and M. Lebel (ed. and trans.) (198I) Denys d'Halicarnasse: Opuscules rhétoriques, Tome 3: La composition stylistique. Paris: Les Belles Lettres.

Auvray-Assayas, C. and D. Delattre (eds.) (200I) Cicéron et Philodème: La polémique en philosophie. Paris: Éditions Rue d'Ulm.

Avery, H. C. (I99I) 'Was Eratosthenes the Oligarch Eratosthenes the Adulterer?' - Hermes ( I I9), 380-4. 


\section{Bibliography}

Avezzù, G. (I99I) Lisia: Contro i tiranni (Contro Eratostene). Venice: Marsilio Editori.

Balla, C. (2004) 'Isocrates, Plato, and Aristotle on Rhetoric' - Rhizai (I), 45-7I.

Baraz, J. (2012) A Written Republic: Cicero's Philosophical Politics. Princeton University Press.

Barnes, J. (1982) The Presocratic Philosophers. [2000 reprint.] London: Routledge.

Barwick, K. (I963) 'Das Problem der isokrateischen Techne' - Philologus (I07), 43-60.

Bastianini, G. and A. Casanova (eds.) (2007) I papiri di Saffo e di Alceo: Atti del convegno internazionale di studi, Firenze, 8-9 giugno 2006. Florence: G. Vitelli.

Batstone, W. W. (I985) 'Commentary on Cooper: Oratory, Philosophy, and the Common World' - Proceedings of the Boston Area Colloquium in Ancient Philosophy (I), 97-I I3.

Benoit, W. (I990) 'Isocrates and Aristotle on Rhetoric' - Rhetoric Society Quarterly (20), 25I-9.

Bernard, H. (I997) Hermeias von Alexandrien: Kommentar zu Platon's 'Phaedrus'. Tübingen: Mohr Siebeck.

Berti, E. (1997) La filosofia del "primo" Aristotele. 2nd edn. Milano: Vita e pensiero.

Beversluis, J. (2000) Cross-Examining Socrates: A Defense of the Interlocutors in Plato's Early Dialogues. Cambridge University Press.

Blank, D. L. (I985) 'Socratics versus Sophists on Payment for Teaching' Classical Antiquity (4/I), I-49.

(2003) 'Atomist Rhetoric in Philodemus' - Cronache Ercolanesi (33), 69-88.

(2009) 'Philosophia and technê: Epicureans on the Arts' - The Cambridge Companion to Epicureanism, ed. J. Warren (Cambridge University Press), 2 I6-33.

Blank, T. (2014) Logos und Praxis: Sparta als politisches Exemplum in den Schriften des Isocrates. Berlin: De Gruyter.

Blass, F. (1865) Die griechische Beredsamkeit in dem Zeitraum von Alexander bis auf Augustus: Ein litterarhistorischer Versuch. [1977 reprint.] Berlin: Weidmann.

( I868) Die Attische Beredsamkeit. Band I. Leipzig: Teubner.

(1887) Die Attische Beredsamkeit. Erste Abteilung: Von Gorgias bis zu Lysias. Leipzig: Teubner.

(1892) Die Attische Beredsamkeit. Zweite Abteilung: Isocrates und Isaios. Leipzig: Teubner.

(I893) Die Attische Beredsamkeit. Dritte Abteilung, erster Abschnitt: Demosthenes. Leipzig: Teubner.

Blondell, R. (2002) The Play of Character in Plato's Dialogues. Cambridge University Press. 


\section{Bibliography}

Böhme, P. (2009) Isocrates, Gegen die Sophisten: Ein Kommentar. Berlin: Lit.

Bollansée, J. (I999a) Hermippos of Smyrna and His Biographical Writings: A Reappraisal. Leuven: Peeters.

(ed.) (I999b) Felix Jacoby: Fragmente der griechischen Historiker, Part Iv: Biography and Antiquarian Literature, gen. ed. G. Schepens. Leiden: Brill.

Bonner, S. F. (1938) 'Dionysius of Halicarnassus and the Peripatetic Mean of Style' - Classical Philology (33), 257-66.

(1939) The Literary Treatises of Dionysius of Halicarnassus: A Study in the Development of Critical Method. Amsterdam: Hakkert.

Bons, J. (1996) Poietikon Pragma: Isocrates' Theory of Rhetorical Composition. Dissertation: Nijmegen.

Bostock, D. (I 988) Plato's Theaetetus. Oxford: Clarendon Press.

Bowersock, G. W. (1965) Augustus and the Greek World. Oxford: Clarendon Press.

(1979) 'Historical Problems in Late Republican and Augustan Classicism' - Flashar (I979), 57-75.

Boys-Stones, G. and C. Rowe (eds.) (2013) The Circle of Socrates: Readings in the First-Generation Socratics. Indianapolis: Hackett.

Bringmann, K. (I965) Studien zu den politischen Ideen des Isokrates. Göttingen: Vandenhoeck \& Ruprecht.

Brown, E. (2009) 'Politics and Society' - Cambridge Companion to Epicureanism, ed. J. Warren (Cambridge University Press), I79-96.

Bruns, I. (I896) Das literarische Porträt der Griechen im fünften und vierten Jahrhundert vor Christi Geburt. Berlin: Hertz.

Brzoska, J. (I883) De canone decem oratorum Atticorum quaestiones. Dissertation: Breslau.

Buchheim, T. (1989) Gorgias von Leontinoi: Reden, Fragmente und Testimonien. Hamburg: Meiner.

Buchheit, V. (I960) Untersuchungen zu Theorie des genos epideiktikon von Gorgias bis Aristoteles. Munich: Huber.

Büchler, O. (1936) Die Unterscheidung der redenden Personen bei Lysias:

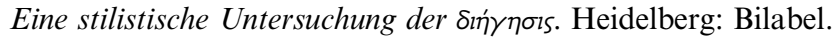

Buchner, E. (1958) Der Panegyrikos des Isocrates: Eine historischphilologische Untersuchung. Wiesbaden: F. Steiner.

Bülow-Jacobsen, A. (ed.) (I994) Proceedings of the 2oth International Congress of Papyrologists, Copenhagen 23-29 August 1992. Copenhagen: Museum Tusculanum Press.

Burk, A. (1923) Die Pädagogik des Isocrates als Grundlegung des humanistischen Bildungsideals: Im Vergleich mit den zeitgenössischen und den modernen Theorien. Würzburg: C. J. Becker.

Burnyeat, M. (I996) 'Enthymeme: Aristotle on the Rationality of Rhetoric' - Oksenberg Rorty (I996), 88-I I5. 


\section{Bibliography}

(1998) 'First Words: A Valedictory Lecture' - Proceedings of the Cambridge Philological Society (43), I-20.

Cairns, D. and R. A. Knox (eds.) (2004) Law, Rhetoric, and Comedy in Classical Athens: Essays in Honour of Douglas M. MacDowell. Swansea: Classical Press of Wales.

Cameron, A. (1995) Callimachus and His Critics. Princeton University Press.

Canevaro, M. (20I3) The Documents in the Attic Orators: Laws and Decrees in the Public Speeches of the Demosthenic Corpus. Oxford University Press.

Canevaro, M. and B. Gray (eds.) (2018) The Hellenistic Reception of Classical Athenian Democracy and Political Thought. Oxford University Press.

Canfora, L. (2018) 'Afterlife (Antiquity and Byzantine Era)' - Martin (20I8b), 43I-52.

Carey, C. (1989) Lysias: Selected Speeches. Cambridge Greek and Latin Classics. Cambridge University Press.

(1990) 'Structure and Strategy in Lysias XXIV' - Greece \& Rome (37), 44-5I.

(1992) Apollodoros against Neaira: [Demosthenes] 59. Warminster: Aris \& Phillips.

(I994) 'Rhetorical Means of Persuasion' -Worthington (I994), 26-45.

(ed.) (2007) Lysiae orationes cum fragmentis. Oxford Classical Texts. Oxford: Clarendon Press.

Cartledge, P. (1987) Agesilaos and the Crisis of Sparta. London: Duckworth. (2009) Ancient Greek Political Thought in Practice. Cambridge University Press.

Castagnoli, L. (2010) Ancient Self-Refutation: The Logic and History of the Self-Refutation Argument from Democritus to Augustine. Cambridge University Press.

Charalabopoulos, N. G. (2012) Platonic Drama and Its Ancient Reception. Cambridge University Press.

Chiron, P. (I993) Démétrios: Du style. Paris: Les Belles Lettres.

(2002) Pseudo-Aristote: Rhétorique à Alexandre. Paris: Les Belles Lettres.

Chroust, A.-H. (1973) Aristotle: New Light on His Life and on Some of His Lost Works. Vol II. London: Routledge.

Clarke, M. L. (197I) Higher Education in the Ancient World. London: Routledge \& Kegan Paul.

Classen, C. J. (2010) Herrscher, Bürger und Erzieher: Beobachtungen zu den Reden des Isocrates. Spudasmata (I33). Hildesheim: Georg Olms.

Clay, D. (I994) 'The Origins of the Socratic Dialogue' - Vander Waerdt (I994), 23-47.

Cocurullo, M. (200I) 'Il contributo dei papiri alla conoscenza di Lisia' Papyrologica Lupiensia (I0), I I3-70.

Cole, T. (I99I) The Origins of Rhetoric in Ancient Greece. Baltimore, MD: Johns Hopkins University Press. 


\section{Bibliography}

Collins II, J. H. (2015) Exhortations to Philosophy: The Protreptics of Plato, Isocrates, and Aristotle. Oxford University Press.

Collins Edwards, L. (20I0) 'Shifting Paradigms: Mimesis in Isocrates' Mitsis and Tsagalis (2010), 377-400.

Cooper, C. R. (1992) The Development of the Biographical Tradition on the Athenian Orators in the Hellenistic Period. Dissertation: University of British Columbia.

(2000) 'Philosophers, Politics, Academics: Demosthenes' Rhetorical

Reputation in Antiquity' - Worthington (2000), 224-45.

Cooper, J. M. (1985) 'Plato, Isocrates and Cicero on the Independence of Oratory from Philosophy' - Proceedings of the Boston Area Colloquium in Ancient Philosophy (I), 77-96.

Cope, E. M. ( I867) An Introduction to Aristotle's Rhetoric. With Analysis, Notes and Appendices. London: Macmillan.

(I877) The Rhetoric of Aristotle, vol. III: Commentary. Cambridge University Press.

Cornell, T. (ed.) (2013) The Fragments of the Roman Historians. 3 vols. Oxford University Press.

Costil, P. (1949) L'esthétique littéraire de Denys d'Halicarnasse. Paris: Bibliothèque de la Sorbonne.

Covino, R. and C. Smith (eds.) (2010) Praise and Blame in Roman Republican Rhetoric. Swansea: Classical Press of Wales.

Damon, C. (I99I) 'Aesthetic Response and Technical Analysis in the Rhetorical Writings of Dionysius of Halicarnassus' - Museum Helveticum (48), 33-58.

Davies, J. K. (I97I) Athenian Propertied Families, 6oo-30o B.C. Oxford: Clarendon Press.

Davison, C. C. (2009) Pheidias: The Sculptures \& Ancient Sources. London: Insitute of Classical Studies.

de Jonge, C. C. (2005) 'Dionysius of Halicarnassus and the Method of Metathesis' - $C Q$ (55), 463-80.

(2008) Between Grammar and Rhetoric: Dionysius of Halicarnassus on Language, Linguistics and Literature. Leiden: Brill.

(2009) Review of Demetrio: Lo Stile, Nicoletta Marini - Bryn Mawr Classical Review I2 August 2009.

(20I2) 'Dionysius and Longinus on the Sublime: Rhetoric and Religious Language' - AJP (I33), 27I-300.

(2018) 'Demosthenes vs. Cicero: Intercultural Competition in Ancient Literary Criticism' - Eris vs. Aemulatio: Competition in Classical Antiquity, ed. C. Damon and C. Pieper (Leiden: Brill), 300-23.

de Jonge, C. C. and R. Hunter (eds.) (2018) Dionysius of Halicarnassus and Augustan Rome: Rhetoric, Criticism and Historiography. Cambridge University Press. 


\section{Bibliography}

De Quincey, T. (1862) Style and Rhetoric and Other Papers. Edinburgh: Adam and Charles Black.

de Romilly, J. (I954) 'Les modérés athéniens vers le milieu du IVe siècle : Échos et concordances' - Revue des Études Grecques (67), 327-54.

(I958) 'Eunoia in Isocrates or the Political Importance of Creating Good Will' - Journal of Hellenic Studies (78), 92-IOI.

(1992) The Great Sophists in Periclean Athens. Trans. J. Lloyd. Oxford: Clarendon Press.

Denniston, J. D. (I927) 'Technical Terms in Aristophanes' - CQ (2I), I I $3-2$ I.

Depew, D. J. and T. Poulakos (eds.) (2004) Isocrates and Civic Education. Austin: University of Texas Press.

Destrée, P. and P. Murray (eds.) (2015) A Companion to Ancient Aesthetics. Malden, MA, Oxford and Chichester: Wiley-Blackwell.

Devries, W. L. (1892) Ethopoiia: A Rhetorical Study of the Types of Character in the Orations of Lysias. Baltimore, MD: Murphy.

DeWitt, N. W. (1954) Epicurus and His Philosophy. Minneapolis: University of Minnesota Press.

DeWitt, N. W. and N. J. DeWitt (1949) Demosthenes, vol. vir: Funeral Speech, Erotic Essay, Exordia and Letters. Loeb Classical Library. London: Heinemann.

Di Matteo, T. (i997) 'Isocrate nella Retorica di Filodemo' - Cronache Ercolanesi (27), I2 I-36.

Dihle, A. (1977) 'Der Beginn des Attizismus' - Antike und Abendland (23), I $62-77$.

Dillon, J. (2003) The Heirs of Plato. Oxford: Clarendon Press.

Dindorf, W. (1855) Scholia graeca in Homeri Odysseam. Oxford University Press.

(I970) Scholia Graeca in Aeschinem et Isocratem. [Reprint of I852 edn.] Hildesheim: Dr. H. A. Gerstenberg.

Dodds, E. (1959) Plato: Gorgias. Oxford: Clarendon Press.

Dominik, W. J. (ed.) (I997) Roman Eloquence: Rhetoric in Society and Literature. London: Routledge.

Dorandi, T. (I990) 'Per una ricomposizione dello scritto di Filodemo sulla Retorica' - Zeitschrift für Papyrologie und Epigraphik (82), 59-87.

(2013) Diogenes of Laertius: Lives of Eminent Philosophers. Cambridge Classical Texts. Cambridge University Press.

Douglas, A. E. (1956) 'Cicero, Quintilian, and the Canon of Ten Attic Orators' - Mnemosyne (9), 30-40.

Dover, K. J. (1968a) Lysias and the Corpus Lysiacum. Berkeley: University of California Press.

(1968b) Aristophanes: Clouds. Oxford: Clarendon Press.

(1997) The Evolution of Greek Prose Style. Oxford: Clarendon Press. 


\section{Bibliography}

Dow, J. (2015) Passions and Persuasion in Aristotle's Rhetoric. Oxford University Press.

Dugan, J. (2005) Making the New Man: Ciceronian Self-Fashioning in the Rhetorical Works. Oxford University Press.

Düring, I. (I96I) Aristotle's Protrepticus: An Attempt at Reconstruction. Göteborg: Acta Universitatis Gothoburgensis.

Eden, K. (1986) Poetic and Legal Fiction in the Aristotelian Tradition. Princeton University Press.

(I987) 'Hermeneutics and the Ancient Rhetorical Tradition' - Rhetorica (5/I), 59-86.

Edwards, M. J. (I998) 'Notes on Pseudo-Plutarch's Life of Antiphon' - $C Q$ (48), 82-92.

(I999) Lysias: Five speeches (I, I2, I9, 22, 30). Bristol: Classical Press.

(2013) Review of Tarik Wareh Theory and Practice of Life: Isocrates and the Philosophers - Notre Dame Philosophical Reviews 2013.09.I4.

Egger, M. F. (1902) Denys d'Halicarnasse: Essai sur la critique et la rhétorique chez les Grecs au siècle d'Auguste. Paris: A. Picard et fils.

Einarson, B. (1936) 'Aristotle's Protrepticus and the Structure of the Epinomis' - Transactions and Proceedings of the American Philological Association (67), 26I-85.

Engels, J. (2003) 'Antike Überlieferungen über die Schüler des Isocrates' Orth (2003), I75-94.

Erbì, M. (2008) 'Demostene nella Retorica di Filodemo: L'Immagine del

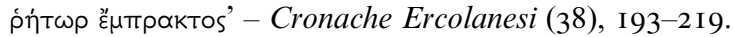

(2OI2) 'Nuove letture in P.Herc. IOO4 col. 58.' - Schubert (20 I2), 205-I I.

Erbse, H. (I97I) 'Platons Urteil über Isocrates' - Hermes (99), I 83-97.

Erskine, A. and L. Llewellyn-Jones (eds.) (20I I) Creating a Hellenistic World. Swansea: Classical Press of Wales.

Eucken, C. (1983) Isocrates: Seine Positionen in der Auseinandersetzung mit den zeitgenössischen Philosophen. Berlin and New York: De Gruyter.

Fantham, E. (2004) The Roman World of Cicero's De oratore. Oxford University Press.

Ferckel, F. (1937) Lysias und Athen: Des Redners politische Stellung zum Gaststaat. Würzburg: Konrad Triltsch.

Ferrari, G. R. F. (1987) Listening to the Cicadas: A Study of Plato's Phaedrus. Cambridge University Press.

(20I0) Sappho's Gift: The Poet and Her Community. Trans. (from the Italian) B. Acosta-Hughes and L. Prauscello. Ann Arbor: Michigan Classical Press.

Finley, M. I. (I975a) 'The Heritage of Isocrates' - Finley (I975b), I93-2 I4. (ed.) (I975b) The Use and Abuse of History. London: Chatto \& Windus.

Fish, J. (20 I Ia) 'Not All Politicians are Sisyphus: What Roman Epicureans were Taught about Politics' - Fish and Sanders (20I I b), 72-IO4. 


\section{Bibliography}

Fish, J. and K. R. Sanders (eds.) (20I Ib) Epicurus and the Epicurean Tradition. Cambridge University Press.

Flashar, H. (ed.) (I979) Le classicisme à Rome, aux Iers siècles avant et après J.-C.: Neuf exposés suivis de discussions. Entretiens sur l'antiquité classique (25). Geneva: Fondation Hardt.

Flower, M. A. (1994) Theopompus of Chios: History and Rhetoric in the Fourth Century BC. Oxford: Clarendon Press.

Focke, F. (I923) 'Synkrisis' - Hermes (58), 327-68.

Ford, A. L. (2002) The Origins of Criticism: Literary Culture and Poetic Theory in Classical Greece. Princeton University Press.

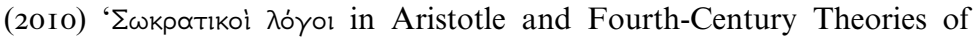
Genre' - Classical Philology (I05), 22 I-35.

Forster, E. S. (1979) Isocrates: Cyprian Orations: Evagoras, ad Nicoclem, Nikokles. New York: Arno Press.

Fortenbaugh, W. W. (2005) Theophrastus of Eresus: Sources for His Life, Writings, Thought, and Influence. Commentary, vol. viII. Leiden: Brill. (ed.) (1992) Theophrastus of Eresus: Sources for His Life, Writings, Thought, and Influence. Leiden: Brill.

Fortenbaugh, W. W., P. M. Huby and A. A. Long (eds.) (I985) Theophrastus of Eresus: On His Life And Work. New Brunswick, NJ: Transaction Books.

Fortenbaugh, W. W. and D. C. Mirhady (eds.) (I994) Peripatetic Rhetoric after Aristotle. New Brunswick, NJ: Transaction Publishers.

Fortenbaugh, W. W. and S. A. White (eds.) (2004) Lyco of Troas and Hieronymus of Rhodes: Text, Translation, and Discussion. New Brunswick, NJ, and London: Transaction Publishers.

Fortenbaugh, W. W. and S. A. White (2006) Aristo of Ceos: Text, Translation and Discussion. New Brunswick, NJ: Transaction Publishers.

Fox, M. (2009) 'Heraclides of Pontus and the Philosophical Dialogue' Heraclides of Pontus: Discussion, ed. W. W. Fortenbaugh and E. Pender (New Brunswick, NJ: Transaction Publishers), 4I-67.

(20II) 'The Style of the Past: Dionysius of Halicarnassus in Context' Schmitz and Wiater (20I I), 93-I I4.

Friemann, S. (I990) 'Überlegungen zu Alkidamas' Rede über den Sophisten' - Der Übergang von der Mündlichkeit zur Literatur bei den Griechen, ed. W. Kullmann et al. Tübingen: Narr.

Gabba, E. (I982) 'Political and Cultural Aspects of the Classicistic Revival in the Augustan Age' - Classical Antiquity (I), 43-65.

Gaines, R. (200I) 'Philodemus and Cicero on Models of Rhetorical Expression' - Auvray-Assayas and Delattre (200I), 259-72.

(2004) 'Cicero, Philodemus and the Development of Late Hellenistic Rhetorical Theory' - Philodemus and the New Testament World, ed. J. T. Fitzgerald. Leiden: Brill. 


\section{Bibliography}

(2005) 'De-canonizing Ancient Rhetoric' - Graff et al. (2005), 6I-73.

Garver, E. (1994) Aristotle's Rhetoric: An Art of Character. University of Chicago Press.

Geffcken, J. (I933) 'Das Rätsel des "Kleitophon"' - Hermes (68), 429-39.

Gelzer, T. (I979) 'Klassizismus, Attizismus und Asianismus' - Flashar (I979), I-4I.

Gerber, D. E. (1982) Pindar's Olympian One: A Commentary. University of Toronto Press.

Giannopoulou, Z. (2013) Plato's Theaetetus as a Second Apology. Oxford University Press.

Gifford, E. H. (I905) The Euthydemus of Plato. Oxford: Clarendon Press.

Gigante, M. (I995) Philodemus in Italy: The Books from Herculaneum.

Trans. D. Obbink. Ann Arbor: University of Michigan Press.

Gigon, O. (1987) Aristotelis opera. Volumen tertium: librorum deperditorum fragmenta. Berlin: De Gruyter.

Gildenhard, I. (2007) Paideia romana: Cicero's Tusculan Disputations. Cambridge Philological Society (30). Cambridge University Press.

Goldhill, S. (2002) The Invention of Prose. Oxford University Press.

(ed.) (2008) The End of Dialogue in Antiquity. Cambridge University Press.

Goold, G. P. (I96r) 'A Greek Professorial Circle at Rome' - TAPA (92), I $68-92$.

Gordon, J. (I999) Turning toward Philosophy: Literary Device and Dramatic Structure in Plato's Dialogues. Philadelphia: Pennsylvania State University Press.

Görler, W. (I988) 'From Athens to Tusculum: Gleaning the Background of Cicero's De oratore' - Rhetorica (6), 2 I5-35.

Gotschlich, E. (I87I) Über die Veranlassung des platonischen Dialoges Gorgias und die Polemik in demselben. Beuthen.

Gottschalk, H. B. (I980) Heraclides of Pontus. Oxford: Clarendon Press.

Goudriaan, K. (1989) Over classicisme: Dionysius van Haliearnassus en zijn program van welsprekendheid, cultuur en politiek. Dissertation: Amsterdam.

Graff, R. (2005) 'Prose versus Poetry in Early Greek Theories of Style' Rhetorica (23), 303-35.

Graff, R. and M. Leff (2005) 'Revisionist Historiography and Rhetorical Tradition(s)' - Graff et al. (2005), I I-30.

Graff, R., A. E. Walzer and S. Mailloux (eds.) (2005) The Viability of the Rhetorical Tradition. State University of New York Press.

Graham, A. J. (2007) 'Plato's Anachronisms' - Corolla Cosmo Rodewald, ed. N. Sekunda. Gdańsk: Foundation for the Development of Gdańsk University.

Gray, V. (I994) 'Images of Sparta: Writer and Audience in Isocrates' Panathenaicus' - Powell and Hodkinson (I994), 223-7I. 


\section{Bibliography}

Greenhalgh, M. (I990) What is Classicism? London: Academy Editions.

Griffin, M. T. (I989) 'Philosophy, Politics, and Politicians' - Griffin and Barnes (I989), I-37.

(200I) 'Piso, Cicero and Their Audience' - Auvray-Assayas and Delattre (2001), 85-99.

Griffin, M. T. and J. Barnes (eds.) (1989) Philosophia togata: Essays on Philosophy and Roman Society I. Oxford University Press.

Griswold, C. J. (I986) Self-Knowledge in Plato's Phaedrus. New Haven, CT: Yale University Press.

Grube, G. M. A. (196I) A Greek Critic: Demetrius on Style. University of Toronto Press.

Guthrie, W. K. C. (1986) A History of Greek Philosophy, vol. Iv: Plato: The Man and His Dialogues: Earlier Period. Cambridge University Press.

Hagen, H. M. (1966) Ethopoiia: Zur Geschichte eines rhetorischen Begriffs. Dissertation: Erlangen.

Hägg, T. (2012) The Art of Biography in Antiquity. Cambridge University Press.

Hall, E. (2013) 'Rhetorical Actors and Other Versatile Hellenistic Vocalists' - Kremmydas and Tempest (2013), I09-36.

Halliwell, S. F. (I990) 'Traditional Greek Conceptions of Character' Pelling (I 990), 32-59.

(1993) Plato: Republic 5. Warminster: Aris \& Philips.

(I994) 'Philosophy and Rhetoric' - Worthington (I994b), 222-43.

(1996) 'The Challenge of Rhetoric to Political and Ethical Theory in Aristotle' - Oksenberg Rorty (I996), I75-90.

(1997) 'Philosophical Rhetoric or Rhetorical Philosophy? The Strange Case of Isocrates' - Schildgen (I997), I07-25.

(2002) The Aesthetics of Mimesis: Ancient Texts and Modern Problems.

Princeton University Press.

(2006) Review of Isocrates and Civic Education, ed. T. Poulakos and

D. Depew - Classical Review (56), 36-7.

(201 I) Between Ecstasy and Truth: Interpretations of Greek Poetics from Homer to Longinus. Oxford University Press.

Hansen, M. H. (I983) 'The Athenian "Politicians", 403-322 BCE' - Greek, Roman, and Byzantine Studies (24), 33-55.

Harding, P. (I973) 'The Purpose of Isocrates' Archidamos and On the Peace' - California Studies in Classical Antiquity (6), I37-49.

(2000) 'Demosthenes in the Underworld: A Chapter in the Nachleben of a

Rhētō' - Worthington (2000), 246-7 I.

(2008) The Story of Athens: The Fragments of the Local Chronicles of Attika. London: Routledge.

Harris, E. M. (2013) 'How to Address the Athenian Assembly: Rhetoric and

Political Tactics in the Debate about Mytilene (Thuc. 3.37-50)' $-C Q$ (63), 94-I09. 


\section{Bibliography}

Harrison, J. R. (2003) Paul's Language of Grace in Its Graeco-Roman Context. Tübingen: Mohr Siebeck.

Haskins, E. V. (2004) Logos and Power in Isocrates and Aristotle. Columbia: University of South Carolina Press.

Haslam, M. W. (1972) 'Plato, Sophron and the Dramatic Dialogue' Bulletin of the Institute of Classical Studies, University of London (I9), I7-38.

Hatzimichali, M. (20I I) Potamo of Alexandria and the Emergence of Eclecticism in Late Hellenistic Philosophy. Cambridge University Press.

Hauser, G. A. (2004) 'Teaching Rhetoric: Or Why Rhetoric Isn't Just Another Kind of Philosophy or Literary Criticism' - Rhetoric Society Quarterly (34/3), 39-53.

Hawtrey, R. S. W. (I98I) Commentary on Plato's Euthydemus. Philadelphia: American Philosophical Society.

Heath, M. (I998) 'Caecilius, Longinus, and Photius' - GRBS (39), 27 I-92.

Heilbrunn, G. (I975) 'Isocrates on Rhetoric and Power' - Hermes (I03), I 54-78.

Helmbold, W. C. and E. N. O’Neil (I959) Plutarch's Quotations. Baltimore, MD: American Philological Association.

Hendrickson, G. L. (I904) 'The Peripatetic Mean of Style and the Three Stylistic Characters' - AJP (25), I25-46.

Herrmann, F.-G. (ed.) (2006) New Essays on Plato: Language and Thought in Fourth-Century Greek Philosophy. Swansea: Classical Press of Wales.

Hessler, J. E. (2018) 'Socratic Protreptic and Epicurus: Healing through Philosophy' - Stavru and Moore (20 I 8), 665-8I.

Hicks, R. D. (1950) Diogenes Laertius: Lives of Eminent Philosophers. Loeb Classical Library. London: Heinemann.

Hidber, T. (1996) Das klassizistische Manifest des Dionys von Halikarnass:

Die Praefatio zu 'De oratoribus veteribus': Einleitung, Übersetzung und Kommentar. Stuttgart: Teubner.

Hirzel, R. (1895) Der Dialog: Ein literaturhistorischer Versuch. Leipzig: Hirzel.

Hordern, J. H. (2004) Sophron's Mimes: Text, Translation, and Commentary. Oxford University Press.

Horn, Ch., J. Müller and J. Söder (eds.) (2009) Platon-Handbuch: LebenWerk-Wirkung. Stuttgart: Metzler.

Hose, M. (I999) 'Die zweite Begegnung Roms mit den Griechen, oder: Zu politischen Ursachen des Attizismus' - Vogt Spira and Rommel (I999), 274-88.

Howland, J. (2004) 'Plato's Reply to Lysias: Republic I and 2 and Against Eratosthenes' - AJP (I25), I79-208.

Howland, R. L. (I937) 'The Attack on Isocrates in the Phaedrus' - CQ (3I), I 5 I-59.

Hubbell, H. M. (I9I3) The Influence of Isocrates on Cicero, Dionysius and Aristides. New Haven, CT: Yale University Press. 


\section{Bibliography}

(I9I6) 'Isocrates and the Epicureans' - Classical Philology (I I), 405-I8.

(I966) 'Cicero on Styles of Oratory' - Yale Classical Studies (19), I 7 I-86.

Hudson-Williams, H. L. (I985) Review of Isocrates: Seine Positionen in der Auseinandersetzung mit den zeitgenössischen Philosophen, Christoph Eucken - Classical Review (35), 20-I.

Hunter, R. L. (2004) Plato's Symposium. Oxford University Press.

(2006) The Shadow of Callimachus: Studies in the Reception of Hellenistic

Poetry at Rome. Cambridge University Press.

(2007) 'Sappho and Latin Poetry' - Bastianini and Casanova (2007), 2 I3-25. (2009) Critical Moments in Classical Literature: Studies in the Ancient

View of Literature and Its Uses. Cambridge University Press.

(20I I) 'The Gods of Callimachus' - Acosta-Hughes et al. (20 I I), 245-63. (2012) Plato and the Traditions of Ancient Literature: The Silent Stream. Cambridge University Press.

(2014) Hesiodic Voices: Studies in the Ancient Reception of Hesiod's Works and Days. Cambridge University Press.

Hutchinson, D. S. and M. R. Johnson (2005) 'Authenticating Aristotle's Protrepticus' - Oxford Studies in Ancient Philosophy (29), I93-294.

(2010) 'The Antidosis of Isocrates and Aristotle's Protrepticus.' Accessed online: https://docs.google.com/file/d/oB432Ae6vnCJNZDU5OTMxZ jQtZjkyZSooY2RmLThlNDUtZTE2YTFjZDgxMmY I/edit?hl=en_ US\&pli= I.

(2015) Aristotle: Protrepticus. Accessed online: http://www.protrepticus .info/protreprecon20I5i20.pdf (last accessed 25 May 20I5).

Hutchinson, G. O. (I988) Hellenistic Poetry. Oxford: Clarendon Press. Indelli, G. (I994) 'References to Isocrates in PHerc. I007 (Philodemus, Rhetorica IV)' - Bülow-Jacobsen (I994), 36I-6.

(2000) 'I papyri di Lisia: Alcune osservazioni' - Papyrologica Lupiensia (9), I97-204.

Innes, D. C. (I985) 'Theophrastus and the Theory of Style' - Fortenbaugh et al. (I985), 25I-67.

(1994) 'Period and Colon: Theory and Example in Demetrius and Longinus' - Fortenbaugh and Mirhady (I994), 36-53.

(I995) Demetrius: On Style. Loeb Classical Library. Cambridge, MA:

Harvard University Press.

(2002) 'Longinus and Caecilius: Models of the Sublime' - Mnemosyne (55), 259-84.

Irwin, T. (I995) Plato's Ethics. Oxford University Press.

Jaeger, W. (I939) Paideia: The Ideals of Greek Culture. Vol I. Trans. G. Highet. Oxford: Blackwell.

(I944) Paideia: The Ideals of Greek Culture. Vol II. Trans. G. Highet. Oxford: Blackwell.

(I945) Paideia: The Ideals of Greek Culture. Vol III. Trans. G. Highet. Oxford: Blackwell. 


\section{Bibliography}

(1948) Aristotle: Fundamentals of the History of His Development. 2nd edn. Trans. R. Robinson. Oxford University Press.

Jahn, O. (1908) Cicero Brutus. 5th edn, ed. W. Kroll. Berlin: Weidmann.

Janko, R. (200o) Philodemus: On Poems: Book I. Oxford University Press.

(2006) 'Socrates the Freethinker' - The Blackwell Companion to Socrates, ed. S. Ahbel-Rappe and R. Kamtekar (Oxford: Blackwell), 48-62.

Jebb, R. C. (I876) The Attic Orators from Antiphon to Isaeos. 2 vols. London: Macmillan.

Johnson, R. (I957) 'A Note on the Number of Isocrates' Pupils' - AJP (78), 297-300.

Jordan, M. D. (I986) 'Ancient Philosophic Protreptic and the Problem of Persuasive Genres' - Rhetorica (4), 309-33.

Kahn, C. H. (1996) Plato and the Socratic Dialogue: The Philosophical Use of a Literary Form. Cambridge University Press.

Kassel, R. (1976) Aristotelis Ars rhetorica. Berlin: De Gruyter.

Keaney, J. J. (I99I) Harpocration: Lexeis of the Ten Orators. Amsterdam: A. M. Hakkert.

Kennedy, G. A. (1963) Art of Persuasion in Greece. London: Routledge.

(1970) Review of Lysias and the Corpus Lysiacum by K. J. Dover - AJP (9I/4), 495-7.

(1972) The Art of Rhetoric in the Roman World: 300 B.C. - A.D. 300. Princeton University Press.

(1980) Classical Rhetoric and Its Christian and Secular Tradition from Ancient to Modern Times. London: Croom Helm.

(I99I) Aristotle: On Rhetoric: A Theory of Civic Discourse. Oxford University Press.

Ker, J. and C. Pieper (eds.) (20I4) Valuing the Past in the Greco-Roman World. Leiden: Brill.

Kerferd, G. B. (I950) 'The First Greek Sophists' - Classical Review (64), 8-Io. (I98I) The Sophistic Movement. Cambridge University Press.

Kim, L. (2014) 'Archaizing and Classicism in the Literary Historical Thinking of Dionysius of Halicarnassus' - Ker and Pieper (2014), $357-87$.

Knögel, W. (1933) Der Peripatetiker Ariston von Keos bei Philodem. Leipzig: Otto Harrassowitz.

Knox, P. E. (20 I I) 'Cicero as a Hellenistic Poet' - CQ (6I), I92-204.

Kremmydas, C. (2013) 'Hellenistic Oratory and the Evidence of Rhetorical Exercises' - Kremmydas and Tempest (2013), I39-63.

Kremmydas, C. and K. Tempest (eds.) (2013) Hellenstic Oratory: Continuity and Change. Oxford University Press.

Kröner, H. O. (I976) 'Dialog und Rede: Zur Deutung des Isokrateischen Panathenaicus' - Seck (I976), 296-328.

Laistner, M. L. W. (1927) Isocrates: De Pace and Philippus. New York and London: Longmans. 


\section{Bibliography}

Lamb, W. R. M. (i924) Plato: Laches, Protagoras, Meno, Euthydemus. Loeb Classical Library. Cambridge, MA: Harvard University Press.

Laplace, M. (I995) 'Platon et l'art d'écrire des discours: Critique de Lysias et

d'Isocrate, influence sur Denys d'Halicarnasse' - Rhetorica (I3), I-I5.

Laqueur, R. (I9I I) 'Ephoros. 2. Die Disposition' - Hermes (46), 32 I-54.

Latacz, J. (I 966) Zum Wortfeld 'Freude' in der Sprache Homers. Heidelberg: Winter.

Lateiner, D. (198I) 'An Analysis of Lysias' Political Defense Speeches' Rivista storica dell' Antiquità ( I I), I47-6o.

Laughton, E. (I96I) 'Cicero and the Greek Orators' - AJP (82/I), 27-49.

Lebel, M. (I973) 'Évolution de la doctrine de Denys d'Halicarnasse du De Lysia aux De compositione uerborum et De Demosthene II' - Cahiers des études anciennes (2), 79-88.

Lefkowitz, M. (2012) The Lives of the Greek Poets. 2nd edn. London: Bristol

Classical Press.

Leftwich, G. V. (1987) Ancient Conceptions of the Body and the Canon of Polykleitos. Dissertation: Ann Arbor.

Leigh, M. (2004) 'Quintilian on the Emotions' - Journal of Roman Studies (94), I 22-40.

Levene, D. S. (20I0) Livy on the Hannibalic War. Oxford University Press. Livingstone, N. (I998) 'The Voice of Isocrates and the Dissemination of

Cultural Power' - Too and Livingstone (I998), 263-8I.

(200I) A Commentary on Isocrates' Busiris. Leiden: Brill.

Loening, T. C. (I98I) 'The Autobiographical Speeches of Lysias and the Biographical Tradition' - Hermes (I09), 280-94.

(1987) The Reconciliation Agreement of 403/402 BC in Athens: Its Content and Application. Stuttgart: Franz Steiner.

Long, A. G. (2008) 'Plato's Dialogues and a Common Rationale for

Dialogue Form' - Goldhill (2008), 45-59.

(2018) 'Sophists, Epicureans and Stoics' - Canevaro and Gray (2018), 93-I08.

Long, A. A. (1986) Hellenistic Philosophy: Stoics, Epicureans, Sceptics. Berkeley: University of California Press.

(ed.) (I999) The Cambridge Companion to Early Greek Philosophy. Cambridge University Press.

López Cruces, J. L. and Fuentes González, P. P. (2000) 'Isocrate d'Athènes' -Dictionnaire des philosophes antiques, vol. III: D'Eccélos à Juvénal, ed. R. Goulet (Paris: CNRS), 89I-938.

Loraux, N. (I98I) L'invention d'Athènes: Histoire de l'oraison funèbre dans la 'cité classique'. Paris: Mouton.

Lossau, M. J. (1964) Untersuchungen zur antiken Demosthenesexegese. Bad Homburg: Dr. Max Gehlen.

Luraghi, N. (2003) 'Dionysios von Halikarnassos zwischen Griechen und Römern' - Formen römischer Geschichtsschreibung von den Anfängen 


\section{Bibliography}

bis Livius: Gattungen - Autoren - Kontexte, ed. U. Eigler, U. Gotter, N. Luraghi and U. Walter (Darmstadt: Wissenschaftliche Buchgesellschaft), 268-86.

MacDowell, D. M. (I988) Review of Palatinus Graecus 88 and the Manuscript

Tradition of Lysias, M. L. Sosower - Classical Review (38), 403-4. (2009) Demosthenes the Orator. Oxford University Press.

MacEwen, I. K. (2003) Vitruvius: Writing the Body of Architecture. Cambridge, MA: MIT Press.

MacLachlan, B. (1993) The Age of Grace: Charis in Early Greek Poetry. Princeton University Press.

Mandilaras, V. G. (2003) Isocrates: Opera omnia. Vols I-III. Bibliotheca Teubneriana. Munich and Leipzig: K. G. Saur.

Marincola, J. (2014) 'Rethinking Isocrates and Historiography' - Between Thucydides and Polybius: The Golden Age of Greek Historiography, ed.

G. Parmeggiani (Washington, DC: Center for Hellenic Studies).

Marini, N. (2007) Demetrio, Lo Stile. Rome: Edizioni di storia e letteratura.

Mariß, R. (2002) Alkidamas: Über diejenigen, die schriftliche Reden schreiben, oder über die Sophisten. Eine Sophistenrede aus dem 4. Jahrhundert v. Chr. Münster: Aschendorff.

Marrou, H.-I. (I965) Histoire de l'éducation dans l'antiquité. Paris: Éditions du Seuil.

Martin, G. (2018a) 'Introduction' - Martin (2018b), I-4.

(ed.) (20I8b) The Oxford Handbook of Demosthenes. Oxford University Press.

Mathieu, G. and É. Brémond (eds.) (I928-62) Isocrate: Discours. 4 vols. Paris: Les Belles Lettres.

Matijašić, I. (20I8) Shaping the Canons of Ancient Greek Historiography: Imitation, Classicism, and Literary Criticism. Berlin: De Gruyter.

May, J. M. and J. Wisse (eds.) (200I) Cicero: On the Ideal Orator (De Oratore). Oxford University Press.

Mayhew, R. (20I I) Prodicus the Sophist: Texts, Translations, and Commentary. Oxford University Press.

McCabe, M. M. (I994) 'Arguments in Context: Aristotle's Defense of Rhetoric' - Aristotle's Rhetoric: Philosophical Essays, ed. D. J. Furley and A. Nehamas (Princeton University Press), I29-65.

McCoy, M. (2007) Plato on the Rhetoric of Philosophers and Sophists. Cambridge University Press.

McDonald, J. M. S. (I93I) Character-Portraiture in Epicharmus, Sophron, and Plato. Sewanee, TN: University Press.

McDowell, J. (I973) Plato: Theaetetus. Oxford University Press.

Medda, E. (2003) Lysiae in Hippothersem, In Theomnestum, et fragmenta ex incertis orationibus (P.Oxy. XIII I606). Florence: F. Le Monnier.

Mejer, J. (I98I) 'Demetrius of Magnesia: On Poets and Authors of the Same Name' - Hermes ( I09), 447-72. 


\section{Bibliography}

Michelini, A. N. (2000) 'Socrates Plays the Buffoon: Cautionary Protreptic in Euthydemus' - AJP (I2 I), 509-35.

Miller, P. A. (I994) Lyric Texts and Lyric Consciousness: The Birth of a Genre from Archaic Greece to Augustan Rome. London: Routledge.

Mirhady, D. (2004) 'Hieronymus on Isocrates' Style' - Fortenbaugh and White (2004), 443-56.

Mirhady, D. and Y. L. Too (2000) Isocrates I. Austin: University of Texas Press.

Misch, G. (1950) A History of Autobiography in Antiquity. Vol. I. Trans. E. W. Dickes. London: Routledge.

Mitsis, P. and C. Tsagalis (eds.) (2010) Allusion, Authority, and Truth: Critical Perspectives on Greek Poetic and Rhetorical Texts. Berlin and New York: De Gruyter.

Momigliano, A. (I94I) 'Epicureans in Revolt' - Journal of Roman Studies (3I) I 49-57.

(197I) The Development of Greek Biography: Four Lectures. Cambridge, MA: Harvard University Press.

Morgan, K. (2004) 'The Education of Athens: Politics and Rhetoric in Isocrates and Plato' - Poulakos and Depew (2004), I25-54.

Morgan, T. (I998) Literate Education in the Hellenistic and Roman Worlds. Cambridge University Press.

Most, G. W. (2006) Hesiod: Theogony; Works and Days; Testimonia. Loeb Classical Library. Cambridge, MA: Harvard University Press.

Moussy, C. (1966) Gratia et sa famille. Paris: Presses Universitaires de France.

Muir, J. V. (200I) Alcidamas: The Works \& Fragments. London: Bristol Classical Press.

Muir, J. R. (2019) The Legacy of Isocrates and a Platonic Alternative: Political Philosophy and the Value of Education. London: Routledge.

Müller, C. W. (1975) Die Kurzdialoge der Appendix Platonica: Philologische Beiträge zur nachplatonischen Sokratik. Munich: Fink.

Murphy, D. J. (2013) 'Isocrates and the Dialogue' - Classical World (I06), 3 I I-53.

Nails, D. (2002) The People of Plato: A Prosopography of Plato and Other Socratics. Indianapolis: Hackett.

Natoli, A. F. (2004) The Letter of Speusippus to Philip II. Stuttgart: Steiner.

Nichols, M. F. (2009) Vitruvius and the Rhetoric of Display: Wall Painting, Domestic Architecture and Roman Self-Fashioning. Dissertation: University of Cambridge.

Nicolai, R. (2004) Studi su Isocrate: La comunicazione letteraria nel IV sec. a. C. e i nuovi generi della prosa. Rome: Quasar.

Nightingale, A. W. (I995) Genres in Dialogue: Plato and the Construct of Philosophy. Cambridge University Press.

(2004) Spectacles of Truth in Classical Greek Philosophy: Theoria in Its Cultural Context. Cambridge University Press. 


\section{Bibliography}

Norden, E. (I 898) Die antike Kunstprosa: Vom VI. Jahrhundert v. Chr. bis in die Zeit der Renaissance. Leipzig: Teubner.

Norlin, G. (I966) Isocrates. Volume I. London: Heinemann and Cambridge, MA: Harvard University Press.

(I968) Isocrates. Volume II. London: Heinemann and Cambridge, MA: Harvard University Press.

Nussbaum, M. (I986a) The Fragility of Goodness: Luck and Ethics in Greek Tragedy and Philosophy. Cambridge University Press.

(ed.) (I986b) Logic, Science and Dialectic: Collected Papers of G. E. L. Owen. London: Duckworth.

Obbink, D. (2005) 'Lysias 47I5-47I6' - The Oxyrhynchus Papyri (69), I04-I5.

Ober, J. (1998) Political Dissent in Democratic Athens: Intellectual Critics of Popular Rule. Princeton University Press.

(2004) 'I, Socrates... The Performative Audacity of Isocrates' Antidosis' -

Depew and Poulakos (2004), 2 I-43.

Ofenloch, E. (1907) Caecilii Calactini Fragmenta. [1967 reprint.] Stuttgart: Teubner.

O'Gorman, N. (2006) Review of The Viability of the Rhetorical Tradition, ed. R. Graff, A. E. Walzer and J. M. Atwill (State University of New York Press, 2005) in Rhetorical Society Quarterly (36), I07-I3.

Oksenberg Rorty, A. (ed.) (1996) Essays on Aristotle's Rhetoric. Berkeley: University of California Press.

Orth, W. (ed.) (2003) Isocrates: Neue Ansätze zur Bewertung eines politischen Schriftstellers. Trier: Wissenschaftlicher Verlag.

Orwin, C. (I987) 'Cleitophon' - Pangle (I987), I I7-3 I.

Osborne, R. (2000) 'Fourth Century: The Political and Military Narrative' Classical Greece 500-323 BCE, ed. R. Osborne (Oxford University Press), I97-222.

Ostwald, M. (1986) From Popular Sovereignity to the Sovereignity of Law. Berkeley: University of California Press.

Ostwald, M. and J. P. Lynch (I994) 'The Growth of Schools and the Advance of Knowledge' - The Cambridge Ancient History, vol. vi: The Fourth Century B.C. ed. D. Lewis, J. Boardman, S. Hornblower and M. Ostwald (Cambridge University Press), 592-633.

O’Sullivan, N. (I992) Alcidamas, Aristophanes, and the Beginnings of Greek Stylistic Theory. Stuttgart: Steiner.

(I996) 'Written and Spoken in the First Sophistic' - Worthington (I996), I I 5-28.

(I997) 'Caecilius, the "canons" of writers, and the origins of Atticism' Dominik (I997), 32-49.

Overbeck, J. A. (I868) Die antiken Schriftquellen zur Geschichte der bildenden Künste bei den Griechen. Leipzig: Engelmann.

Owen, G. E. L. (I986) 'Tithenai ta phainomena' - Nussbaum (I986b), 239-5I. 


\section{Bibliography}

Palpacelli, L. (2009) L'Eutidemo di Platone: Una commedia straordinariamente seria. Milan: V\&P.

Pangle, T. L. (ed.) (1987) The roots of political philosophy: ten forgotten Socratic dialogues translated, with interpretive studies. Ithaca: Cornell University Press.

Papillon, T. L. (I995) 'Isocrates' techne and Rhetorical Pedagogy' - Rhetoric Society Quarterly (25), I49-63.

(I996) 'Isocrates on Gorgias and Helen: The Unity of the "Helen" Classical Journal (9I), 377-9I.

(I998) 'Isocrates and the Greek Poetic Tradition' - Scholia (7), 4I-6I .

(2004) Isocrates II. Austin: University of Texas Press.

Pelling, C. B. R. (2018) 'Dionysius on Regime Change' - Hunter and de Jonge (2018), 203-20.

(ed.) (I990) Characterization and Individuality in Greek Literature. Oxford: Clarendon Press.

Peterson, S. (20I I) Socrates and Philosophy in the Dialogues of Plato. Cambridge University Press.

Pfeiffer, R. (I968) History of Classical Scholarship: From the Beginnings to the End of the Hellenistic Age. Oxford University Press.

Pfister, F. (I933) 'Isocrates und die spätere Gliederung der Narratio' Hermes (68), 457-6o.

Pitcher, L. V. (2005) 'Narrative Technique in The Lives of the Ten Orators' $C Q$ (55), 2 I7-34.

Platt, H. F. (20I0) Literary Rhetoric: Concepts - Structures - Analyses. Leiden: Brill.

Politis, V. (2015) The Structure of Enquiry in Plato's Early Dialogues. Cambridge University Press.

Pollitt, J. J. (1965) The Art of Ancient Greece: Sources and Documents. 2nd edn I990. Cambridge University Press.

(1974) The Ancient View of Greek Art: Criticism, History, and Terminology. New Haven, CT: Yale University Press.

Porter, J. I. (I995) 'Oi kpıтıkoí: A Reassessment' - Abbenes et al. (I995), $83-$ I09.

- (2006a) 'What is "Classical" about Classical Antiquity' - Porter (2006b), I-65.

(2010) The Origins of Aesthetic Thought in Ancient Greece. Cambridge University Press.

(20 I I) 'Against $\lambda \varepsilon \pi т$ тótns: Rethinking Hellenistic Aesthetics' - Erskine and

Llewellyn-Jones (20I I), 27 I-3I 2.

(2015) 'The Sublime' - Destrée and Murray (2015), 393-405.

(ed.) (2006b) Classical Pasts: The Classical Traditions of Greece and Rome. Princeton University Press.

Poulakos, J. (2004) 'Rhetoric and Civic Education: From the Sophists to Isocrates' - Depew and Poulakos (2004), 69-83. 


\section{Bibliography}

Poulakos, T. (I997) Speaking for the Polis: Isocrates' Rhetorical Education. Columbia: University of South Carolina Press. (200I) 'Isocrates' Use of Doxa' - Philosophy and Rhetoric (34), 6I-78.

(2004) 'Isocrates' Civic Education and the Question of Doxa' -Depew and Poulakos (2004), 44-65.

Poulakos, T. and D. Depew (eds.) (2004) Isocrates and Civic Education. Austin: University of Texas Press.

Powell, A. and S. Hodkinson (eds.) (1994) The Shadow of Sparta. London: Routledge.

Press, G. A. (I993a) 'Principles of Dramatic and Non-Dogmatic Plato Interpretation' - Press (I993b), I07-27.

Press, G. A. (ed.) (I993b) Plato's Dialogues: New Studies and Interpretations. Lanham, MD: Rowman \& Littlefield.

Pritchett, W. K. (I975) Dionysius of Halicarnassus: On Thucydides. Berkeley: University of California Press.

Rabe, H. (I893) Die Zeitfolge der rhetorischen Schriften des Dionys von Halicarnass' - Rheinisches Museum (48), I47-5I.

Rabinowitz, W. G. (1957) Aristotle's Protrepticus and the Sources of Its Reconstruction. Berkeley: University of California Press.

Race, W. H. (I987) 'Pindaric Encomium and Isocrates' Evagoras' - TAPA ( I I 7), I3 I-55.

(1997) Pindar: Olympian Odes; Pythian Odes. Loeb Classical Library. Cambridge, MA: Harvard University Press.

Rackham, H. (1968) Cicero in Twenty-Eight Volumes. IV: De oratore Book III; De fato; Paradoxa stoicorum; De partitione oratoria. Loeb Classical Library. Cambridge, MA: Harvard University Press.

Radermacher, L. (I92 I) Aristophanes' 'Frösche'. Vienna: A. Hölder.

(I95I) Artium Scriptores: Reste der voraristotelischen Rhetorik. Vienna: Rohrer.

Reid, R. S. (I996) 'Dionysius of Halicarnassus' Theory of Compositional Style and the Theory of Literate Consciousness' - Rhetoric Review (I 5), 46-64.

(1997) "Neither oratory nor dialogue": Dionysius of Halicarnassus and the Genre of Plato's Apology' - Rhetoric Society Quarterly (27), 63-90.

Ries, K. (1959) Isocrates und Platon im Ringen um die Philosophia. Dissertation: Munich.

Riginos, A. S. (1976) Platonica: The Anecdotes Concerning the Life and Writings of Plato. Leiden: Brill.

Rist, J. M. (I964) 'Demetrius the Stylist and Artemon the Compiler' Phoenix (18), 2-8.

Roberts, W. Rhys (i 897a) 'Caecilius of Calacte' - AJP (I8), 302-I2.

(I897b) 'The Literary Circle of Dionysius of Halicarnassus' - Classical Review (14), 439-42. 


\section{Bibliography}

(I901) Dionysius of Halicarnassus: The three literary letters: Ep. ad Ammaeum I, Ep. ad Pompeium, Ep. ad Ammaeum II. Cambridge University Press.

Roisman, J., I. Worthington and R. Waterfield (2015) Lives of the Attic Orators: Texts from Pseudo-Plutarch, Photius, and the Suda. Oxford: Clarendon Press.

Roochnik, D. (1996) Of Art and Wisdom: Plato's Understanding of Techne. Philadelphia: Pennsylvania State University Press.

Roser, C. N. (2019) The Epistemic Value of Logos: Gorgias, Isocrates and Plato on the Possibility of Giving Reasons to Others. Dissertation: Humboldt Universität zu Berlin.

Rosillo López, C. (20I0) 'Praising Caesar: Towards the Construction of an

Autocratic Ruler's Image between the Roman Republic and the Empire' - Covino and Smith (2010), I 8 I-98.

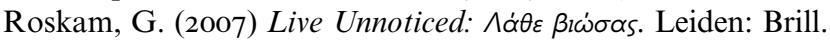

Ross, D. (1995) Aristotle. 6th"edn. London: Routledge.

Rossetti, L. (20I8) 'Philosopher Socrates? Philosophy at the Time of Socrates and the Reformed Philosophia of Plato' - Stavru and Moore (2018), 265-98.

Roth, P. (2003) Der Panathenaicus des Isocrates: Übersetzung und Kommentar. Munich: K. G. Saur.

Rouse, W. H. D. (1924) Lucretius: De rerum natura. Loeb Classical Library. Cambridge, MA: Harvard University Press.

Rowe, C. J. (I998) Plato: Symposium. Warminster: Aris \& Philips.

(2000) 'Cleitophon and Minos' - Cambridge History of Greek and Roman

Political Thought, ed. C. J. Rowe, M. Schofield, S. Harrison and M.

Lane (Cambridge University Press), 303-9.

Rubinstein, L. (2000) Litigation and Cooperation: Supporting Speakers in the Courts of Classical Athens. Stuttgart: Steiner.

Rue, R. (I993) 'The Philosopher in Flight: The Digression (I72C-I77c) in Plato's Theaetetus' - Oxford Studies in Ancient Philosophy ( I I ), 7 I-Ioo.

Ruffell, I. A. (20 I I) Politics and Anti-Realism in Athenian Old Comedy: The Art of the Impossible. Oxford University Press.

Russell, D. A. (I981a) Criticism in Antiquity. London: Duckworth.

(I98 Ib) 'Longinus Revisited' - Mnemosyne (34), 72-86.

(I990) 'Ethos in Oratory and Rhetoric' - Pelling (I990), I97-2 I2.

Rutherford, I. (I998) Canons of Style in the Antonine Age: Idea-Theory and Its Literary Context. Oxford: Clarendon Press.

Sacks, K. S. (I983) 'Historiography in the Rhetorical Works of Dionysius of Halicarnassus' - Athenaeum (6I), 65-87.

Sandys, J. E. (I885) M. Tulli Ciceronis Ad Marcum Brutum Orator. Cambridge University Press.

(I897) Isocrates: Ad Demonicum et Panegyricus. [I979 reprint.] London: Longmans Green. 


\section{Bibliography}

Schäublin, C. (I982) 'Selbstinterpretation im "Panathenaicus" des Isocrates?' - Museum Helveticum (39), I65-78.

Schenkeveld, D. M. (I964) Studies in Demetrius, On Style. Amsterdam: A. M. Hakkert.

(i968) 'Oi kpıтıkoi in Philodemus' - Mnemosyne (2 I), I76-2 I4.

(I975) 'Theories of Evaluation in the Rhetorical Works of Dionysius of Halicarnassus' - Museum Philologum Londiniense (I), 93-I07.

(I983) 'Linguistic Theories in the Rhetorical Works of Dionysius of Halicarnassus' - Glotta (6I), 67-94.

(2000) 'The Intended Public of Demetrius's On Style: The Place of the

Treatise in the Hellenistic Educational System' - Rhetorica (I 8), 29-48.

Schiappa, E. (I990) 'Did Plato Coin Rhêtorikê?' - AJP (I I I), 460-73.

(I995) 'Isocrates' Philosophia and Contemporary Pragmatism', Rhetoric,

Sophistry, Pragmatism, ed. S. Mailloux (Cambridge University Press), 33-6o.

(I999) The Beginnings of Rhetorical Theory in Classical Greece. New Haven, CT: Yale University Press.

Schildgen, B. D. (ed.) (I997) The Rhetoric Canon. Detroit, MI: Wayne State University Press.

Schindel, U. (1967) 'Untersuchungen zur Biographie des Redners Lysias' Rheinisches Museum für Philologie ( I I0), 32-52.

Schleiermacher, F. (I 836) Schleiermacher's Introductions to the Dialogues of Plato. Trans. W. Dobson. Cambridge and London: Deigthon \& Parker.

Schlikker, F. W. (I940) Hellenistische Vorstellungen von der Schönheit des Bauwerks nach Vitruv. Berlin: Archäologisches Institut des Deutschen Reiches.

Schmid, W. ( 1887) Der Atticismus in seinen Hauptvertretern: Von Dionysius von Halikarnass bis auf den zweiten Philostratus. Stuttgart: Kohlhammer.

Schmitz, T. A. and N. Wiater (eds.) (20I I) The Struggle for Identity: Greeks and Their Past in the First Century BCE. Stuttgart: Steiner.

Schneeweiss, G. (2005) Aristoteles: Protreptikos: Hinführung zur Philosophie. Darmstadt: Wissenschaftliche Buchgesellschaft.

Schofield, M. (I999) 'Social and Political Thought' - Algra et al. (I999), 739-70.

(2006) Plato: Political Philosophy. Oxford University Press.

(2008) 'The Ciceronian Dialogue' - Goldhill (2008), 63-84.

(ed.) (2013) Aristotle, Plato and Pythagoreanism in the First Century BC: New Directions for Philosophy. Cambridge University Press.

Scholz, P. (1998) Der Philosoph und die Politik: Die Ausbildung der philosophischen Lebensform und die Entwicklung des Verhältnisses von Philosophie und Politik im 4. und 3. Jh. v. Chr. Stuttgart: Steiner.

Schubert, P. (ed.) (2012) Actes du 26e Congrès international de papyrologie. Geneva: Librairie Droz. 


\section{Bibliography}

Schultze, C. (1986) 'Dionysius of Halicarnassus and His Audience' - Past Perspectives: Studies in Greek and Roman Historical Writing, ed. I. S. Moxon, J. D. Smart and A. J. Woodman (Cambridge University Press), I 2 I-4I.

Schütrumpf, E. (I994) 'Some Observations on the Introduction to Aristotle's Rhetoric' - Aristotle's Rhetoric: Philosophical Essays, ed. D. J. Furley and A. Nehamas (Princeton University Press), 99-I I6.

Schwarze, S. (I999) 'Performing ppóvๆois: The Case of Isocrates' Helen' Philosophy and Rhetoric (32), 78-95.

Seck, F. (ed.) (i976) Isocrates. Darmstadt: Wissenschaftliche Buchgesellschaft.

Sedley, D. N. (2003) 'Philodemus and the Decentralisation of Philosophy' Cronache Ercolanesi (33), 3 I-4I.

(2004) The Midwife of Platonism: Text and subtext in Plato's Theaetetus.

Oxford University Press.

(ed.) (2012) The Philosophy of Antiochus. Cambridge University Press.

Segal, C. (I962) 'Gorgias and the Psychology of the Logos' - Harvard Studies in Classical Philology (66), 99-I55.

Sermamoglou-Soulmaidi, G. (2014) Playful Philosophy and Serious Sophistry: A Reading of Plato's 'Euthydemus'. Berlin and New York: De Gruyter.

Shackleton Bailey, D. R. (2000) Valerius Maximus: Memorable Doings and Sayings. Loeb Classical Library. Cambridge, MA: Harvard University Press.

Shuckburgh, E. S. (1979) Lysias: Five Speeches. Bristol Classical Press.

Sidwell, K. (2009) Aristophanes the Democrat. Cambridge University Press.

Silk, M., I. Gildenhard and R. Barrow (2014) The Classical Tradition: Art, Literature and Thought. Malden MA, Oxford and Chichester: WileyBlackwell.

Sinclair, R. K. (I988) Democracy and Participation in Athens. Cambridge University Press.

Slings, S. R. (I995) 'Protreptic in Ancient Theories of Philosophical Literature' - Abbenes et al. (I995), I73-92.

(1999) Plato: Clitophon. Cambridge Classical Texts. Cambridge University Press.

Smith, R. M. (I992) 'Photius on the Ten Orators' - GRBS 33, I59-89

(I995) 'A New Look at the Canon of the Ten Attic Orators' - Mnemosyne (48), 66-79.

Smith, R. W. (1974) The Art of Rhetoric in Alexandria: Its Theory and Practice in the Ancient World. M. Nijhoff: The Hague.

Snell, B. (1959) Pindarus. Pars prior: Epinicia. Leipzig: Teubner.

Snell, B. and H. Maehler (I970) Bacchylides: Carmina cum fragmentis. [post B. Snell edidit H. Maehler.] Leipzig: Teubner. 


\section{Bibliography}

Solmsen, F. (I94Ia) 'The Aristotelian Tradition in Ancient Rhetoric I' AJP (62/I), 35-50.

(I94Ib) 'The Aristotelian Tradition in Ancient Rhetoric II' - AJP (62/2), I69-90.

Sommerstein, A., S. Halliwell, B. Zimmermann and J. Henderson (eds.) (I993) Tragedy, Comedy and the Polis: Papers from the Greek Drama Conference, Nottingham, I8-20 July I990. Bari: Levante editori.

Sosower, M. L. (1987) Palatinus Graecus 88 and the Manuscript Tradition of Lysias. Amsterdam: Hakkert.

Starr, J. and T. Engberg-Pedersen (eds.) (2004) Early Christian Paraenesis in Context. Berlin: Walter De Gruyter.

Stavru, A. and C. Moore (eds.) (2018) Socrates and the Socratic Dialogue. Leiden: Brill.

Steidle, W. (I952) 'Redekunst und Bildung bei Isocrates' - Hermes (80), 257-96.

Sudhaus, S. (I889) 'Zur Zeitbestimmung des Euthydems, des Gorgias, und der Republik' - Rheinisches Museum für Philologie (44), 52-64.

(I893) 'Aristoteles in der Beurtheilung des Epikur und Philodem' Rheinisches Museum für Philologie (48), 552-64.

(1896) Philodemi Volumina rhetorica. 2 vols. Leipzig: Teubner.

Swancutt, D. M. (2004) 'Paraenesis in Light of Protrepsis: Troubling the Typical Dichotomy' - Starr and Engberg-Pedersen (2004), I I3-54.

Tanner, J. (2006) The Invention of Art History in Ancient Greece: Religion, Society and Artistic Rationalisation. Cambridge University Press.

Tarán, L. (198I) Speusippus of Athens: A Critical Study with a Collection of the Related Texts and Commentary. Leiden: Brill.

Tarrant, H. (2000) Plato's First Interpreters. London: Duckworth.

Taylor, C. (2007) 'A New Political World' - Debating the Athenian Cultural Revolution: Art, literature, philosophy and politics 430-380 BC, ed. R. Osborne (Cambridge University Press), 72-90.

Tigerstedt, E. N. (1965) The Legend of Sparta in Classical Antiquity. Vol. I. Stockholm: Almquist \& Wiksell.

Timmerman, D. M. (I998) 'Isocrates' Competing Conceptualization of Philosophy' - Philosophy and Rhetoric (3 I), I45-59.

Todd, S. C. (I990) 'The Use and Abuse of the Attic Orators' - Greece \& Rome (37), I59-78.

(1993) The Shape of Athenian Law. Oxford: Clarendon Press.

(200o) Lysias: Translation with Introductions and Notes. Austin: University of Texas Press.

(2007) A Commentary on Lysias: Speeches I-II. Oxford University Press.

Too, Y. L. (1995) The Rhetoric of Identity in Isocrates. Cambridge University Press.

(2008) A Commentary on Isocrates' Antidosis. Oxford University Press.

Too, Y. L. and N. Livingstone (eds.) (I998) Pedagogy and Power: Rhetorics of Classical Learning. Cambridge University Press. 


\section{Bibliography}

Trapp, M. (I990) 'Plato's Phaedrus in Second-Century Greek Literature' Antonine Literature, ed. D. A. Russell (Oxford University Press), I $4 \mathrm{I}-73$.

Trevett, J. C. (I990) 'P.Oxy. 2537 and Isocrates' Trapeziticus' - Zeitschrift für Papyrologie und Epigraphik (80), 22-6.

(I996) 'Aristotle's Knowledge of Athenian Oratory' - $C Q$ (46/2), 37 I-9.

Tritle, L. A. (1988) Phokion the Good. London: Croom Helm.

Tsitsiridis, S. (2013) Beiträge zu den Fragmenten des Klearchos von Soloi. Berlin: de Gruyter.

Tukey, R. H. (I909) 'The Composition of the De oratoribus antiquis of Dionysius' - Classical Philology (4), 390-404.

Usener, S. (1994) Isocrates, Platon und ihr Publikum: Hörer und Leser von Literatur im 4. Jahrhundert v. Chr. Tübingen: G. Narr.

Usher, S. (1965) 'Individual Characterisation in Lysias' - Eranos (63), 99-I I9.

(1974) Dionysius of Halicarnassus: Critical Essays I. Loeb Classical Library. Cambridge, MA: Harvard University Press.

(I976) 'Lysias and His Clients' - GRBS (I7), 3 I-40.

(1985) Dionysius of Halicarnassus: Critical essays II. Loeb Classical Library. Cambridge, MA: Harvard University Press.

(1989) Review of In Defense of Rhetoric, B. Vickers (Oxford, I988) Classical Review (39), 4I-3.

(1990) Isocrates: Panegyricus and To Nicocles. Warminster: Aris and Philips. (I999) Greek Oratory: Tradition and Originality. Oxford University Press. (2004) 'Lysias for Pleasure?' - Cairns and Knox (2004), I I3-2 I.

van der Meeren, S. (2002) 'Le protreptique en philosophie: Essai de définition d'un genre' - Revue des Études Grecques ( I I5), 59I-62 I .

(20 I I) Aristote: Exhortation à la Philosophie. Le dossier grec. Paris: Les Belles Lettres.

Van Hook, L. (I986) Isocrates. Volume III. Loeb Classical Library. Cambridge, MA: Harvard University Press.

van Wyk Cronjé, J. (I986) Dionysius of Halicarnassus: De Demosthene: A Critical Appraisal of the Status Quaestionis... Hildesheim: Olms.

Vander Waerdt, P. A. (ed.) (I994) The Socratic Movement. Ithaca, NY: Cornell University Press.

Vatai, F. L. (I984) Intellectuals in Politics in the Greek World. London: Croom Helm.

Veteikis, T. (20I I) 'References to Isocrates in Aristotle's Art of Rhetoric' Literat $\otimes r a(53 / 3), 7-40$.

Vickers, B. (I988) In Defense of Rhetoric. Oxford: Clarendon Press.

Viidebaum, L. (2018) 'Dionysius and Lysias' Charm' - de Jonge and Hunter (2018), I06-24.

Vogt Spira, G. and B. Rommel (eds.) (1999) Rezeption und Identität: Die kulturelle Auseinandersetzung Roms mit Griechenland als europäisches Paradigma. Stuttgart: Steiner. 


\section{Bibliography}

Walbank, F. W. (I98I) The Hellenistic World. Cambridge, MA: Harvard University Press.

Walberer, G. (1938) Isocrates und Alkidamas. Dissertation: Hamburg.

Walker, J. (20I I) The Genuine Teachers of This Art: Rhetorical Education in Antiquity. Columbia: University of South Carolina Press.

Wallace-Hadrill, A. (2008) Rome's Cultural Revolution. Cambridge University Press.

Wardy, R. (1996) The Birth of Rhetoric: Gorgias, Plato and Their Successors. London: Routledge.

Wareh, T. (2012) Theory and Practice of Life: Isocrates and the Philosophers. Cambridge, MA: Harvard Center for Hellenic Studies.

Weaire, G. (2005) 'Dionysius of Halicarnassus' Professional Situation and the De Thucydide' - Phoenix (59), 246-66.

Wehrli, F. (1968) Die Schule des Aristoteles: Texte und Kommentar. Demetrios von Phaleron. Basel: Schwabe.

(1969) Die Schule des Aristoteles: Texte und Kommentar. Klearchos. Basel: Schwabe.

Weische, A. (1972) Ciceros Nachahmung der attischen Redner. Heidelberg: Carl Winter.

Weissenberger, M. (2003) 'Lysias I905-2000' - Lustrum (45), 7-I66.

Wersdörfer, H. (1940) Die Philosophia des Isocrates im Spiegel ihrer Terminologie: Untersuchungen zur frühattischen Rhetorik und Stillehre. Dissertation: Leipzig.

West, M. L. (I966) Hesiod: Theogony. Oxford: Clarendon Press. (1978) Hesiod: Works and Days. Oxford: Clarendon Press.

Whitehead, D. (2004) 'Isocrates for Hire: Some Preliminaries to a Commentary on Isocrates I6-2 I' - Cairns and Knox (2004), I 5 I-85.

Wiater, N. (20Ira) The Ideology of Classicism: Language, History, and Identity in Dionysius of Halicarnassus. New York: De Gruyter.

(20 I Ib) 'Writing Roman History - Shaping Greek Identity: The Ideology of Historiography in Dionysius of Halicarnassus' - Schmitz and Wiater (20 I I), 6I-92.

Wilamowitz-Möllendorff, U. von (I900) 'Asianismus und Atticismus' Hermes (35), I-52.

Wilcox, S. (I943a) 'Isocrates' Genera of Prose' - AJP (64/4), 427-3 I.

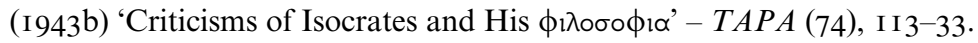

Wilms, H. (I995) Techne und Paideia bei Xenophon und Isocrates. Stuttgart: Teubner.

Wisse, J. (1989) Ethos and Pathos from Aristotle to Cicero. Amsterdam: Hakkert.

(I995) 'Greeks, Romans, and the Rise of Atticism' - Abbenes et al. (I995), $65^{-82}$.

(200I) 'Atticists, Academics and Epicureans: Response to Robert Gaines' - Auvray-Assayas and Delattre (200I), 273-82. 


\section{Bibliography}

Woerther, F. (2013) 'Propositions pour une nouvelle édition des fragments de Caecilius de Calè-Actè' - Revue de philologie, de littérature et d'histoire anciennes (87/2), I33-49.

(2015) Caecilius de Calè-Actè, Fragments et témoignages. Paris: Les Belles Lettres.

Wolpert, A. and K. Kapparis (eds.) (201 I) Legal Speeches of Democratic Athens: Sources for Athenian History. Indianapolis: Hackett.

Woodruff, P. (I999) 'Rhetoric and Relativism: Protagoras and Gorgias' Long (I 999), 290-3I0.

Wooten, C. W. (I974) 'The Speeches in Polybius: An Insight into the Nature of Hellenistic Oratory' - AJP (95), 235-5I.

(1977) 'Cicero's Reactions to Demosthenes: A Clarification' - Classical Journal (73/I), 37-43.

(1994) 'Peripatetic Tradition in the Literary Essays of Dionysius of Halicarnassus' - Fortenbaugh and Mirhady (I994), I 2 I-30.

(20I8) 'Rhetorical Technique' - Martin (20 I8b), 407-I8.

Worthington, I. (I993) 'Once More, the Client/Logographos Relationship' $C Q(43 / \mathrm{I}), 67-72$.

(I994a) 'The Canon of the Ten Attic Orators' - Worthington (I994b), 244-63.

(2013) Demosthenes of Athens and the Fall of Classical Greece. New York:

Oxford University Press.

(ed.) (I994b) Persuasion: Greek rhetoric in Action. London: Routledge.

(ed.) (I996) Voice into Text: Orality and Literacy in Ancient Greece. Leiden: Brill.

(ed.) (2000) Demosthenes: Statesman and Orator. London: Routledge.

Xanthakis-Karamanos, G. (I979) 'The Influence of Rhetoric on FourthCentury Tragedy' - $C Q$ (29), 66-76.

(I980) Studies in Fourth-Century Tragedy. Athens: Akadēmia Athēnōn.

Yunis, H. (1996) Taming Democracy: Models of Political Rhetoric in Classical Athens. Ithaca, NY: Cornell University Press.

(20 I I) Plato: Phaedrus. Cambridge Greek and Latin Classics. Cambridge University Press.

(ed.) (2003) Written Texts and the Rise of Literate Culture in Ancient Greece. Cambridge University Press.

Zajonz, S. (2002) Isocrates' Enkomion auf Helena: Ein Kommentar. Göttingen: Vandenhoeck \& Ruprecht.

Zanker, P. (1995) The Mask of Socrates: The Image of the Intellectual in Antiquity. Berkeley: University of California Press. 


\section{INDEX}

Academy, 39n. I8, 40, 56, 73, I0on. 24, I27n. 47, I66, 233

advantage, 80-I, 84, 90-I, 94, 97, 22 I see also gain

Aeschines, I2, I4n. 40, 33, 33n. 33, I77, 2Ion. 80,236

Alcibiades, I02

Alcidamas, Io6-IO, I53-4, 236

ambivalence, 5I, 66, I I3

ancient rhetorical tradition, 4-5, I4-I6, I 82, 244 see also rhetorical tradition

Antiphon, 2II, 236

Antisthenes, 52, 59n. 67, 63n. 8, 8In. 63, 9I, 98n. I 5

Apollodorus, 22, 25, 27, 32

apology, 240

Ariston of Ceus, I4I

Aristophanes, 43n. 27, 47n. 37, 93, 98n. I8, I52, 225n. 2 I

Aristotle, 2, IIn.33, I3, 56-8, 65n. I5, 8on. 6o, 85n. 70, 88, 91, 93, 99n. I9, I04, I40, I44, I47, I53n. 45, I56n. 5I, I58, I6I-2, I64-5, I72, I84, I99, $224,228,235-7,239,240$. 54

on style, I87, I93

treatment of Isocrates, I26-35

arrangement, 2, I8I

artlessness, I94

Assembly (Athenian), 77n. 5I, 78n. 53, I 58, I85-6, 2I 9

astronomy, 85, 96

Athenaeus, 25n. 23, I44-5

Athens, 5, 8, II-I3, I9-24, 26-7, 32-3, 39, 4In. 22, 44-7, 59n. 67, 63, 68, 7In. 29, 75, 90, 92-I06, I07, II2, II 4, I I 7, I20, I25, I27-8, I32n. 56, I33, I44, I46n. 30, 2 I I-I3, 224, 233

Atticism, 24, I9In. 42

audience, 3on. 40, 33, 45, 47, 52, 60, 68, 82, 93, I03, I09-I0, I28, I46n. 30,
I 75, I78-9, I94, 20I-4, 222-3, 240 see also readership

Augustus, I5, 2I 2-I3

authenticity, 20-2, 28n. 35, 39-40

authority, 77, 95n. I2, I19, I60-3, I67, I 75, I95, 200, 227, 230, 243

authorship, I9-2I, 34, 40, 59, I44n. 20, 202, 2I 2n. 85, 243

beautiful (ka $\lambda$ ós), 36, 54, I I3, I6 I

biography, 22n. I I, 24, 32, 48n. 39, 62 n. I, I 84,2 I 6 n. 5

blame, I59, I86n. 34

body, 40, 85, I29, I7 I

Bonner, Stanley Frederick, I6, I76-8I, I83n. 3I, I86-8, I90, 205n. 7I, 209, 2I 4 n. I, 228n. 27

Caecilius of Caleacte, 27n. 29, I80-2

Callicles, 26n. 24, 97, I I In. I5, I I4, I I 7, I $23-5$

Callimachus, I72n. 95

Callisthenes of Olynthus, I 43

canon of ten Attic orators, I I, I9n. I, 27, I47, I80, I84, 2 I5

Cato, I7I

Cephalus, 23, 56

see also Lysias,

character, 25-6, 35-48, 5I, 53-5, 58n. 64, 62n. I, 63, 84-5, 96, II4, I24n. 38, I29, I3In. 56, I40-I, I88, I93-6, 208, 2I9, 220-I, 223, 227, 229, 23 I see also èthopoiía

charm (xóp1s), 67, I16, I23, I50-3, I55, I74, I90, I95-20I, 205-8

Chrysippus, 233, 237-8

Cicero, 7n. I7, I4, 25, 27n. 28, 36-7, 58n. 64, 86n. 76, 88, г27, І32n. 56, I39, I43n. I6, I47, I55, I6In. 70, I63-9, I70-5, I79, I80n. 22, I9In. 


\section{Index}

42, 202n. 65, 205n. 68, 208, 224 n.

I9, 237n. 46

citizenship, 98n. I6, I79, 2 I In. 84

clarity, I34n. 64, I87-8, I89, 203, 207, 224n. I 8

classicism, 4n. 9, I83n. 3I, I9In. 42, 204n. 67, 238n. 49

Clearchus of Soloi, I40

comedy, 47, 93, I5I-2

commonplace, I, $55,58 \mathrm{n}$. 64, Io In. 26 , I 95, 200, 225

composition, 2, 6n. I4, I5, 23n. I3, 49-50, 53n. 50, 66, 7I-2, I08, I27,

I33, I50n. 42, I54, I57-9, I64n. 75, I7I, I77, I93-4, I98, I99n. 58, 220, $237-8,242$

Corax, 224

corpus Lysiacum, 5n. I2, Ion. 29, I9-22, 24, 27-3I, 34-6, I40, 2 I 2

see also Dover, Kenneth

Council (Athenian), 78n. 53, I 85

courtroom, 29, 37, 4I, 48, 66, 7I-2, I I8n. 25, I64, I69, 2 I9-20

criticism, 4n. II, 5, 9, I5, I6, 20, 2In. 7, 29, 37, 4I-4, 5I-2, 55n. 52, 60, 70, 72-3, 75-6, 95, I02, II0-I I, I I4n. I8, I2I, I23, I25, I28, I32n. 56, I34n. 64, I35, I39, I42, I46, I47, I50-3, I56, I63, I7I, I76, I79-82, I90, I92, I95-6, 200-I, 203, 205, 207, 208, 209, 210, 2I 8-22, 227, 229, $238-40,244$

culture, II, I2, 22, 59n. 67, 65, 79n. 57, 96, I06, I49, I5In. 43, I73, I76, 202n. 65,230

deception, 52, I94n. 48, 20 I delivery, 34, I46-7, I78, 202, 2 I9

Demetrius, see Ps. Demetrius

Demetrius of Magnesia, 208

Demetrius of Phalerum, I44, I 5 In.43

democracy, 23, 27, 45-6, 95n. I2, 99 n. 22, I04, 2I In. 84, 2 I 2

Demosthenes, I2-I4, I5, 33-4, 46, I40-I, I45, I47, I60, I66, I70, I7I-3, I76-8, I80n. 22, I8I, I82, I84, I9I, I99-20I, 205, 206, 207-8, 2IO, 2 II , 227n. 26, 228n. 27, 235-7, 24I, 243 dialectic, 56n. 56, 7 In. 28, I3In. 55

dialogue (form of writing), $7,35,38-42$, 45-6, 52, 59, 7In. 28, 73, 9In. 87, 94-6, 98, II8, I24n. 38, I26n. 42, I27, I3I, I67n. 8I, I69n. 85, 224, 229

Dinarchus, I76, 208-9, 2I2n. 85, 243

Diogenes Laertius [DL], 33n. 5, 36, 55-6, 59, I26n. 42, I40, I5In. 43, I6on. 69

Dionysius of Halicarnassus,

as historian, I5, I43n. I6, I44, I76, 243

as literary critic, 5, 8, 9, I4, I5, I9, 20, 24, 25, 27, 29-3I, 36, 57, I47, I 50-I, I76, I77-8, I84-96, I96-20I, 2OI-I3, 2I4-23, 237-9, 243

as teacher, 9, $16,176,183,210,217$, $236,24 \mathrm{I}-2$

audience of, I78-82, 203-4

classicism and, 183,222

on (true) philosophy, 9, 65, I I8, 2 I4, 2I6-I 7, 223-5, 226-7, 228-36, 240, 242

rhetorical tradition and, I In. 30, I6, 25, I39, I83, 203, 243-4

Rome and, I76, 203-5, 210, 2I2, 2 I4 discourse, 4, II, 27n.27, 29, 48, 49, 53, $63,64,65-71,74,77,84,87,88$, Iо I, I04, I08-9, I28n. 5I, I29, I47-8, I60, I68, I82, I85-6, 203n. 66, 2I5-I6, 220, 223, 225, 237-8, 240, 24I, 242

disciplines, 85, 96, I65

Dover, Kenneth, 5n. I2, IO, I9-20, 2 In. 7, 22-6, 28n. 32, 32n. 2, 43-4, 55n. 52

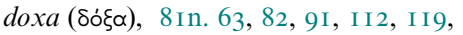
I22n. 35, I85, 219

see also opinion

education, 2, 4n.I0, 7, 9, II-I2, I3, I5n. 48, I9n. 2, 4I, 62, 64, 65, 67-8, 69-7I, 73, 76-9, 8I, 86-7, 92-I04, I06-I4, II7-20, I24-6, I27-3I, I32, I39, I4In.9, I42n. I0, I43, I46, I47, I49, I56, I6on. 70, I62n. 72, I63, I66, I67, I69, I73, I75, I79, I94n. 48, 200, 203-4, 205n.7 I, 2I 4, 2I6n. 


\section{Index}

5, 2 I 7-20, 222-3, 225, 229-30, 238n. 49, 244

elite, I4n. 4I, 38, 46, 62, 68, I00, I04, I35, I 49, I79, 204

eloquence, 76n. 48, I64, I67, I74

emotions, 24, I09-IO, I20, I25, I8In. 25, I88, I93, 205, 208

enthymeme, 2, 57n. 60

Ephorus, I42-3

epic, 68

see also Hesiod; Homer

Epicrates, 45-7, 6on. 70

Epicureanism, 93n. 8, I48, I55-63, I70, I 73

see also Philodemus

epistemology, see knowledge

Eratosthenes, 48n. 40, 60

eristics, 7In. 28, 96, I09, 2 I 7

ethics, 98, II4, I34, 228

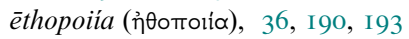

èthos, II4

excellence, 53n. 50, 90-I, 97, rorn. 27, I02, I I 2, I 25, I26, I 85, 205

exhortation, I29, I32n. 56, 22 I

experience, 67n. I9, 79, 8 In. 63, 84, I I 2-I3, I I9, I 24, I 58, I 73, I98, 205 see also practice

expertise, 95n. I2, I97,

24 I-2

fees, 76n. 45, 98-I00, I 22

gain, 90, 97, 99

see also advantage

geometry, 85, 96

Gorgias, 25n. 23, 33n. 5, 52, 66, 69-70, 75, 8 In. 63, 83, 92, 96n. I2, I00, I07, II3, I22, I32n. 59, I53-4, I66n. 79, I69, 223-6, 229

Gorgias (Plato's dialogue), 42, 46, 97, I I I, I 2 I-2, I35, I4I, I67n. 8I

grammar, I44, 2 I9, 228

gravitas, 37

Greekness, 222 see also identity

handbooks, 2n. 4, 26, 29, 87-9, I86, 226, 236

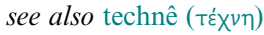

Harpocration, 24n. I7, 29n. 37, 34n. 7, I 43-4, I45n. 26

Hegesias of Magnesia, I75

Hermippus of Smyrna, I44-6

Hermogenes, I3n. 38, I84

Herodotus, I4In. 9, I8I, I88, I90

Hesiod, 65, 67n. I8

hiatus, I 54

Hieronymus of Rhodes, I44, I46-7

Hieronymus the philosopher, I44, 2 I9, 230, 234n. 39

Hippias, I I 3

history, 7, I0, I2, 20n. 6, 46, 50, 84, 88n. 79, 89, I27, I34, I40, I42-3, I46, I62, I76, I79, I80, 239n. 52

of rhetoric, In. 2, 3, 4, 9, II, I3, I5, $3 \mathrm{I}, 64$

Homer, 65, 68n. 20, I I3, I4In. 9, I52 see also epic

humor, I72-3

Hyperides, I73, I77, 208, 2 I on. 80, 236, 243

Iamblichus, I30, I3 In. 55

identity, I73, I 79, 2 I 6, 2 I 7, 222

ideology, 20, 24, I43, I49, I82, 203

ignorance, 69, 95, I23

imitation, 49n. 42, 65-6, 84, I4In. 9, I 47, 220, 223, 234

see also mimesis ( $\mu$ ín一ाs)

invention, 20I, 226

irony, 7, 37, 48n. 39, 97n. I4, I I I, I I2, I74n. 97, I92n. 44, I95, 224, 227, 244

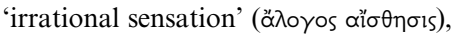
I 97-9, 203, 205, 24I-2

Isaeus, I76-7, I83, I87n. 36, I99, 20 In. $63,205-6,2$ Io-I I, 236

Isocrates,

ambivalence about his works, II, $62-4,2$ I 5

as model for Cicero, I63-9

as part of the Attic canon of ten orators, 8, I47, 2 I 5

as rival of Plato, Aristotle and other

Socratics, I In. 33, I 2, 52, 75, I 27-35, I6 In. 7I, I62

as teacher, 8, 78, I09-IO, I2I, I44, I 47, 2 I 8, 223 


\section{Index}

Isocrates (cont.)

biographical tradition and, 5n. I2, 62, 2 I 6

epideictic oratory and, I67, 24I

importance for Dionysius of H., 8-9, I6, 65, II 8, I39, I47, I83, 206-7, 2IO, 2I 4-44

influence on the rhetorical tradition, I3, 57, 63, 64, 2IO, 2 I 7

knowledge and, 82-3, II3, II9, I59n. 68, 233

Lysias, relationship with, 57n. 63, 58-9, I73-4, 2I5

on philosophy and philosophia, 63-4, 74-5, 78-87, 90-4, 96, I I O, I I9, I24, $2 \mathrm{I} 5,2 \mathrm{I} 6$

on politikoi logoi, 68,238

on sophists, 75-7, 8 I, 83, 90, 96, I I 8n. 25 , I 20

panhellenism and, I49

Plato's portrayal of, 5, 6-8, 49-5I, I Io-26, I63

poetic tradition and, 65-8

political influence of, I03-5, I47-8, I 68, 21 7, 223

portrayal of Athens, 96

pupils, 57n. 63, 86n. 76, I05n. 40, IIо, I22, I4I, I44-6, I54, I6on. 70, 2I 7, $223,242-3$

Socrates, relationship with, 90-I05

school of, 7, I I, 63, 76n. 45, 93-5, I00, I08, II2, I2I, I44, I45-6, 2 I7

style of, 9, I2, 65, 68-74, I32-3, I54, I56, I66, I9I, 203, 2I 5, 2I 8-2 I

written discourses and, 5, 9, I I , 63, 66, 78,87, I09, 2I 5

judgement, 9n. 25, 49, 193-4, 208-9, 220, 222, 233, 24I

justice, 4In. 22, 44, 87, I25-6, 2I2n. 87, 2 I9, 22 I

kairos (kaıрós), I97, 220

knowledge, 2 In. 9, 42, 43, 46, 50n. 43, 52, 76, 8 In. 63, 86, 89n. 84, 97, 98n. I6, I04, II8-22, I59, I65, I96, 209-I0, 240-2

as opposed to opinion, II $2-13$, II 9 , I 22 limits of, $82-3,233,240$

see also Isocrates, knowledge and,

kritikoi, I70n. 87, I97-8

see also Pausimachus; Philodemus,

language, I5, 24, 53, 55n. 52, 8I, 90, 97, II3, II7, I42, I5On. 42, I58, I72, I88-9I, I94, 196, 206-9, 2I9, 230, 239-40 see also style

letters, 29, 87, I53n. 45, I77, I79n. I5, I $85-6$

logic, 2, 233, 237-8

logographoi, 27n. 27, 32, 35, 58, I I4n. I 8, I 59n. 68

$\log o s, 2$

Longinus, see Ps. Longinus

love, 6, 29n. 37, 5I, 54, I 94

Lycurgus, I6o, I87n. 36, 236

Lysias,

apology for Socrates, 36-8

as accomplished writer, 5, 6, I0, I9-20, 27-8, 34, I7I-2, I94

as model for simple style, 9, IO, I I, 37, I5I-3, I55, I70-4, I80, I90-2, I96, 207, 2 I 8

as speechwriter, logographos

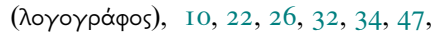

I I3, I 53, 20 I

as teacher of rhetoric, $26-7,33,46$, II 3 characterization and, 35, 55, I93-4 charm of (Xópı), I52, I96-20 I, 206 criticisms of, 48-50, 52, 53, I95 importance for Dionysius of H., 9, I6, 30, I 76-205, 206-I3, 2I4, 2 I 5

Platonic portrayal of, 5, 6, 7-8, I0, 3I, 38-55, 60-I, II3, I75, I92n. 44 political context of, $22-5,45,2$ I I-I3 relationship between Isocrates and, 57-9, 68, 72, 73, II4, I75, I9I, 206, 2I 4 n. I, 2 I 6

representative of rhetoric, $6,7, \mathrm{I0}, \mathrm{I} 3$, 22, 5I, 59-60, I I4, I39-4I, I 50, I 55, I 70, I73, I82-3, 207-I0, 243-4 see also corpus Lysiacum

mathematics, 85

Metaneira, 32

metaphor, 207 


\section{Index}

metaphysics, I63, 228, 238n. 49, 242 metathesis, 9n. 24

method, 7, I9, 39, 4I-4, 48, 69, 84, 86-7, 90-I, IIIn. I4, II2, II9, I42n. Io, I45n. 28, I59, I69, I78, I80, I82, I85-6, I90, I98n. 58, I99, 206, 209-IO, 2I 4n. I, 22 I-2, 235, 239-40 mimesis ( $\mu i \mu \eta \sigma \varsigma s), 65$, I30n. 54, I89, 237 see also imitation

money, 76n. 45, I00-I, 2I 7, 225, 229, $23 \mathrm{I}$

see also fees; wealth

morality, I2, 47-8, 52, 60, 6I, 65, 70, 84, IIO, II4, II7, I22, I3I, I43, I93, I94, 207, 208, 2 I0, 2I 2, 2 I9, 220, 230 motivations, 85, 99, I02, I46, 227, 238

Muses, 53

music, 96n. I2, I98, 238n. 49, 24I

myth, 53, 66n. I6, 7In. 29, II3

nature, 8, 48n. 40, 49, 82, 87, I20n. 30, I23, I 29, I67, I78, I93, I98, 233, 240

Neaira, 32

obscurity, 5, 76, I40, I89, 203

opinion, 83-4, 90, IO I, II $2-13$, I22n. 35, I33, I65, I82, 2I9, 23 I

see also doxa ( $(\delta \dot{\xi} \alpha)$

orality, II, 74, 78, I07

oratory, 3n. 5, 20n. 6, 49n. 42, 57, 78n. 54, 95n. II, II8n. 25, I33, I40-I, I47, I58, I60, I64, I66n. 79, I68-9, I 72, I73, I75, 202, 222, 236, 238

ornamentation, 2, I89

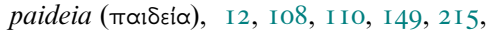
2 I 8,220

see also education

papyri, 28n. 33, I39-4I, I49, I55-6, I63

Pausimachus, I97 see also kritikoi

pedagogy, 2 I 5 see also education

performance, 47, 78, I09, I66, 202n. 64, 204

Pericles, 23, II3, I60

personification, I5I

persuasion, 3n. 5, I I, 50, 5I, 52, 7In. 29, 85,94, I 57, I70, I89, 20 I
Philochorus, I44

Philodemus, I39, I46n. 32, I48, I54, I55-63, I68, I69-70, I73, I97 see also Epicureanism

philosopher, 5, 8, I2, I3, 24, 34, 43, 50, $55,62,63,64,70,72,75,77,80-4$, 90, 91, 92, 94, 97-8, I00, I02, I06, I I4n. I 8, I I 8-2I, I23, I28-30, I35, I39, I40, I44-8, I57, I6I-3, I66, I68, I73, I75, I95, 205, 2I5, 2I6, 2I 1 , 224, 230-4I

'philosophical rhetoric', 2, 7, 9, I I7, I64, $223,228,232$

philosophical training, see training philosophy,

as opposed to practical life, 4I, II7, I 24, 238-9

as training of the mind, 85-6, I23-4 controversy around, 7, IIn. 33, I09-IO, I I2, II4-I6, I2 I, I29-3I

Dionysius' 'true' (Isocratean), 2 I4-I5, 2 I6-I7, 220-36, 238-4I, 244

institutionalization of, 93-4, I44 Isocratean, 9, I I-I 2, 62-5, 68, 7I, 73-87, 90-I, 96-7, Iо3-4, IIO, I I5, I I9-26, I35, I43, I47-9, I56, I60, I62, I64, I67

Plato's conception of, 52, 97-8, I20-I Photius, 58, I80n. 20, I8I

phronesis (фрóvпoเs), 80, 95

Plato,

as critic of rhetoric, 6, 50-I, 97, 98n. I6, I I4n. I 8, I I 5, I22, 225, 226, 229, 244

as head of school (Academy), Ioon. 24, I 2 I, I44, I66

as writer (of dialogues), 25-6, 45, 9I, 95, 96n. I2, I52, I53n. 45, I69n. 85, I 95, I96n. 52

conception of philosophy, $7,77,84 \mathrm{n}$. 68, I I 2, 233n. 37

impact on the rhetorical tradition, 5, 7-8, I3, 50-I, 56, 59-6I, 65, I32n. 59, I4In. 9, I60, I66, I73, I82-3 on Lysias, IO, 2I, 24, 27n. 27, 28, 3I, $33,35,38-55,56,58-6$ I, 73, I 72-5, 2I 5,244

Phaedrus, I, 6, 8, I0, I6, 2I, 22, 25, 26, 27n. 27, 28, 3I, 33, 38-9, 40, 45-55, 
56, 59-60, 65, 73, 92, I Io, I I I-I4, I I 8, I25, I35, I6I-3, I67, I69n. 86, I 72-3, I74-5, I82, I92, 2 I 5, 226-7, 228, 229n. 32, 243-4

quarrel for philosophy, 74n. 39, I29, 224

reception in Dionysius of $\mathrm{H} .$, 8, I39, I4I, I83, I9I, I92-4, 205n. 7I, 2 I 5, 224, 226-7, 228-9, 23In. 34, 238n. 49, 239, 243-4

relationship with Isocrates, 7, I 2, 63, 64, 93, 94, I03, I Iо-26, I48, I68-9, I 75, 2 I 5, 244

pleasure, 68, 99, I24, I89, I97n. 56, 238 Plutarch, see Ps. Plutarch poetic tradition, 64-8

poetry, 5, 20, 65-8, I42, I48, I 52, I 72

Polemarchus, 24, 49n. 4I

polis, 87, 95, 97n. I4, I05, 2 I 7

politicians, I2, I3n. 37, I4, 77n. 5I, 78, 82, 95, I I4, I24, I58, I68, 2 I 7

politics, I3, 24n. I6, 33, 68, 77, 94, 98n. I6, 99-Ioon. 23, I02, I04, I06, I I I, I I5-I6, I2 I, I23, I3 I, I34, I55n. 49, I 57n. 53, I58, I68, I68n. 84, I70n. $89,217,222,225,230$

Polybius, I40, I40n. 4

Polycrates, 69-70, IOI-2

poverty, I74

power, 3n. 7, Ion. 27, 47, 50, 7I, 79, 82, 85, I29, I3 I, I58, I68, I72n. 93, I8I, I89, I97, 200, 204-5, 22 I, 226

practice, 26, 46n. 33, 47, 5In. 45, 52, 58n. 64, 64, 66, 74, 75, 76, 79, 81, 83, 84, 86n. 74, 87, 96, I04, I08-9, I I I, I22, I30, I58, I65, I76, I99n. 58, $205,228,229,232,236,238,242$

praise, $27,36,38,43,47,49,66,69 n .26$, 88, 95, IOI, IO2, II4, II5, II9, I35, I52, I55, I59, I64, I67n. 82, I7I, I74, I75, I92, I95-6, 222, 227

Praxiphanes, I48

Proclus, 56n. 56

Prodicus, 92, I I3, I I6, 223-6

proof, 82-3, 85, I9I, 237

prose,

genres of, 68n. 2I, 69, 7In. 28 n. 29, I07n. 4, I9I, 242
Isocratean, 9, 64, 66-73, I Io, I46, I47, I49-50, I 54, I62n. 72, I64, 203, 2 I 7-20

Lysianic, I9-20, I7I, I9I, 203

Plato's, I 52

Protagoras, 52, 73, 75, 8In. 63, I I3, I 53n. 45, 224n. I 8, 239

protreptics, 43, 43n. 26, 2 IO

Ps. Demetrius,

on charm, I50, I99

on Isocrates, I53-5

on Lysias, I40, I50-3, I93

Ps. Longinus, I80-I

Ps. Plutarch, I4n. 4I, I9n. I n. 2, 24, 27, 27n. 29, 29, 29n. 36, 57n. 63, I84

Quintilian, 36-7, 88-9, I43n. I6, I67n. 8 I, 2 Ion. 82

quotation, 57, I32, 208, 219, 243

readership, 28n. 33, I47, I49, I64n. 77, 203-4

see also audience

realism, 57, 207

rhetoric,

as discipline, 2, 4, 5, 9, I4, 5I, 68, I06, I 26n. 42, I42, I 50, I 52, I 55, I57, I6I, I67n. 8I, I68-9, I70, I72, I73, I75, 204, 220, 223

as style, I43, I55, I70, I7I, I75, 204, 2 I 6, 2 I 8, 244

definition of, 2, 50-I, I08-9, I22, I 57-9, I67n. 8I, 220

deliberative, I3

education and, 2, 9, I2, I6, IOIn. 27, I 07-8, I I4, I39, I4In. 9, I44, I47, I49-50, I6on. 70, I63-4, I67, I73, I74, I75, I76, I9In. 42, 203

epideictic, 167

forensic, I3, 2 I9

history of, In. 2, 3, 4, 62, 64, 224

in Aristotle, I32-3, I35, I93, 240n. 54

in Dionysius of H., I5-I6, I39, I77-83, I90, I94, 200-I, 203, 204n. 67, 205, 207, 2I0, 2I4, 2I 7-I8, 220-I, 223-4, 227, 228-37, 240, 243-4

Isocratean, II-I 2, I 5, 63-4, 72, 74-5, 77-9, 82n. 64, 87-9, 94, I09-IO, 


\section{Index}

I I 4n. I 8, I44-6, I62n. 72, I63, I64, I67-8, I69, I75, 2 I 5, 2 I 7-I 8, 223, 230, 244

Lysianic, IO-II, I 5, I9, 2 I-2, 26-7, $28,30-\mathrm{I}, 33-4,36-8,58 \mathrm{n} .64,72$, I67, I69, I92, 244

moral status of, IIO, I22, 228

philosophical, 9, 62, I I7, I56, I59, I62n. 72, I65-7, 2 I4, 223, 228

Plato's portrayal of, 6-8, 39, 45-6, 48n. 39, 49, 50, 52, 55, 59-6I, 96n. I2, I I I, I I4, I I7, I I 8, I63, I67n. 8I, 226 power of, 50

school of, I 58

sophistic, I 56-60, I62n. 72, I69-70 theory of, I, 2, 5, I4, I6, 63, I39-40, I 5 In. 43, I63, I83n. 3I, I86, 224

rhetorical tradition, 3-4, 5-6, 9, Io, I 2-I6, I 9, 22, 38, 59-65, I62, I75, I 82-3, 2I 7, 227, 240, 244

rhetorikē (ф́пторıкท́), 5In. 45, 74, 77-8, Io9n. 9, I 22, I 57, 228, 230, 232

rhythm, 2 I 8

rivalry, I In. $33,38,40,55,58$, I I 2 , I I 4n. I9, I 27-8, 205n. 7I

Rome, I5, I5n. 45, 35, I32n. 56, I35, I39-79, 20I-I4, 233

slander, 77, 232n. 35

Socrates,

as character in Plato's dialogues, I, 6, 7, 8, 39, 4I-4, 45-54, 6I, 89, 95-6, I IO-II, I I3-25, I4I, I62, I67, I69n. $85,192,226$

as philosopher, 25n. 23, 42, 57n. 62, 96-8, I02, 229-30, 234

fees and, 98-9

influence on Athens, 94-6, I04-5, 225

Isocrates' engagement with, 70n. 27, 8In. 63, 90-I05, 225

trial of, 33-4, 36-8, 69, 92-3, 96, 97n. I4, IoIn. 27, I44n. 22

Socratic dialogues, 73, 94-5, 229

sophists, 3n. 5, I2, 27, 32, 33, 48, 52, 72, 73, 74, 75-8, 80-3, 87, 89, 90, 96-IOI, IO6-IO, I I4, II5, I I7, I I 8n. 25, I I9-20, I22, I 24, I26, I32n. 59, I 56-6I, I62n. 72, I69-70, 223, 224-6, 229-30 soul, 83, 85, 85n. 72, I30, I67n. 8I

sound, 38, 78, 84, I98

Spartans, 46n. 35, $23 \mathrm{I}$

speechwriter, 6, 8, I0, 20, 22, 24, 27, 30, $32-4,38,48,58$, I I3, I2 I, I39, I 52-3, I73, I84, 20I, 2 I 4

see also logographoi

Speusippus, 56-8, I48

Stoics, I60, 228, 234

style,

Asianist, I75, I80, I9I

Attic, 9, I7I, I 74-5

Demosthenes', I3n. 37, I4, 200, 207-8

elegant, I50-3, 203n. 66

grand (forceful), I4, I53, I72n. 93, 207, 2 I I

in Aristotle, 2, I32, I33

in Dionysius of H., I5, I50, I84, I86, I9I, I92-6, I98, 20I-IO, 2I8-22, $227,238,239,242-4$

Isocratean, I 2, 65, I09-IO, I32, I42-4, I46-7, I49, I 54-5, I64, I9I, 206, 207, 2 I4-I5, 2 I8-22, 230, 242-3

Lysianic, 6, 8, 9n. 25, IO-I I, 22, 29, 30, 49, 52, 56n. 60, 60-I, 72, 73, I 52, I 70-I, I74, I75, I8I-2, I84, I86, I92-6, I98, 20I-2, 204-5, 206-7, 2 IO, 2 I 5, 244

middle, 207

ornate, 7In. 29, 203, 204

plain, 7In. 29, 72, I07n. 6, I5I-3, I55, I 70, I74, I90, 207

Plato's, 8, I95, 227

rhetoric and, I, 3, 21, 6I, I64n. 74, I 73, 204

Thucydidean, 202, 240

see also virtues of style

sublimity, I8I, 20In. 63

succession, I45-6, 224

synkrisis, I80, I82

Syrianus, I 84

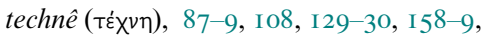
I 70, I73, 24I

terminology, 74, 90, 97, Ioon. 23, I09, I35, I5In. 43, I55, I 57n. 56, I78, I86, I90, I92, 206, 208-Io, 230, 233n. 37,234

theater, I 42 


\section{Index}

Themison, I28, I29

Theodectes, 4In. 22, I42, 236

Theodorus (of Byzantium), II3, I72, 236

Theophrastus, 57, I86, I88, I96n. 53, I99n. 59

Theopompus (of Chios), I $42-3$

theory, I-2, 3n. 5, 4n. I0, I2-I6, 63, 79n. 57, I32, I39-40, I5In. 43, I63, I86-8, I90, I93, I96, 205, 223n. I4, 224

Thrasymachus, 39n. I7, 6on. 70, II3-I4, I I 7, I32n. 59, 236

Thucydides, I4In. 9, I76, I79n. I5, I82, I88-9I, I96, 202-3, 207, 2I I, $229 n$. $32,238-40$

Timaeus, I44, 243

Tisias, I9n. 2, 25, II3 , 223-6, 229

training, 50, 64, 70, 78-9, 8In. 63, 82-7, 96, I IO, I23-4, I57, 224 truth, 44, 52, 7I, 8In. 63, 98n. I6, 99, I03, I04, I43, I93, 226, 232, 239-40

Usher, Stephen, 4n. 8, 6n. I5, 9n. 25, Io, 20-I, 3on. 40, 35, 55n. 52, I76n. 3, I77, I84, I88n. 38, I93n. 47, I94, I96n. 53, I99n. 6o, 200, 2 I In. 83, 23 I

Valerius Maximus, 36-7

virtues of style, I86-96, I99, 205

voice, 30, 5I, I04, I34n. 64, 210n. 82, $219,224 n$. I8

war, I5, 46n. 34 ก. 36, 67n. I9, I03, 223, $23 \mathrm{I}$

wealth, Ion. 27, 23-4, 46-8, 75, 90, 96-I00, I03-5, 2I6, 22 I, 225, 229-30

Xenophon, 33, 99n. I9 n. 20, I52, 229n. 32 